\title{
Accounting for performance evaluation : effects of uncertainty on the appropriateness of accounting performance measures
}

Citation for published version (APA):

Hartmann, F. G. H. (1997). Accounting for performance evaluation : effects of uncertainty on the appropriateness of accounting performance measures. [Doctoral Thesis, Maastricht University]. Universiteit Maastricht. https://doi.org/10.26481/dis.19970620fh

Document status and date:

Published: 01/01/1997

DOI:

10.26481/dis.19970620fh

Document Version:

Publisher's PDF, also known as Version of record

Please check the document version of this publication:

- A submitted manuscript is the version of the article upon submission and before peer-review. There can be important differences between the submitted version and the official published version of record.

People interested in the research are advised to contact the author for the final version of the publication, or visit the DOI to the publisher's website.

- The final author version and the galley proof are versions of the publication after peer review.

- The final published version features the final layout of the paper including the volume, issue and page numbers.

Link to publication

\footnotetext{
General rights rights.

- You may freely distribute the URL identifying the publication in the public portal. please follow below link for the End User Agreement:

www.umlib.nl/taverne-license

Take down policy

If you believe that this document breaches copyright please contact us at:

repository@maastrichtuniversity.nl

providing details and we will investigate your claim.
}

Copyright and moral rights for the publications made accessible in the public portal are retained by the authors and/or other copyright owners and it is a condition of accessing publications that users recognise and abide by the legal requirements associated with these

- Users may download and print one copy of any publication from the public portal for the purpose of private study or research.

- You may not further distribute the material or use it for any profit-making activity or commercial gain

If the publication is distributed under the terms of Article 25fa of the Dutch Copyright Act, indicated by the "Taverne" license above, 



\title{
Accounting for \\ Performance Evaluation
}

\author{
Effects of Uncertainty \\ on the Appropriateness \\ of Accounting \\ Performance Measures
}





\title{
Accounting for Performance Evaluation
}

\author{
Effects of Uncertainty \\ on the Appropriateness \\ of Accounting \\ Performance Measures
}

\section{PROEFSCHRIFT}

ter verkrijging van de graad van doctor aan de Universiteit Maastricht, op gezag van de Rector Magnificus, Prof. Mr. M.J. Cohen, volgens het beshuit van het College van Decanen, in het openbaar te verdedigen op vrijdag 20 juni 1997 om 16.00 uur.

door

Frank Gerard Hans Hartmann

geboren te Rotterdan 
Promotores:

Prof. Dr. W.F.J. Buijink

Prof. Dr. T.L.C.M. Groot (Vrije Universiteit Amsterdam)

Prof. Dr. K.A. Merchant

Beoordelingscommissie: Prof. Dr. S.J. Maijoor (voorzitter)

Prof. Dr. J.L. Bouma (Rijksuniversiteit Groningen)

Prof. Dr. A. van Witteloostuijn 


\section{Contents}

\section{Chapter 1 \\ Introduction}

1.1 Accounting for performance evaluation 1

1.2 Management control

1.2.1 The demand for control in organizations 3

1.2.2 The supply of controls in organizations \&

1.2.3 The appropriateness of controls 9

1.3 The role of APM in management control 11

1.3.1 Budgets and control 11

1.3.2 Responsibility accounting 13

1.4 Summary and overview of the remainder of this dissertation 15

$\begin{array}{ll}\text { Notes to Chapter } 1 & 17\end{array}$

\section{Chapter 2}

The appropriateness of APM: literature review and four directions for further inquiry

2.1 Introduction 21

2.2 Empirical evidence of the appropriateness of APM 21

2.2.1 Functional and dysfunctional consequences of budgeting 21

2.2.2 Functional and dysfunctional consequences of APM $\quad 22$

2.2.3 Functional and dysfunctional consequences of APM in context 23

$2.3 \quad$ Uncertainty as a contextual factor in APM research 25

2.3.1 The relevance of uncertainty to APM research $\quad 25$

2.3.2 Uncertainty and the appropriateness of APM: theory 27

2.3.3 Uncertainty and the appropriateness of APM: evidence . 29

$2.4 \quad$ Evaluation and four directions for our research 30

$\begin{array}{lll}2.5 & \text { Summary } & 32\end{array}$

Notes to Chapter 2

\section{Chapter 3}

Uncertainty and the appropriateness of APM: development of hypotheses

3.1 Introduction 35

3.2 The meaning and measurement of appropriateness of APM 35

3.2.1 Appropriateness in previous APM research 35

3.2.2 The use of APM, performance and job attitudes as criterion measures $\begin{array}{ll}\text { of fit } & 37\end{array}$

3.2.3 Goal clarity and agreement with evaluation criteria as criterion

3.2.4 Managerial opinions about the appropriateness of APM 44

3.3 Uncertainty and the appropriateness of APM 45

3.3.1 Two types of uncertainty 45

3.3.2 Environmental uncertainty and the appropriateness of APM 46 


\section{CONTENTS}

3.3.3 Task uncertainty and the appropriateness of APM 49

3.4 Appropriateness of APM and managers' tolerance for ambiguity 51

3.4.1 The "tolerance for ambiguity" concept and its use in previous accounting research 51

3.4.2 TFA and the appropriateness of APM 53

3.4.3 The interactive effects of uncertainty and TFA on the appropriateness of APM $\quad 55$

3.5 Appropriateness of APM and the underlying dimensions of RAPM 57

3.5.1 Differences in empirical RAPM measurement $\quad 57$

3.5.2 Variety in RAPM measurement: an overview 58

3.5.3 Two dimensions of RAPM: development of hypotheses 61

3.6 Summary and overview 63

Notes to Chapter $3 \quad 66$

Chapter 4

Research method

$\begin{array}{lll}4.1 & \text { Introduction } & 71\end{array}$

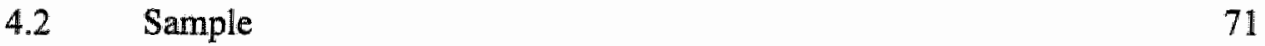

4.2.1 Sampling method, some general remarks 71

$\begin{array}{lll}4.2 .2 & \text { Sample of organizations } & 72\end{array}$

4.2.3 Sample of respondents within each organization 73

$\begin{array}{lll}4.3 & \text { Measurement instruments } & 74\end{array}$

4.3.1 Selection of measurement instruments, some general remarks $\quad 74$

4.3.2 Measurement of contextual variables and additional descriptives $\quad 75$

$\begin{array}{lll}\text { 4.3.3 Measurement of APM variables } & 76\end{array}$

4.3.4 Measurement of dependent variables $\quad 77$

4.3.4.1 Appropriateness of APM as an outcome and as an opinion $\quad 77$

4.3.4.2 Outcome variables: goal clarity and agreement with evaluation criteria 78

4.3.4.3 Opinion variable: felt appropriateness of APM $\quad 80$

4.4 Development of the questionnaire 80

4.4.1 Choice of language of the questionnaire $\quad 80$

4.4.2 Translation, composition and pretest of the questionnaire 81

$\begin{array}{lll}\text { 4.4.3 Final format and layout of the questionnaire } & 82\end{array}$

4.5 Distribution of the questionnaire and follow-up 83

4.6 Response rate $\quad 83$

$\begin{array}{lll}4.7 & \text { Final interviews } & 84\end{array}$

Notes to Chapter $4 \quad 85$

Chapter 5

Descriptive statistics and item analyses

$\begin{array}{lll}5.1 & \text { Introduction } & 89\end{array}$

$\begin{array}{lll}5.2 & \text { Sample characteristics } & 89\end{array}$

5.3 Analyses of measurement instruments (item analyses) 91 


\section{ACCOUNTING FOR PERFORMANCE EVALUATION}

5.3.1 Introduction to the analyses 91

5.3.2 Contextual variables 92

5.3.3 APM variables 93

5.3.4 Dependent variables 95

5.3.4.1 Outcome variables: goal clarity and agreement with evaluation criteria 95

5.3.4.2 Opinion variable: felt appropriateness of APM 98

$5.4 \quad$ Test for bias from nonresponse 98

5.5 Summary 99

$\begin{array}{ll}\text { Notes to Chapter } 5 & 100\end{array}$

\section{Chapter 6}

Results: tests of hypotheses

6.1 Introduction

6.2 The impact of task and environmental uncertainty on the appropriateness of APM

6.2.1 Environmental uncertainty and the appropriateness of APM ( $\mathrm{Hla}_{3} \mathrm{Hlb}$ and $\mathrm{Hlc}$ )

6.2.2 Task uncertainty and the appropriateness of APM $(\mathrm{H} 2 \mathrm{a}, \mathrm{H} 2 \mathrm{~b}$ and $\mathrm{H} 2 \mathrm{c}) 106$

6.3 The impact of TFA and uncertainty on the appropriateness of APM 108

$\begin{array}{lll}6.3 .1 & \text { Tests of hypotheses concerning TFA } & 108\end{array}$

6.3.2 TFA and the appropriateness of APM (H3a, H3b and $\mathrm{H} 3 \mathrm{c}) \quad 109$

6.3.3 TFA, environmental uncertainty and the appropriateness of APM 111

6.3.4 TFA, task uncertainty and the appropriateness of APM (H5a, H5b and $\mathrm{H} 5 \mathrm{c}$ ) 114

6.4 The effects of RFQ and RT on goal clarity (GC) and agreement with $\quad 117$

$\begin{array}{llr}6.4 .1 & \text { Test of hypotheses concerning RFQ and RT } & 117 \\ 6.4 .2 & \text { RFQ, RT, environmental uncertainty and the appropriateness of APM } & \\ & \text { (H6) } & 118\end{array}$

$\begin{array}{ll}\text { 6.4.3 RFa and H6b) } & \\ \text { RF, RT, task uncertainty and the appropriateness of APM (H7a and } & 119\end{array}$ $\begin{array}{ll}\mathrm{H} 7 \mathrm{~b}) & 119 \\ & 121\end{array}$

$\begin{array}{lll}6.5 & \text { Summary and overview } & 123 \\ \text { Notes to Chapter } 6 & \end{array}$

\section{Chapter 7}

\section{Summary and conclusions}

$7.1 \quad$ Introduction 125

7.1 Introduction $\quad 125$

$\begin{array}{lll}7.2 & \text { Summary and overview of empirical findings } & 125\end{array}$

$\begin{array}{ll}\text { 7.2.1 } & \text { Four directions of inquiry } \\ 7.2 .2 & \text { Differences in effects of environmental uncertainty and task }\end{array}$

7.2.3 The effect of tolerance for ambiguity 127 
7.2.4 Multi-dimensionality of RAPM

7.2.5 Meaning and measurement of "appropriateness" of APM

7.3 Conclusions and implications

7.4 Strengths and weaknesses of this study

7.5 Suggestions for further research

\section{Appendices}

Appendix A Overview of APM studies concerning uncertainty

Appendix B Overview of accounting literature concerning TFA

Appendix C Overview of differences in RAPM measurement

Appendix D Sample of organizations

Appendix E Descriptive statistics on interviews

Appendix $\mathrm{F}$ Measurement instruments included in the questionnaire

Appendix $\mathrm{G}$ Factor-analysis of the FAAPM-instrument

Appendix $H$ Response analysis

Appendix I Correlation matrix

Appendix $J$ Test for bias from non-response

Appendix $L$ Further analyses of the three-way interactions between uncertainty and TFA

References

Summary in Dutch (Nederlandse samenvatting) 197

$\begin{array}{ll}\text { Acknowledgements } & 200\end{array}$

$\begin{array}{ll}\text { Curriculum Vitae } & 201\end{array}$ 


\section{List of abbreviations}

EU: environmental uncertainty

TU: task uncertainty

TFA: tolerance for ambiguity

RAPM: reliance on accounting performance measures

RFQ: reliance on financial and quantitative information

RT: reliance on targets

GC: goal clarity

AEC: agreement with evaluation criteria

JRT: job-related tension

JSA: job satisfaction

FAAPM: felt appropriateness of accounting performance measures

FUOB: felt usefulness of budgets 


\section{Chapter 1 Introduction}

\subsection{Accounting for performance evaluation}

This dissertation presents an empirical study about the use of accounting information for management control. It addresses the use of accounting information by superiors to evaluate the performance of their subordinate managers. The general purpose of this dissertation is to further examine whether and when the use of accounting information is appropriate for these individual, managerial performance assessments. In particular, this dissertation examines how uncertainty in the subordinate manager's working environment affects the appropriateness of using accounting information for managerial performance evaluation.

In pursuit of this purpose the dissertation aims to contribute to the empirical literature that over the last four decades has examined the effects and effectiveness of budgetary control systems. In particular, this dissertation contributes to a specific area within the literature that has explored the effectiveness of the use of budgets for management control, by examining the relationship between a construct called Reliance on Accounting Performance Measures [Kren and Liao 1988, p. 281] and the work related attitudes and behaviors of managers. In this area of the literature Reliance on Accounting Performance Measures (RAPM) denotes a construct that applies to the performance evaluation of subordinate managers in decentralized organizations, and that signifies:

:...the extent to which superiors rely on, and emphasize those performance criteria which are quantified in accounting and financial terms, and which are prespecified as budget targets' [Harrison 1993, p. 319]. ${ }^{1}$

In conformity with this definition, empirical research in this area of the literature examines the effectiveness of three combined aspects of budgetary control systems: first, the quantitative and financial nature of the information these systems provide; second, the use of this information to set and communicate individual managerial targets through budgets, and third; the use of this information and these budgetary targets to assess managerial performance. In the remainder of this dissertation we will address the body of empirical literature that has focused on these three aspects of budgetary control systems with APM research, in conformity with its focal concept, Accounting Performance Measures (APM). 
In its examination of the effectiveness of using APM for managerial performance evaluation, contemporary APM research shares three distinct characteristics. First, APM research applies a behavioral perspective, drawing on theoretical insights from the field of organization behavior [Hopwood 1983; Kren and Liao 1988, p. 290]. APM research thus emphasizes that the effectiveness of budgetary control systems not only depends on the system's inherent, technical qualities, but also on how organizational members use information from the system [Briers and Hirst 1990, p. 374]. ${ }^{2}$ The behavioral orientation further delineates APM research from the economic literature on performance evaluation and compensation, which is mainly developed within the principal-agent paradigm [see, e.g., Eisenhardt 1985; Kirby et al. 1991].$^{3}$ In APM research, the effectiveness of using APM for managerial performance evaluation is measured by its effects on the workrelated attitudes and behaviors of subordinate managers. These latter concepts are not usually regarded to be part of the economic vocabulary [Baker et al. 1988, p. 594]. ${ }^{4}$ In sum, the behavioral orientation in APM research is reflected in its focus on the attitudes and behaviors that managers show in response to the use of APM for target setting and subsequent performance evaluation [Briers and Hirst 1990, p. 373].

Second, contemporary APM research applies contextual rather than universalistic perspectives in its examination of the appropriateness of APM for managerial performance evaluation. Especially over the last two decades APM studies have primarily looked at the impact that contextual factors have on the relationship between the use of APM and managers' attitudinal and behavioral responses by adopting research frameworks in which:

...the effectiveness of using budget data in performance evaluation is hypothesized to depend on the context in which the [budget data] are used' [Imoisili 1989, p. 325]. ${ }^{5}$

A third characteristic of APM research is its use of research methods for data collection and data analysis, common to psychological and sociological research [Merchant and Simons 1986; Brownell 1995]. In particular, APM studies have typically used questionnaire surveys as the means of data collection. ${ }^{6}$ The data analysis and tests of hypotheses are typically done by applying correlation and regression techniques to functional relationships between variables [Merchant and Simons 1986, p. 191].

In our aim to contribute to APM research, in this dissertation we also adopt the behavioral, contextual and methodological characteristics outlined above. The methodological characteristics of this dissertation will be further discussed in Chapters 4 and 6 of this study, in which we describe the methods used for data collection and analysis. The contextual perspective is exemplified in this dissertation's focus on the role of uncertainty in the subordinate manager's working environment as a factor affecting the appropriateness of APM. The behavioral perspective follows from this dissertation's focus on the use of APM by superiors, and on managers' attitudes and responses toward the use of APM. These attitudes and responses are regarded to be an indication of the contextual appropriateness of APM. In sum, the overall research question of this 
dissertation is:

What is the impact of uncertainty in the subordinate managers" working environment on the appropriateness of APM for managerial performance evaluation?

We will further motivate this research question in Chapter 2, after a review of previous empirical APM research. The research framework and the specific variables for our study will then be further presented in Chapter 3. In the remainder of this introductory chapter, we continue with positioning our research question in the management control and accounting literature in Sections 1.2 and 1.3. Section 1.2 contains an overview of the management control subject area, and addresses the role of performance evaluation in management control, and the meaning of the term 'appropriateness' of controls. Section 1.3 discusses the role of budgets and budgetary information for management control and positions the use of APM in the area of responsibility accounting. Section 1.4 closes this chapter with a summary and an overview of the structure of the remainder of this dissertation.

\subsection{Management control}

\subsubsection{The demand for control in organizations}

The literature on management control offers a great variety of definitions of both the general concept of 'control' and the more focused concept of "management control" [Otley and Berry 1980; Hofstede 1981; Machin 1983; Merchant and Simons 1986; Fisher 1995]. As Otley and Berry [1980, p. 231] note however, connotations of the term "control' essentially boil down to two ideas:

'The most common idea [...] is that of dominance; the domination of one individual or group by another through the exercise of power. However, there is a second strand of meaning that emphasizes the idea of regulation and the monitoring of activities'.

In most definitions of management control the ideas of dominance and regulation reappear. Yet these definitions further point to certain distinct characteristics of management control as an organizational phenomenon. One such characteristic is that organizations have a demand for control, which originates in organizations having objectives, the attainment of which is the prime responsibility of its management. ${ }^{7}$ This orientation is reflected in Ouchi's [1979, p. 833] definition of management control as:

"...the mechanisms through which an organization can be managed so that it moves towards its objectives",

and in Otley and Berry's [1980, p. 231] definition of management control as:

'...the ways in which organisations manage and regulate their affairs so as to remain viable and to achieve their chosen ends or objectives'. 


\section{ACCOUNTING FOR PERFORMANCE EVALUATION}

In addition, definitions of management control often recognize that management control comprises a set of intentional activities [see, e.g., Machin 1983]. In other words, management control is not the accidental "mechanisms through which" or "ways in which" organizational objectives are achieved, but rather involves a systematic and rational combination of activities, instruments and techniques, used to ensure that management strives to attain the organizational objectives [Anthony 1965; Hofstede 1981; Merchant 1989]. Lowe [1970] in this vein defines a management control system as:"

'... a system of organizational information seeking and gathering, accountability and feedback designed to ensure that the enterprise adapts to changes in its substantive environment and that the work behaviour of its employees is measured by reference to a set of operational sub-goals (which conform with overall objectives) so that the two can be reconciled and corrected for'.

In combination, these definitions present management control as a set of rational and formal activities aimed at organizational goal attainment. The rationality and formality of control are most clearly illustrated by the general control model that appears in the work of, for example, Anthony [1965, 1981], Otley and Berry [1980], and Anthony and Govindarajan [1995]. This model presents management control as an essentially cybernetic process, consisting of four steps that follow a systematic order [Anthony 1981, p. 8]:

'First, a standard of desired performance is specified. Second, there is a means of sensing what is happening in the organization and communicating this information to a control unit. Third, the control unit compares this information with the standard. Fourth, if what is actually happening does not conform to the standard, the control unit directs that corrective action be taken, and the directive is conveyed as information back to the entity'.

The best known example of a cybernetic control process is the functioning of a thermostat that controls the room temperature [Anthony 1981; Klein 1989]. As Anthony [1981, p. 8] explains:

'The thermostat has a preset standard of the desired temperature in a room. It receives information about the actual temperature. If the actual temperature differs from the standard temperature, the thermostat directs the heating unit or the cooling unit to turn itselfon?

The general control model, with its focus on cybernetics and its use of the thermostat analogy, provides a clear illustration of the three core features of any formally controlled process, which are standard setting, performance evaluation and feedback [Flamholtz and Das 1985; Merchant and Simons 1986; Otley et al. 1995]. Over the last decades, however, several authors have questioned the practical applicability of the model, and its overly "technical' orientation [e.g., Hofstede 1978, 1981; Otley and Berry 1980; Dermer and Lucas 1986; Argyris 1990; Macintosh and Scapens 1990, 1991]. In particular, 
several attempts have been made to describe and understand management control in organizational reality, by explicitly challenging the assumptions underlying the cybernetic model [Ouchi 1979; Otley and Berry 1980; Hofstede 1978, 1981]. ${ }^{8}$

A first challenge to the cybernetic model is posed by the fact that management control is not concerned with controlling a single mechanical process ("the organization'), but with controlling human behavior in decentralized and complex organizations. Merchant and Simons [1986, p. 184] therefore note:

‘...understanding the control process in complex organizations ultimately requires study of (1) the actions of organizations and their members and (2) the processes by which desirable outcomes or goals are elaborated and achieved".

Consequently, although the rationality and formality of management control systems may be intended, management control as a practice must go beyond a strict application of the cybernetic model. Anthony himself therefore also notes [1981, p. 36]:

'Although systematic, the management control process is by no means mechanical [...] Although in some cases there are mechanical ways of comparing actual performance with a standard, a determination of whether or not the difference between actual and standard is significant usually must be made by human beings, and the action to alter behavior also involves human beings'.

This implies not only that management control is a human activity, but also that humans are the objects of management control. In other words, the control unit in the cybernetic control model, which observes differences between 'actual' and 'standard' and subsequently takes the necessary, corrective actions in real organizations is a human being. In addition, the process of standard setting, evaluating performance and providing feedback also relates to human beings, and their behaviors. In this sense, management control should be seen as a 'practical activity of managers' [Otley et al. 1995, p. S31.], which, in combination with the earlier mentioned goal orientation, is summarized in Anthony's [1981, p. 8] definition of management control as:

"...the process by which managers influence other members of the organization to implement the organization's strategies:

and in Fisher's [1995, p. 25] definition of management control as:

'...the control managers exercise over other managers'.

A second, and related, challenge to the cybernetic control model is posed by the recognition that managers perform their activities in a specific organizational environment. The cybernetic model of control is a typical closed model, which does not account for any context or environment [e.g., Ansari 1979]. In reality, organizations and their managers often face dynamic and unpredictable environments, and consequently may often have ambiguous, multiple and changing goals [Emmanuel et al. 1990]. It is generally believed that this is increasingly the case for contemporary organizations [Simons 1987a; Otley 1994, p. 291; Otley et al. 1995, p. S39]. Furthermore, organizations consist of people working in joint effort, which implies that the outcomes 


\section{ACCOUNTING FOR PERFORMANCE EVALUATION}

of organizational processes are the result of collective, rather than individual efforts [Anthony and Govindarajan 1995, p. 6]. Therefore, in reality standard setting and subsequent performance evaluation is less straightforward and subject to more uncertainty than the cybernetic control model suggests, based on its assumptions of separate, predictable and stable processes [Otley and Berry 1980, pp. 238-241; Hofstede 1981, pp. 194-195; Otley 1994, p. 291]. In combination with the central position of human beings in control processes, this may cause managers to be faced with a lack of possible corrective actions, or with an insufficient knowledge of the effects of such actions on the processes they want to control, especially since these processes themselves also involve human behavior [Otley and Berry 1980, pp. 239-240; Hofstede 1981, p. 195; Anthony and Govindarajan 1995, p. 6]. In contrast, the cybernetic control model assumes that 'the controller' does possess a set of alternative actions, the outcomes of which he can predict with certainty [Otley 1994, p. 291].

In combination, these factors cause control processes to be more uncertain and more ambiguous than the cybernetic model can depict. In particular, they are sources of divergence between the assumptions of stability and predictability of cause-effect relationships in the cybernetic control model, and the context of management control as an observable practice of managers [Otley and Berry 1980; Hofstede 1981]. We present these potential conflicts in Table 1.1, in which we confront the assumptions underlying the general cybernetic model with the potential effects of uncertainty in organizational reality. This comparison follows the four steps in the control process, as outlined by Anthony $[1981$, p. 8].

Table 1.1 The general controll modell and the effects of uncertainty

\begin{tabular}{|l|l|l|}
\hline $\begin{array}{l}\text { Step in the control process } \\
\text { [Anthony 1981] }\end{array}$ & $\begin{array}{l}\text { Assumption of general control } \\
\text { model: }\end{array}$ & Potential effects of uncertainty \\
\hline \begin{tabular}{l|l} 
1. Standard setting \\
goals are clear and stable, and can \\
be translated in operational standards
\end{tabular} & $\begin{array}{l}\text { goals are ambiguous and changing; } \\
\text { link with concrete outputs ambiguous }\end{array}$ \\
\hline $\begin{array}{l}\text { 2. Performance } \\
\text { measurement }\end{array}$ & $\begin{array}{l}\text { outputs can be unambiguously } \\
\text { measured in tems of the standard }\end{array}$ & $\begin{array}{l}\text { individual managerial outputs cannot } \\
\text { be measured }\end{array}$ \\
\hline 3. Performance evaluation & $\begin{array}{l}\text { outputs can be unambiguously } \\
\text { compared with preset standards }\end{array}$ & $\begin{array}{l}\text { no possibility to interpret results in } \\
\text { terms of the goals }\end{array}$ \\
\hline $\begin{array}{l}\text { 4. Feedback for corrective } \\
\text { actions }\end{array}$ & $\begin{array}{l}\text { manager possesses set of actions } \\
\text { and knows their effect on the process }\end{array}$ & $\begin{array}{l}\text { no actions available or effect of } \\
\text { actions is unknown }\end{array}$ \\
\hline
\end{tabular}

Although the challenges outlined may hinder the practical application of 'pure' cybernetics for management control, they do not limit the usefulness of the model to describe the essence of formal management control processes. Therefore, Fisher [1995, p. 26] concludes that the management control literature shows a consensus that formal control systems are essentially cybernetic, acknowledging that: 
'The cybernetic definition does not explicitly define the mechanisms and performance measures that constitute a control system, but rather defines the formal control process.'

So far we discussed that the existence of organizational goals results in the demand for control that ensures systematic and purposeful managerial action. An alternative level of analysis that explains the demand for control is that of the individual manager. The consequence of the fact that management control is a human activity, taking place in an uncertain organizational environment is the occurrence of what Merchant [1982, 1985a] calls 'control problems', that potentially obstruct the attainment of organizational objectives. Control problems, for example, originate in human beings having "personal limitations' and a 'lack of direction". Organizational managers have a lack of direction when they do not know what is expected of them, for example because the standard they should meet is unclear or subject to change. Furthermore, managers may have a lack of direction if they do not know what actions to take, since they are uncertain, and have a lack of information, about what the results of those actions will be [Merchant 1982, p. 43]. Personal limitations may obstruct the attainment of organizational objectives when managers are 'simply unable to do a good job', because of limited decision making and information processing skills [Merchant 1982, p. 43; 1985a, p. 7]. It is likely that these control problems are intensified by the complexity and uncertainty that managers are confronted with. Besides these two problems, Merchant [1982, p. 43; 1985a, p.6] points to a third source of control problems originating in managers' lack of motivation to achieve the goals and targets set for them. Whereas there is no logical ground to assume that a thermostat would have the ambition to do other things than just controlling the room temperature, managers in reality may have personal goals that are not congruent with those of the organization. For example, managers may aim to maximize personal power or wealth to the detriment of the organization as a whole. Furthermore, their motivation to achieve organizational goals may be negatively affected by uncertainty about what the effects, and the associated payoffs, of their efforts will be. In the management control vocabulary such personal managerial aims, and the associated managerial actions, are examples of 'dysfunctional behavior' [e.g., Birmberg et al. 1983], which is a broad term relating to all managerial behavior running against the attainment of organizational objectives.

In sum, the demand for management control in organizations can be illustrated at different levels of analysis. At the organizational level, the demand for control originates in the existence of organizational objectives that have to be attained through systematic and purposeful human action. At the managerial level, the demand for management control stems from the existence of control problems, originating in managers potentially having 'personal limitations', a 'lack of direction', and 'motivational problems'. Although distinct in their origin, these latter control problems have the important common consequence of potentially causing dysfunctional behavior, and being an impediment to organizational goal attainment. In particular, this latter 'managerial' level is the focus of the APM literature and of this dissertation. 


\subsubsection{The supply of controls in organizations}

Organizations use various methods to control the behaviors of their managers, and to solve or mitigate the control problems mentioned above. These methods are called 'controls', which in contrast with the singular 'control' relate to the specific mechanisms and tools that organizations can and do apply to ensure functional managerial behaviors, and to avoid dysfunctional managerial behaviors [e.g., Dermer and Lucas 1986, p. 474]. In essence therefore:

'Controls are necessary to guard against the possibility that people will do something the organization does not want them to do or fail to do what they should" [Merchant 1985a, p. 4].

In reality the number of controls that organizations can and do apply to ensure functional managerial behaviors approaches infinity. In response, the management control literature has revealed the development of several taxonomies that reduce the infinite number of controls to some broad classes of control archetypes [see, e.g., Ouchi 1979; Hofstede 1981; Merchant 1982, 1985a]. A well-known taxonomy by Ouchi [1979] classifies controls as either clan control, bureaucratic control or market control, depending on whether goal-congruent managerial behavior is the outcome of social, formal or market rules. This classification and some examples are contained in Table 1.2 below. ${ }^{10}$

Table 1.2 Ouchi's taxonomy of management controls

\begin{tabular}{|l|l|l|}
\hline Type & Goalcongruent behavior is ensured by: & Examples of control imechanisms: \\
\hline Clan control & social processes & group spirit, teamwork \\
\hline Bureaucratic control & formal rules and procedures & budgets, work procedures \\
\hline Market control & having to obey the rules of the market & prices \\
\hline
\end{tabular}

An alternative classification by Merchant $[1982,1985$ a] divides controls into personnel control, action control and results control, depending on whether the control is directed at the input, the process or the output of the managerial function. "Table 1.3 below outlines Merchant's classification, and provides some associated management control system elements.

Table 1.3 Merchant's taxonomy of management controls

\begin{tabular}{|l|l|l|}
\hline Type & Attempt to ensure goal-congruent behavior by' & Examples of design elements: \\
\hline Personnel control & assuring the availability of 'good' managers & hiring policies, training \\
\hline Action control & specifying actions managers should (not) take & budgets, work procedures \\
\hline Results control & 'rewarding" or 'punishing' certain results & target setting and pay pollicies \\
\hline
\end{tabular}


There is an important difference between the two taxonomiles. Whereas Ouchi's classification specifies the causes of observed goal-congruent behavior ('Why do managers act to attain organizational objectives?"), Merchant proposes classes of tools that organizations can apply in response to occurring control problems ('How can organizations solve their problems associated with lack of direction, personal limitations and motivational problems?'). In other words, whereas Ouchi's taxonomy attempts to classify 'all' control mechanisms, both formal and informal, Merchant emphasizes a subset of these mechanisms that can be regarded as elements of formal management control system design, as depicted earlier with the general control model [cf. Fisher 1995, p. 25]. ${ }^{12}$ Therefore, Merchant's categories together broadly equal the class of bureaucratic control outlined by Ouchi, since they all point to the formal selection, design and use of controls within the organization. ${ }^{13}$ In this dissertation, the use of these latter bureaucratic or formal controls, and in particular the use of the budget, are the central topic of interest.

The purpose of developing control taxonomies is clearly educational, since they provide control practitioners and researchers with a vocabulary to address management control (system design) at a conceptual level. In this sense, the taxonomies implicitly point out the choices available to the organization, for the design and use of management controls. In addition, these taxonomies are a potential starting point for developing theory about the use and effectiveness of different controls in different situations both in and between organizations. This latter purpose is of most relevance to the research question in this dissertation, but the role of these and other taxonomies in theory building and testing has been limited so far, and will be limited in this dissertation. The main reason is that the classes of controls themselves do not point to empirically observable phenomena. First, many controls observed in reality cannot be unambiguously classified in one of the categories, since they combine different types of control. For example, the use of budgets for control combines such aspects as target setting, restriction of expenditures and performance evaluation, which prohibits its explicit and unique classification. Second, the classes outlined are too broad to be empirically meaningful. For example, target setting, performance evaluation and feedback, which we distinguished as critical features of formal control systems [see Section 1.2.1 above], do not fit explicitly in the classification, but in some way are part of the general classes of 'bureaucratic control' [Ouchi 1979], and 'action control' and 'results control' [Merchant 1985a].

\subsubsection{The appropriateness of controls}

Given the demand for control and the availability of different types of controls, a central issue in the use and design of management control systems is the choice of controls that are appropriate. The behavioral orientation in management control implies that both for our understanding of the functioning of management control systems, and for their design, knowledge of their effect on human behavior is paramount. 
As Lawler and Rhode [1976, p. 6] note:

The crucial aspect of any control system is its effect on behavior [...] The system needs to be designed in a way that assists, guides and motivates management to make decisions and act in ways that are consistent with the overall objectives of the organization'.

For the design of management control systems, the implication is that we have to understand what controls are needed given the nature of the control problems that exist. In other words, we have to understand how managerial control problems, which were classified as 'lack of direction', "personal limitations' and 'motivational problems", cause a need for certain controls. Equally important, however, is the assessment of whether the controls that are needed, are also actually feasible [Ouchi 1979, p. 839; Hofstede 1981; Merchant $1985 \mathrm{a}$, p. 47]. Merchant even regards the feasibility of controls the dominant factor in management control system design, as he notes [Merchant 1985a, p. 47]:

'One of the major control decisions managers must make is which types of controls to use or emphasize. These control choice decisions are complex, but probably the single most significant factor affecting the choice of control(s) is feasibility'.

A well known example of the feasibility of controls is found in Ouchi's more detailed analysis of the application of bureaucratic controls. Adopting the principle of cybernetic control, Ouchi focused on performance evaluation as the essential requirement for the feasibility of any form of bureaucratic control [Ouchi 1977, p. 97; 1979, p. 839]. ${ }^{14}$ Ouchi analyzed whether, for achieving control, the measurement and evaluation of the performance of managers (steps 2 and 3 in the control process) should be based on the assessment of their behaviors or their outputs. ${ }^{15}$ Based on the work of Thompson [1967] on organizational uncertainty, Ouchi specified two antecedent conditions that determine the feasibility of behavior and output measurement. Ouchi argued that to be able to rely on the measurement of behavior knowledge is needed on the cause-effect relationship between behaviors and results. Only then:

$\therefore$ supervisors can rationally achieve control by watching and guiding the behavior of their subordinates' [Ouchi 1977 p. 97].

Similarly, a necessary condition for the measurement and evaluation of the output is the ability to measure (individual) managerial output. In sum, Ouchi expected that the two conditions determine the contextual feasibility of the use of performance evaluation for control, as presented in Table 1.4. 
CHAPTER 1 INTRODUCTION

Table 1.4

The feasibility of different forms of performance evaluation

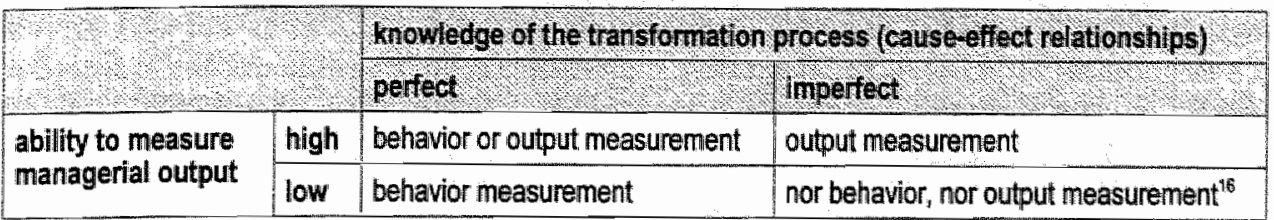

Ouchi's analysis is partial. It focuses on the performance evaluation aspect of control, and it furthermore assumes that agreement exists between supervisor and subordinate on the goals and standards for performance evaluation [cf. Birnberg et al. 1983, p. 115]. However, even this simplified scheme provides a useful illustration of the relationship between the need for controls, discussed earlier, and their feasibility, since the two contextual dimensions that Ouchi uses equal those that challenge the assumptions of the cybernetic model of control.

In the remainder of this dissertation, we will refer to the need and feasibility of controls simultaneously as the 'appropriateness' of controls. ${ }^{17}$ Therefore, the use of a certain control is appropriate when it meets the need for control, when it is feasible and thus when its use results in functional managerial behavior and output. In contrast, the use of a certain control is inappropriate when it does not meet a need for control, when it is infeasible, and when its use does not counter, or even enhances dysfunctional managerial behavior. This description of the concept of appropriateness thus reflects the behavioral perspective in management control, which implies that the appropriateness of controls is ultimately determined by its effects on managerial behavior.

\subsection{The role of APM in management control}

\subsubsection{Budgets and control}

Although management control has gained acceptance as an independent subject area over the last decades, its central and cybernetic concepts of target setting, performance evaluation and feedback are strongly rooted in management accounting [e.g., Ansari 1977; Machin 1983; Parker 1986; Otley et al. 1995]. This is reflected in the definitions of Lowe [1970, see Section 1.2.1], describing a management control system as a 'system of organizational information seeking and gathering, accountability and feedback', and in Anthony's [1965] early definition of management control systems as:

'Those formal, systematically developed, organization-wide, data-handling systems which are designed to facilitate management control'.

As Machin [1983, p. 24] argues, this latter definition points to a historical bond between management accounting and management control since:

$\therefore$ in the early 1960s the only 'formal systematically developed, organization- 
wide, data-handling systems which were designed to enable managers etc... ' were accounting based. [and] were studied by qualified accountants .

However, as Parker and Lewis [1995, p. 212] note, the emphasis in management control on management accounting concepts and techniques is persistent and can even be considered "topical' because in business and management:

'...the dominant themes of the 1990 s have become financial discipline, efficiency measurement, market solutions and the commercial 'bottom line' [...] This contemporary environment and its attendant philosophies have sponsored the persistence of the classical management approach towards control in bath organizational management and management accounting'.

The 'classical management approach towards control' in the terminology of Parker and Lewis [1995] is known as the theme of responsibility accounting in the management accounting literature. Responsibility accounting addresses the use of accounting techniques for control in decentralized organizations, and in particular emphasizes the use of budgets as the primary (accounting) instrument for contro] [Otley et al. 1995, p. $\$ 39]$. In the accounting and control literature, a budget is typically defined as:

and as:

$$
\text { '... a formal, quantitative expression of plans ' [Horngren et al. 1996, p. 254], }
$$

‘... a plan, usually expressed in monetary terms and usually for a period of one future year' [Anthony 1981, p. 87].

The empirical literature shows support for Parker and Lewis" contention, evidencing the important role of budgets in contemporary organizations, in both the private and public sector [see, e.g., Umapathy 1987; Skinner 1990; Merchant and Riccaboni 1990; Otley 1990]. Typically, the management accounting literature points out several distinct functions of budgets that together shape the 'budgetary control system' [see, e.g., Hofstede 1967, p. 23; Emmanuel et al., 1990, p. 162; Horngren et al. 1996, pp. 257$258] .{ }^{18}$ These functions are summarized and described in Table 1.5 below.

Table 4.5 The control functions of budgets

\begin{tabular}{|l|l|}
\hline Function & Description \\
\hline 1. Autharizing & $\begin{array}{l}\text { formal authorization of manager to spend a given amount of money on } \\
\text { specific activities in a certain period }\end{array}$ \\
\hline 2. Forecasting or planning & formulate expectations and targets for individual manager \\
\hline 3. Communication & communicate targets and actual performance to individual managers \\
\hline 4. Measuring (evaluation) & comparing actuall performance with planned performance and targets \\
\hline
\end{tabular}

The above functions of the budget clearly point to its role for control, since the different 
functions of the budget neatly correspond to the steps in the cybernetic control process outlined earlier [Searfoss 1976, p. 375]. Budgetary control systems are also a clear example of information seeking and gathering systems [see Lowe 1971; Anthony 1965; Ansari 1977], that provide accountability and feedback [Roberts 1991, p. 363]. Budgeting thus supports the essential control elements of target setting, performance evaluation and feedback for individual managers [Kenis 1979, p. 707; Armstrong 1989, p. 31]. This causes budgets to be an important source of controls, and allows budgets to be labeled as bureaucratic instruments [Ouchi 1977; 1979], with an emphasis on elements of results control and action control [Merchant 1982, 1985a]. Therefore and in sum, the management accounting literature strongly emphasizes the formal and cybernetic theory of control [e.g., Birnberg et al. 1983; Argyris 1990]. In this literature, the use of budgets for managerial performance evaluation is further elaborated in the subarea of responsibility accounting.

\subsubsection{Responsibility accounting}

In the management accounting literature, the term 'responsibility accounting' applies to both a subject area and an organizational practice. Responsibility accounting as a practice applies in decentralized organizations to individual managers who are, as supervisors, responsible for a separate and distinct area of organizational activity. Such areas are labeled 'responsibility centers" if the authority and responsibility of these managers not only pertain to functionall demands, but also extend to the costs and profits of such areas [e.g., Vancil 1979, p. 35; Ezzamel 1990, p. 15].

Responsibility accounting as a subject area therefore addresses the use of accounting information (i.e., costs, revenues and profits) and accounting techniques (especially budgeting) to plan, coordinate, measure and evaluate the performance of responsibility centers and their managers [e.g., Kaplan and Atkinson 1989; Horngren et al. 1996, Horngren et al. 1997]. The similarity between these functions in particular and those of management control systems in general is an additional reason that today authors even equate management control and responsibility accounting [Anthony and Govindarajan 1995, p. 16]. ${ }^{19}$ Furthermore, it explains why an organization's budgeting system is generally regarded as the primary instrument that serves the organizational need for management control [e.g., Parker and Lewis 1995; Fisher 1995].

A central issue in the literature on responsibility accounting concerns the appropriateness of using budgets for the performance evaluation of the responsible manager. On the one hand, it is pointed out that budgets, and the information they contain, are useful for managerial target setting and performance evaluation. As, for example, Merchant [1985a, p. 92] points out, budgets are relatively cheap, systematic, objective and relevant sources of information about managerial performance. On the other hand, the literature on responsibility accounting devotes considerable attention to the problem of controllability, which concerns the question to what extent a manager should be held accountable for 
budget items that he cannot influence by his own actions [e.g., Horngren et al. 1997, p. 192; Atkinson et al. 1997, p. 564]. A strict and normative answer to this question has been formulated as the controllability principle, stating that:

$\therefore$... the manager of a responsibility center should be assigned responsibility only for the revenues, costs, or investment that responsibility center personnel control' [Atkinson et al. 1997, p. 564].

The controllability principle is fundamental to responsibility accounting [Hirst 1983a; Choudhury 1986, p. 189; Merchant 1987, p. 316]. On the one hand, the principle underlies the traditional and well accepted accounting view of decentralization, as expressed in the classification of responsibility centers (cost centers, profit centers and investment centers) [Miller 1982, p. 36; Otley et al. 1995, p. S39; Atkinson et al. 1997, p. 564]. On the other hand, the principle contains an admonition regarding the uncritical use of budgetary information for managerial performance evaluation, particularly in uncertain and complex environments. In this latter sense, the principle expresses a specific response in the case of budgetary control systems to the general problems associated with the use of cybernetic control in dynamic and uncertain environments. Especially this latter use and meaning of the controllability principle are not without problems. On the one hand, it is generally accepted that adherence to the principle is desirable, since the principle represents that performance evaluations should be 'fair' [e.g., Merchant 1987, p. 317]. Choudhury [1986, p. 189] thus notes:

$\therefore$ the notion of being answerable (only) for what one is able to influence, may be viewed as conforming to a commonly held concept of justice...'.

On the other hand; a strict application of the principle would imply that in most cases the use of budgets for managerial performance evaluation, and thus for management control would not be feasible, since in uncertain and complex organizations, with people working in joint effort, the possibility to single out individual responsibilities is severely limited [cf. Hirst 1983a, p. 29]. As, for example, Horngren et al. [1997, p. 192] explain:

$\therefore$..few costs are clearly under the sole influence of one manager. For example, costs of direct materials may be influenced by a purchasing manager, but such costs also depend on market conditions beyond the manager's control. [...] Moreover, managers often work in teams. How can individual responsibility be evaluated in a team decision?"

The tension between the apparent logic of the controllability principle, and its apparent linited practical applicability has lead to different opinions about its value. For example, Hirst [1983a, p. 36] points out that the principle is paradoxical. On the one hand, decentralization is an important means of enhancing the controllability of organizational processes, and budgets are important tools to formalize decentralization, by means of creating responsibility centers. On the other hand, a strict application of the controllability principle would hinder the subsequent use of the budget for managerial performance evaluation. This and similar paradoxes, which point to the apparent limited feasibility of 
formal controls in cases where they may be most needed, are mentioned throughout the control literature [e.g., Ouchi and Maguire 1975; Vancil 1979]. ${ }^{20}$ In response, some authors stress the importance of budgetary control, and warn against overemphasizing the principle [e.g., Choudhury 1986]. Others point to the limited empirical evidence for the use of the principle [e.g., Merchant 1989; Otley 1990]. Atkinson et al. [1997, p. 564] summarize these opinions by noting:

'Although the controllability principle seems to be appealing and fair, it can be difficult, often misleading, and undesirable to apply in practice'.

Others stress the validity of the principle, noting that it relates to the value of the information generated by the budgetary control system, and noting the potential limited 'informativeness' of budgetary data in complex, dynamic and thus uncertain environments. In this sense, Horngren et al. [1996, p. 343] for example note:

'Costs that are completely uncontrollable tell nothing about a manager's decisions and actions because, by definition, nothing the manager does will affect the costs'.

Especially this latter tension between the advantages and disadvantages of using budgets for managerial performance evaluation, highlighted by the controllability principle, has lead to the body of research that investigates the appropriateness of the use of budgetary control systems. It is this literature to which this dissertation aims to contribute.

\subsection{Summary and overview of the remainder of this dissertation}

The overview in this chapter so far allows us to further specify the research question of this dissertation, and to position this question in the management control and management accounting literature. First, responsibility accounting points to the application of budgets for controlling individual managers of responsibility centers. ${ }^{21}$ Budgets are an important source of formal control, being bureaucratic instruments [Ouchi $1977,1979]$ that contain elements of result control and action control [Merchant 1982, 1985a]. The use of budgetary information for managerial performance evaluation, which is the focal topic of the literature on responsibility accounting, equals the concept of RAPM that we discussed at the beginning of this chapter.

Second, we have discussed the relationship between uncertainty and the need for control in organizations. The need for control generally stems from organizations having objectives that need to be achieved through human beings, complemented with a specific need for controls stemming from the existence of managerial control problems. We have argued that the uncertainty and ambiguity organizations are confronted with, are important determinants of this need for control. In general, uncertainty challenges the assumptions underlying the general cybernetic conception of control. More specifically, uncertainty is likely to intensify the control problems associated with managers' lack of direction, personal limitations and motivation. 
Third, our discussion illustrated that uncertainty does not only affect the need for control, but also the feasibility of controls. Uncertainty generally challenges the practicability of the steps in the cybernetic model of control, and in particular is argued to affect the feasibility of different forms of performance evaluation. In the literature on responsibility accounting, the effect of uncertainty on control and performance evaluation is reflected in the controllability problem. This problem essentially addresses the apparent discrepancy between the 'fairness' of holding managers only accountable for budgets that are controllable, and the limited feasibility of doing so in uncertain and complex organizations. But, in addition, this problem points to a more general theme concerning the effects of uncertainty on the appropriateness of using budgets for managerial performance evaluation. This theme, and the elements it contains, underlies the research question that we already specified in the beginning of this chapter;

What is the impact of uncertainty in the subordinate managers' working environment on the appropriateness of $A P M$ for managerial performance evaluation?

The structure of the remainder of this dissertation is as follows. In Chapter 2, we review the empirical literature that has investigated the contextual appropriateness of APM. Based on this review of the literature, we will conclude that the impact of uncertainty on the appropriateness is not well understood, and needs further study. Therefore, in Chapter 2 we further develop the research question by specifying four directions for further empirical inquiry. First, we discuss the meaning and measurement of the concept of 'appropriateness' of APM. Second, we argue that different types of uncertainty exist, which may affect the appropriateness of APM differently. Third, we argue that the manager's personality may affect the appropriateness of APM. Finally, we propose to examine potential dimensions underlying the RAPM construct.

These four directions are followed in Chapter 3, where hypotheses are developed concerning the relations between uncertainty and the appropriateness of APM. Chapter 4 then describes the method used in the empirical study designed to test these hypotheses. Data were gathered using a questionnaire instrument, used in a survey among 250 responsibility center managers in eleven Dutch organizations, from which 196 usable responses were obtained. Chapter 5 presents descriptive statistics and item analyses for the variables measured with the questionnaire instrument. Chapter 6 subsequently presents the results of the tests of the hypotheses developed in Chapter 3. Finally, Chapter 7 discusses the findings and their implications considering the four directions of inquiry. This chapter further addresses some limitations of this study, and presents suggestions for further research. 


\section{Notes to Chapter 1:}

1. The label 'RAPM' was introduced by Hirst [1981]. Alternative and synonymous labels for this construct are Budget Emphasis [e.g., Brownell and Dunk 1991], Supervisory Style [e.g., Briers and Hirst 1990] and Supervisory Evaluation Style [e.g., Harrison 1992].

2. See for technical perspectives towards (budgetary) control systems for example Kim [1988] and Kallman and McKinnon [1989]. Technical aspects of control and information systems are the focus of the literature on Information Technology (IT) and Accounting Information Systems (AIS) [e.g., Cushing et al, 1996; Laudon and Laudon 1996].

3. See, e.g., Baiman and Noel [1985], Demski and Sappington [1989] and, for overviews of the economic literature on control in particular, Baiman [1982, 1990]. See for a discussion of differences between the organizational and economic approaches to control, e.g., Eisenhardt [1985] and Kren and Liao [1988].

4. The notion of effectiveness is certainly economic, yet the operationalization of effectiveness in terms of managerial behaviors and attitudes is not part of mainstream economic theory. Baker et al. [1988, p. 594] note with regard to performance evaluation and compensation: 'Typical explanations offered by psychologists, behaviorists, human resource consultants, and personnel executives are distinctly uneconomic - focusing on notions such as fairness, equity, morale, trust, social responsibility, and culture'. See for the assumptions in economic theory, and the main focus in agency frameworks on pay rather than performance evaluation, e.g., Neu [1992, pp. 224-225].

5. In the development of these frameworks both the overall APM paradigm as well as individual APM studies have been greatly influenced by contingency theory [see, e.g., Otley 1980, and Chapter 2 of this dissertation]. This has not only led to the explicit inclusion of contextual variables in APM research models, but also to the adoption of the concept of 'fit' as the 'ultimate' dependent variable. Contextual APM research therefore generally formulates its research questions in terms of the effectiveness rather than just the effects of the use of budgetary control systems.

6. In the last decades, case and field study methods have entered the area of budgetary control research [see, e.g., Ferreira and Merchant 1992, for an overview]. None of these studies can, based on our criteria, be classified as APM studies, because of their very different methods of data collection and analysis, and their typical wider scope than the use of APM alone.

7. Note that the often used term "organizational goals" is imprecise. Anthony and Govindarajan [1995, p. 5] note in this respect: 'Literally, the organization is inanimate and cannot have goals. The goals are the goals of the leader or leaders of the organization'.

8. See Anthony [1981, p. 37], Hofstede [1981, p. 196] and Otley and Berry [1980, p. 236] for a discussion of the assumptions underlying the general cybernetic control model. These assumptions include: (1) the existence of unambiguous and stable objectives; (2) the measurability of outputs; ( 3 ) the existence of a "predictive model" that contains knowledge of the effects of interventions in the process; and, (4) the availability of a set of corrective 'control actions'.

9. In other words, a distinction should be made between a 'cybernetic model' of control and a model of 'cybernetic control'. Certainly, much management control practice is not strictly 
cybernetic, but the cybernetic model is a clear and concise summary of the essential features of a formal management contro] process [see, e.g., Flamholtz and Das 1985; Merchant and Simons 1986; Otley et al. 1995]. The distinction is not always recognized. [e.g.; Hofstede $1981]$.

10. This classification was derived by observing management control practice in a distribution division of a large company, and in particular by asking how, for each of the people working in the division, the individual contribution to the company's overall goals could be assessed. Ouchi found that divisional salespeople were essentially controlled by the market mechanism [Ouchi 1979, p. 835]. Market competition did not only result in the establishment of "fair prices' for the company's products, but also provided the salespeople's managers with relatively simple criteria for evaluating sales performance. In addition, Ouchi found that the people in the warehouse were controlled by the establishment of a bureaucratic mechanism of rules and routines, and by subsequently monitoring and directing the behavior of these people in accordance with these rules and routines [Ouchi 1979, p. 835-386]. Finally, Ouchi observed the importance of the informal and social mechanisms to support the function of market and bureaucratic control. Many people are intrinsically motivated to do what is best for the company. For controlling their behaviors this means that: :... once the manager knows they are trying to achieve the "right" objectives, he can eliminate many costly forms of auditing and surveillance' [Ouchi 1979, p. 837].

11. Personnel control relates to the input (i.e., a manager with certain capabilities). Action control to the process (the actions a manager takes), and results controls relate to the outputs (the results or accomplishments of a manager).

12. An example of the difference in approach is, for example, Ouchi's category of clan control. Ouchi observes the existence of social processes that contribute to organizational control. In contrast, Merchant aims at specifying what organizations can actually do to enhance these social processes (e.g., the design of hiring and training policies). Another example is the use of systems of transfer-pricing in multi-divisional organizations. Although such systems do contain elements of market control, as the price mechanism is used to obtain organizational and managerial goal-congruence, Merchant emphasizes that such mechanisms need to be designed in response to observed control problems. Therefore, while Ouchi focuses on control as the outcome of organizational processes, Merchant focuses on controls as designed solutions to control problems. Puxty and Chua [1989, p. 115] note an underlying difference between organization theory and management theory: 'Organisation theorists [...] ask questions concerning the way organisations operate. Management theorists take as a much closer focus the question of what a manager should do to make his organisation operate better", a distinction that also underlies the debate about "normative' verus 'positive' accounting [e.g., Christenson 1983]. Argyris [1988, p. 105] notes in this respect: 'Merchant appears to me to have a theory about educating managers to use control in business organizations [...] His book [Merchant 1985a] is closer to taking action [...]'. Note also the distinction in Section 1.2 .1 between management control definitions reflecting 'accidental' mechanisms in contrast with definitions emphasizing "systematic and rational" control processes.

13. See also the difference between 'general control mechanisms' and 'formal control systems' discussed by Fisher [1995, pp. 25-26]. 
14. Performance measurement and evaluation is argued by many to be the crucial element of formal control systems [see, e.g., Birnberg et al. 1983, p. 116; Ferris and Haskins 1988, p. 14; Horngren and Foster 1991, p. 881; Bruns 1992, p. 14; Coates et al. 1992, p. 135]. Ouchi's adoption of the cybernetic principle of control is reflected by him noting: 'Because the process of control [...] is basically a process of monitoring something, comparing it with some standard, and then providing selective rewards and adjustments, it suggests a very simple scheme. In controlling the work of people and of technologies, there are only two phenomena which can be observed, monitored and counted; behavior and the outputs which result from behavior' [Ouchi 1977, p. 97].

15. Note that Ouchi's [1977, 1979] frameworks apply to all "workers" in an organization, rather than only to "managers". For purposes of focus, we only consider managers in our discussion. Note also that the focus on performance evaluation is paralleled by an explicit shift towards a prescription for the design of control mechanisms.

16. In Ouchi [1977, p. 98] the type of control feasible in this cell is called 'ritual' as opposed to the 'rational' control associated with behavior or output measurement. In a later paper [Ouchi 1979 , p. 839], this cell denotes the use of "clan control'. See Merchant [1982, p. 47] for a similar classification of the "personnel control', "action control" and "results control" categories.

17. See, e.g., Govindarajan [1984] and Brownell [1985, p. 504] for earlier literal uses of the term 'appropriateness' in an APM context.

18. As Hofstede [1967, Chapter 2] illustrates, both the meaning of the word 'budget' and the use of budgets for control originate in governmental finance. The budget's original and typical control function lies in limiting allowable expenses for a certain period [Horngren $e t$ al. 1996, p. 254]. In contemporary organizations however the role of budgets for control both includes and exceeds this original function.

19. Anthony and Govindarajan [1995, p. 16] state: 'Management accounting has three subdivisions: full cast accounting, differential accounting, and management control. [...]. Management control (also called "responsibility accounting") is the subject matter of this text'.

20. Ouchi and Maguire [1975, p. 568] point to the paradox of using output performance measures with decentralization, stating: 'The use of output measures is largely a result of the demand for quantifiable, simple measures. Paradoxically, output measures are used most when they are least appropriate: in the face of complexity [and] interdependence'. Baker et al. $[1988$, p. 598$]$ note the tension between decentralization as a way to profit from 'specific knowledge' of the subordinate on the one hand, and the subsequent obligation for the superior to choose the "correct objective measure of subordinate performance" on the other hand. Vancil [1979] addresses as a general theme the 'ambiguity' associated with decentralization and control, noting that control implies freedom and restriction simultaneously. Finally, Thompson [1967, p. 145$]$ points to the "paradox of administration", noting that organizations" administrations aim at flexibility, while being mainly occupied with the reduction of uncertainty.

21. Therefore, addressing control problems from a responsibility accounting viewpoint ties the control problem to the specific managerial level of analysis [Merchant 1985a; Flamholtz and Das 1985]. This mitigates a problem noted by, e.g., Flamholtz and Das [1985] who argue that 


\section{ACCOUNTING FOR PERFORMANCE EVALUATION}

management control frameworks could do better in their specification of whether they address control at the organization level (organizational control), at the departmental level (departmental controll) or at the level of the individual manager (management control). 


\section{Chapter 2 \\ The appropriateness of APM: literature review and four directions for further inquiry}

\subsection{Introduction}

In this chapter, we present an overview and evaluation of the empirical literature that has studied the appropriateness of APM. This overview starts in Section 2.2 with a presentation of the origins of this literature and its development over the last four decades. The final part of this section presents a brief overview of recent APM studies that have tested contextual frameworks in which the appropriateness of APM depends on the situation in which APM are used. This overview continues in Section 2.3 where the focus is on those APM studies that have assessed the effects of uncertainty on the appropriateness of APM. This section discusses the arguments used in these studies, and presents an overview of their findings. Section 2.4 closes this chapter with an evaluation of these findings and a specification of four directions for further empirical inquiry that we will follow in the remainder of this dissertation.

\subsection{Empirical evidence of the appropriateness of APM}

\subsubsection{Functional and dysfunctional consequences of budgeting}

APM research originated in the fifties when the behavioral aspects of budgeting received academic interest [Bimberg et al. 1983, p. 116]. While early research accepted (1) the essential functions of budgets in organizations, and (2) the usefulness of the general cybernetic control model for understanding responsibility accounting frameworks, the human involvement in the budgeting process became a focal research topic. A study by Argyris [1952] provided support for the importance of the behavioral factor in understanding the effectiveness of budgets. In a case study among factory supervisors in four production firms, Argyris found that budgets seemed to have behavioral effects that should be regarded as 'dysfunctional' for management control. Budgets were often perceived as a 'source of pressure and tension', forcing factory supervisors to just focus on their own departmental problems. Consequently, these supervisors expressed negative attitudes toward their superiors, and toward budget procedures. Argyris' finding was important because it suggested that dysfunctional behavior is not merely a given factor 
that should be countered by the application of controls, but that dysfunctional behavior could indeed be invoked by the use of controls itself (in this case, budgets). Subsequent empirical budgetary research in the sixties and seventies aimed at explaining rather than just describing such budget-related behaviors [Ferris and Haskins 1988]. For example, DeCoster and Fertakis [1968] investigated the relationship between budget pressure and leadership style. Essentially, these studies attempted to explain (dys)functional reactions to budgeting by focusing on two steps in the budgeting process: (1) the way in which the budget was prepared [e.g., Hofstede 1967; Milani 1975]; and, (2) the use of budgets to control and evaluate managerial performance [DeCoster and Fertakis 1968; Hopwood 1972; Swieringa and Moncur 1972, 1975; Otley 1978].

Regarding budget preparation, early research by Hofstede [1967] and Milani [1975] suggested that the effects of budgeting depended on the extent to which subordinate managers were allowed to participate in the budgeting process and therefore to influence budget setting. This line of research was continued by focusing on the concept of 'budgetary participation' [e.g., Ronen and Livingstone 1975; Brownell 1981; Brownell and McInnes 1986; Chenhall and Brownell 1988]. ${ }^{1}$ Regarding the use of the budget as a tool for performance evaluation, Hopwood [1972] and later Otley [1978] focused on the use of budgetary information by superiors to evaluate their subordinate's performance. As the latter two studies are commonly regarded as the starting point for APM research [e.g., Kren and Liao 1988; Briers and Hirst 1990], Section 2.2.2 discusses these studies in more detail.

\subsubsection{Functional and dysfunctional consequences of APM}

Hopwood [1972, 1973] replaced the concept of 'budget pressure' from Argyris [1952] and DeCoster and Fertakis [1968] with the more focused concept of supervisory style. Essentially, Hopwood [1972] questioned whether dysfunctional reactions to budgeting were an inevitable consequence of the inherent characteristics of accounting information contained in the budget, or the effect of the use made by superiors of accounting information to evaluate the performance of their subordinate managers. Hopwood [1972, pp. 157-158] points to four inherent limitations of accounting information to assess individual managerial performance, thereby implicitly elaborating on the problems addressed by the controllability principle.

'First, not all the relevant dimensions of managerial performance are included in accounting reports since neither accountants nor managers have developed comprehensive measures and standards.

Second, even considering the economic aspects of performance, an organization 's economic cost function is rarely known with precision and an accounting system can only attempt to approximately represent its complexity [...].

Third, the accounting data are primarily concerned with representing outcomes, while managerial activity is concerned with the detailed process giving rise to the final outcomes $[\ldots]$. 
Fourth, the main emphasis of accounting reports is on short-term performance indexes while the evaluation of managerial performance is often concerned with more long-term considerations."

Hopwood [1972] formulated the general expectation that dysfunctional behavior associated with the use of accounting performance information resulted from superiors neglecting these defects and using budgets in an absolute or 'budget-constrained' way. In particular, Hopwood [1972] expected and indeed found that such a strict use of the budget standard to evaluate managerial performance negatively affects managers' levels of job-related tension, job attitudes, social relations and would indeed spur dysfunctional behavior (here; dysfunctional decision making and data manipulation). In particular such effects were argued to be the consequence of:

$\therefore$ disagreement and conflict between [the subordinate] and his supervisor over the dimensions, and their values, on which the job is described and evaluated. [...] Furthermore, even if the cost-center manager tries to improve his performance in terms of the accounting indexes, the behavior which is necessary to achieve this is not always clear if some of the reported costs are not under his contral [...]' [Hopwood, 1972, p. 161].

Hopwood's hypotheses were based on role theory, which had been developed in the work of Kahn et al. [1964]. As this quotation illustrates, Hopwood's particular theoretical expectation was that strict emphasis on budget attainment would cause 'role conflict', resulting in the dysfunctionall consequences mentioned [Hopwood 1973]. Role conflict was defined as the "simultaneous occurrence of two (or more) sets of pressures such that compliance with one would make more difficult compliance with the other" [Kahn et al. 1964, p. 19]. Thus, Hopwood argued that emphasis on meeting the budget would cause a conflict since the budget only imperfectly represents the underlying true demands of the managerial job.

Hopwood's [1972] study, which was done in a cost-center environment, was replicated by Otley [1978] who studied the effects of RAPM in a profit-center environment. Otley's findings essentially contradicted Hopwood's findings, as he found no significant relations between budget emphasis and either job-tension or negative social relations. Furthermore, Otley [1978] found positive relations between budget emphasis and managers' budgetary performance, which falsified Hopwood's suggestion that a high reliance on APM would be universally inappropriate.

\subsubsection{Functional and dysfunctional consequences of APM in context}

The contradictory findings in the Hopwood [1972] and Otley [1978] studies provided a strong motivation for further empirical research [Briers and Hirst, 1990]. Given the similarity of the two studies" research questions and methods, much of this research focused on potential differences in managerial characteristics between the Hopwood and 
Otley samples. This attention was warranted given Otley's [1978, p. 123] remark about the sample of profit-center managers that he investigated:

'The present study was designed to eliminate technical failings in the accounting system, as far as possible, by observing the operation of a well designed system in a type of organization that was well suited for the application of budgetary control'.

This notion of 'suitability' of APM laid the track for the explicit inclusion of contextual variables in research models that could explain situational differences between the Hopwood and Otley findings [Kren and Liao 1988, p. 282]. The common argument in these studies is that such contextual variables determine the extent to which information from the budgetary control system reflects 'true' managerial performance. In other words, although these studies generally accept that accounting reports may have inherent defects, as Hopwood did, they reason that the extent to which accounting reports are defective, and the extent to which their use leads to dysfunctional consequences, depends on the exact context in which they are used for control and performance evaluation.

Over the last two decades, several contextual variables have been investigated in an attempt to understand the conditions under which the use of APM is effective or ineffective. These studies have not been designed to test 'the' contingency theory of organizations, but have used the contingency framework to develop and test propositions about the contextual appropriateness of APM [cf. Schoonhoven 1981]. ${ }^{2}$ Overall, these efforts have produced a body of literature that we have labeled APM research. Brownell and Dunk [1991, p. 703] note about the development of APM research:

'The continuing stream of research devoted to this issue constitutes, in our view, the only organized critical mass of empirical work in management accounting at present.'

Despite the noted "organized critical mass" [cf. Lau et al. 1995, p. 360], studies within the paradigm vary widely in their level of analysis and the nature of contextual variables investigated. Contextual variables examined range from 'national culture' (predicting that APM are more appropriate in some countries than in others) to 'personality' (predicting that APM are more appropriate for some managers than for others). In many of these APM studies, the contextual variable chosen is argued to account for a systematic situational difference between the Hopwood and Otley samples [Kren and Liao 1988, p. 282]. These studies explicitly investigate possible differences in personal and organizational characteristics between cost center (Hopwood) and profit center (Otley) managers [e.g., Hirst 1983b]. Other studies are not motivated by the contradictory findings from these two early studies and focus on ad-hoc factors that are expected to influence relationships examined earlier. Examples of the latter type of studies are those that combined the earlier mentioned 'budget participation' construct, to explain differences in the appropriateness of APM [e.g., Brownell 1982b].

As excellent and fairly recent summaries of this contingency APM literature have 


\section{CHAPTER 2 LITERATURE REVIEW}

appeared elsewhere [Brownell 1987b; Kren and Liao 1988; Briers and Hirst 1990; Fisher 1995], we limit our presentation here to the summary above and a brief overview of these studies and the contextual variables used in Table $2.1 .^{3}$

Table 2.1 Overview of the use of contextual variables in APM research

\begin{tabular}{|l|l|}
\hline Contextual factors & Studles \\
\hline National culture & Harrison [1992, 1993]; Lau et al. [1995] \\
\hline Environmental characteristics & $\begin{array}{l}\text { Hirst [1983b]; Merchant [1984]; Govindarajan [1984]; Brownell [1987a]; } \\
\text { Ezzamel [1990]; Merchant [1990] }\end{array}$ \\
\hline Strategy & $\begin{array}{l}\text { Govindarajan and Gupta [1985]; Merchant [1985b]; Simons [1987b, 1990]; } \\
\text { Govindarajan [1988] }\end{array}$ \\
\hline $\begin{array}{l}\text { Task and departmental } \\
\text { characteristics }\end{array}$ & $\begin{array}{l}\text { Merchant [1981]; Hirst [1983b]; Brownell [1985]; Brownell and Hirst [1986]; } \\
\text { Macintosh and Daft [1987]; Govindarajan [1988]; ;moisill [1989]; Williams et } \\
\text { all [1990]; Brownell and Dunk [1991]; Ross [1995]; Lau ef all [1995] }\end{array}$ \\
\hline Budget participation & $\begin{array}{l}\text { Brownell [1982]; Brownell and Hirst [1986]; Brownell and Dunk [1991]; } \\
\text { Aranya [1990]; Harnison [1992, 1993]; Lau et al. [1995] }\end{array}$ \\
\hline Leadership style & Hopwood [1974]; Merchant [1990] \\
\hline Mlanagerial roles & Macintosh and Williams [1992] \\
\hline Relation with supervisor & Ross [1994] \\
\hline Personality & Govindarajan [1988]; Harnison [1993] \\
\hline
\end{tabular}

\subsection{Uncertainty as a contextual factor in APM research}

\subsubsection{The relevance of uncertainty to APM research}

As we discussed before, the partially contradictory findings of the Hopwood [1972] and Otley [1978] studies provided a strong motivation for the inclusion of contextual variables in research models to better explain the effects and appropriateness of APM. An important second reason for the inclusion of such contextual variables was the prior development of the contingency theory of organizations and the availability of contingency frameworks to management accounting researchers [Otley 1980, p. 416; Kren and Liao 1988, p. 283]. Preceding the development of contingency APM research, there were already several attempts to develop comprehensive contingency frameworks for management accounting and control in the seventies. Some of these frameworks were normative and explicitly directed at accounting and control system design [e.g., Lorange and Scott Morton 1974; Gordon and Miller 1976; Waterhouse and Tiessen 1978; Amigioni 1978; Daft and Macintosh 1978]. Others served as a basis to test hypotheses predicting contingency fit between certain characteristics of the organization and its accounting system [e.g., Bruns and Waterhouse 1975; Hayes 1977].

The merit of these frameworks lies in their general acknowledgment of the 
influence of the organizational and environmental context on the effectiveness of accounting systems, rather than in their findings, which are inconclusive [Sathe 1978, p. 91; Hopwood 1978, p. 8; Otley 1980, p. 417]. However, the main reason for citing these early efforts here is to illustrate their strong reliance on the contingency factors typically used in preceding organizational contingency research, which are related to the uncertainty stemming from the organization's environment and task technology [Sathe 1978 , p. 183; Otley 1980, p. 419]. In these early frameworks, the environmental factor comprises such aspects as the dynamism, heterogeneity [Gordon and Miller 1976], predictability [Waterhouse and Tiessen 1978], complexity and variability [Amigioni 1978] of the organization's external environment. Task technology reflects such aspects as the variety [Daft and Macintosh 1978] and routineness [Waterhouse and Tiessen 1978] of tasks. With their focus on the environment and the task technology these frameworks thus extended the earlier work in organizational behavior [e.g., Burns and Stalker 1961; Woodward 1965; Lawrence and Lorsch 1967; Thompson 1967; Perrow $1967,1970]$ to management accounting and control. With the environment and task technology described with complexity, variety and dynamism, this extension also implied the adoption of the concept of uncertainty as a dominant factor in the relationship between environment and technology on the one hand and the design, functioning and effectiveness of accounting and control systems on the other.

In the organizational behavior literature, the prime importance of the uncertainty concept to both organizational design and organizational research was recognized earlier by several authors. With regard to organizational research, Downey and Slocum [1975, p. 562], for example, argued that uncertainty had become the 'central concept' of organizational contingency research. Similarly, Miles and Snow [1978, p. 254] conclude that:

$\therefore$ the concept of uncertainty has emerged as a primary variable linking a great number of organizational characteristics to conditions in the environment'.

With regard to organizational design, Thompson [1967, p. 159] argued that uncertainty is the "fundamental problem' of complex organizations and that dealing with uncertainty is the "essence' of administrative processes. Similarly, Galbraith [1977, p. 36] noted that:

Uncertainty is the core concept upon which the organization design frameworks are based".

Unsurprisingly therefore, the central role of the concept of uncertainty was reflected in the first two APM studies that adopted a contingency perspective in their attempt to solve the Hopwood versus Otley controversy [Hirst 1983b; Govindarajan 1984; see also Brownell 1987b]. In other and later APM studies, uncertainty remained an important factor and was often the implicit factor behind the contextual operational variable chosen for empirical analysis. For example, Merchant [1984] investigated differences in the appropriateness of APM for subordinate managers of departments operating with different production technologies and in different markets, based on the expected difference in the level of uncertainty that the two kinds of departments would face. 
Brownell [1985] investigated differences in the appropriateness of APM between R\&D and production departments, based on the assumption that the two would face different levels of environmental uncertainty. Both Imoisili [1989] and Macintosh and Daft [1987] investigated departmental interdependence and argued that this latter variable was an important cause of uncertainty in the manager's working environment.

In the next section, we will review these and other APM studies that used uncertainty as an explicit or implicit contextual variable affecting the appropriateness of APM. First, Section 2.3.2 presents an overview of the theoretical arguments presented in these studies. Section 2.3.3 then presents the empirical evidence from these studies. Section 2.4 evaluates the evidence and develops four directions for further examination of the relationship between uncertainty and the appropriateness of APM, which form the basis of the remainder of this thesis.

\subsubsection{Uncertainty and the appropriateness of APM: theory}

As we discussed in Chapter 1 , the appropriateness of controls encompasses the need for controls and the feasibility of controls. We also discussed that uncertainty affects the control process in two major ways. First, uncertainty enhances the need for controls especially since uncertainty is a major cause of managerial control problems. Second, we have argued that uncertainty is likely to limit the feasibility of certain types of controls, as a result of a lack of unity and clarity of goals, as well as a limited knowledge of causeeffect relationships. In particular, we used the controllability problem to illustrate the implications of complexity and uncertainty for the applicability of budgetary control.

Most of the APM studies that have examined the impact of uncertainty on the appropriateness of APM have focused on the feasibility problem and have consequently hypothesized an adverse effect of uncertainty on the appropriateness of APM. The hypotheses are typically based on two successive sets of arguments.

First, the studies argue that uncertainty affects the extent to which APM represent 'true' managerial performance. Following Hopwood's arguments regarding the general defects of accounting information for performance evaluation (see Section 2.3.2) and in line with the arguments related to the controllability principle, these studies argue that uncertainty causes a discrepancy between subordinates' 'true' performance and their performance recognized by the accounting systems. This is argued to adversely affect subordinates' dispositions against the use of APM for the evaluation of their performance. In particular, uncertainty is said to affect subordinates' perceptions of the controllability, the completeness and the relevance of APM. According to the controllability argument, uncertainty manifests itself as changing conditions that affect the controlled process. Uncertainty causes predictions to be difficult and thus hinders budgetary target setting. As Govindarajan [1984, p. 128] notes:

'Performance evaluation presupposes targets - either explicit (e.g. budgets) or 
implicit. To arrive at a-priori targets that can serve as valid standards for subsequent performance evaluation ${ }_{\text {, }}$ one must be able to predict the conditions that will exist during the coming year'.

In addition, uncertainty makes it difficult to judge ex-post whether good (poor) managerial performance measured in accounting terms is the result of good (poor) managerial effort or (un)lucky circumstances [e.g., Govindarajan 1984, p. 128; Brownell 1985]. A similar line of reasoning is found in, for example, Williams et al. [1990] and Imoisili [1989]. Therefore, dysfunctional consequences of using APM under uncertainty result from not applying or not being able to apply the controllability principle.

The completeness argument stresses that uncertainty causes APM to be incomplete measures of performance, which means that they reflect "only some of the activities and outcomes associated with task performance' [Hirst 1981, p. 771]. For example, Hirst argued that APM are typically internally oriented and focus on managers' individual task performance, whereas uncertainty enhances the need for information about how managers' performances interact and are interdependent. This latter information is typically not transmitted through the accounting system and a strict use of APM does not recognize subordinates' efforts completely. Similar arguments are put forward by Govindarajan and Gupta [1985], Merchant [1990] and Ross [1995]. Some authors have extended the completeness argument to formulate the expectation that uncertainty also affects the relevance of APM [Govindarajan 1984, p. 128; Govindarajan and Gupta 1985 , p. 54]. The central argument concerning relevance is that in some circumstances financial performance is not a good indicator of real performance, since financial performance typically emphasizes short term performance, whereas other than financial factors determine an organization's long term viability. In such circumstances, subordinates will perceive APM to be less relevant for judging their performance.

Second, in the development of hypotheses these studies attempt to predict the consequences of the uncontrollability, incompleteness or irrelevance of APM. Some studies predict that, since these characteristics are seen as undesirable aspects of performance measures and limit the feasibility of the use of APM, superiors will be reluctant to use these measures and will emphasize other performance measures [e.g., Merchant 1984, Govindarajan 1984]. Other studies predict that their use by superiors will lead to dysfunctional subordinate reactions, following a line of reasoning similar to Hopwood [1972] and Otley [1978]. For example, Imoisili [1989] expects that the use of APM under high uncertainty will enhance job-related tension. Govindarajan [1988] and Brownell and Dunk [1991] expect that the use of inappropriate APM will reduce subsequent subordinate performance. Sometimes, the two kinds of expectations about the effect of uncertainty on appropriateness of APM are combined. For example, Merchant [1984] predicts both a decrease in the use of APM by superiors and an increase in dysfunctional consequences when APM are used, as a result of higher uncertainty. 


\subsubsection{Uncertainty and the appropriateness of APM: evidence}

The findings of the studies just cited provide inconclusive evidence regarding the effects of uncertainty on the appropriateness of APM. The number of studies showing outright support for the negative impact of uncertainty on the appropriateness of APM is limited. Hirst [1983b] found a significant interaction of uncertainty and RAPM affecting jobrelated tension. His results showed that under conditions of high (low) uncertainty, a greater reliance on APM resulted in higher (lower) levels of job-related tension. This suggested that APM would be appropriate under conditions of low uncertainty and inappropriate under conditions of high uncertainty. Yet, there are at least four reasons that limit a generalization of this finding to a general relationship between uncertainty and the appropriateness of APM.

First, in later studies that attempted to replicate Hirst's [1983b] findings, no interaction effects of uncertainty and RAPM on job-related tension were found [Brownell and Hirst 1986; Imoisili 1989; Brownell and Dunk 1991; Lau et al. 1995; Ross 1995].

Second, Hirst [1983b] did not find support for the expected interaction effect of RAPM and uncertainty on superior-subordinate relations, which he proposed as an alternative measure for the appropriateness of APM, following Hopwood [1972]. This suggested that conclusions about the contextual appropriateness of APM depend on the specific criterion variable used.

Third, Hirst's finding that APM are less appropriate under higher levels of uncertainty have not generally been confirmed by studies focusing on the performance effects of using APM under uncertainty. Merchant [1984], Brownell [1985] and Lau et al. [1995] did not find evidence of uncertainty affecting the relationship between the use of APM and managerial performance, which they predicted. In contrast, studies by Brownell [1987a] and Govindarajan [1988] appear to confirm the interaction effect of uncertainty on the relationship between the use of APM and managerial performance.

Finally, also studies predicting an effect of uncertainty on the use of APM by superiors provided mixed results. Merchant [1984] only found limited support for an effect of uncertainty on the use of APM. Govindarajan [1984] found that other measures than APM were used more frequently under conditions of low uncertainty, but he did not test the significance of the difference in use of APM. ${ }^{4}$ Govindarajan and Gupta [1985] found evidence for a larger use of nonaccounting information in SBU's under conditions of high uncertainty, but he also found that the use of APM seemed not to be affected by uncertainty.

In contrast also positive evidence exists that APM are especially useful in situations of high uncertainty [cf. Simons 1987a, p. 341]. Ezzamel [1990] found that APM were used more frequently under conditions of high uncertainty, the rationale of which was that larger, decentralized firms, studied by Ezzamel, would emphasize formal communication means when faced with uncertainty. Ezzamel's study builds upon and confirms earlier findings [e.g., Khandwalla's 1972; Merchant 1981; Simons 1987b] that a positive relationship exists between the uncertainty originating in market factors (e.g., 
competition) and the use of formal controls such as budgets and accounting controls. Similarly, Macintosh and Daft [1987] found a positive relationship between departmental interdependence, an important source of uncertainty [e.g., Thompson 1967] and the emphasis placed on meeting budgetary targets. A detailed overview of these studies and their findings is presented in Appendix A.

\subsection{Evaluation and four directions for our research}

The above discussion allows several conclusions. First, the concept of uncertainty appears to be an important factor in both theoretical and empirical frameworks that address the appropriateness of APM. Not only have uncertainty variables been explicitly used in research frameworks, but uncertainty is also an important factor underlying some of the specific research variables chosen. Second, despite the apparent agreement on the importance of uncertainty as a contextual factor, empirical research is limited and lacks clear and consistent evidence regarding its impact on the appropriateness of APM. Not only have replication studies been unsuccessful since they have failed to confirm earlier findings, but also the variety of theoretical and empirical models used hinders uniform conclusions [cf. Lau et al. 1995]. APM studies vastly differ in their samples, instruments used and statistical tests applied. Third, theories that underlie expectations about the appropriateness of APM under uncertainty appear to be incomplete at best. For example, Hirst [1983b] originally expected a curvilinear relationship between the use of APM and subordinate job-related tension, arguing that in situations of low uncertainty, where APM are relatively complete, a high reliance on APM may 'overly structure' the working environment, also leading to job-related tension. Thus, Hirst's original expectation was that APM may be inappropriate both under high and under low uncertainty and appropriate under medium levels of uncertainty [Hirst 1981]. So far, no empirical proof has supported this initial expectation, but the linear relationship found instead has been wrongly equated with his original theory ever since [see, e.g., Brownell 1987a]. Moreover, since also evidence exists that uncertainty may enhance the appropriateness of APM, a theoretical focus on the negative effect of uncertainty on the appropriateness of APM is likely to be incomplete.

Noting these and other problems, Briers and Hirst [1990, p. 385] sharply criticize the underdevelopment of theory in many APM studies:

'Of particular concern is the inclusion of variables in hypothesis with little supporting explanation. For example, some studies use box diagrams with arrows indicating causally related variables. Although this is a parsimonious way of communicating connections, the supporting argument in some studies is only suggestive $[\ldots]$. ${ }^{5}$

Consequently, following the general research question proposed in Chapter 1, in the remainder of this dissertation we will further investigate the relations between uncertainty and the appropriateness of APM. Although our general purpose is to better understand 


\section{CHAPTER 2 LITERATURE REVIEW}

the effect of uncertainty on the appropriateness of APM, we will do so by developing and exploring four directions of further investigation that may provide explanations for the reported lack of consistent evidence in previous APM research. The four directions are briefly introduced below and will be elaborated upon in Chapter 3 .

The first direction that we will explore is based on the possibility that the conflicting results of tests for the appropriateness of APM under uncertainty are a result of the limited focus in theories used so far concerning the meaning of the concept of appropriateness. The review of the studies reveals that studies have generally focused on the feasibility of APM, arguing that uncertainty limits the feasibility of using APM and thus concluding that APM will be more appropriate under conditions of low uncertainty. This bias can be historically explained as the start of the debate was about the unforeseen, undesired and dysfunctional behavioral effects of using budgets. Although we have argued in Chapter 1 that feasibility is an important element in management control system design and therefore also in the use of APM, we will illustrate that a further understanding of the effects of using APM under uncertainty can be found by explicitly including the effect of uncertainty on the need for controls in research frameworks. As we will argue in the following chapter, this implies the use of other criterion variables than those that are currently used in APM studies.

Second, after the discussion of the criterion variables, we will reexamine the arguments put forward in earlier APM research to predict the effect of uncertainty on the appropriateness of APM. In particular, we will argue that the type (source) of uncertainty is probably more important than is recognized in previous studies that predict effects of uncertainty on the appropriateness of APM. In particular, we will refine the arguments for task uncertainty and environmental uncertainty independently and will develop hypotheses that predict a different impact of environmental uncertainty and task uncertainty on the appropriateness of APM.

Third, we will extend current APM research frameworks by exploring the effects of managers' personality on the appropriateness of APM. Whereas previous APM studies have mainly focused on uncertainty as a factor external to the manager, we will explore the effects of managers' personal and general attitudes toward uncertainty on the appropriateness of APM. Personality factors have been mentioned as important determinants of managerial behavioral and attitudinal reactions to budgeting [e.g., Murray 1990, p. 119]. So far, however, no study has explicitly studied personality to explain the appropriateness of APM under uncertainty. In particular, we will study the effects of the personality variable "tolerance for ambiguity' (TFA) [e.g., Budner 1962; Norton 1975]. Previous research in organizational behavior and accounting suggests that this variable is important for explaining a person's attitudes, behaviors and information preferences in uncertain environments [e.g., Downey and Slocum 1975, Duncan 1972, Dermer 1973]. Our general expectation is that this personality factor may also determine subjects' responses to the use of APM.

Fourth and finally, we will further explore the meaning of the RAPM construct. As we will demonstrate in Chapter 3, empirical measurement of this construct varies 
widely across studies [e.g., Hopwood 1972; Hirst 1983b, Govindarajan 1984]. We will argue in Chapter 3 that such different measurements of RAPM may reflect differences in meaning of the RAPM construct between studies. In particular, we will argue that there is reason to believe that the RAPM construct is multidimensional, implying that tests of the appropriateness of APM may in fact have been tests of the appropriateness of subdimensions of RAPM [cf. Briers and Hirst 1990]. In Chapter 3 we will examine two such potential subdimensions, by developing hypotheses that differentiate between the effect of uncertainty on the appropriateness of using accounting information for managerial performance evaluation and the effect of uncertainty on using targets for managerial performance evaluation.

\subsection{Summary}

In this chapter we presented an overview of the APM literature, with a focus on empirical studies that have examined the appropriateness of APM under uncertainty. Based on this overview, we concluded that uncertainty is an important variable in contemporary APM research, which confirms its dominant role in the organizational behavior literature. Our understanding of the effects of uncertainty on the appropriateness of APM however is limited. In particular, there is considerable empirical evidence suggesting that uncertainty may enhance the appropriateness of APM, whereas the common hypothesis suggests the opposite. Based on this observation, we formulated four directions for the extension of the paradigm. These four directions will be further developed in the next chapter, in which they will lead to the development of several hypotheses. 


\section{Notes to Chapter 2:}

1. Budgetary participation research looks at the functional and dysfunctional consequences of subordinate participation in budgetary settings. Functional consequences may result from information sharing between superior and subordinate and from a positive effect of participation on subordinates' budgetary goal-acceptance and subsequent motivation [e.g., Brownell and McInnes 1986; Dunk 1993]. Dysfunctional consequences may result from subordinates attempting to negotiate 'slack' in their budgets [e.g., Dunk 1993]. See Brownell [1982a] for an overview of the early literature on budgetary participation.

2. We prefer the label "contextual factors' instead of "contingency factors'. APM studies do not attempt to test 'the' contingency theory of organizations which generally concerns the rellationship between environment, strategy and organizational structure. Instead, APM. studies adopt the basic philosophy of contingency research, using various variables from the performance evaluation context. For example, 'personality' qualifies as a contextual variable in APM research, although it is not a contingency factor in a traditional sense. Note however that a reference to 'the' contingency theory of organizations is not without problems [e.g., Otley 1980; Schoonhoven 1981; Fisher 1995].

3. In Table 2.1 only those studies are included that explicitly refer to the concept of APM, as described in the introductory chapter and that explicitly use contextual frameworks. This excludes studies investigating the relationships between contextual variables and managerial preferences for certain kinds of management accounting information [e.g., Chenhall and Morris 1986; Gul and Chia 1994; Mia and Chenhall 1994; Fisher 1996] and studies investigating the effects of RAPM universalistically [e.g., Merchant $1985 \mathrm{c}$; Lal et al. 1996].

4. To be precise, Govindarajan [1984] compared the relationship between uncertainty and the use of APM for different levels of performance. The proper test would have meant a test of the interaction of APM and uncertainty to affect performance. The two tests are not equivalent [see also Appendix K].

5. Briers and Hirst [1990] remark is intendedly general, without a precise specification of 'good' and 'bad' studies. Note that this critique reiterates many of Otley's comments made ten years earlier, in a review of contingency research in management accounting. Otley [1980, p. 414] noted for example: 'The contingency approach is invoked so it seems, in order to cover up some of the embarrassing ambiguities that exist in the universalistic approach'. 
ACCOUNTING FOR PERFORMANCE EVALUATION 


\section{Chapter 3 \\ Uncertainty and the appropriateness of APM: development of hypotheses}

\subsection{Introduction}

In this chapter we develop the four directions for empirical inquiry that we specified in the previous chapter. This chapter is structured as follows. In Section 3.2 we will develop the first direction concerning the meaning of the concept of appropriateness, and we will discuss and evaluate the criterion variables that were used in previous empirical APM studies to measure the appropriateness of APM. Based on the evaluation we will select alternative criterion variables that together allow for a more precise assessment of the appropriateness of APM under uncertainty. Based on this discussion, Section 3.3 then develops our second direction for enquiry. In this section, we develop hypotheses about the appropriateness of APM under uncertainty. In these hypotheses we differentiate between two types of uncertainty in the manager's working environment; task uncertainty and environmental uncertainty. Section 3.4 then extends these analyses by exploring the effect of managers' personality on the appropriateness of APM, in line with our third direction for further inquiry. In particular, we will develop hypotheses in which the appropriateness of APM depends on managers' tolerance for ambiguity. Section 3.5 then develops our fourth direction for further inquiry, by discussing the meaning of the RAPM construct, and the various ways in which this construct has been measured in previous APM research. In particular, we conclude that the RAPM construct may be multidimensional, which clearly has empirical implications. For testing these implications, several hypotheses are developed. Finally, Section 3.6 presents a summary of this chapter and an overview of the hypotheses.

\subsection{The meaning and measurement of appropriateness of APM}

\subsubsection{Appropriateness in previous APM research}

Studies that empirically examine the contextual appropriateness of APM have to choose a variable that serves as a criterion for the appropriateness of APM [e.g., Otley 1980]. In contingency terminology, such a criterion variable serves to measure the "fit" between the use of APM and the contextual variable of interest [e.g., Schoonhoven 1981]. As our 
review of uncertainty related APM studies in the previous chapter illustrates, several such criterion variables have been used. Below we will pay explicit attention to these criterion variables, which fall in the following three categories.

First, our review of the APM literature revealed that many studies have examined the effect of uncertainty on the use of $A P M$ by superiors [e.g., Merchant 1984; Govindarajan 1984]. In these studies, the appropriateness of APM under uncertainty is determined by the relationship between uncertainty and the use of APM. In other words, the use of APM is seen to reflect its contextual appropriateness, and a positive (negative) correlation between uncertainty and the use of APM is an indication of the (in)appropriateness of APM under uncertainty [e.g., Fisher 1995, p. 34].

Second, studies have used measures of performance as a criterion variable [e.g., Brownell 1985, 1987a]. In these studies, the appropriateness of APM is displayed by the effect of uncertainty on the relationship between the use of APM and subordinates' performance levels. In particular, the use of APM is (in)appropriate under high uncertainty if the relationship between the use of APM and subordinate performance is more positive (negative) for higher levels of uncertainty.'

Third, studies have used subordinates' job-related attitudes as criteria for fit [e.g., Hirst 1983b; Ross 1995]. These studies are similar to the second class mentioned above in that they include an explicit outcome variable to assess contextual fit. However, these studies do not use a measure of performance, but instead examine the effect of uncertainty on the relationship between the use of APM and factors like job-related tension and job satisfaction.

The three different forms of testing the appropriateness of APM under uncertainty used in previous APM research are graphically illustrated in Figure 3.1.

Figure 3.1 Different models for testing the appropriateness of APM

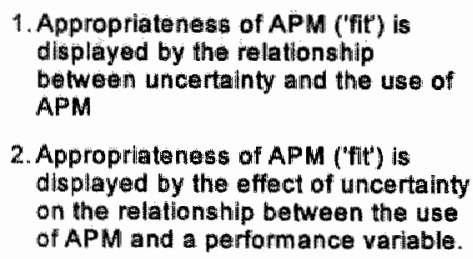
displayed by the relationship between uncertainty and the use of APM

2. Approprtateness of APM ("fit') is displayed by the effect of uncertainty on the relationship between the use of APM and a performance variable.

3. Appropriateness of APM ("fit") is displayed by the effect of uncertainty on the relationship between the use of APM and job-related attitude variable
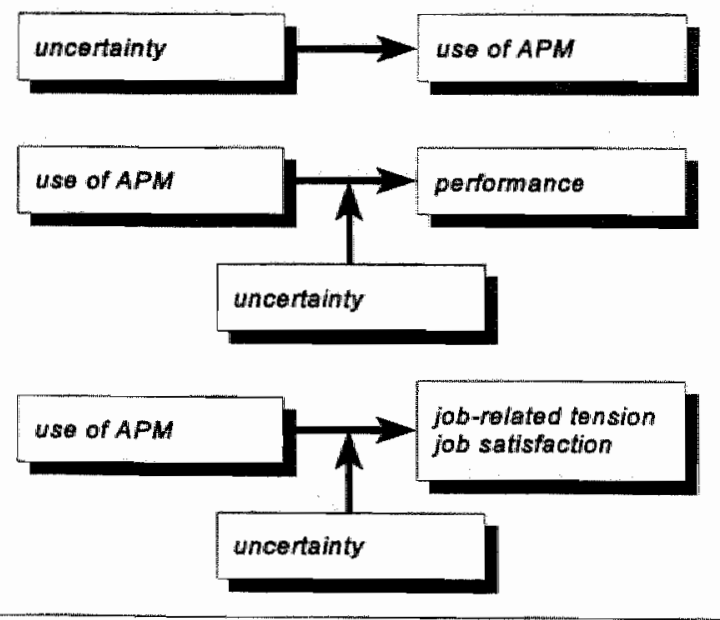


\section{CHAPTER 3 DEVELOPMENT OF HYPOTHESES}

In the remainder of this section, we will evaluate the usefulness of these variables for establishing fit between the use of APM and uncertainty, and thus to assess the effect of uncertainty on the appropriateness of APM. The discussion will point to theoretical and empirical problems associated with the three types of criterion variables previously used, and will result in a proposal of two alternative criterion variables. These alternative criterion variables are goal clarity and agreement with evaluation criteria. We will show that these variables underlie most of the theoretical arguments used to explain the appropriateness of APM under uncertainty. Furthermore, we expect that the use of these variables allows to reconcile some inconsistencies and contradictory findings in earlier APM research. In addition, we will propose and use a third criterion variable that directly addresses the opinion a manager has about the appropriateness of APM.

\subsubsection{The use of APM, performance and job attitudes as criterion measures of fit}

As the general purpose of management control systems is to contribute to the attainment of organizational objectives, an obvious criterion variable to test the effectiveness of these systems is a measure of organizational performance [e.g., Smith 1983, p. 750]. In this sense, Otley [1980, p. 425] notes:

...explicit consideration of organizational effectiveness is a vital part of a true contingency theory of control system design.'

The implications of this argument are twofold. First, it implies that tests of the fit between contingency factors and the accounting system should include an explicit outcome variable as a criterion [cf., e.g., Brownell 1985 p. 503; Gul 1991, p. 57]. Second, it suggests that a measure of organizational effectiveness is the most obvious candidate. Below we will discuss the implications and validity of this point of view for APM research. In our discussion we will follow the three classes of criterion measures specified above.

\section{Use of APM as an indication of the appropriateness of $A P M$}

In essence, the above argument excludes the 'use of APM' as an indication of its contextual appropriateness. Since we have defined appropriateness of controls in terms of the need and feasibility of controls for directing managerial behavior, the APM paradigm is not a theory that attempts to explain the choice of performance criteria by superiors for subordinate performance evaluation criteria. Instead, APM studies develop theories about the appropriateness of using APM in terms of subordinates" behaviors, and not superiors' choices. ${ }^{2}$ Therefore, although the "use of APM" is an indicator of its appropriateness, the arguments add up to the conclusion that it should not be the primary indicator of appropriateness. Therefore, we will not use it as a criterion for appropriateness in this study. 


\section{Performance as a criterion measure}

The use of measures of organizational effectiveness in APM research appears equally problematic, especially when we consider the typical unit-of-analysis in APM research, and the validity of measures of performance in the APM paradigm. Regarding the former, APM research is concerned with the subunit level within organizations, such as business units or functional departments, and with individual managers. In other words, APM research does not examine the general or organization-wide characteristics of management control systems, but the use of information from these systems by individual superiors for the evaluation of their individual subordinate subunit managers [see also Brownell 1987a, p. 187]. Therefore, APM studies are not about predicting fit between the 'organization-wide' budgetary control system and its context, but about the use of information from this system for managerial performance evaluation. A criterion variable used to assess the appropriateness of APM should therefore reflect the subunit level of performance, which suggests that measures of organizational performance and effectiveness are not adequate but that either departmental or managerial performance measures should be used.

In addition however, a validity problem exists with the use of any organizational, departmental or managerial performance measure as the criterion variable. This problem originates in the paradox of selecting an 'appropriate' performance variable, and thus defining performance, for research purposes in a research paradigm that examines the 'appropriateness' of performance measures. An example is Otley's [1978] use of 'budgetary performance' as a criterion variable for the appropriateness of APM. As Otley's study was about the appropriateness of budget-related performance measures, this logically excludes this variable as the dependent criterion variable. ${ }^{3} \mathrm{~A}$ positive relation between the use of APM and budgetary performance only supports the general believe that the performance dimensions emphasized by superiors, will be strived for by subordinate [Ridgway 1956; Merchant 1985a; Baker et al. 1988]. Finally, as some authors point out, it is possible that RAPM is not a cause but a consequence of performance. That is, the performance of a manager, his department or the organization overall may determine what style of evaluation is used [e.g., Otley 1978; Imoisili 1989; Briers and Hirst 1990$].{ }^{4}$ If so, performance is not an outcome but rather a determinant of RAPM. Although we do not know whether these difficulties are the cause of the inconsistent evidence in APM research that has used 'performance' as the criterion variable, they do raise doubt about the inclusion of performance as a criterion variable in APM research [cf. Briers and Hirst. 1990, p. 382].

\section{Job-related attitudes as a criterion measure}

Even without considering the level-of-analysis issue (see above), Otley [1980, p. 421] notes that there are 'substantial difficulties' in the measurement of organizational effectiveness [cf. Campbell 1977]. He concludes:

¿... it may be sensible as an interim measure to be content with the measurement of intervening variables, that is, variables which are thought to pre-dispose an organisation towards effective rather than ineffective operation: 
Consequently, APM studies have focused on job-related attitudes and especially jabrelated tension as criterion variables [e.g., Hopwood 1972; Otley 1978; Hirst 1983b; Imoisili 1989]. The use of job-related tension is motivated on the following three grounds. First, job-related tension is argued to be the typical consequence of managers facing 'role conflict', stemming from superiors emphasizing APM, and thus emphasizing uncontrollable, incomplete and irrelevant performance targets [Hopwood 1972; Otley 1978], a fact also recognized in the organizational behavior literature [e.g., Gupta and Beehr 1979; Schuler 1980]. Therefore, job-related tension is not merely used as a "second best' predictor of the ultimate variable of interest (performance), but is also supposed to be a more direct measure of the effectiveness of control system use. Second, as already explained, job-related tension is used because it is claimed to be a cause of managerial dysfunctional behavior [e.g., Hirst 1981; Merchant 1990]. Recall that the explanation of managers' dysfunctional reactions to budgeting was an important initial objective of behavioral accounting research [Argyris 1952]. Third, job-related tension has been adopted as a criterion variable in replication studies that attempt to explain the contradictory results of the Hopwood and Otley studies [e.g., Hirst 1983b; Imoisili 1989; Ross 1995]. Job-related tension was selected in these studies as the conflicting results between the two studies were especially attributable to differences in the relationship between RAPM and job-related tension.

Yet, at least three reasons exist why the validity of job-related tension as a criterion variable for the appropriateness of APM may be limited. First, while there is some empirical support for a positive relationship between job-related tension and dysfunctional behavior [Hopwood 1972; Jaworski and Young 1990], there is no conclusive evidence on the relationship between job-related tension and performance. In particular the organizational behavior literature suggests that the relationship between job-related tension and performance is curvilinear, with medium levels of job-related tension associated with high performance, and high and low levels of job-related tension associated with low performance [see for overviews, Schuler 1980; Jamal 1984, p. 2, Tosi et al. 1994, p. 276]. ${ }^{5}$ Therefore, job-related tension is not a good proxy for performance. Second, job-related tension is not a valid measure of the overall appropriateness of APM, in other words of the net effects of both functional and dysfunctional managerial responses to RAPM. In Otley's words, using job-related tension seems to focus on the predispositions toward lower performance, especially when it is conceived as a predictor of dysfunctional behavior [e.g., Merchant 1990]. A focus on a dependent variable that measures only dysfunctional behavior seems only partially useful, especially since there is empirical evidence that uncertainty may enhance the appropriateness of APM. ${ }^{6}$ Finally, job-related tension is not a precise measure for assessing the appropriateness of APM. Studies using job-related tension to assess the appropriateness of APM in fact rely on other constructs to derive empirical hypotheses and to explain the findings. Therefore, Briers and Hirst's [1990] warrant caution regarding exclusive reliance on the job-related tension and instead recommend that APM studies should examine more 'immediate outcomes' of the use of APM [Briers and Hirst 1990 , p. 395]. In the section below, we will select and motivate two such "more 
immediate outcomes" of the use of APM that we will use as criteria for the appropriateness of APM.

\subsubsection{Goal clarity and agreement with evaluation criteria as criterion measures}

In this section we will introduce and motivate the use of two more immediate outcomes of the use of APM, which are agreement with evaluation criteria and goal clarity. We will discuss these two alternative criterion variables below, and will motivate their use in this study in two ways. First, we will illustrate that these constructs underlie many expectations and explanations of contextual (in)appropriateness of APM in previous APM research. Second, we will pay attention to the theoretical foundation of these two criteria in other fields of research.

\section{Agreement with evaluation criteria}

A close examination of the arguments that link the infeasibility of using APM, and the negative outcomes of its use in terms of lower performance, more dysfunctional behavior and higher job-related tension, reveals that these expectations are generally based on the assumption that subordinates will judge the APM criteria which are used in their evaluation as "unfair". Recall that already Hopwood's [1972] expectation about a positive relation between the use of APM and job-related tension was a result of:

"... disagreement over the dimensions, and values, on which the job is described and evaluated' [Hopwood 1972, p. 161; see also Section 2.2.2].

Similarly, Otley [1978, p. 132] found regarding job-related tension that:

... such tension is associated with the degree of agreement a manager has with the criteria being used to evaluate his performance".

These and similar arguments are frequently used throughout the APM literature to predict the contextual appropriateness or inappropriateness of APM [e.g., Hirst 1981, p. 779; Hirst 1983b, p. 597; Dunk 1990, p. 173; Ross 1994, p. 131]. In a study on the appropriateness of APM under different levels of budget participation and task uncertainty, Lau et al. [1995, p. 360] argued that under certain conditions the use of APM:

'... is unlikely to be stressful to subordinates as they are likely to agree with the choice of evaluation criteria".

These studies thus suggest that disagreement with evaluation criteria is an important consequence of using APM in uncertain environments, and an important cause of subsequent job-related tension. This in turn suggests that disagreement with evaluation criteria is a more immediate outcome of APM than job-related tension. Also in studies focusing more broadly on "control systems", the effectiveness of such systems has been argued, and shown, to be affected by its "fairness" [e.g., Vancil 1979, pp. 89-92; 
Merchant 1989, p. 87]. Recall from Chapter 1 that faimess is also an explicit consideration in the application of the controllability principle [Choudhury 1986; Atkinson et al. 1997]. In most of the literature mentioned, fairness has been either not, or only loosely defined. A theoretical foundation for the concept, and its relevance for explaining and predicting subordinate reactions to performance evaluations, is provided in the organizational behavior literature [see, e.g., Landy et al. 1978; Fulk et al. 1985]. In particular, in this literature equity theory is used to explain individuals' perceptions about the fairness (equity, justice) of the performance evaluations they receive, and their subsequent attitudinal and behavioral reactions. As Landy [1989, pp. 389-390] explains:

'The general proposition [in equity theory] states that individuals form a ratio of their inputs in a given situation to their outcomes in that situation. Inputs are defined as anything the individual feels she personally contributes [...] Outcomes are all factors that the individual perceives as having some personal value (e.g., money, promotions, or praise)' The individual [...] compares the value of that ratio with the value of the ratio for "significant others"."

Based on this notion, individuals are expected to experience distress if they perceive themselves being over rewarded or under rewarded. This distress may subsequently not only lead to job-related tension, but also to attempts to restore equity by adapting the efforts put into a job [Huseman et al. 1987, p. 222; Lindquist 1995, p. 125]. From this point of view, an individual's perceived fairness of the performance evaluation received, is likely to be negatively affected by emphasizing uncontrollable performance criteria. Such criteria do not well reflect individuals' efforts, and subsequent attempts to restore equity will likely result in lower efforts, since increased efforts will also not be 'fairly' reflected in higher performance in terms of these criteria. Perceived faimess of evaluation criteria may also affect the acceptance of those criteria as working goals, which is a prerequisite for the effectiveness of any form of target setting [e.g., Early et al. 1989; Locke and Latham 1990]. In an experimental setting, Lindquist [1995] in particular demonstrates the relevance of faimess to the acceptability of budgetary goals. ${ }^{8}$

In sum, we propose that agreement with evaluation criteria (AEC) is an essential and theoretically relevant determinant of the appropriateness of APM.

\section{Goal clarity}

In addition, our review of APM studies showed empirical evidence of positive effects of uncertainty on the appropriateness of APM, which can be described with the concept of goal clarity. Recall that Hirst [1983b] found that under conditions of low uncertainty lower levels of RAPM were associated with higher levels of job-related tension, for which he offered the following explanation [Hirst 1983b, p. 602]:

'The reason for the increase in the reported tension may depend on the nature of the replacement performance evaluation systems. If they involve more general and less precise performance criteria, then the increase in reported tension may be explained by an increase in role ambiguity due to a reduction in the clarity of the formal work requirements.' 
In a similar vein, Ross [1995, p. 9] explained his finding that there is no relationship between RAPM and job-related tension as follows:

'The lack of clarity and objectivity associated with subjective performance evaluation measures may be intensified when environmental uncertainty is perceived to be high, leading to higher levels of job-related tension than would be associated with a budget constrained performance evaluation style'.

These findings are consistent with the need subordinate managers have for control. Especially, the explanations offered by Hirst and Ross point to the control problem of 'lack of direction' that is enhanced by using subjective and qualitative, rather than objective and quantitative measures of performance. These findings are also consistent with the goal theoretic literature that is occupied with predicting the effects of goal attributes (goal difficulty and goal specificity) on subjects' motivation and subsequent task performances. In this literature, goal specificity is a construct that signifies managerial perceptions of the specificity, as opposed to the vagueness, of the working goals they have to achieve [Hollenbeck and Klein 1987, p. 214; Locke et al. 1989, pp. 271-272; Locke and Latham 1990, p. 49]. As Locke et al. [1989, pp. 272-273] explain:

'Vague goals can be interpreted in many different ways by different people; as gaals become more specific the leeway for interpretation is progressively reduced".

In their respective overviews of the empirical literature on goal theory, both Locke and Latham [1990] and Rodgers and Hunter [1991] conclude that goal-setting, defined as setting difficult and specific goals consistently shows a positive influence on task performance. In addition, goal specificity has in particular been found to enhance performance [Early et al. 1987], reduce job-related tension [Lyons 1971; Schuler 1980], enhance job satisfaction [Steers 1976], and reduce performance variability [Locke and Latham 1990, p. 49]. ${ }^{9}$ The former effects, regarding performance, job satisfaction and job-related tension, are important in light of previous APM studies investigating the effects of APM on these variables. The latter effect, regarding performance variability, is important since it relates to the role of budgets to coordinate activities between organizational departments [see, e.g., Merchant 1981, p. 815; Macintosh and Daft 1987]. In addition, another advantage of specific information on goals is that it implies specific feedback, which also affects performance positively [Murray 1990; Luckett and Eggleton 1991]. These empirical findings are supplemented in the normative literature on applied settings for goal theory, in management-by-objectives (MBO) systems [McConkie 1979, p. 32; Kahn and Shrerer 1990]. ${ }^{10}$ Earlier, Tosi [1975, p. 150] concluded:

"From these studies, and an abundance of other data on target setting, goal clarity and similar concepts, it can be concluded that the "motivating" effect of the budget derives from simply the fact that it is a statement of explicit goals'.

The evidence for goal clarity as a relevant variable to assess the appropriateness of APM is supported by Hopwood [1972; 1973]. Whereas the Hopwood [1972] study is 


\section{CHAPTER 3 DEVELOPMENT OF HYPOTHESES}

remembered for finding a positive relationship between RAPM and job-related tension, this study also reports a negative relationship between the absolute emphasis placed on "meeting the budget" and "concern with cost' and subordinates' job-related tension [Hopwood 1973, p. 85]. "Additionally, Hopwood [1972] found a positive relationship between emphasis on 'meeting the budget' and goal clarity, for which he gave the following explanation [Hopwood 1972, p. 173]:

'Of itself, concern with meeting the budget can result in quite favorable consequences. This might reflect the fact that one purpose of the budget is to clearly set out the objectives for a cost center. While this certainly cannot be done with perfect accuracy, it is possible to carefully and cautiously use the budget for this purpose, and thereby add an important element of structure and clarity to the job environment." ${ }^{2}$

Therefore, we believe that goal clarity (GC) is a suitable criterion variablle that captures a relevant second dimension of the appropriateness of APM.

In sum, in the development of hypotheses in the remainder of this chapter we choose to focus on two outcomes of the use of APM, which are goal clarity (GC) and agreement with evaluation criteria (AEC). Our reasons for focusing on these variables can be summarized as follows.

First, GC and AEC appear to be the underlying factors on which expectations about the relationship between the use of APM and job-related attitudes and performance have been based in previous APM studies. Therefore, their explicit and simultaneous examination allows a more comprehensive test of the effects of APM, which also implies a test of the theories used in these previous studies. Furthermore, the explicit test of these underlying variables corresponds with Briers and Hirst's [1990, p. 395] argument concerning the current state of theoretical development of APM research, and their recommendation that studies should examine the more 'immediate outcomes' of using APM

Second, both GC and AEC are theoretically supported to be relevant and desirable outcomes of performance appraisal (systems), especially since a lack of goal clarity and agreement with evaluation criteria may be associated with the earlier mentioned three types of managerial control problems (personal limitations, motivational problems, lack of direction).

Third, the empirical findings in APM research and their interpretation suggest that the appropriateness of APM may be a relative rather than an absolute matter. In other words, the outcomes of using APM under uncertainty, in terms of performance or jobrelated tension, may be the result of a combination or even a tradeoff of positive (GC) and negative (AEC) effects [see Ross 1995, p. 9]. This suggest that our understanding of the appropriateness of APM may be enhanced by enabling a simultaneous and explicit assessment of such positive and negative effects of using APM. A focus on a single and overall performance or attitudinal variable may, in contrast, hide such a tradeoff. We further believe that $\mathrm{GC}$ and $\mathrm{AEC}$ are especially relevant outcome variables, which are 
related to the issue of feasibility and need for controll that we discussed as a general concern in the application of controls. Therefore, the use of these variables enables us not only to capture both the positive and negative effects of using APM under uncertainty, but also to address these effects in terms of both the feasibility and need for APM.

\subsubsection{Managerial opinions about the appropriateness of APM}

Our discussion combined with the findings from previous APM studies suggests that the appropriateness of APM may be a combination of positive and negative outcomes of using APM. This implies that we also have to reassess the negative relationship between uncertainty and the controllability, completeness and relevance of APM that is the fundamental assumption underlying all expectations about the inappropriateness of APM under uncertainty. As we discussed in Chapter 2, an important assumption underlying predictions of the inappropriateness of APM under uncertainty is that managers will feel a discrepancy between the true demands of their tasks, their 'true' performances and the representations of those in accounting and budgetary information. This implies that uncertainty causes subordinate managers to be predisposed against the use of APM. This assumption has not been directly tested, since APM studies have focused on the effects of uncertainty on the use of APM and on the outcomes of using APM. Therefore, only limited direct evidence exist of the effect of contextual factors on managers' opinions about the appropriateness of APM, with a notable exception of Hirst's [1983a] test and finding of a negative relationship between uncertainty and a variable called controllability of financial outcomes [Hirst 1983a, pp. 34-35]. To fill this gap, we will use a third criterion variable which we call felt appropriateness of $A P M$ (FAAPM). This variable reflects managers' opinions about the appropriateness of budgetary data for performance evaluation, and reflects subordinates' opinions in terms of the informativeness of budgets and the acceptability of budgetary goals.

In sum, we will use an opinion variable in addition to the two outcomes variables ( $\mathrm{GC}$ and $\mathrm{AEC}$ ), for the following reasons. First, assumptions regarding managerial opinions about the appropriateness of APM play a vital role in developing expectations about the contextual appropriateness of APM, since underlying the expectations of dysfunctional consequences is the supposition that uncertainty reduces the controllability, relevance and completeness of APM. Second, the use of an opinion variable allows us to compare our findings with those studies that have studied how preferences for certain aspects of management accounting information are affected by contextual factors [e.g., Merchant 1981; Gordon and Narayanan 1984, Chenhall and Morris 1986; Lyne 1992].

In sum, we will use three variables to serve as criteria for the appropriateness of APM. Both goal clarity and agreement with evaluation criteria serve as outcome variables, since they relate to the outcomes of using APM. The variable felt appropriateness of APM serves as an opinion variable, relating to subordinate's disposition against the use of APM. The basic relationships that we will investigate using these three variables, are 


\section{CHAPTER 3 DEVELOPMENT OF HYPOTHESES}

together graphically depicted in Figure 3.2 .

Figure 3.2 Relationships to be investigated in this dissertation

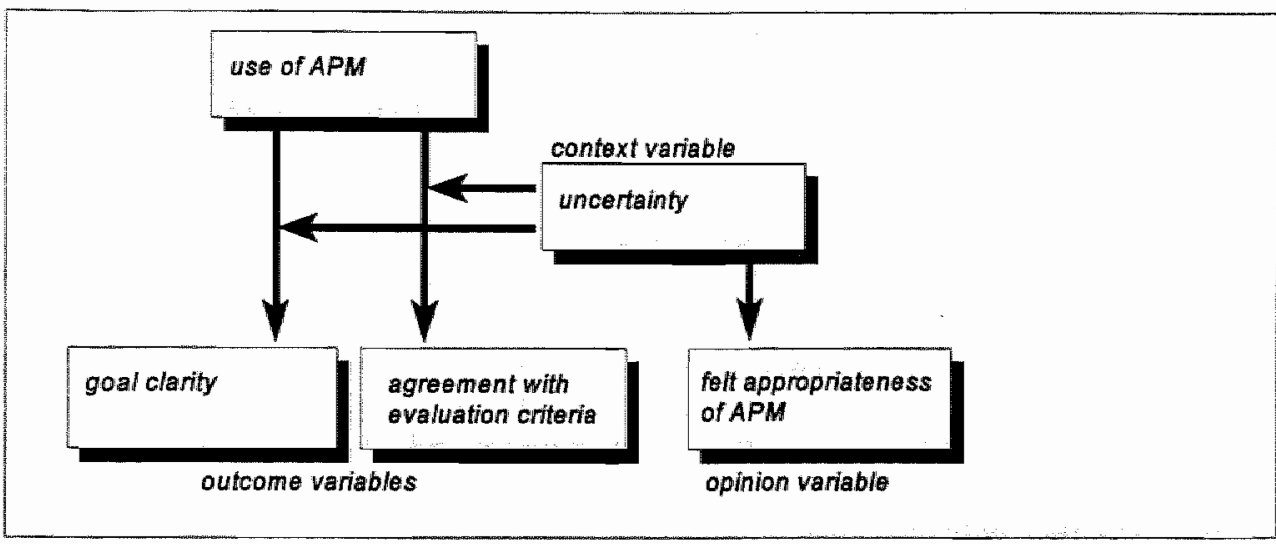

\subsection{Uncertainty and the appropriateness of APM}

\subsubsection{Two types of uncertainty}

Earlier, we argued that uncertainty is the dominant concept in explaining the appropriateness of APM. We did not, however, yet present a formal or operational definition of this concept, but instead referred to its connotations such as the complexity, variability, and unpredictability of the 'environment' in which managers operate. Although there seems to be agreement in the literature about the importance of uncertainty as an overall construct, there is apparent disagreement about how uncertainty should be operationalized [Downey and Slocum 1975, p. 567; Galbraith 1977, p.36]. Galbraith [1977, p. 36] notes, for example, that:

'... there is a great deal of uncertainty about the concept of uncertainty. On a general level, everyone understands what uncertainty is. It is the inability to predict future outcomes or states of the world. But when it comes to specifically measuring uncertainty $[. .$.$] the concept is not understood."$

This lack of agreement on the operationalization of uncertainty is in the APM literature reflected by the different uncertainty constructs used. In particular, although the studies examining the impact of uncertainty on the appropriateness of APM have used similar theoretical arguments to predict effects of "uncertainty", they have used different operational concepts and associated measurements of uncertainty. The two most fundamental and most often used types uncertainty explored in the APM literature are 'task uncertainty' [e.g., Hirst 1983b] and 'environmental uncertainty' [e.g., Grovindarajan 
1984]. ${ }^{13}$ These variables reflect the origins of the APM paradigm in organizational contingency research, in which the two constructs originate and dominate [Downey et al. 1977; Withey et al. 1983; Campbell 1988; see also Chapter 2]. Although definitions differ between studies, task uncertainty reflects the uncertainty sternming from the inherent nature of the managerial task [e.g., Withey et al. 1983]. Environmental uncertainty, in contrast, reflects the uncertainty stemming from sources external to the organization [e.g., Ewusi-Mensah 1981]. More formal definitions of the constructs are presented below.

In APM research, a distinction between the two concepts has not always been clearly made, regarding both empirical measurement of the constructs, and development of theoretical relationships about the concepts. An example of the measurement issue is Hirst's [1983b] study that introduced uncertainty in the APM paradigm. Although Hirst's contingency variable was labeled 'task uncertainty', the instrument that was used to measure this variable included both task uncertainty and environmental uncertainty elements [Hirst 1983b, p. 599]. In addition, there appears to be rather careless labeling of the construct with the Hirst [1983b] study being referred to as one concerning 'environmental uncertainty" [e.g., Merchant 1990], and the Govindarajan [1984] study being referred to as one concerning 'task uncertainty' [e.g., Kaplan and Mackey 1992].

In this section, we will show that there is both theoretical and empirical support for the proposition that the source of uncertainty does matter in predicting effects on the appropriateness of APM. In particular, we will show that an explicit recognition of the difference between environmental uncertainty and task uncertainty may enhance our understanding of the effect of uncertainty on the appropriateness of APM. In the previous section, we showed that APM research links the issue of controllability, completeness and relevance to managerial reactions by managers disagreeing with the use of accounting performance measures as they consider them unfair. We also discussed how APM research evidences the positive effect of accounting performance measures by explicitly stating clear and well-defined goals. Therefore, and based on our discussion in Section 3.3, it is needed to coalign these partly opposite findings by more specifically looking at the effects of task uncertainty and environmental uncertainty on the variables that we specified in the previous section, and to assess these effects simultaneously for a single sample. Therefore below we will (re)consider the relationships between task uncertainty, environmental uncertainty and managerial goal clarity, agreement with evaluation criteria and managers' felt appropriateness of $A P M$.

\subsubsection{Environmental uncertainty and the appropriateness of APM}

We define envirommental uncertainty in line with its previous use in the organizational and control literature as the uncertainty stemming from factors in the organization's environment. Ewusi-Mensah [1981, p. 302] defines the organizational environment as: i...consisting of all variables - people and things (e.g., laws and regulations) - 
external to the organization but capable of producing or causing conditions which can [...] affect the state of the organization and its future* .

Govindarajan [1984, p. 127] defines environmental uncertainty subsequently as the:

'...umpredictability in the actions of the customers, suppliers, competitors and regulatory groups that comprise the external environment".

\section{Environmental uncertainty and goal clarity}

In a discussion about the usefulness of budgeting under conditions of uncertainty, Horngren et al. [1996, p. 257] point out that budgeting may be especially useful in uncertain organizational environments. In contrast to the arguments in many APM studies, he notes:

"Skeptical managers have claimed, "I face too many uncertainties and complications to make budgeting worthwhile for me". Be wary of such claims. Planning and budgeting are especially important in uncertain environments. $A$ budget allows systematic rather than chaotic reaction to change."

This argument has received considerable empirical support. First, as Merchant [1989, chapter 5] shows, many uncertainties can be managed. This means that environmental uncertainty is not a given dimension, affecting outcomes after the budget has been set, but can be explicit input in the budgeting process. Simons [1987a, p. 359] notes that uncertainty is likely to impact the whole process of planning and control, rather than the use of formal controls as such. He notes:

...uncertain environments require more information sharing and personal exchange. The sharing and exchange process, however, does not occur in the absence of formal control procedures' [Simons 1987a, p. 359].

Indeed, such formal controls may stimulate the interactions required. [cf. Simons 1995], which may explain the empirical evidence showing that environmental uncertainty (EU) enhances the usefulness of formal procedures and budgets [Khandwalla 1972; Simons 1987b; Ezzamel 1990; Parker and Lewis 1995]. We posit that this argument extends to the use of APM for managerial performance evaluation. Second, although EU seems to enhance the desire for more than purely budgetary data, there is only weak evidence for an overall negative effect of EU on the appropriateness of APM. Studies by Govindarajan [1984] and Govindarajan and Gupta [1985] found that the level of environmental uncertainty did not affect the importance attached to APM. Third, both theoretical arguments and empirical evidence exist suggesting that APM are especially functional in conditions with high environmental uncertainty. Since environmental uncertainty is the uncertainty associated with task outcomes, which are caused by factors from the extemal environment [cf. Govindarajan 1984], in uncertain conditions, budgets and the associated APM may function as a 'buffer' against too much environmental uncertainty [Thompson 1967; Hayes 1977; Merchant 1984]. Merchant [1984, p. 293] thus notes: 
$\therefore$.. the budget can be used for buffering by treating it as a foxed performance commitment, regardless of how the market is changing.'

In addition, there is evidence supporting an increase in the use of budgetary control, specifically caused by increasing dynamism of the environment in which organizations operate [Simons 1987a; Ezzamel 1990; Otley 1990; Parker and Lewis 1995]. For the individual manager, the use of budgets for buffering may be expressed in terms of goal clarity. In this role, the budget may reduce the amount of information that subordinates need in order to manage their operations [Galbraith 1977; Merchant 1981; Gordon and Narayanan 1984; Chenhall and Morris 1986; Ezzamel 1990]. Some evidence for this function of buidgets is provided by Ezzamel [1990] who found that higher levels of EU were associated with greater reliance on the budget. Similarly, an early study by Khandwalla [1972] found that increased market competition resulted in more cost-related control. These two studies provide evidence that especially under high EU budgeting is a useful procedure, since it forces to consider the uncertainty that needs to be dealt with [Merchant 1989, Chapter 5]. Furthermore, we expect that the dysfunctional consequences of subjective performance evaluation may extend to situations of high environmental uncertainty [Ezzamel 1990; Rizzo et al. 1970]. As Ross [1995, p. 9] notes:

'The lack of clarity and objectivity associated with subjective performance evaluation measures may be intensified when environmental uncertainty is perceived to be high, leading to higher levels of job-related tension than would be associated with a budget constrained performance evaluation style'.

Based on these considerations we expect with regard to goal clarity:

\section{HIa: The effect of RAPM on GC is more positive for higher levels of $E U$}

\section{Environmental uncertainty and agreement with evaluation criteria}

For the interaction effect of RAPM and environmental uncertainty on agreement with evaluation criteria, we are not able to formulate a directional hypothesis. The objectivity argument points to higher levels of AEC associated with the use of APM for higher levels of EU, given that objectivity is a positive trait of performance evaluations. In contrast, the aspects of controllability, relevance and completeness indicate that AEC may be lower for higher levels of EU, since they put the manager at the risk of being evaluated on factors outside his control. However, there is also reason to assume that these three aspects are not as much affected by environmental uncertainty. For example, evidence exists that the controllability principle is often not applied [Merchant 1987, 1989; Otley 1990]. In addition, since environmental uncertainty stems from factors outside the job, for the individual manager performing a job, the use of APM may in fact enhance the controllability, completeness and relevance of accounting information, because of the 'buffering' function of budgets mentioned before. As these arguments point to opposite effects, and we cannot judge which of these effects is dominant, we formulate Hypothesis $1 \mathrm{~b}$ in the null-form: 


\section{CHAPTER 3 DEVELOPMENT OF HYPOTHESES}

\section{H1b: The effect of RAPM on AEC is not affected by the level of EU}

\section{Environmental uncertainty and managers' felt appropriateness of APM}

With regard to opinions about the appropriateness of APM, the above arguments can be summarized as follows. Environmental uncertainty has a neutral (AEC) to positive (GC) effect on the appropriateness of APM. Thus, Hypotheses $1 \mathrm{a}$ and $1 \mathrm{~b}$ are consistent with an overall positive relationship between EU and managers" felt appropriateness of APM. Therefore, we formulate Hypothesis $1 \mathrm{c}$ as follows:

\section{Hlc: FAAPM is higher for higher levels of EU}

\subsubsection{Task uncertainty and the appropriateness of APM}

We define task uncertainty in line with previous definitions for this construct. Generally, task uncertainty is '...the uncertainty associated with task outcomes ' [Hirst 1983b]. Since we want to emphasize the source of uncertainty, we more specifically define the construct as 'uncertainty associated with task outcomes, which is caused by the complexity and diversity of the tasks performed'.

\section{Task uncertainty and goal clarity}

For the impact of task uncertainty on the relationship between the use of APM and goal clarity, the argument is more complicated than for environmental uncertainty. In principle, the goal-theoretic arguments presented above for environmental uncertainty to a certain extent also hold for task uncertainty. Specific performance measures add structure to the working environment, and since such structure is especially needed with complex tasks it may be expected that task uncertainty also positively affects the relationship between the use of APM and goal clarity [Hirst 1983b; Early et al. 1987; Ross 1995]. There is however a fundamental difference between the effect of task uncertainty and the effect of environmental uncertainty on the extent to which APM may provide this structure. Task uncertainty is an inherent job characteristic. In other words, although a certain goal may be specific and thus 'objectively' clear, task uncertainty poses a problem regarding the attainment of such a goal. Locke and Latham [1990, p. 260] note in this respect regarding the effectiveness of goal-setting with high task uncertainty:

[i] i more complex tasks, however, effort does not necessarily pay off' so directly. One must decide where and how to allocate effort. [...] Thus in more complex tasks, the plans, tactics, and strategies used by the individual play a larger role in task performance than they do in simpler tasks where the number of different strategies is more limited and are generally known to all performers.'

The consequence is that although the use of APM may itself result in specific targets, under higher levels of task uncertainty managers may suffer from what Milliken [1987] 


\section{ACCOUNTING FOR PERFORMANCE EVALUATION}

calls response uncertainty, which reflects the perceptual uncertainty how a certain objective should be accomplished. Therefore, we expect that the effect of task uncertainty on the appropriateness of APM in terms of GC is the combined effect of accounting performance measures positively adding to the structure to the working environment, in terms of providing clear and specific objectives [e.g., Early et al. 1987], and task uncertainty leading to confusion, and not clarity, over the way in which the budget target should be attained [cf. Hirst 1987; Early 1985; Wood et al. 1987; Early et al. 1989; Sawyer 1992]. Since these two arguments point to opposite effects of task uncertainty on the relationship between the use of APM and goal clarity, we are not able to state a directional hypothesis and we formulate Hypothesis $2 \mathrm{a}$ in the null-form.

\section{H2a: The effect of RAPM on GC is not affected by the level of TU}

\section{Task uncertainty and agreement with evaluation criteria}

As we argued before, the dysfunctional consequences of using APM under high TU can for the larger part be summarized under the concept of AEC [e.g., Otley 1978; Hirst $1981,1983 \mathrm{~b}$; Ross 1994]. For AEC, the arguments from these previous APM studies are relatively straightforward. Previous APM research points to a negative moderating effect of TU on the relationship between RAPM and AEC, because of managers disagreeing with the potentially incomplete and irrelevant and uncontrollable accounting performance measures. In particular, managers will not readily accept targets which they perceive to be risky to attain, because of TU in their jobs [cf. Early 1985; Locke and Latham 1990]. Furthermore, we expect that managers will judge that the efforts in their work are not fairly represented in the outcomes in terms of APM, since these outcomes are in part determined by factors beyond their control. In summary, the following hypothesis is derived:

$H 2 b$ : The effect of RAPM on AEC is more negative for higher levels of $T U$

\section{Task uncertainty and managers' felt appropriateness of APM}

Regarding managerial opinions about the appropriateness of APM, the above arguments point to a neutral (GC) to negative (AEC) effect of TU on the appropriateness of APM, and are consistent with the hypotheses that TU has a negative effect on managers' opinions about the appropriateness of APM. Hypothesis $2 \mathrm{c}$ is therefore formulated as follows:

H2c: FAAPM is lower for higher levels of TU 


\subsection{Appropriateness of APM and managers' tolerance for ambiguity}

\subsubsection{The 'tolerance for ambiguity' concept and its use in previous accounting research}

In the preceding section, expectations were formulated about the relationship between the appropriateness of APM and uncertainty originating in managers' tasks and environments. This section extends the previous analysis by exploring the potential impact of subjects' individual attitudes toward uncertainty on the appropriateness of APM. In particular this section examines the extent to which the personality construct 'tolerance for ambiguity' (TFA) contributes to the explanation of the appropriateness of APM under uncertainty. Although the use of personality variables in accounting and control research is not uncommon [see, e.g., Collins 1978; Brownell 1982b; Frucot and Shearon 1991; Harrison 1993; Fisher 1996], they have received only little attention in APM research so far. However, these and other studies suggest that personality, and TFA in particular, may affect individuals' attitudes toward uncertainty and their preferences for certain kinds of information in uncertain situations [e.g., Duncan 1972, p. 314]. In particular, these and others studies emphasize that individual differences exist in the perception of, preference for, and ability to handle uncertainty in the working environment [e.g., Downey et al. 1975; 1977]. Therefore, we also expect that TFA may explain individuals' preferences for APM under conditions of uncertainty.

The remainder of Section 3.4 is structured as follows. Below we first introduce the TFA concept, and present the findings from previous accounting studies that have used the TFA concept. Sections 3.4.2 and 3.4.3 then examine the relationship between TFA and the appropriateness of APM. In Section 3.4.2 the examination will address the direct effect of TFA on managers' opinions and attitudes toward APM. Section 3.4.3 examines the role of TFA as a potential moderator of the relationships between uncertainty and the appropriateness of APM that we specified in the previous section. Both sections end with the formulation of several hypotheses.

The concept of TFA originates in the personality literature [Frenkel-Brunswik 1949; Budner 1962]. TFA is a personality variable that concerns the general feelings and attitudes of an individual toward ambiguity and ambiguous situations. ${ }^{14}$ Since ambiguity means 'uncertainty of meaning' [Dermer 1973, p. 512], an ambiguous situation is a situation:

'... which cannot be adequately structured or categorized by an individual because of lack of sufficient cues ' [Budner 1962, p. 30].

A situation is likely to be perceived as ambiguous when it is uncertain, changing or unstable, or when it confronts the individual with new and unfamiliar problems [Duncan 1972, p. 314; Dermer 1973, p. 512; Ho and Rodgers 1993, p. 109]. In particular, the ambiguity of such a situation lies in the information that individuals receive from or about such a situation. Norton $[1975$, p. 608$]$ in this sense defines intolerance for 
ambiguity as:

$\therefore$... a tendency to perceive or interpret information marked by vague, incomplete, fragmented, multiple, probable, unstructured, uncertain, inconsistent, contrary, contradictory, or unclear meanings as actual or potential sources of psychological discomfort or threat.' ${ }^{15}$

In personality research, the TFA construct is used to explain individual attitudinal and behavioral responses to ambiguity and ambiguous situations [e.g., Frenkel-Brunswik 1949; Martin and Westie 1959]. Individuals with high TFA are generally expected to seek out and enjoy ambiguity, and they are expected to excel in the performance of ambiguous tasks [MacDonald 1970; Ebeling and Spear 1980; Lysonski and Durvasula 1990]. In contrast, individuals with low TFA are expected to show opposite responses, caused by their tendency to perceive ambiguous situations as sources of threat [Budner 1962, p. 30; Frone 1990, p. 310] and their need to:

'...avoid undefined or misinterpretable stimuli' [Dermer 1973, p. 521].

Individuals with low TFA therefore dislike ambiguous situations and will seek ways to avoid them. Furthermore, they are less able to deal with the ambiguity in the situations they face, will show higher levels of stress in uncertain working environments [Frone 1990], and will act to reduce ambiguity [Martin and Westie 1959, p. 513; MacDonald 1970, p. 791; Lewin et al. 1994, p. 196]. The literature identifies two main ways for ambiguity reduction [Budner 1962, p. 30]. First, individuals with low TFA may "deny" the ambiguity by preferring "black and white' information that conceals the ambiguity [MacDonald 1970, p. 791]. Second, individuals with low TFA may have a tendency to collect more information about situations they perceive as ambiguous [Budner 1962, p. 30; Bennet et al. 1990]. TFA thus is strongly related to the concept of uncertainty, which we defined earlier as the difference between the information needed and possessed [cf. Galbraith 1977].

In accounting research, the TFA concept has so far been mainly used to examine differences in individual preferences for accounting information in decision making contexts [see; e.g., Dermer 1973; Gul 1984, 1986; Pincus 1990]. Dermer [1973, p. 511] motivates the attention to personality variables and in particular TFA in accounting research by noting that:

...cognitive characteristics of an information user may affect his perception of what information is important and, hence, may affect how information influences his ultimate behavior:

Consequently, as Gul [1986, p. 99] notes, the focus on personality variables aims at:

'...the improvement of accounting information systems design so that it is most suited to users' information processing needs'.

Empirical accounting research that uses the TFA concept revolves around three main research questions. First, studies have used TFA to predict and explain the type of information desired by decision makers [Dermer 1973; Oliver and Flamholtz 1978]. In 
particular, these studies use the ambiguity reduction argument to formulate the expectation that individuals with low TFA have a stronger preference for accounting information than individuals with high TFA. As Dermer [1973, p. 513] explains:

"Intolerants" attempt to reduce the threats in ambiguous situations [...] by manifesting a preference for readily interpretable stimuli. Thus, when evaluating the importance of information, they may tend to judge factual data (e.g. expressed in numbers) to be more important than abstract or conceptual data. ?

Second, studies have used TFA to predict and explain the amount of information subjects use or want for their decision making tasks [Dermer 1973; McGhee et al. 1978; Oliver and Flamholtz 1978]. Based on a similar ambiguity reduction argument, these studies expect that when making decisions, individuals with low TFA will prefer and use more information than individuals with high TFA [see e.g, McGhee et al. 1978, p. 683]. Finally, studies have investigated the effect of TFA on subject's decision confidence, given a certain fixed amount or type of information [Dermer 1973; McGhee et al. 1978; Gul 1984,1986$].{ }^{16}$ Generally, these studies predict that individuals with low TFA will be less confident in their decisions than individuals with high TFA [Gul 1986, p. 100].

In Appendix B, an overview is presented of the results of these studies. Studies pursuing the last two kinds of research questions have not found consistent evidence for an effect of TFA on the amount of information used or the degree of decision confidence. Pratt [1980, p. 503] explains this by pointing out that the direction of individual responses to ambiguity is not yet fully understood:

'There are a number of ways in which "intolerants" might reduce perceptions of uncertainty [...]. They may ignore uncertainty, fail to recognize uncertainty [...] or act as if there were certainty. Any of these explanations suggest that "intolerants" would show greater confidence and seek less information than "tolerants". 17

The evidence from the two studies that investigated the effect of TFA on the type of information preferred is limited, yet in support of the relevance of the TFA construct. In particular, Oliver and Flamholtz [1978] could not test the related hypotheses, as their data characteristics violated the assumptions of the statistical model they intended to use for the analysis [see, Oliver and Flamholtz 1978, pp.149-151]. The findings from the Dermer [1973, p. 518] study however provide clear support for the hypothesis that individuals with low TFA have a stronger preference for accounting information than individuals with high TFA. In particular, Dermer [1973, p. 518] found that:

...individuals intolerant of ambiguity do rate current internal financial information higher in importance'.

\subsubsection{TFA and the appropriateness of APM}

Although Dermer's finding relates to the use of accounting information for decision 


\section{ACCOUNTING FOR PERFORMANCE EVALUATION}

making, there are several reasons to expect that this finding extends to the use of APM. First, the labels Dermer uses for accounting information correspond to the central aspects of APM often emphasized in the APM literature [e.g., Hayes 1977; Govindarajan 1984]. Second, his findings support the general expectation proposed in personality research regarding individuals' reactions in terms of ambiguity reduction, which are not restricted to decision making contexts alone, but also result in a greater preference for specific feedback [Bennet et al. 1990], which budgets can provide [Luckett and Hirst 1989; Luckett and Eggleton 1991]. Third, the ambiguity reduction may be regarded as a response to the managerial lack of direction problem, and may be explained by a manager's need for structure [Neuberg and Newsom 1993]. Managerial lack of tolerance for ambiguity further is an example of the 'limited cognitive skills' mentioned as a "personal limitation" by Merchant [1982, p. 43]. Finally, a possible relationship between TFA and the preferred types of information for performance evaluation is suggested by Norton's [1975] measurement instrument for TFA. This instrument contains the following item to which individuals with low TFA would typically respond with agreement:

"In a situation in which other people evaluate me, I feel a great need for clear and explicit evaluations' [Norton 1975, pp. 616]

Below, we will develop theory and hypotheses about the impact of TFA on the appropriateness of APM. Our main hypothesis is that TFA affects the relationships that we specified in Hypotheses 1 and 2 above. Therefore, the hypotheses we derive for the effect of TFA will be developed relative to these earlier hypotheses. In addition, we will first look at the direct effect of TFA on the appropriateness of APM.

As our discussion of goal clarity in Section 3.3 suggests, the use of APM contributes to 'clear' and 'explicit' evaluations. In sum therefore, we expect that the tendency of individuals with low TFA to reduce the ambiguity in their working environment will result in both a stronger agreement with the use of APM for performance evaluation and a stronger effect of the use of APM on goal clarity. Furthermore, subjects with low TFA will especially dislike the ambiguity potentially caused by subjective performance evaluations [Hirst 1983b; Ross 1995]. These expectations are expressed in the following hypotheses.

H3a: The effect of RAPM on GC is more positive for individuals with low TFA than for individuals with high TFA

and:

H3b: The effect of RAPM on AEC is more positive for individuals with low TFA than for individuals with high TFA

Regarding managers' opinions about the appropriateness of APM, the above arguments, and the hypotheses derived, are consistent with an overall positive relationship between TFA and managers' felt appropriateness of APM. Therefore, we formulate Hypothesis 
$3 c$ as follows:

H3c: FAAPM is higher for individuals with low TFA than for individuals with high TFA

\subsubsection{The interactive effects of uncertainty and TFA on the appropriateness of APM}

The concept of TFA captures individuals' attitudes towards information received in and from uncertain situations. Since such uncertain environments can be alternatively labeled as situations with high task uncertainty or environmental uncertainty, we expect that individual responses to task uncertainty and environmental uncertainty may be affected by an individual's TFA. In other words, individual responses to uncertainty may be an interactive effect of the uncertainty stemming from the task and environment in which the individual functions, and his tolerance for ambiguity. A similar line of reasoning is followed in several previous accounting studies in which it is argued that individual responses to information characteristics are not a linear function of TFA, as expressed in our hypotheses 3 , but are a function of the interaction between TFA and environmental attributes [e.g., McGhee 1978; Gul 1986, p. 99; Faircloth and Ricchiute 1981, p. 61]. To explore this possibility, we will extend our analysis by examining the possible interactions between TFA and the two uncertainty variables. Our general hypothesis is that subjects with low TFA are more sensitive to the impact of uncertainty on the appropriateness of APM. In the following section however, we will explore separately the effects of TFA for the two uncertainty variables and the three independent variables. This exploration is based on the relationships between uncertainty and the appropriateness of APM specified earlier [see Sections 3.3.2 and 3.3.3, and Figure 3.1]. In other words, we will examine whether the interaction effects of RAPM and uncertainty on goal clarity and agreement with evaluation criteria will be different for individuals with low and high TFA. This also implies that we will especially attempt to further develop the previous hypotheses in which we formulated directional predictions.

\section{TFA and envirommental uncertainty}

In Section 3.3 .2 we examined the relationship between environmental uncertainty and the appropriateness of APM. In particular, we formulated three hypotheses about the effects of environmental uncertainty on the appropriateness of APM. In this section we examine whether these effects differ for managers with low TFA and managers with high TFA.

We expected that environmental uncertainty has a positive effect on the relationship between RAPM and goal clarity (Hla). Recall that the arguments presented to support this expectation were based on the role of budgets and accounting information as a "buffer" against the environment. In other words, the budget serves as a device to reduce the complexity of the environment, and thus to reduce the ambiguity in the 
working environment. In particular, we expected that this effect would be higher for higher levels of environmental uncertainty. If we extend these arguments for TFA, the use of APM can be interpreted as a way to reduce ambiguity. Since subjects with low TF $A$ are generally believed to strive for such ambiguity reduction, we expect that their preference for APM under high environmental uncertainty will be higher than for subjects with high TFA. Subjects with high TFA may have no need for this reduction, and may feel that this reduction is a simplification of the 'real' environment. Gupta and Govindarajan [1984] show positive evidence that managers with high TFA are better able to deal with environmental uncertainty. Furthermore, as Gordon and Narayanan [1984] found, environmental uncertainty seems to enhance the need for additional and other than accounting information [cf. Gordon and Miller 1976]. Individuals with high TFA are expected to dislike the reduction in information that is the consequence of using APM, especially since they do not need it [Dermer 1973, p. 513]. In sum, we expect that the positive effect of environmental uncertainty on the relationship between RAPM and goal clarity will be more positive for subjects with low TFA, than for subjects with high TFA. This is expressed in the following hypothesis.

H4a: The effect of EU on the relationship between $R A P M$ and $G C$ is more positive for individuals with low TFA than for individuals with high TFA

For the impact of environmental uncertainty on the relationship between RAPM and agreement with evaluation criteria, we did not develop a directional hypothesis (H1b). The reason was that there are different and opposite ways in which environmental uncertainty may affect this relationship. Because TFA relates to the individual responses to uncertainty, we can in this case derive a direction for the impact of TFA on this relationship neither. We therefore formulate the following hypothesis in the exploratory null-form:

H4b: There is no difference in the effect of $E U$ on the relationship between RAPM and AEC between individuals with low TFA and individuals with high TFA

With Hypothesis 1c we formulated the expectation that environmental uncertainty leads to more positive opinions about the appropriateness of APM, as a result of the dominant positive effect of environmental uncertainty on the relationship between APM and goal clarity. Based on the arguments presented for Hypothesis $4 \mathrm{a}$, we expected that the relationship between environmental uncertainty and opinions about the appropriateness of APM is more positive for subjects with low TFA. This is expressed in the following hypothesis:

H4c: The effect of EU on FAAPM is more positive for individuals with low TFA than for individuals with high TFA 
TFA and task uncertainty

In Section 3.2.3 we argued that task uncertainty (TU) affects the relationship between RAPM and managers" agreement with evaluation criteria. We also formulated the expectation that task uncertainty negatively affects managers" opinions regarding the appropriateness of APM. For the effect of RAPM on goal clarity we did not formulate a directional hypothesis, since we argued that two opposite effects may be present. We now explore how these relationships may differ for subjects with low TFA, as opposed to subjects with high TFA.

Task uncertainty may increase the extent to which RAPM results in specific goals, but at the same time task uncertainty may hinder the achievability of those goals. Therefore, overall, we did not expect an effect of task uncertainty on the relationship between RAPM and goal clarity. Therefore, we formulate the following hypothesis in the exploratory null-form as well:

H5a: There is no difference in the effect of $T U$ on the relationship between RAPM and GC between individuals with low TFA and individuals with high TFA

With Hypothesis $2 b$, we expressed the expectation that task uncertainty has a negative effect on the relationship between RAPM and agreement with evaluation criteria. The main reason for this expectation was that task uncertainty decreases the controllability, completeness and relevance of APM, and that subjects would agree less with such less complete performance measures. We now expect that this negative impact is more negative for subjects with low TFA, compared to subjects with high TFA. Not only does the TFA concept reflects individuals' reactions toward the incompleteness and uncontrollability of information [see Norton's 1975 definition above], but we also expect that subjects with low TFA will perceive a greater effect of task uncertainty on the incompleteness of APM. In sum therefore, we expect that subjects' objections toward APM will be stronger for people with low TFA, which results in the following hypotheses:

H5b: The effect of TU on the relationship between RAPM and AEC is more negative for individuals with low TFA than for individuals with high TFA and:

HSc: The effect of TU on FAAPM is more negative for managers with low TFA than for managers with high TFA

\subsection{Appropriateness of APM and the underlying dimensions of RAPM}

\subsubsection{Differences in empirical RAPM measurement}

Although previous APM literature applies similar descriptions of the RAPM construct 


\section{ACCOUNTING FOR PERFORMANCE EVALUATION}

in its development of theory and hypotheses, this literature also revealls to be dissimilar regarding empirical RAPM assessment for subsequent hypothesis testing. This is not only evidenced by the variety of instruments used to assess RAPM [e.g., Bruns and Waterhouse 1975, Hopwood 1972, Hirst 1983b, Govindarajan 1984], but also by the variety of methods used to obtain variable scores for statistical analysis of the hypotheses from even the same 'basic' RAPM instruments. Brownell and Dunk [1991, p. 702] note in this respect:

$\therefore$ the measurement of budget emphasis in performance evaluation [RAPM] is far from settled. That researchers have achieved as much towards reconciling the Hopwood [1972] and Otley [1978] results is quite remarkable when one considers the variations of measurement of budget emphasis:.

Although our analysis in this and the previous chapter does not support the enthusiasm over the 'achievements' made, this remark clearly expresses the concern that differences in RAPM measurement may have caused differences in findings concerning the appropriateness of APM. In this section we will explore this possibility. The section is structured as follows. Section 3.5.2 illustrates the diversity in RAPM measurement. It presents an overview of the different uses of Hopwood's [1972] RAPM instrument, which is the most frequently used instrument in APM research [e.g., Hopwood 1972; Otley 1978; Brownell 1982b, 1987a; Harrison 1992, 1993; Ross 1995], and present three alternative RAPM instruments used in studies that have been particularly influential in the development of the contextual perspective in RAPM research [Hirst 1983; Govindarajan 1984; Govindarajan and Gupta 1985]. Section 3.5.3 then discusses the implications of these differences. In particular, it is argued that the differences in RAPM measurement may point to two dimensions underlying the RAPM construct. Based on this discussion, Section 3.5.4 develops hypotheses about the appropriateness of RAPM under task- and environmental uncertainty, that specifically address two underlying dimensions of the RAPM construct. Such explicit recognition of separate dimensions may not only explain inconsistencies between earlier APM studies, but may indeed enhance our understanding of the exact aspect of RAPM that causes the use of APM to be contextually (in)appropriate.

\subsubsection{Variety in RAPM measurement: an overview}

\section{Hopwood's [1972] RAPM instrument}

The original Hopwood [1972] RAPM instrument consists of eight items reflecting eight performance criteria that superiors can use in evaluating the performance of their subordinate managers. Two of these eight performance criteria are accounting related. They ask respondents to indicate the emphasis their superiors put on the manager 'meeting the budget' and the manager's "concem with cost". The other six criteria relate to other aspects of managerial performance, such as managers' concern with quality, their general effort in their work and their cooperation with other employees in the organization. ${ }^{18}$ In Hopwood's study respondents were asked to, first, rate the perceived 


\section{CHAPTER 3 DEVELOPMENT OF HYPOTHESES}

importance of each criterion on a five-point scale and, second, to rank the eight criteria in order of perceived importance. Hopwood then used the ranks of the two accounting related criteria to determine three classes of 'supervisory style', as showed in Table 3.1 below. ${ }^{19}$ Additionally, Hopwood used a continuous measure based on the absolute score on the "meeting the budget" item.

Table 3.1 Derivation of three supervisory stylles [Hopwood 1972]

\begin{tabular}{|c|c|c|c|}
\hline \multicolumn{2}{|c|}{ Relative ranks of accounting criteria } & \multicolumn{2}{|c|}{ 'meeting the budget } \\
\hline 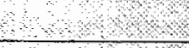 & & in top three & not in top thiee \\
\hline \multirow[t]{2}{*}{$\begin{array}{l}\text { concern with } \\
\text { cost'? }\end{array}$} & In top three & \multirow[t]{2}{*}{$\begin{array}{l}\text { Budget Constrained style } \\
\text { ( - high RAPM) }\end{array}$} & $\begin{array}{l}\text { Profit Conscious style } \\
\text { ( medium RAPM) }\end{array}$ \\
\hline & not in top three & & $\begin{array}{l}\text { Non-accounting style } \\
(\sim \text { low RAPM) }\end{array}$ \\
\hline
\end{tabular}

In later APM research, alternative formats of this instrument have been used. The formats differ from the original in two respects. First, they include changes of the number and exact wording of the criteria, and, second, they use different procedures in the derivation of the RAPM variable scores for use in the statistical analyses. For example, Otley [1978] changed one of the eight items to adapt the instrument to a profit-center environment, substituting the original 'concern with costs' item by a "how much profit I make' item. Brownell and Hirst [1986] extended the original scale with two additional items, and changed one item to make it suitable for a sales-environment ('concern with costs and revenues' instead of 'concern with cost').

Most of the differences, however, stem from the way in which variable scores were derived from the 'raw scores' obtained with the instrument. In contrast to Hopwood's derivation of three classes of 'supervisory style', others have used the scale to derive a dichotomous (i.e., high/low) measurement of RAPM, based either on the ranks [Brownell 1982b] or on the absolute scores [Harrison 1992, 1993] of the accounting related items in the scale. An overview of the instruments is presented in Appendix C. In particular this overview serves to illustrate that, with only one exception, no two studies have used exactly the same version of this instrument.

\section{Three supposedly equivalent RAPM instruments}

Besides the differences in use of the same instruments, the variety in RAPM measurement is enhanced by the development and use of other measures. For example, Hirst [1983b] developed and used an instrument that measures the reliance on quantitative performance information. ${ }^{20}$ Govindarajan [1984] and Govindarajan and Gupta [1985] measured RAPM as the extent to which managerial bonuses depend on objective performance data ('formula-based approach') as opposed to superiors' subjective considerations ('subjective approach'). Yet both these studies explicitly point out that the instrument they used was designed to be equivalent to the Hopwood 
instrument. For example Govindarajan [1984, p.125] states:

"It is worth noting that strictly "formula-based" and strictly "subjective" approaches are analogous to Hopwood"s "budget-constrained" and "nonaccounting" styles. In addition, a combination of subjective and formula-based approaches is similar to Hopwood's "profit-conscious" style."

However, although this instrument may capture some of the aspects associated with the use of APM, it does not cover the full APM versus low APM distinction. Brownell $[1987 b, p .187]$ remarks in this sense regarding Govindarajan's alternative RAPM instrument:

'...Govindarajan 's decision to move away from Hopwood's instrument remains a curiosity'.

Additionally, Govindarajan and Gupta [1985] attempt to measure the use of "long-term" versus 'short-term' performance criteria for bonus determination. Although the authors do not explicitly claim the equivalence of their instrument and other RAPM-instruments, the items of the instrument reveal that it particularly discriminates between accounting and non-accounting performance criteria [see Govindarajan and Gupta 1985, p. 59]. ${ }^{21} \mathrm{~A}$ summary of the characteristics of the alternative instruments is presented in Table 3.2 below.

Table 3.2 Alternative instruments to measure RAPM

\begin{tabular}{|l|c|l|l|}
\hline Author & Tems & RAPMis. \\
\hline Hirst [1983] & 5 & Reliance on quantitative performance criteria and targets \\
\hline Govindarajan [1984] & 1 & Percentage of bonus that is 'objectively' determined \\
\hline $\begin{array}{l}\text { Govindarajan and Gupta } \\
\text { [1985] }\end{array}$ & $7+5$ & $\begin{array}{l}\text { Reliance on long-run ( non-accounting) and short-run } \\
\text { ( accounting) criteria }\end{array}$ \\
\hline
\end{tabular}

The selection of measurement instruments and the derivation of variable scores for statistical analysis from the 'raw scores' obtained with these instruments, is typically considered an issue of research design and research method selection. ${ }^{22}$ However, if different instruments reflect differences in constructs measured, the selection of instruments becomes one of theory, instead of method. This is especially the case when the deviations from the original RAPM measurement, as illustrated above, are theoretically meaningful. First, these differences raise the question whether in fact different aspects of RAPM have been measured. If so, the differences in empirical findings can be, partly, attributed to differences in RAPM measurement. ${ }^{23}$ Second, it raises the related question what the exact aspect of APM it is, that determines its contextual appropriateness in terms of goal clarity and agreement with evaluation criteria. 


\section{CHAPTER 3 DEVELOPMENT OF HYPOTHESES}

\subsubsection{Two dimensions of RAPM: development of hypotheses}

Below we will explore this question by focusing on the differences between the Hopwood instrument and the alternative instruments used by Hirst [1983b], Govindarajan [1984] and Govindarajan and Gupta [1985]. In a direct comparison of the Hopwood [1972] and Hirst [1983b] RAPM instruments and in an attempt to replicate Hirst's findings by using the Hopwood RAPM instrument, Ross [1995, p. 3] argues that the content of these measures is different:

In each of the five questions used by Hirst [1983, p. 603-604] the emphasis is on the use of quantitative criteria for performance evaluation. [..] Although financial information is part of the quantitative information that could be used for performance evaluation it is also likely that non-financial quantitative information would be included in a manager's definition of "quantitative" "24,2s

This argument follows Ross' unsuccessful attempt to replicate Hirst's [1983b] interactive effect of task uncertainty and RAPM on job-related tension. Similarly, Ross' argument may explain why Brownell and Hirst [1986] failed to replicate Hirst's [1983b] findings. Also differences in interpretations may result. For example, since the Govindarajan and Gupta [1985] instrument to measure long-term and short-term orientation in performance evaluation reflected a simultaneous difference between low and high reliance on APM, their finding that different levels of environmental uncertainty did not affect the importance attached to short-term performance criteria may be alternatively explained by the fact that financial and quantitative information is appropriate, regardless the level of environmental uncertainty. Besides such general concern for the lack of equivalence of RAPM measurements, it has further been proposed in the literature that RAPM is a multidimensional rather than unidimensional variable. In reaction to the Hopwood [1972] study, Kahn [1972, p. 186] already suggested that when the effects of RAPM are examined, in fact a combination of different aspects of RAPM is investigated. A similar comment is made by Briers and Hirst [1990, p. 391]. They suggest that RAPM may be a combination of different dimensions, which include the "extent' to which, and the 'manner' in which APM are used by superiors. Furthermore, Kenis [1979] distinguished between an 'evaluative' and a 'punitive' use of APM.

If we reconsider our original definition of RAPM (see Chapter 1), there seems to be support for a related but more fundamental division of the RAPM construct. Recall that we used Harrison's [1993, p. 319] definition of RAPM, which was: "...the extent to which superiors rely on, and emphasize those performance criteria which are quantified in accounting and financial terms, and which are prespecified as budget targets. "This definition, with our emphasis added, suggests that there are two dimensions underlying RAPM that relate to (1) the use of financial and quantitative performance criteria (the use of accounting information), and to (2) the reliance on prespecified targets (the use of targets). Therefore, rather than extending the RAPM concept with additional aspects of 'supervisory behavior', we propose that the nature of the information (financial and quantitative) and the strictness in which performance is assessed in relation to preset 
targets, is fundamental to the original RAPM construct. The two associated variables that we will explore are: reliance on financial and quantitative information (RFQ) and reliance on targets (RT). ${ }^{26}$

These dimensions seem to be in conformity with Hopwood's original measure in which the difference between the "profit-conscious" and "budget-constrained" styles did not originate in differences in importance of accounting information (- extent), but rather in the simultaneous use of accounting information and targets ( $\sim$ manner) ${ }^{27}$ More importantly, both theoretical and empirical support exists for the importance of these dimensions. Previous APM research suggests that the target dimension is critical for the controllability argument, being the specific dimension underlying hypotheses about the inappropriateness of APM under uncertainty. For example, Govindarajan [1984] stresses that uncertainty hinders target setting, but not necessarily the use of accounting information. In contrast with Ross' observation noted earlier, Hirst [1987] argues that the use of quantitative and accounting criteria are largely similar and the major difference between high and low RAPM is the reliance on targets. In addition, the positive effects of using APM under uncertainty seem to be caused by the accounting dimension of APM. Recall that Hirst [1983b] noted that an advantage of APM was their use for clear and explicit evaluations. Hopwood [1972] found evidence that attention paid to accounting information (but not the relatively large emphasis on attaining certain preset targets) in fact reduced job-related tension. Therefore, below we will extend our analysis from Section 3.3 by explicitly taking into account these two separate dimensions. The question is whether an explicit recognition of the two dimensions underlying the traditional RAPM construct does enhance our understanding of the effect of uncertainty on the relationship between the use of APM and goal clarity and agreement with evaluation criteria that we specified earlier in Section 3.2. Below we develop hypotheses that allow to explicitly test these differences in effect.

Environmental uncertainty, reliance on financial and quantitative information, and targets

With Hypotheses la, we formulated the expectation that the relationship between RAPM and GC is more positive for higher levels of EU. Based on findings of Govindarajan and Gupta [1985], Ezzamel [1990] and Khandwalla [1972], who all found that environmental uncertainty did not decrease, and even enhanced the usefulness of accounting information, we expect that the effect expected in Hypothesis la is caused by the accounting dimension of RAPM and not so much by the target dimension of RAPM. In other words, we expect that emphasis on APM may enhance managers' goal clarity especially in situations of high environmental uncertainty by clear specification of the dimensions of desired performance, and not so much by emphasizing the attainment of preset targets. To explore these expectations simultaneously, we propose the following combined hypothesis:

H6a: The effect of RFQ on GC is more positive for higher levels of $E U$, and the effect of $R T$ on $G C$ is not affected by the level of $E U$ 


\section{CHAPTER 3 DEVELOPMENT OF HYPOTHESES}

For the effect of EU on the relationship between RAPM and AEC (H1b), we did not formulate a directional hypothesis, since we expected that there would be opposite effects, the relative size of which could not be determined beforehand. For the same reason, we do not formulate a directional hypothesis here. Hypotheses $6 \mathrm{~b}$ therefore is stated in the null-form as follows:

H6b: The effect of RFQ on AEC and the effect of RT on AEC are not affected by the level of $E U$

Task uncertainty, reliance on financial and quantitative information, and targets In Section 3.2.2 hypotheses were developed about the appropriateness of RAPM under task uncertainty. In particular, Hypothesis $2 \mathrm{a}$ expressed the expectation that there would be no interactive effect between TU and RAPM on GC. Therefore, we did not formulate a directional hypothesis for the effect of TU on the relationship between RAPM and GC, since we expected that there would be opposite effects, the relative size of which could not be determined beforehand. For the same reason, we choose not to formulate a directional hypothesis here. Hypotheses 7a therefore is stated in the null-form as follows:

H7a: The effect of RFQ on GC and the effect of RT on GC are not affected by the lewel of $T U$

With Hypothesis $2 b$, we expected that a negative interactive effect exists between TU and RAPM on AEC. Here we will further explore how the hypothesized effects can be decomposed as effects of RFQ and RT, by testing a combined hypothesis. This hypothesis is based on an alternative explanation of Hirst [1983b] findings, in which negative responses to RAPM are the consequence not of using accounting information for performance evaluation, but rather of using targets - whatever their nature. In particular, we argue that the problems caused by RAPM under uncertainty could be attributed to the emphasis on attaining potentially uncontrollable targets, but there is no reason to assume that a lack of controllability is the exclusive problematic consequence of using accounting targets. ${ }^{28}$ Therefore, we expect that the negative effect of TU on the relationship between RAPM and AEC is primarily due to the strict use of preset targets. We therefore propose to test the following combined hypothesis:

$H 7 b$ : The effect of RFQ on $A E C$ is not affected by the level of $T U$, whereas the effect of $R T$ on $A E C$ is more negative for higher levels of TU

\subsection{Summary and overview}

In this chapter hypotheses were developed about the appropriateness of APM under conditions of uncertainty. In Section 3.2 the measurement of the concept of appropriateness in previous research was evaluated which resulted in the selection of 
three dependent variables to measure appropriateness in this study. Based on this discussion, Sections 3.3, 3.4 and 3.5 developed hypotheses for empirical investigation. In Section 3.3 the effect of task and environmental uncertainty on the appropriateness of APM was investigated. This section relied on previous APM research in that it attempted to refine existing theory about the said relationships. Section 3.4 extended existing theory by exploring the impact of the concept of TFA. It was argued that since the TFA concept relates to individual preferences for uncertainty it may affect subjects" preferences for APM both directly and as a moderator of the relationships specified earlier. Finally, Section 3.5 provided a second extension of existing theory by a further exploration of the meaning of the RAPM construct. In particular it was argued that RAPM consists of two separable dimensions, related to the use of accounting information and the use of targets. For both these dimensions, their interactions with task and environmental uncertainty were explored., resulting in the formulation of several combined hypotheses.

An overview of the hypotheses formulated is presented in Table 3.3 below. This overview presents the contextual variables, the APM variables, and the appropriateness variables, following the order in which the hypotheses were derived. 
CHAPTER 3 DEVELOPMENT OF HYPOTHESES

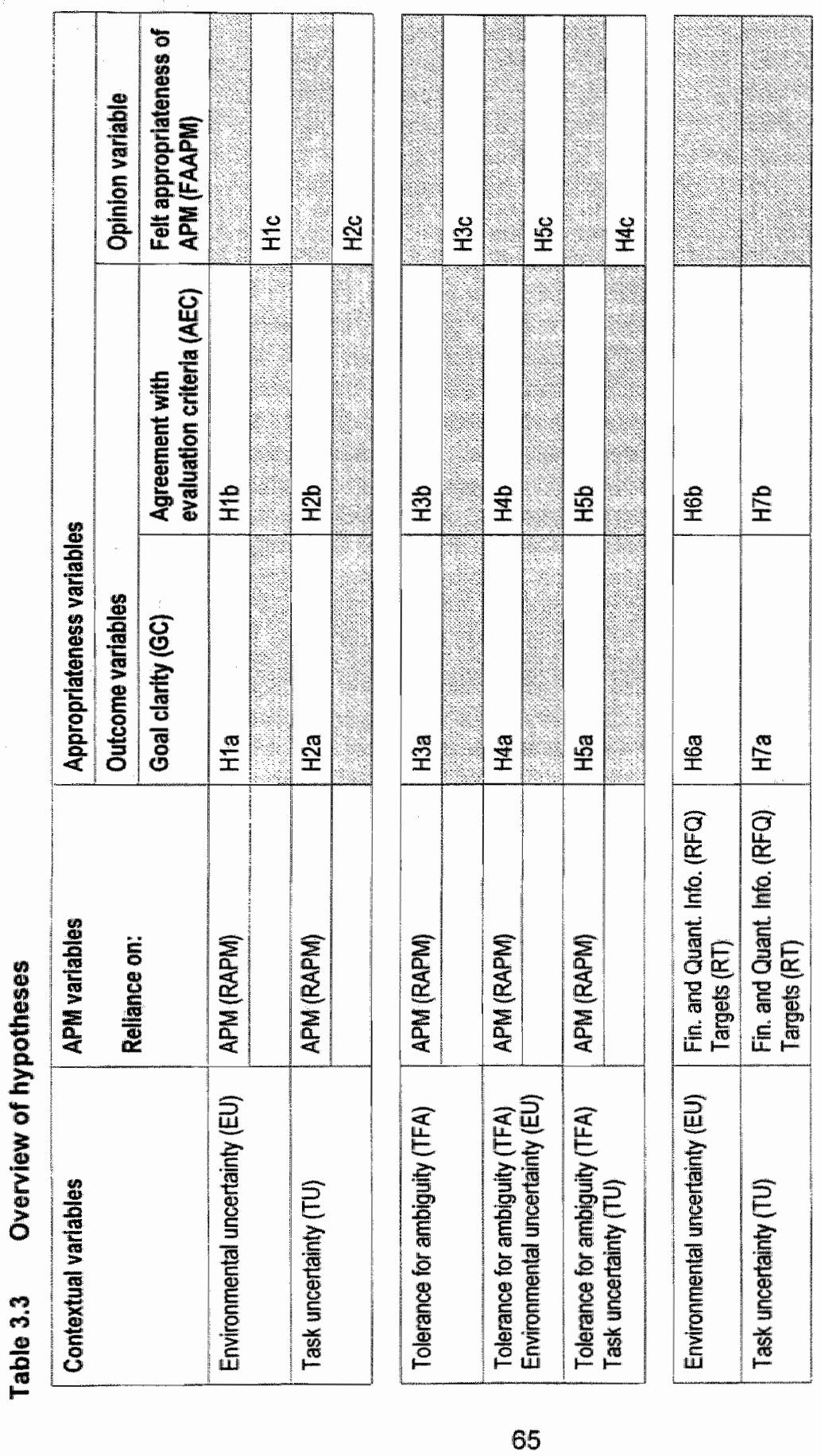


Notes to Chapter 3 :

1. The effect of uncertainty on the relationship between the use of APM and subordinate's

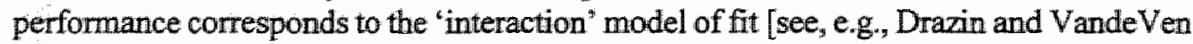
1985; Fisher 1995; Selto et al. 1995], since performance is the outcome of an interaction between uncertainty and the use of APM. We explain the interaction phenomenon more in detail in Appendix $K$. In contrast, the earlier mentioned model of fit, in which the use of APM indicates the existence of fit corresponds to the "selection" model of fit. See Venkatraman [1989] and Venkatraman and Camillus [1984] for overviews.

2. Although a theory predicting superior choice is not available, some APM studies suggest that other factors than appropriateness in terms of subordinates" reactions determine superiors' choice of performance criteria. For example, Otley $[1978$, p. 138] argues that actual performance influenced the reliance on APM, suggesting that APM are more emphasized in units with low profitability [cf. Imoisili 1989, Briers and Hirst 1990]. Keeley [1977] found that supervisors may reduce their own uncertainty by emphasizing objective performance measures [cf. Hartmann 1995]. Ouchi [1978] and Barrett et al. [1992] found evidence for a "contagion effect", which implies that superiors tend to use the performance criteria by which their own performance is evaluated also for evaluating the performance of their subordinates [cf. Ansari 1977, p. 110]. Hopwood [1974] suggests a relationship between 'leadership style' and the preference for performance criteria. In addition, the organization behavior literature points to the importance of sociological and psychological variables that determine the choice of performance criteria [e.g., Rahman and McGosh 1976; Neu 1992; Judge and Ferris 1993]. Prendergast and Topel [1993] discuss the choice of evaluation criteria by superiors from an economics perspective.

3. The question is of course why if practitioners cannot find a (situationally) suitable performance measures, the researcher would? Although there is nothing wrong with studying the effect of RAPM on budgetary performance, it would merely be an empirical test of the "You get what you pay for" adage in management control [see, e.g, Merchant $1985 \mathrm{a}$, P. 73], rather than a good proxy for appropriateness. Similar remarks can be made about the "performance" variable used in Govindarajan [1984], Govindarajan and Gupta [1985] and Govindarajan [1988], which relates to the 'effectiveness of strategy implementation' [cf. Gupta and Govindarajan 1984] rather than 'performance'.

4. An additional problem associated with performance measures is the reliability of the scores obtained in questionnaires studies. See for a discussion of this issue Chapter 4.

5. Also for job satisfaction the evidence of a positive relationship with performance is at best modest [Fisher 1980; Iaffaldano and Muchinksy 1985; Meyer et al. 1989]. See also Camman $[1976$, p. 310$]$ who strongly argues that satisfaction is a result, rather than a determinant of performance.

6. This same argument also holds for studies emphasizing 'dysfunctional behavior', and concluding the inappropriateness of APM. Although dysfunctional behavior may be an indication of APM being inappropriate, it is the net result of functional and dysfunctional behavior that in our view determines the appropriateness of APM. 


\section{CHAPTER 3 DEVELOPMENT OF HYPOTHESES}

7. Landy [1989, p. 392] continues by explaining that such 'significant others' may by other individuals inside the organization, but may also relate to an individual's perceptions of his own worth.

8. In addition, Fulk et al. [1985] demonstrated that individuals" perceptions of the faimess of performance evaluations is affected by the level of trust put in the evaluator. Note that Ross [1 994] found that trust-in-supervisor lowered the job-rellated tension effects of using APM. Magner et al. [1995] found that the trust-in-supervisor is, reversely, affected by the perceived faimess of budgetary targets. Whatever the exact causal direction of these relationships, they do support the relevance of the concept of 'faimess'.

9. The studies mentioned have looked at differences in effects of goal specificity and goal difficulty. Locke et al. [1989, p. 284] summarize the difference as: "Goal specificity serves a direction function by indicating exactly what acceptable performance consists of, while goal level [i.e., goal difficulty] serves an energizing function by mobilizing the effort required to attain the required performance.

10. In a review of 37 textbooks on MBO McConkie finds that $97 \%$ percent of these texts inciude the statement that 'goals and objectives should be specific'. Note that MBO has been advocated before the development of goal theory [Locke and Latham 1990; Tosi et al. 1994]. Schuler et al. [1989, p. 240] interestingly use responsibility accounting as an example of MBO.

11. Indeed, the negative association between RAPM and job-related tension [Hopwood 1972] is neglected even in later APM research that specifically builds on the Hopwood study. The importance of the difference between RAPM as the relative emphasis on the budget (positively associated with job-related tension) and RAPM as the absolute emphasis on meeting the budget (negatively associated with job-related tension) is the subject of Section 3.5.

12. Hopwood measured this construct with a single item: 'Do you know what is expected of you in your job? ' [Hopwood 1972, p. 173, fn. 38]

13. Recall from Chapter 2 the identification in APM research of several other sources of uncertainty (e.g., strategy, markets, managers' function, departmental interdependency). We choose here to focus on task uncertainty and environmental uncertainty as the fundamentally different concepts, which may both comprise various such other sources of uncertainty.

14. Several definitions of personality exist. Two recent definitions are: 'Personality is the complex arganization of cognitions, affects, and behaviors that gives direction and pattern (coherence) to a person's life' [Pervin 1996, p. 414]; and: 'We define personality as consistent behovior patterns originating within the individual' [Burger 1993, p. 4].

15. The focus on the information or cues received from certain situations leads some to classify IFA as a cognitive variable rather than a personatity variable [see, e.g., Dermer 1973; Pratt 1980; Gul 1984].

16. In particular, Gul [1986] investigated the decision confidence of users of financial accounting information given qualified and unqualified accountant reports. 


\section{ACCOUNTING FOR PERFORMANCE EVALUATION}

17. In a similar vein, Pincus [1990, p. 153] notes that there is no specific theory that predicts the direction people take to reduce ambiguity. Note also the implicit equation of "ambiguity" and 'uncertainty" in this quotation, which emphasizes that ambiguity is related to a lack of information. Galbraith [1977, pp. 36-37] defined uncertainty as the '...difference between the amount of information required to perform the task and the amount of information already possessed by the organization".

18. The full six non-accounting criteria are: cooperation with colleagues; getting along with one's boss; the effort put into the job; concern with quality, the attitude towards work and company, and; the ability to handle subordinates.

19. Hopwood [1972] intended to derive four classes. Because of lack of respondents in one of the original classes (Budget Profit), respondents in this class were added to the Budget Constrained category.

20. Hirst [1983b, p. 598] motivates not using the Hopwood instrument by arguing that Hopwood's instrument was designed for manufacturing settings.

21. The following seven criteria were considered "long-term": sales growth rate, market share, new product development, market development and political/public affairs. The following five criteria were considered "short-term": operating profits, profit-to-sales, cash-flow, return on investment and cost reduction programs [Govindarajan and Gupta 1985 , p. 59].

22. This is evidenced by the typical discussion of instrument selection in the method section of papers, as indeed in the method section of this dissertation in Chapters 4 and 5. See for a paper discussing the "meaning' of RAPM e.g., Harrison [1992].

23. There is a third reason to be concemed about the meaning of RAPM. Ross [1995] wonders whether the RAPM instruments provide constant measurement of the underlying construct. He suggests that 'budget emphasis' has a different connotation in the nimeties when compared with the seventies. See Osigweh [1989] for a discussion of the relevance of these kinds of changes in the meaning of concepts.

24. To put this argument more clearly, it is well possible that for managers evaluated on quantitative technical standards the Hopwood instrument would indicate a 'nonaccounting style' (low RAPM) whereas the Hirst instrument would indicate 'high RAPM'.

25. Several authors have pointed to the difference between the use of the Hopwood [1972] scale to derive absolute versus relative measures of RAPM [Harrison 1992, 1993; Ross 1995, p. 3]. In the original ranking procedure, 'high' levels of RAPM corresponded with 'high' relative rankings of the accounting related criteria. Research using the absolute scores on these criteria does not allow for any "relativity". The importance of this distinction, however, was displayed by Hopwood's [1972] different results regarding the use of relative versus absolute reliance on budget attainment. In recent research, however, it seems that authors return to the relative concept of RAPM, by using the ranking procedure [Ross 1994, 1995], or by relating absolute scores on the accounting criteria to the score of the non-accounting criteria [Harrison 1992, 1993]. This regained consistency avoids the question of giving substantive meaning to the difference between absolute and relative RAPM scores. The point made here is that the difference between absolute and 


\section{ChAPTER 3 DEVELOPMENT OF HYPOTHESES}

relative RAPM scores is easily interpreted in a methodological and statistical sense, but that it is less easy to see the substantive difference between "high absolute reliance on APM' and 'high relative reliance on APM'.

26. The equivalence of 'financial and quantitative' information and 'accounting' information is intended, and follows Harrison [1993]. We use the variable label RFQ for denoting the 'accounting" dimension of RAPM to avoid confusion with the original RAPM variable.

27. The difference between RAPM as 'manner' or as "extent' of the use of APM is reflected in the relative importance of the two accounting related items in his scale. This multidimensionality has been abandoned since Otley [1978, p. 128-129] who argued that the styles formed a unidimensional continuum. Although references to the earlier distinction have been made [Brownell 1982b; Briers and Hirst 1990], unidimensionality has been the 'empirical norm' ever since.

28. Such non-accounting targets are for example production targets stated in quantitative terms, as used in MBO systems [e.g., Murray 1990; Hartmann 1995]. 
ACCOUNTING FOR PERFORMANCE EVALUATION 


\section{Chapter 4 \\ Research Method}

\subsection{Introduction}

To test the hypotheses derived in the previous chapter empirically, data were gathered by means of interviews and by questionnaires distributed in a sample of 250 Dutch managers with budget responsibility. These managers were employed in eleven organizations in the Netherlands, out of twelve organizations that were initially approached for participation. This chapter presents the method of data collection, and is organized as follows. Section 4.2 presents the sample selection regarding participating organizations and managers. Section 4.3 then discusses the selection and development of the measurement instruments contained in the questionnaire to measure the variables. Section 4.4 describes the steps taken in the composition and pretest of the questionnaire. Section 4.5 discusses the procedures followed in the distribution and collection of the questionnaires. Section 4.6 presents information on response rates obtained with the questionnaire survey. Finally, Section 4.7 provides information about the interviews held in the participating organizations after conducting the survey.

\subsection{Sample}

\subsubsection{Sampling method, some general remarks}

The sampling method used here follows the sampling procedure adopted in many APM and other budgetary studies that use a contingency theoretic framework in combination with a questionnaire survey methodology [see, e.g., Merchant 1981, Rockness and Shields 1984, Brownell and McInnes 1986, Williams et al. 1990, Ross 1994]. This sampling method comprises two phases: first the selection of participating organizations, and second the selection of participating managers within each of those organizations.

In previous APM and other budgetary survey studies this method typically, although not necessarily, has not resulted in the establishment of 'fully' random samples [Lindsay 1995, p. 38]. 'Instead, the method is adopted as a means to approximate random sampling in situations in which random sampling is not feasible for economical or practical reasons [e.g., Brownell and Dunk 1991]. In this study the choice of sampling 


\section{ACCOUNTING FOR PERFORMANCE EVALUATION}

method is also partially the result of a tradeoff between the costs and benefits of random sampling [e.g., Pedhazur and Pedhazur 1991, p. 319]. The choice for the method adopted here was based on the following considerations.

First, although random sampling maximizes the chance of drawing valid inferences from research findings to the whole population [Kalton 1989, p. 90; Freedman et al. 1991, pp. 306-308; Lindsay 1995, p. 37], this study, and much of the APM and budgetary research, has a more limited aim. The budgetary-contingency paradigm adopted here is still largely of an exploratory nature. It aims at explaining differences in observed practices, or even, differences between earlier empirical studies, rather than at developing and testing universally valid laws [Kren and Liao 1988; Briers and Hirst 1990]. ${ }^{2}$ The procedure to ensure variation in the key independent variables by first selecting organizations that vary in types of industry and activities engaged in, seems better to serve this more limited aim [Emory and Cooper 1991, p. 275]. ${ }^{3}$ Section 4.2 .2 below discusses the selection and sample of organizations.

Second; especially when using a questionnaire survey methodology, the research design should attempt to control and reduce the problem of nonresponse [Alreck and Settle 1985, p. 45; Pedhazur and Pedhazur 1991, p. 320]. Nonresponse potentially causes response bias, which results in differences between random sampling as an (ex-ante) intention of research design, and random sampling as an (ex-post) consequence of the research design [Emory and Cooper 1991, p. 274]. The method involving sampling in two phases can be considered to focus on optimizing ex-post randomness, since it implies that organizational support is first obtained to enhance the chances of obtaining subsequent participation of the respondent's within those organizations.

Finally, random sampling requires the a priori establishment of the population from which a sample is drawn, and to which inferences are made. As for the focal population in this dissertation, public data on managers with budget responsibility are simply not available [e.g., Alreck and Settle 1985, p. 70; Oppenheim 1992, p. 43]. ${ }^{4}$ Especially the use of additional sampling criteria, which are discussed in Section 4.2.3 below, required the cooperation of officials in each organization, and therefore initial organizational support.

\subsubsection{Sample of organizations}

One criterion for the selection of organizations for participation was their location in the Netherlands, and their employment of Dutch managers. The primary reason for using this criterion was that it implied restricting the analysis to one country, thereby controlling for the potential bias from (national) cultural factors influencing the budgeting behaviors under study. ${ }^{5}$ An additional reason was that this focus allowed the researcher to present the study to be one of budgeting practices and behaviors in the Netherlands, which was believed to enhance the organizations' willingness to participate. There were two additional selection criteria. First, the sample of organizations as a whole should have a 
high expected variance on the contingency dimensions used as explanatory variables in the research model. This was ensured by selecting companies from different industries, of different sizes, and by selecting both private and public organizations. ${ }^{6} \mathrm{~A}$ second and practical criterion was the estimated availability of access to officials within the organizations of interest and the related chance of obtaining their cooperation. Based on these criteria, initially twelve organizations were approached and asked to take part in the research project. All agreed to explore the possibility of participation.

In each of these twelve organizations interviews were conducted with one or more senior management officials. These interviews served three purposes. A first purpose was to learn about, and to understand the organizations' budgeting and performance evaluation systems. This facilitated the discussion and assessment of the applicability of the subject of this study for each individual organization. A second purpose was to assess whether budgeting and performance evaluation were, at the point in time this study was conducted, considered topics important enough to create the organization's interest in further participation in the research project. A third purpose, related to the second, was to ask for support for conducting the research in the company or, in case that this support had to be obtained at higher levels within the organization, to make a request for this support.

During these interviews it was explained that participation in the research project implied the organization's cooperation in (1) the selection of respondents, (2) the distribution of the questionnaires by internal mail, (3) the writing and attachment of a letter of endorsement by the organization's official and (4) administrative support for the necessary mailing and follow-up procedures. Of the twelve organizations initially approached, eleven organizations agreed to further participation in the research project. ${ }^{\text {? }}$ Appendix $\mathrm{D}$ contains descriptive statistics on the sample of these eleven, participating organizations. Descriptive statistics on the interviews held are presented in Appendix E.

\subsubsection{Sample of respondents within each organization}

After the support for conducting the study had been received, the sample of respondents within each organization was selected by an official in that organization. The reasons for the selection of the internal samples by these officials were twofold.

First, the questionnaire survey was designed to be anonymous as to elicit a candid and high response. A direct approach of the respondent by the researcher would potentially signal the opposite to the respondent [Brownell 1995, p. 33]. Although during the initial interviews it appeared that many officials did not object to supply respondents' names and addresses for direct mail, uniformity in research design across organizations forced us to take this procedure across the sample. Second, we believed that the selection of respondents by the company official would contribute to the representativeness of the overall sample, as it reduced the potential for any intentional or unintentional selection bias by the researcher. The potential danger of bias by the selecting official was believed to be minimal for two reasons. First, selectors were 


\section{ACCOUNTING FOR PERFormanCE EVALUATION}

explicitly instructed to select a broad sample of managers. Second, the chance that the selection bias would be systematic for the eleven selectors was judged to be negligible.

The company official in charge of the selection of respondents was asked to base this selection on five selection criteria. First, the respondents selected should be managers, in that they were in charge of a distinct area of responsibility and had at least one functional subordinate [cf. Hirst 1983b]. Second, the respondents should have a

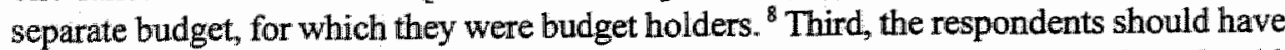
experienced at least one budgeting and performance evaluation cycle, and thus should be familiar with the organization's budgeting and performance evaluation systems. Fourth, the respondents should be selected across functional areas and positions in the organizational hierarchy, and should both include line and staff managers. Fifth, again to limit potential confounding effects from different national cultures, respondents should be native Dutch and work in the Netherlands. Finally, the officials were asked to make the sample as large as possible within the constraints given.

As a result, a total of 250 managers were selected for participation. The sample size per organization ranged from 9 to 56 , with a mean and median number of managers per organization of 22.8 and 24 respectively. The sample sizes especially reflect the organization's size and responsibility center structure. Descriptive statistics on the sample of organizations, and on the sample size per organization are contained in Appendix D.

\subsection{Measurement instruments}

\subsubsection{Selection of measurement instruments, some general remarks}

As the budgeting and organizational behavior literatures provide a variety of measurement instruments, even to measure identical variables, a selection had to be made regarding the choice of instruments included in the questionnaire. Four selection criteria were used. The first criterion for selection was that the instrument, when possible, should have been used in previous APM or other accounting survey studies to enhance the comparability of findings. Second, the instrument should have shown satisfactory reliability and validity in those studies, and should also be theoretically sound for the current study. Third, the instrument should be as limited in length as possible; that is, in cases where several measurement instruments were available that met the criteria of previous use, reliability and validity, the shorter instrument was chosen. Finally, the set of measurement instruments as a whole should have no overlap in individual items.

The remainder of this section discusses the choice of instruments to measure the variables. Section 4.3 .2 presents the selection of measurement instruments for the three contextual variables; environmental uncertainty (EU), task uncertainty (TU) and tolerance for ambiguity (TFA). This section also presents the variables on age, tenture and position, which were included in the questionnaire for descriptive purposes only. Section 4.3.3 presents the selection and development of questionnaire instruments for the three APM variables; $R A P M$, reliance on financial and quantitative criteria (RFQ) and 
reliance on targets $(R T)$. Section 4.3 .4 presents the selection and development of the three dependent variables; goal clarity $(G C)$, agreement with evaluation criteria $(A E C)$ and felt appropriateness of APM (FAAPM).

The discussion and presentation of the measurement instruments in the section below are limited to their choice and composition. Appendix F presents the full questionnaire. Chapter 5 will present descriptive statistics and item analyses for each of the variables measured by these instruments for our sample.

\subsubsection{Measurement of contextual variables and additional descriptives}

\section{Environmental uncertainty (EU)}

The instrument to measure environmental uncertainty used in this study consists of five attributes of the respondent's organizational environment. These five attributes were derived from the scales used previously by Govindarajan [1984] and Merchant [1990], and relate to the behavior of (1) customers, (2) competitors and (3) suppliers, as well as to (4) the existence of technological developments in the field of work and (5) the occurrence of legal and political developments. For each of these five attributes respondents were asked to indicate on six-point fully (verbally) anchored scales both the perceived predictability and the perceived impact on work and performance, which resulted in a ten-item overall instrument. ${ }^{9,10}$

The use of this instrument implies the use of a perceptual, rather than an objective measure for environmental uncertainty. Hence uncertainty is not viewed as an objective or physical trait of the environment, but rather as the individual's perceptual response to that environment [Downey et al. 1975]. "Although budgetary research shows the application of objective industry statistics occasionally [e.g., Kren 1992], ${ }^{12}$ the dominant view is that when explaining attitudinal and behavioral responses to budgeting, perceptual rather than objective measures of uncertainty should be used [cf. Dill 1958; Lawrence and Lorsch 1967; Duncan 1972, Govindarajan 1984].

The instrument used also implies an assessment of the predictability instead of the volatility of the environment [cf. Lorsch and Allen 1973; Gordon and Narayanan 1984; Merchant 1990] and thus reflects the view that volatility as such is a necessary but not a sufficient condition for uncertainty [cf. Khandwalla 1972; Downey and Slocum 1975; Miles and Snow 1978; Govindarajan 1984; Ezzamel 1990; Kren 1992; Kren and Kerr 1993]. ${ }^{13}$ Finally, the focus on both impact and predictability was applied following Khandwalla $[1972$, p. 277], who argued that uncertainty is a combination of both factors. Consequently, it was expected that the focus on both impact and predictability would enhance the explanatory power of the instrument in comparison with Merchant [1990] and Govindarajan [1984], in which the focus was on predictability alone.

Task uncertainty (TU)

Task uncertainty was measured with an instrument developed by Withey et al. [1983]. 


\section{ACCOUNTINIG FOR PERFORMANCE EVALUATION}

The instrument asks respondents to indicate on five-point fully anchored scales their level of agreement with a total of nine statements related to the analyzability and the variability of their tasks. Sample items from this instrument are: 'My tasks are the same from dayto-day'; and, 'There is an understandable sequence of steps that can be followed in doing my work'.

Withey's instrument was developed by analyzing and combining items from several existing instruments originally designed to measure task technology [e.g., VandeVen and Delbecq 1974; VandeVen and Ferry 1980]. ${ }^{14}$ The instrument has been used previously in APM-research by Brownell and Hirst [1986] in which it showed a high reliability. ${ }^{15}$

\section{Tolerance for ambiguity (TFA)}

Tolerance for ambiguity was measured with the instrument developed by MacDonald [1970]. This instrument asks respondents to state whether they agree or disagree with a total of twenty statements. Sample items are: 'If I were a doctor, I would prefer the uncertainties of a psychiatrist to the clear and definite work of a surgeon'; and, 'There is a right way and a wrong way to do almost everything'.

In accounting research the original version of the MacDonald instrument has previously been used by Gul $[1984,1986]$. A Dutch translation of the instrument has been used by Van de Poel [1985] and Vaassen [1994]. This version was used in this study, after some minor corrections of the translation. ${ }^{16}$

\section{Descriptive variables}

Several descriptive variables were included in the questionnaire to generate additional information about the managers in the sample, and to allow for establishing whether the sampling criteria had been met (see Section 4.2.3 above). The descriptive variables measured were the respondent's age, tenure and position in the organization. Additionally, two measures of departmental size were included, both relating to the number of subordinates employed in the respondent's area of responsibility [Merchant 1981, 1984; Ezzamel 1990]. One measure asked for the total number of subordinates in the respondent's area of responsibility, including any subdivision or subsection. The second measure assessed the respondent's span of control and asked for the number of subordinates under direct supervision of the respondent.

\subsubsection{Measurement of APM variables}

Reliance on APM (RAPM)

RAPM was measured with the instrument developed and used by Hopwood [1972]. This instrument was chosen as it has been the most frequently used RAPM instrument in previous research, albeit in different formats [e.g., Otlley 1978; Brownell 1985, 1987a; Brownell and Hirst 1986; Harrison 1992, 1993]. One adaptation from the original Hopwood-version was made for this study, in order to make the instrument applicable 
to both cost and profit-center environments. For this purpose, a profit-related performance criterion was added following Otley [1978], which resulted in a nine-item overall scale. Respondents were asked to rate the importance of each of these nine performance criteria on five-point scales.

Reliance on financial and quantitative measures ( $R F Q$ ) and reliance on targets ( $R T$ ) The second APM measurement instrument was specifically developed for this study to measure separately: (1) the extent to which superiors rely on financial and quantitative (i.e. accounting) performance information; and, (2) the extent to which superiors rely on preset targets. The instrument consisted of nine questions. Respondents were asked to indicate, on five-point scales, the importance their superiors attach to financial information, quantitative information and the attainment of preset targets for (a) the general evaluation of their performance by their superior, (b) the determination of monetary rewards, and (c) their chances of obtaining longer-term non-monetary rewards such as promotion. These three latter factors together present a broader focus on the use of performance evaluation than a strict focus on monetary rewards, and were partially based on the APM instrument developed and used by Hirst [1983b].

\subsubsection{Measurement of dependent variables}

\subsubsection{Appropriateness of APM as an outcome and as an opinion}

As was presented in Chapter 3 the hypotheses concerning the appropriateness of APM focus on goal clarity (GC) and agreement with evaluation criteria (AEC) as outcome variables and on felt appropriateness of accounting performance measures (FAAPM) as an opinion variable. The selection of measurement instruments for these three variables will be discussed in the sections below.

Section 4.3.4.2 deals with the selection and development of instruments to measure $G C$ and $A E C$ variables. These variables are labeled outcome variables, since they relate to the outcomes of using APM in terms of subordinate manager"s job-related attitudes. Additional to these two focal outcome variables, this section also discusses the selection of measurement instruments for job-related tension, job satisfaction and performance. These latter three instruments were included in the questionnaire to allow for validation of the GC and AEC variables, and comparison with previous APM research, in which they have frequently been used (see Chapter 3). Section 4.3.4.3 deals with the instrument developed for this study to measure FAAPM. Recall that FAAPM is an opinion variable, since it captures the subordinate manager"s opinion about the appropriateness of APM. This section also discusses the selection of an additional opinion variable, felt usefulness of budgets, which has been used in previous APM research to measure managers' general attitudes toward budgets overall. This variable was also included in the questionnaire to validate our focal opinion instrument FAAPM. 


\subsubsection{Outcome variables: goal clarity and agreement with evaluation criteria}

\section{Goal clarity (GC)}

Goal clarity was measured by combining items from two existing instruments. The first instrument is the instrument for goal specificity, which was adopted from Steers' [1976] task-goal attributes questionnaire. This instrument has been used previously in a budgetary context by Kenis [1979], who changed the wording of the items to capture budgetary goal specificity. In this study, we used the original version. The instrument consists of three items, using five-point fully anchored scales. A sample item for this instrument is: 'My work objectives are very clear and specific; I know exactly what my $j o b$ is: The second instrument is the instrument for role ambiguity, which was used in Rizzo et al. [1970] and House [1971]. The instrument contains five items and was used with five-point fully anchored scales. A sample item from this instrument is: 'I know exactly what is expected of me in this job. The items and their wording of this latter instrument are largely similar to those of the instrument developed and used by Kahn et al. [1964]. The two instruments were used in combination to enhance the validity and explanatory power of the goal clarity measurement. ${ }^{17}$

Agreement with evaluation criteria ( $A E C$ )

In the budgetary literature, AEC as a separate variable has been used by Hopwood [1972], Otley [1978] and Dunk [1990]. In these three studies the construct was measured with a single-item instrument that asks the respondent's overall agreement with the evaluation criteria used by his or her superior. To better reflect the theoretical content of this construct, and to increase the reliability of its assessment, a new instrument was developed for this study. ${ }^{18}$ The development was based on explicit criteria for fair performance measures from Emmanuel et al. [1990, p. 232], from the measurement of fairness in the equity literature [e.g., Landy et al. 1978; 1980], and on the implicit definitions of this concept in the budgetary literature that uses evaluation fairness as an intermediating, but unmeasured, variable [e.g., Hopwood 1972; Govindarajan 1984]. Sample items for this instrument are: 'Certain achievements and actions which I think are important in my functioning are overlooked by my superior when he evaluates me' (Reversed); 'The evaluation I receive is based on a complete picture of my true performance'; and, "In general, Ifeel that the criteria my superior uses to evaluate me are honest and fair'. For each of these nine statements, subjects were asked to indicate their level of agreement on five-point fully anchored scales.

Variables included for validation purposes

As we explained in the introduction, we included three instruments in the questionnaire to enable validation of our two focal outcome variables, goal clarity (GC) and agreement with evaluation criteria ( $A E C)$. These additional instruments measured job-related tension, job satisfaction and performance. Job-related tension (JRT) was measured using an eight-item scale derived from the measures developed and used by Kahn et al. [1964], House and Rizzo [1972] and Jaworski and Young [1990]. Although in the budgetary 


\section{CHAPTER 4 RESEARCH METHOD}

literature the job-tension instrument developed by Kahn et al. [1964] is the most frequently used [Hopwood 1972; Otley 1978; Hirst 1983b; Brownell and Hirst 1986; Harrison 1992], we used only two items from this scale, since the other items show too much overlap with the items we use to measure goal clarity in this study. ${ }^{19}$ The two items used from this scale were 'I often worry about the amount of work I have to do'; and, 'I often worry that the amount of work interferes with how well it gets done'. Three items were used from the Jaworksi and Young [1990] scale asking respondents to state the amount of stress encountered (1) in the work in general, (2) during performance evaluation sessions and (3) when not meeting work goals. In addition three items from the House and Rizzo [1972] scale were added, that reflected elements of stress not captured by the items from the Kahn et al. [1964] and Jaworksi and Young [1990] scales. ${ }^{20}$ These latter items relate to the interference of work with personal life and health. The composition of a job-tension scale from different existing scales was judged to be valid as Jex et al. [1992] provide support for the equivalence of different instruments to measure job-related tension. Job satisfaction (JSA) was also included for validation purposes only, and was measured using an instrument developed and used by Kahn et al. [1964] which has been applied in a budgetary context by Hopwood [1973] and Swieringa and Moncur [1975]. The seven items included in the instrument relate to different concepts underlying job satisfaction, such as satisfaction with the job, satisfaction with the employing organization and the propensity to leave [Smith et al. 1969]. In its original form, the instrument consisted of five, five-point scale items and two dichotomized (yesno) items. The adaption made in this study was to use five-point scales for all items. A minor rewording of the two original dichotomous items was therefore necessary. A sample item from the instrument is: 'If I had the chance to do the same kind of work for the same pay, but in another company, I would certainly stay here'.

The third instrument that was included in the questionnaire to validate our $\mathrm{GC}$ and AEC variables was an instrument to measure managerial performance. With two questions, respondents were asked to give an overall self-rating of their personal performance and departmental performance, both on a scale from 1 to $10 .{ }^{21}$ Self-ratings were used instead of some external performance rating for practical and theoretical reasons. First, the literature provides evidence that the reliability of self-ratings is not necessarily lower than that of, for example, superior ratings. Although self-ratings are likely to be biased [Baker et al. 1988, p. 607], it has been demonstrated to be unsystematic [e.g., Merchant 1981; Chenhall and Brownell 1988]. Second, for the current sample obtaining an identical or comparable measure of overall individual or departmental performance from each of the participating organizations appeared practically impossible..$^{22}$ The choice to use a relative simple measure, rather than, for example, the multidimensional instruments developed and used by Mahoney [1963], VandeVen and Ferry [1980] and Govindarajan [1984], was based on the following additional consideration; budgetary studies using multidimensional measures consistently show significant correllations between the individual performance dimensions and the overall performance measure [Brownell 1982b, Brownell and Hirst 1986; Brownell and Dunk 1991] ${ }^{23}$ 


\subsubsection{Opinion variable: felt appropriateness of APM}

FAAPM relates to a subject's opinion about the extent to which his performance can be reflected in financial and quantitative, budgetary terms. As no existing instrument to measure FAAPM was available in the literature, a new instrument was developed for this study that consisted of twelve items. The selection and formulation of the twelve items was based on the definition and conceptual content of FAAPM in this study, which in turn was based on the use of the concept of appropriateness in earlier studies [Argyris 1952; Hopwood 1972; Govindarajan and Gupta 1985; Hirst 1981, 1983b; Brownell 1981, 1985; Dunk 1990; Emmanuel et al. 1990; Baker 1992]. In conformity with the discussion in Chapters 2 and 3 of this study, we included questions related to the controllability, the completeness and the relevance of budgetary performance. Sample items are: If I perform well as manager, it is directly reflected in more positive budget variances"; 'Budget variances provide a complete overview of the functioning and performance of my department'; and, 'Budget variances are irrelevant for determining whether or not my department has performed well' (Reversed). ${ }^{24}$ For each of these items, respondents were asked to indicate their level of agreement on a five-point scale.

Additional to this new FAAPM instrument an instrument from previous budgetary research was included that measures the felt usefulness of budgeting (FUOB) [e.g., Bruns and Waterhouse 1975; Swieringa and Moncur 1975; Kenis 1979; Merchant 1981; Chenhall and Morris 1986]. This five-item instrument, originally derived by factoranalyses from the Budget-Related Behavior questionnaire [Swieringa and Moncur 1972, 1975], asks respondents to state on five-point scales the extent to which they feel that their budgets enable them (1) to perform well, to be (2) flexible and (3) innovative and to (4) keep track and (5) improve their performance. As we explained in the introduction to this section, this instrument was included in the questionnaire as a check on the validity of the newly developed FAAPM instrument, and also to provide a link with the existing budgetary and APM literature. ${ }^{25}$

\subsection{Development of the questionnaire}

\subsubsection{Choice of language of the questionnaire}

The partial use of measurement instruments used previously in the Anglo-Saxon budgetary research required a choice about the language of the questionnaire. Although Dutch managers could generally be expected to understand English to a sufficient degree to fill out an English questionnaire, at least three reasons existed for using a Dutch, translated, text instead.

First, to enhance the willingness for participation, the empirical study was presented both to the organizations asked for support, and to the individual managers as a study of budgeting in the Netherlands, in Dutch organizations and among Dutch managers. Second, we decided that asking questions in English to a sample of $n$ Dutch 
managers would imply a $n$-times translation of each of these questions. Consequently, differences in experience with English texts within the population were believed to pose a potential threat to the reliability of the responses, even with an on average good command of English among the target population. Third, the use of a Dutch questionnaire provided the possibility to correct for differences between Anglo-Saxon and Dutch business terms. However, after the final version of the questionnaire had been composed, the need for this latter type of corrections appeared to have been negligible.

\subsubsection{Translation, composition and pretest of the questionnaire}

The composition of the questionnaire involved several steps, including the translation of the originally English measurement instruments, tests on the translation accuracy for each of these instruments and pretests of draft versions of the questionnaire among members of the target population. In the remainder of this section each step taken in the composition and test of the questionnaire is presented in a chronological order.

As a first step, the selected Anglo-Saxon instruments were translated into Dutch by the author, and a first full Dutch draft version of the questionnaire was prepared. This draft version was presented to five Dutch colleague members of the accounting faculty and four external reviewers. The last group consisted of Dutch managers holding positions in general management, control and accounting and research and development in four different companies. All nine people were requested to comment on both the wording and the understandability of the individual items, and especially to judge the content validity of the newly developed instruments. Based on the comments received, some changes in wording were made and a second draft version of the questionnaire was prepared.

To assess and optimize the accuracy of the translation of the instruments, an additional testing procedure was followed for this second draft version, which is often applied in cross-lingual and cross-cultural budgetary research [Bimberg and Snodgrass 1988; Daniel and Reitsperger 1991]. The second draft version of the questionnaire was presented to a native American, who was familiar with the area of research and possessed fluency in both English and Dutch. A back translation was made of the items into English, which was compared with the original versions of the items. Differences between the original and back translated version were discussed leading to some minor additional changes in the wording of some items, and to a third draft version of the questionnaire.

In the final testing phase, this third draft version was pretested with four managers in the field of production, technical support, logistics and sales in two of the participating organizations. During individual interviews the managers filled out the whole questionnaire, and were asked to give any comment they might have on the content or layout of the questionnaire. The purpose of these interviews was to test whether the questionnaire was understandable, attractive and easy to fill out, and to estimate the time needed to complete it. These interviews were concluded with an explanation by the 


\section{ACCOUNTING FOR PERFORMANCE EVALUATION}

researcher of the constructs measured by each of the measurement instruments.

Additionally, this third draft version of the questionnaire was mailed to the contact persons in each participating organization with a request for comments on content and layout, with follow-up telephone calls. None of these pretests led to additional changes in content or wording. Some aspects of the layout, however, and some of the introductory statements were adapted, to enhance the attractiveness and make the concepts used as clear as possible for each participating organization. After this round of pretests, a final version of the questionnaire was prepared and printed.

\subsubsection{Final format and layout of the questionnaire}

For the final design, format and layout of the questionnaire, several guidelines from Dillman's [1978] Total Design Method were followed. ${ }^{26}$ Following the rules for mail surveys proposed by this method has shown to deliver satisfactory response rates by Dillman [1978, pp. 22-23] and by Jaworski and Young [1992] and Merchant [1981, $1984]$ in budgetary research studies. ${ }^{27}$ For this study the application of the guidelines from the Total Design Method implied the following for the questionnaire package sent to each respondent.

\section{Cover letter}

A separate cover letter was attached which briefly introduced the research project, asked the participation of the respondent and expressed gratitude with this participation. The letter contained a handwritten signature and was printed on university stationary. This letter guaranteed anonymity of responses, explaining that no one within their company would see the questionnaire they had filled out, and no report would be made of individual answers.

\section{Questionnaire format and layout}

The final version of the questionnaire was a twenty-page booklet in A4 format. The first two pages of the questionnaire contained the instructions for filling out, briefly and in general terms explained the purpose of the study and stated that filling out would take approximately 30 minutes. ${ }^{28}$ These introductory pages also contained the researcher's full name, address and telephone number. The last pages of the questionnaire gave the respondents ample space for a personal reaction to the questionnaire. ${ }^{29}$

\section{Mailing}

A self-addressed prepaid answering envelop was included, and an additional selfaddressed, pre-stamped postcard, which the respondent could use to indicate that he had filled out the questionnaire, and wished to receive the results of the study. 


\subsection{Distribution of the questionnaire and follow-up}

The packages of questionnaires were delivered personally to the contact persons in each organization. Each questionnaire and the envelope containing it carried an identical and unique code. Each package of questionnaires was accompanied by a code book that contained the codes of all the questionnaire packages delivered. Each contact person was asked to attach the organization's letter of endorsement to each individual questionnaire package, to put the name and internal address of every individual respondent on the envelop, as well as behind the identical code in the code book and to send the packages to the respondents by internal mail. This coding procedure thus allowed the questionnaires to be traced when needed, without breaking anonymity.

Approximately two weeks after distribution, a postcard was sent to each respondent, thanking those that had already returned the questionnaire and asking those that had not yet done so again for their support and participation. Again, these cards were sent by the contact person through the internal mail system in each organization. The cards contained the researcher's handwritten signature. Both the mailing of the questionnaire packages and the mailing of the follow-up card were checked by follow-up telephone calls. Approximately two weeks after sending the postcards, the contact persons were approached by telephone for a second follow-up. In four organizations, the numbers of questionnaires not yet received were reported and the contact person promised to contact these people personally. The contact persons in another five organizations promised to send a general reminder to all respondents. Also these latter steps were checked by telephone calls with each of the contact persons.

\subsection{Response rate}

Of the 250 questionnaires distributed, 206 questionnaires were returned, which corresponds with an overall response rate of 82.4 percent. This response rate compares favorably to the response rates reported in previous studies that followed a similar research method, and is much higher than response rates regarded as typical for mailed questionnaires [Backstrom and Hursch-César 1981, p. 118; Alreck and Settle 1985, p. 45; Emory and Cooper 1991, p. 333]. ${ }^{30}$ The response rates for the individual organizations were satisfactory too, and ranged from 72.0 to 100.0 percent.

of these 206 questionnaires received, ten questionnaires were deemed not usable for further statistical analysis. In these ten cases, one or more of the questions related to the key research variables were not filled out. As this was believed to be an indication of potential inappropriateness of the questionnaire as a whole for those respondents, it was decided not to use any part of these questionnaires, and to delete them listwise [Oppenheim 1992, p. 281]. The number of usable questionnaires therefore amounted to 196 , corresponding to a usable response rate of 78.4 percent. Further statistics on response rates are contained in Appendix $\mathrm{H}$. 
A total of 163 respondents returned the additional card, which corresponds to 65.2 percent of the total number of questionnaires distributed, and to 79.1 percent of the number of questionnaires returned. Of these 163 respondents, all indicated that they wished to receive the results of the study. Due to the anonymity of this card, no statistics per organization are available.

\subsection{Final interviews}

The third and final stage of the empirical part of this study consisted of interviews in each of the eleven participating organizations, with the managers that had earlier approved their organization's participation. The purpose of these interviews was to, first, obtain some additional data on the organization as a whole, and second to discuss some findings concerning their organization. Statistics on these interviews are included in Appendix E. ${ }^{31}$ 


\section{Notes to Chapter 4 :}

1. Random sampling is more formally known as probability sampling which implies that every member in a population of $n$ members has an equal and non-zero chance of $1 / n$ of being selected [e.g., Pedhazur and Pedhazur 1991, p. 321]. Based on a survey of budgetary and control studies published between 1980 and 1987 in Accounting. Organizations and Society, The Accounting Review and the Journal of Accounting Research that used a questionnaire survey methodology Lindsay [1995, p. 38] concludes that random sampling is '... virtually' mon-existent'. Note that since random sampling relates to a procedure and not to an outcome, it does not provide a guarantee against biased samples, nor a guarantee for the generalizability of findings [cf. Lindsay 1995, p. 38; Lal et al. 1996, p. 485].

2. Where and when a research paradigm leaves the status of "exploratory" is partly a matter of subjective judgment. However the lack of unity and consistency in findings [see Kren and Liao 1988; Briers and Hirst 1990; Lindsay 1995; and Chapter 2 of this study] suggests that the label 'exploratory' is still appropriate for the present area of study. Emory and Cooper [1991, p. 273] advocate the use of non-random purposive sampling for exploratory research.

3. In addition, the method used here implies the study of more than one organization, which lowers the risk of drawing inferences from potential idiosyncrasies of single organizations.

4. Although annual reports are a potential source of such information, the information they generally contain does not provide detailed nor complete information about the organization's managerial population.

5. See Harrison [1992, 1993] for an example of the influence of national culture on the appropriateness of budgeting and the use of APM.

6. The inclusion of public organizations in the sample is not typical for budgetary control research, but is precedented by, for example, Giroux et al. [1986] and Williams et al. [1990]. Williams et al. [1990, pp. 221] interestingly note that origins of contingency studies in management accounting lie in the work of James Thompson and Max Weber, for whom the distinction between private and public organizations was irrelevant.

7. One of the twelwe organizations went through the introductory interviewing stage of the research, and showed great interest in the subject of research. After the questionnaires had been handed over, the official contacted felt unable to distribute them among managers in his organization. The main reason was that the organization was in the midst of a process of evaluating its current budgeting system and felt that allowing additional external research would be inappropriate and "...a wrong signal". Therefore, we believed that both the interviews, and the displayed willingness to participate in the research project provided support for the contemporary interest in budget related issues in general [see, e.g., Parker and Lewis 1995, and Chapter 1 of this dissertation], and for the organizations approached in particular. Also many organizations' explicitly motivated their participation with the desire to obtain some data on budget-related issues for their own organization. In addition, several people mentioned the '...positive attitude of this organization toward academic research".

8. The first two selection criteria together ensured that the respondents qualify as 'responsibility center managers". 
9. Five points of this scale measured the extent of predictability and impact for the specific factors. Additionally subjects could indicate that the specific factor was not a part of their working environment. The pretests of the questionnaire indicated the necessity of this 'nulloption'. See also Appendix F, Table F.1 for the full text of this instrument.

10. This type of scaling, used throughout the questionnaire, is usually referred to as 'Likert' scaling after its creator [e.g., Alreck and Settle, 1985, pp. 133-135].

11. Downey and Slocum [1975, p. 615] argue that physical environmental attributes are several 'steps' removed from the possible perception of uncertainty. Physical attributes are first perceived by the individual, and only then can cause uncertainty perceptions. Downey et al. [1975] empirically demonstrate this distinction.

12. Kren [1992] uses industry statistics on market, technological and income volatility as a measure of uncertainty.

13. A third type of measures focuses on the consequences instead of on the sources of environmental uncertainty, namely the individual's potential perceived lack of information for taking particular decisions. A measure for this construct was developed by Duncan [1972] and used in an accounting context by Ferris [1977] and Hirst [1983b]. Since it is not a specific measure of environmental uncertainty, and because its validity has been severely criticized [see, e.g., Downey and Slocum 1975], its use was not considered for this study.

14. This latter concept originates in the work of Thompson [1967] and Perrow [1967, 1970] as a two-dimensional concept that relates to the analyzability and variability of tasks faced by a subject. In APM research task uncertainty is generally considered a unidimensional concept, which implicitly follow Perrow's [1967] notion that the two concepts will often be empirically related [see, for an exception, Brownell and Dunk 1991]. Note that the dimensions of analyzability and variability (number of exceptions) from Perrow [1967] correspond with Thompson's [1967] dimensions knowledge of cause-effect relations and repetitiveness [cf. Brownell and Hirst 1986, p. 244].

15. Although Withey's et al. instrument [1983] originally consists of ten items, Brownell and Hirst [1986] refer to it as a nine-item instrument. An obvious explanation for this difference is the close resemblance of two items in the original instrument, which are nearly equall in wording. Also in this study a nine-item version is used by not using one of these two 'equal' items.

16. The adaptation was made based on the direct linguistic comparison with the original version and an analysis of standard deviations, item-total correlations for each of the twenty items and the reliability in these two previous studies This latter version was tested in a convenience sample of 54 graduate accounting students who filled out, as part of a larger questionnaire, both the MacDonald [1970] instrument and its translated Dutch version with two distractor tests in between. The scores on the two instruments were highly and significantly correlated $(\mathrm{r}=0.84, \mathrm{p}=0.0000$, two-tailed). Three items showing a significant difference in mean response between the English and Dutch versions were checked and corrected.

17. The combined instrument was expected to have a greater construct validity than either of its two constituting instruments. The goal clarity concept includes both a more 'objective' goal characteristic (specificity) and a more "subjective" goal characteristic (ambiguity). However, 


\section{CHAPTER 4 RESEARCH METHOD}

the instruments were expected to correlate highly and significantly. Furthermore, it was expected that the larger total number of items to measure goal clarity would positively affect the reliability of its measurement.

18. In the organizational psychology literature, an instrument has been developed by Landy et al. $[1978,1980]$ to measure 'perceived fairness and accuracy of performance evaluation'. Although this construct is related to the construct we intend to measure, we did not consider the associated instruments since it also consists of a single item only, and it addresses the total performance evaluation process, as opposed to the more specific performance evaluation criteria which are the object of interest in our study. For the latter reason, also the instrument developed and used by Giles and Mossholder [1990] was not considered for use.

19. Overlap (similar items across different instruments) is an important source of artificial correlation [cf. Podsakoff and Organ 1986, p. 535]. By doing so, we also ensured that we used a measure for job-related tension that asked directly for tension experiences, rather than for the existence of 'stressors' that only potentially cause job-related tension. Recall from Chapter 3 our motivation to focus on the more specific constructs (GC and AEC) instead of on job-related tension.

20. Jaworksi and Young [1990] state that their instrument is based on House and Rizzo [1972], yet both the item content and item wording shows little resemblance.

21. The scale of 1 to 10 was chosen for two reasons. First, it resembles the system of school grades used generally in the Netherlands, and therefore was judged to be easy to understand. Second, although in Kenis [1979] and Merchant [1981, 1984, 1985b] five-point scales were used - asking respondents to compare their own (departmental) performance with other's (departments') performances - it was not clear on beforehand whether respondents in the present sample would find a basis for comparison.

22. The same problem is reported in Merchant [1981, 1984]. Contact persons in some of the organizations moreover saw both practical as well as legal limitations to gathering official individual performance information. Furthermore, in some organizations this information was not centrally available, or was regarded 'strictly confidential'. The use of a potentially more easily available financial performance measure, such as budgetary performance [Otley 1978] was not considered for the reasons presented in Chapter 3 .

23. Two additional reasons for using this instrument were the following. First, the use of the two single items limited the size of the questionnaire as a whole. Second, the instrument was preferred over multidimensional instrument because the latter type of instruments presuppose the elements that should underlie performance, without testing the applicability of each of these dimensions for each individual manager [cf. Young 1996].

24. A related instrument, measuring general managerial attitudes towards the use of budgets, was developed and used by Daley et al. [1985]. A sample item from this instrument is: "It is nor appropriate to hold a manager responsible for his initial budget. Rather, changing circumstances must be considered in evaluating performance' [Daley et al. 1985, p. 100]. This instrument was not considered for use, since it asks for managers' general attitudes, rather than specific opinions.

25. Although the felt usefulness of budgeting (FUOB) instrument originally consists of five items, Kenis [1979] reports the use of a four-item version. In this study we use the full five- 
item instrument as reported in Merchant [1981].

26. See for similiar guidelines also Backstrom and Hursch-César [1981], Alreck and Settle [1985, Chapter 7] and Oppenheim [1992, Chapter 7]. Dillman's method however is often explicitly referred to [see, e.g., Emory and Cooper 1990, p. 333].

27. Jaworski and Young [1992] explicitly mention their use of this method. In a personal conversation (January 1995) Merchant noted that he used many of the prescriptions from this method for his 1981 and 1984 papers.

28. The purpose of the study was explained in general terms with no reference made to the relationships to be tested, to avoid that the questionnaire would itself would reveal any theory to be tested. For the same reason, we chose an order of the variables which did not correspond with the order of the variables presented in this chapter, and did not use any variable labels.

29. To enhance the attractiveness of the layout of the questionnaire it was digitally photocopied to obtain a letter quality equal to printing. Furthermore, the questionnaire had an attractive cover page which was printed on high quality paper. The questionnaire package further contained a pen with the questionnaire's title ('Budgettering en Beoordeling') and the name of the university ('Rijksuniversiteit Limburg). Additionally, the package contained the researcher's business card.

30. This response rate was reached despite the fact that in some organizations the questionnaires were distributed during summer holiday. In the initial interviews, all officials were asked to state the period in which the distribution of questionnaires could best take place. Although all questionnaires were distributed to the organizations within time, and well before summer holiday, three organizations did not manage to internally distribute the questionnaires within the period specified. This accounts for most of the variance in mean response times between organizations.

31. The interviews were not aimed at finding responses to overall findings of the study, although some of these findings were discussed, but instead were aimed at discussing findings for each individual organization. The reasons for this focus were threefold. First, we believed, and found, that officials were less able to comment on results for the whole population than for their own organizations. Second, we believed that the possibility for a 'clear' discussion of the results of many hypotheses was limited, since the majority of hypotheses in this study predicted interaction effects. Finally, most officials were primarily interested in the practical implications of the findings for their own organization, especially when this interest had been an important reason to participate. 


\section{Chapter 5 \\ Descriptive statistics and item analyses}

\subsection{Introduction}

This chapter contains a preliminary analysis of the data obtained with the questionnaire survey, before performing the statistical analyses of the hypotheses in the next chapter. It presents descriptive statistics on the sample of 196 managers and an analysis of the reliability of the measurement instruments used in the questionnaire. Furthermore, it presents the derivation of variable scores from the survey data and the results of a test for potential bias from nonresponse. This chapter is structured as follows. Section 5.2 describes the main characteristics of the sample, in terms of the age, tenure and positions of the respondents. Section 5.3 contains the item-analyses for each of the measurement instruments contained in the questionnaire. These analyses aim at the assessment of the reliability of the instruments used. They result in a description of the derivation of scores for variables for use in the research model, from the "raw scores' obtained with the measurement instruments. Finally, Section 5.4 presents the results of the test for potential bias from nonresponse.

\subsection{Sample characteristics}

The average age of the respondents in the sample of 196 was 46.2 years. Respondents had, on average, worked with their present employers for 18.1 years, and had been, on average, for 5.7 years in their present positions. The average number of employees in the respondents" area of responsibility, which includes both the respondent's department and subdepartments, was 79.0. On average, the respondents' span of control, as measured by the number of employees under direct supervision, was 8.8 . Table 5.1 below contains further descriptive statistics on these variables. 


\section{ACCOUNTING FOR PERFORMANCE EVALUATION}

Table 5.1 Descriptive statistics on descriptive variables

\begin{tabular}{|c|c|c|c|c|c|c|}
\hline \multirow[t]{2}{*}{ Position variables } & \multirow[t]{2}{*}{ mean } & \multirow[t]{2}{*}{ stal.dex } & \multirow[t]{2}{*}{ median } & \multicolumn{2}{|c|}{ actual range } & \multirow[t]{2}{*}{$n^{1}$} \\
\hline & & & & min & $\max$ & \\
\hline Age & 46.18 & 6.88 & 47 & 31 & 61 & 195 \\
\hline Tenure with organization & 18.05 & 10.37 & 18 & 1 & 42 & 194 \\
\hline Tenure in position or function & 5.66 & 5.17 & 4 & 1 & 32 & 192 \\
\hline Span of control & 8.82 & 9.01 & 6 & 1 & 72 & 195 \\
\hline Employees in area of responsibility & 79.02 & 213.19 & 26 & 1 & 2500 & 195 \\
\hline
\end{tabular}

The division of respondents over functional areas within the total sample of 196 is presented in Table 5.2 below. In combination with the data in Table 5.1, this overview provides an indication that the sampling criteria, that aimed at obtaining variance in respondents over different functional areas, were effective. Table 5.2 presents both the absolute number and proportion of respondents that report to work in the specific area. As many respondents stated more than one functional area, the total number of functional areas mentioned (281) exceeds the sample size (196).

Table 5.2 Division of respondents over functional areas

\begin{tabular}{|l|c|c|}
\hline Functlonal area & $\begin{array}{c}\text { Number of respondents in functional area } \\
\text { Nosolute number of respondents } \\
\text { per area }\end{array}$ & $\begin{array}{c}\text { Percentage of total areas } \\
\text { mentioned }\end{array}$ \\
\hline General management & 65 & $23.1 \%$ \\
\hline Intemal Service \& Support & 52 & $18.5 \%$ \\
\hline Marketing \& Sales & 45 & $16.0 \%$ \\
\hline Finance \& Accounting & 37 & $13.2 \%$ \\
\hline Production & 28 & $10.0 \%$ \\
\hline Research and Development & 23 & $8.2 \%$ \\
\hline Procurement & 17 & $6.0 \%$ \\
\hline Personnel \& organization & 7 & $2.5 \%$ \\
\hline Technical services & 4 & $1.4 \%$ \\
\hline Other & 3 & $1.1 \%$ \\
\hline Total & 281 & $100 \%$ \\
\hline
\end{tabular}




\section{ChAPTER 5 DESCRIPTIVE STATISTICS AND ITEM ANALYSES}

\subsection{Analyses of measurement instruments (item analyses)}

\subsubsection{Introduction to the analyses}

Chapter 4 presented the selection of measurement instruments included in the questionnaire. In this section, the discussion and presentation concerns the derivation of scores on variables, for use in the statistical analyses in the next chapters, from the scores obtained with the instruments.

For the greater part of the instruments used in the questionnaire, obtaining variable scores from the instrument scores is a relatively straightforward process, especially where multi-item Likert-type instruments are used. These instruments have been designed, and previously used, to derive variable-scores by calculating the sum or mean of the scores on the items they comprise [cf. Emory and Cooper 1991, p. 219; Pedhazur and Pedhazur 1991, p. 125; Nunnally and Bermstein 1994, p. 294; Oppenheim 1992, pp. 195-200]. However, such derivation is preceded by an assessment of the instrument's reliability, for which the calculation of the instrument"s coefficient- $\alpha$ is advocated [e.g., Carmines and Zeller 1979; Cortina 1993; Nunnally and Bernstein 1994; Brownell 1995]. ${ }^{2}$ Coefficient- $\alpha$ provides an estimate of an instrument's reliability, as it expresses the interrelatedness of items comprising the instrument, and thus reflects the internal consistency of multi-item instruments [e.g., Cortina 1993, pp. 99-100]. ${ }^{3}$ However, as Cortina [1993, pp. 101-103] argues and shows, coefficient- $\alpha$ is not a good measure for an instrument's homogeneity. Homogeneity denotes the extent to which an instrument measures a single attribute, and thus is unidimensional [cf. Pedhazur and Pedhazur 1991, pp. 102-103]. Therefore, Cortina [1993, p. 103] argues that the calculation of an instrument's coefficient- $\alpha$ should be accompanied by a test for the instrument's unidimensionality, and advocates the use of factor-analytic methods for this latter purpose [cf. Carmines and Zeller, 1979, pp. 6370; Oppenheim 1992, pp. 166-167]. ${ }^{4}$

In the next three sections, reliability analyses are performed for each of the multiittem instruments contained in the questionnaire. The analyses are presented in separate sections for the contextual variables, the APM variables and the dependent variables, following the order of presentation of the instruments in Chapter 4. Each of these measurement instruments is tested for internal consistency and homogeneity, by calculating coefficient- $\alpha$ 's and performing factor analyses. The factor analyses use the principle-component method for factor determination, and factors are extracted that have eigenvalues of more than one. ${ }^{5}$ As for the outcomes of these analyses, it should be noted that the use of factor analysis for tests of the homogeneity of multi-item instruments is not without critique. ${ }^{6}$ Apart from some general concern with the subjectivity of ad-hoc factor interpretations, Nunnally and Bernstein [1994, p. 316-317] suggest that the use of factor analysis for tests of homogeneity is likely to overestimate the number of dimensions of the instrument. ${ }^{7}$ More specifically, Carmines and Zeller [1979, pp. 62-70] illustrate that such overestimation is a typical result of non-random measurement error, which, in cases of a multi-item instrument, is caused by the instrument containing reverse items. As this applies for nearly all instruments used in this study, the results from the 
factor analyses done here are interpreted with caution. This implies, first, that the factor analyses were done primarily to explain (potentially) low coefficient- $\alpha$ 's, rather than to define new variables, and second, that more importance is attached to the results from the factor analyses for the instruments designed specifically for this study, than for instruments that have previously have been used successfully [Kim and Mueller 1978, p. 45]. In sum, the factor analyses are used here as positive evidence of unidimensionality only. Given the said overestimation of the number of factors underlying the scale, factor analyses that show unidimensionality of an instrument will be regarded as a, more or less, 'strong' proof for unidimensionality of the instrument.

In the sections below, only a summary is given of the coefficient- $\alpha$ calculations, the factor analyses, and the descriptive statistics of the variable. Appendix F contains additional information on the analyses for each instrument. ${ }^{8}$ Appendix I contains a correlation matrix for all variables in this study.

\subsubsection{Contextual variables}

Environmental Uncertainty (EU)

As the previous chapter presented, the instrument for environmental uncertainty consisted of ten items. For this instrument a coefficient- $\alpha$ of 0.70 was obtained, which is well above the scores obtained with previous uses of the instrument by Govindarajan [1984] and Merchant [1990]. Subsequent factor analysis revealed that the ten items loaded on three factors, which supports the general notion that this variable is multi-dimensional [e.g., Downey et al. 1975; Mintzberg 1979; Buchko 1994]. However, to be consistent with the use of the instrument in previous research no attempt was made to interpret the factor contents, and a variable score for EU was subsequently calculated as the mean of the scores on the ten items. ${ }^{9}$

\section{Task Uncertainty (TU)}

The coefficient- $\alpha$ for the nine-item scale was a satisfactory $0.87 .{ }^{10}$ Subsequent factor analysis revealed an indication of multi-dimensionality of the scale, as the items appeared to load on two factors. After Varimax-rotation [Norušis 1994 c, p. 79 ; Nunnally and Bernstein 1994, p. 506], it appeared that the items loading on the two factors did not correspond to the a-priori dimensions of analyzability and variability that are sometimes, but not always regarded to be theoretically important independent factors in APM studies [e.g., Hirst 1983b, Brownell and Hirst 1986; Imoisili 1989; Brownell and Dunk 1991]. Therefore, and because of the satisfactory coefficient- $\alpha$, no attempt was made to interpret the factors, and an overall score for TU was calculated as the mean of the scores on the nine items.

\section{Tolerance for Ambiguity (TFA)}

For each of the instrument's twenty statements, the 'agree' and 'disagree' scores were recoded into scores of +1 for answers denoting high tolerance for ambiguity, and scores 
of -1 for answers denoting low tolerance for ambiguity [cf. MacDonald 1970; Van de Poel 1986; Vaassen 1994]. An initial analysis of item-total correlations of this recoded scale revealed negative item-total correlations for two of the twenty items. For the remaining 18-items a coefficient- $\alpha$ of 0.61 was obtained. ${ }^{11}$ Although this $\alpha$-score suggests a relatively low level of reliability for this instrument, it is in line with the scores reported with some previous uses of the original, English scale [MacDonald 1970; Kirton 1981], and exceeds the scores obtained with earlier use of the Dutch, translated version of this scale [Van de Poel 1986, Vaassen 1994]. The scores on these 18 items were added to obtain one overall score for TFA. ${ }^{12}$ Because the items in the scale are dichotomous, no further factor analysis to test for multi-dimensionality was performed [Kim and Mueller 1978, p. 74]. Table 5.3 below summarizes the descriptive statistics on the three contextual variables.

Table 5.3 Descriptive statistics on contextuall variables

\begin{tabular}{|l|c|c|c|c|c|c|c|c|c|c|}
\hline Contextual variables & mean & std. & \multicolumn{3}{c|}{ theorefical range } & \multicolumn{2}{c|}{ actual range } & a & n \\
\hline Environmental Uncertainty (EU) & 2.65 & 0.72 & 0.00 & 5.00 & 0.00 & 4.00 & 0.70 & 196 \\
\hline Task Uncertainty (TU) & 3.54 & 0.67 & 1.00 & 5.00 & 1.89 & 4.89 & 0.87 & 196 \\
\hline Tolerance for Ambiguity (TFA) & 3.50 & 5.67 & -18.00 & 18.00 & -10.00 & 18.00 & 0.61 & 196 \\
\hline
\end{tabular}

Table 5.4 below depicts the Pearson correlation coefficients among the three contextual variables. Note that the correlation coefficient for TFA and TU is significant and positive. This suggests that subjects showing higher TFA are those perceiving their tasks as more uncertain. In turn, this suggests that TFA and TU are not themselves correlates of a common underlying variable, which would have been signaled by a negative correlation. Note also the small and negative correlation between $\mathrm{EU}$ and $\mathrm{TU}$, which supports the distinctness of these two sources of uncertainty [see also Chapter 3]. ${ }^{13}$

Table 5.4 Correlation matrix of contextual variables: EU, TU and TFA

\begin{tabular}{|l|r|r|}
\hline Pearson correlation coefficients (p yalues) $n=196$ & $T \mathrm{~T}$ & $\mathrm{TPA}$ \\
\hline$E U$ & $-0.1379 \quad(p=0.054)$ & $-0.1407 \quad(p=0.049)$ \\
\hline$T U$ & & $0.4164 \quad(p=0.000)$ \\
\hline
\end{tabular}

\subsubsection{APM variables}

As was presented in Chapter 3, two measurement instruments for RAPM were included in the questionnaire. The first was the instrument developed by Hopwood [1972]. The 
second instrument was developed for this study. For these two instruments, separate and comparative analyses were performed, which are discussed below.

We discussed in Chapter 3 that APM studies using the Hopwood [1972] instrument show great diversity in the derivation of RAPM variable-scores from the "raw" scores for the instrument. For this study a RAPM score was derived following a procedure similar to that used by Harrison [1992, 1993]. ${ }^{14}$ First, the maximum of the scores on the 'concern with cost' and 'concern with profit' criteria was taken. ${ }^{15}$ Second this score and the score on the 'meeting the budget' criterion were added after it was established that the correlation coefficient between the two scores was 'highly significant' $(\mathrm{r}=0.58, \mathrm{p}=0.000)$ [cf. Brownell 1982b; Lau et al. 1995]. Third, this latter summed score was divided by the summed score on the remaining six non-accounting items [cf. Harrison 1992, 1993]. This procedure was used to obtain a continuous RAPM score, denoting the relative importance attached to APM.

The analysis for the nine-item APM-instrument designed for this study to measure reliance on financial and quantitative information (RFQ) and reliance on targets (RT), consisted of three steps. First, calculations of coefficient- $\alpha$ and factor analyses were performed for each of the three separable sets of items, each belonging to one 'initial' variable. The results, which showed both satisfactory coefficient- $\alpha$ 's and unidimensionality for each of these three variables, are presented in Table 5.5 below.

Table 5.5 Results from initial analysis of RFQ and RT instruments

\begin{tabular}{|c|c|c|c|}
\hline \multirow{2}{*}{ Initial variables for the new $\mathrm{APM}$ scales ( $=196$ ) } & \multirow[t]{2}{*}{ a } & \multicolumn{2}{|c|}{ factor analysis. } \\
\hline & & factors & variance explained \\
\hline Reliance on financial performance information & 0.82 & 1 & $74.0 \%$ \\
\hline Reliance on quantitative performance information & 0.78 & 1 & $69.6 \%$ \\
\hline Reliance on targets & 0.75 & 1 & $68.7 \%$ \\
\hline
\end{tabular}

Second, the subsequent analysis showed that the two variables used to measure reliance on financial and quantitative measures (RFQ), reliance on financial performance information and reliance on quantitative performance information, were as expected highly and significantly correlated $(r=0.86, p=0.000)$. The mean of the scores for these two variables was therefore used to obtain a measure of reliance on financial and quantitative information (RFQ). The correlations between this latter RFQ variable and the variables from which it was derived were $0.96(p=0.000)$ and $0.97(p=0.000)$ for reliance of financial performance measures and reliance on quantitative performance measures, respectively. Additional support for the reliability of the RFQ-measure was found after calculating the coefficient- $\alpha$ of the six-items, which was 0.90 . A subsequent factor analysis furthermore revealed that all six items loaded on a single factor, which explained 66.8 percent of variance. As a result, a total of three APM variables was 
CHAPTER 5 DESCRIPTIVE STATISTICS AND ITEM ANALYSES

derived for the analysis. Descriptive statistics on these variables are presented in Table 5.6 below.

Table 5.6 Descriptive statistics on APM variables

\begin{tabular}{|l|c|c|c|c|c|c|c|c|c|}
\hline APM variables & mean & std & theoretical range & actual range & o & n \\
\hline RAPM & 0.29 & 0.07 & 0.07 & 1.67 & 0.08 & 0.60 & n.a. & 196 \\
\hline Rel. on Fin. \& Quan. info. (RFQ) & 2.81 & 0.91 & 1.00 & 5.00 & 1.00 & 4.93 & 0.90 & 196 \\
\hline Reliance on Targets (RT) & 3.38 & 0.90 & 1.00 & 5.00 & 1.00 & 5.00 & 0.80 & 196 \\
\hline
\end{tabular}

Table 5.7 below reports on the correlation coefficients among the three variables and shows that the three variables are, as expected, positively and significantly correlated.

Table 5.7 Correlation matrix of APM variables

\begin{tabular}{|l|r|r|}
\hline Pearson correlation coefficlents ( $p$ values) $)=196$ & RFQ & RT \\
\hline RAPM & $0.5186 \quad(p=0.000)$ & $0.2397 \quad(p=0.001)$ \\
\hline RFQ & & $0.5239 \quad(p=0.000)$ \\
\hline
\end{tabular}

\subsubsection{Dependent variables}

\subsubsection{Outcome variables: goal clarity and agreement with evaluation criteria}

Goal clarity (GC)

As discussed in the previous chapter, GC was measured with items from the instruments for goal specificity and role ambiguity. An initial analysis for these instruments revealed a coefficient- $\alpha$ of 0.70 for the three-item goal specificity scale. Subsequent factor analysis showed that these three items loaded on a single factor, which explained 63.0 percent of variance. An overall sub-score for goal specificity was therefore calculated as the mean score on the three items. The five-item scale for role ambiguity provided a coefficient $\alpha$ of 0.73 . Also for this scale, factor analysis resulted in a single factor, which explained 50.4 percent of variance. The sub-score for role ambiguity was subsequently calculated as the mean score on the five items. Further analysis showed that the two measures were, as expected, highly and significantly correlated supporting the relatedness of the two constructs $(r=0.74, p=0.000) .{ }^{16}$ Therefore, the overall score for goal clarity was calculated as the mean of the two sub-scores. The correlations between the GC variable and the goal specificity and role ambiguity sub-scores were $0.94(p=0.000)$ and $0.92(p=0.000)$, respectively. 
Agreement with evaluation criteria (AEC)

For the nine-item instrument for AEC developed for this study, a coefficient- $\alpha$ of 0.87 was obtained. In the subsequent factor analysis, two factors were extracted, As it appeared, after rotation, that these two factors corresponded with the six 'normally' coded and the three reverse-coded items, and because of the satisfactory coefficient- $\alpha$, no attempt was made to interpret the factors, and a single overall score for AEC was obtained by calculating the mean of the scores on the nine items [cf. Carmines and Zeller 1979].

Variables included for validation purposes

Coefficient- $\alpha$ for the eight-item job-related tension (JRT) instrument was a satisfactory 0.81 . Subsequent factor analysis revealed no sign of multidimensionality, as only one factor was extracted, that explained 43.0 percent of variance. An overall score for JRT was therefore calculated as the mean of the scores on the eight items. For the seven-item job satisfaction (JSA) instrument, a coefficient- $\alpha$ of 0.71 was calculated. Subsequent factor analysis revealed two factors, which seemed to differentiate between satisfaction with the job and satisfaction with the organization. However, since this difference was of no interest for the validation purpose of measuring JSA in our study, and since the coefficient- $\alpha$ was acceptable, one overall score for JSA was calculated as the mean of the scores on the seven scale items. The two iterns used to measure performance were highly and significantly correlated $(r=0.50 ; p=0.000)$. The mean of the scores on the two items was taken to obtain an overall Performance score.

Table 5.8 Descriptive statistics on outcome variables

\begin{tabular}{|c|c|c|c|c|c|c|c|c|}
\hline \multirow[t]{2}{*}{ Outcome variables } & \multirow{2}{*}{ mean } & \multirow{2}{*}{ std. } & \multicolumn{2}{|c|}{ theorefical range } & \multicolumn{2}{|c|}{ actual range } & \multirow[t]{2}{*}{ a } & \multirow[t]{2}{*}{ n } \\
\hline & & & min & $\max$ & $\min$ & $\max$ & & \\
\hline Goal clarity (GC) & 3.83 & 0.56 & 1.00 & 5.00 & 1.90 & 5.00 & n.a. & 196 \\
\hline Agreement with Eval. Crit. (AEC) & 3.74 & 0.58 & 1.00 & 5.00 & 2.11 & 5.00 & 0.87 & 196 \\
\hline Job-related Tension (JRT) & 2.84 & 0.66 & 1.00 & 5.00 & 1.00 & 4.63 & 0.87 & 196 \\
\hline Job satisfaction (JSA) & 3.99 & 0.51 & 1.00 & 5.00 & 2.71 & 5.00 & 0.71 & 196 \\
\hline Performance & 7.53 & 0.67 & 1.00 & 10.00 & 5.00 & 9.00 & n.a. & 196 \\
\hline
\end{tabular}

Table 5.8 above summarizes the descriptive statistics on the two focall outcome variables ( $G C$ and $A E C$ ), and the three additional variables that we included in the questionnaire for validation of the two focal variables (JRT, ISA and Performance).

To test the validity of our two focal outcome variables, GC and $\mathrm{AEC}$, we did two additional analyses. First, as presented in Table 5.9, we calculated the correlation coefficients for the relation between the focal outcome variables, $\mathrm{GC}$ and $\mathrm{AEC}$, and the 


\section{CHAPTER 5 DESCRIPTIVE STATISTICS AND ITEM ANALYSES}

three additionally included JRT, JSA and Performance variables. Note that these figures indicate that GC and $\mathrm{AEC}$ are negatively related to JRT, and positively related to JSA and Performance. The direction of these relationships, and their statistical significance provide support for the validity of our two focal outcome variables, since they support the arguments, and the underlying results from previous studies, presented in Chapter 3.

Table 5.9 Correlation matrix of the outcome variables (partial)

\begin{tabular}{|c|c|c|}
\hline Pearson correlation coefficients (p valiues) $1=196$ & $G \mathrm{GC}$ & AEC \\
\hline JRT & $-0.2116 \quad(p=0.003)$ & $-0.2170 \quad(p=0.002)$ \\
\hline JSA & $0.4489 \quad(p=0.000)$ & $0.3827 \quad(p=0.000)$ \\
\hline Performance & $0.1675 \quad(p=0.019)$ & $0.1403 \quad(p=0.050)$ \\
\hline
\end{tabular}

Second, we analyzed the bivariate relationships between RAPM and the five focal and additional outcome variables; goal clarity (GC), agreement with valuation criteria (AEC), job-related tension (JRT), job-satisfaction (JSA) and Performance. The results are presented in Table 5.10 below. These results suggest support for the arguments we put forward in Chapter 3 to select GC and AEC as our focal independent outcome variables. First, Table 5.10 evidences that significant relationships exist between RAPM and both $\mathrm{GC}$ and $\mathrm{AEC}$, whereas no significant relationships exist between RAPM and the three additionally included variables. This supports our contention that GC and AEC may indeed be more immediate consequences of RAPM, than JRT, JSA and Performance. Second, these results show that the bivariate relationships between RAPM and GC, and RAPM and AEC have an opposite sign. RAPM is positively related to GC and negatively related to $\mathrm{AEC}$. In combination, these data therefore suggest also support for our contention that the appropriateness of RAPM, in terms of the previously used outcome variables (JRT, JSA and Performance), may be a combination of positive and negative effects on $\mathrm{GC}$ and $\mathrm{AEC}$. ${ }^{17}$

Table 5.10 Correlation mattrix of RAPM and the outcome variables (partial)

\begin{tabular}{|l|l|r|}
\hline Pearson correlations coefficients (p values), $n=196$ & Variables & RAPM \\
\hline Focal outcome variables in this study & GC & $0.2329 \quad(p=0.0010)$ \\
\hline & AEC & $-0.1251 \quad(p=0.0806)$ \\
\hline $\begin{array}{l}\text { Variables included to test the validity of the outcome } \\
\text { variables in this study }\end{array}$ & JRT & $0.0519 \quad(p=0.4703)$ \\
\cline { 2 - 3 } & JSA & $0.1062 \quad(p=0.1383)$ \\
\hline & Performance & $-0.0152 \quad(p=0.8326)$ \\
\hline
\end{tabular}




\subsubsection{Opinion variable: felt appropriateness of APM}

For the twelve-item scale felt appropriateness of accounting performance measures (FAAPM) a coefficient- $\alpha$ of 0.88 was obtained. In the subsequent factor analysis, three factors were extracted. The results of the factor analysis are presented in Appendix G. As this instrument had been designed specifically for this study, it was decided to base the variable score of FAAPM on the scores on the six items that loaded on the first factor, to increase its precision [cf. Dunk 1993]. ${ }^{18}$ Additional analyses for these six items showed only a limited 'loss" for the coefficient- $\alpha$ score (0.84), and in the subsequent factor analysis of this six-item subscale, a single factor was extracted that explained 57.2 of variance. A further analysis showed a highly significant correlation $(\mathrm{r}=0.91, \mathrm{p}=$ 0.000 ) between the FAAPM score based on the six-items and based on the original twelve-item scale. The variable-score for FAAPM was subsequently obtained by calculating the mean of the scores on the six items. For the five-item instrument for felt usefulness of budgeting (FUOB), that was included for validation of the new FAAPM instrument, a coefficient $\alpha$ of 0.83 was obtained. In the subsequent factor analysis a single factor was extracted, that explained 59.1 percent of variance. A total score for FUOB was therefore calculated as the mean of the scores on the five items. Descriptive statistics on these variables are presented in Table 5.11 below.

Table 6.11 Descriptive statistics on opinion variables

\begin{tabular}{|c|c|c|c|c|c|c|c|c|}
\hline \multirow{2}{*}{ Opinion variables } & \multirow[t]{2}{*}{ mean } & \multirow{2}{*}{$\begin{array}{l}\text { std } \\
\text { dev }\end{array}$} & \multicolumn{2}{|c|}{ theoretical range } & \multicolumn{2}{|c|}{ actual range. } & \multirow[t]{2}{*}{ o } & \multirow[t]{2}{*}{ i. } \\
\hline & & & min & $\max$ & min & $\max$ & & \\
\hline Felt Appropr. of APM (FAAPM) & 2.60 & 0.92 & 1.00 & 5.00 & 1.00 & 5.00 & 0.84 & 196 \\
\hline Felt Usefuln. of Budgets (FUOB) & 3.34 & 0.87 & 1.00 & 5.00 & 1.00 & 5.00 & 0.83 & 195 \\
\hline
\end{tabular}

The two opinion variables FAAPM and FUOB were, as expected, positively and significantly correlated $(\mathrm{r}=0.4413, \mathrm{p}=0.000, \mathrm{n}=195)$ which supports the validity of the new focal opinion variable (FAAPM).

\subsection{Test for bias from nonresponse}

Although both the overall response rate and the response rates for each participating organization were satisfactory, a test for bias caused by nonresponse was conducted. This test was performed by comparing mean scores on the key research variables for early anc late responders in the sample of the questionnaires returned [Oppenheim 1966, p. 34]. The logic of this type of test for response bias lies in the assumption that nonrespondents show a greater similarity to late respondents than to early respondents [Brownell 1995 p. 34]. If, therefore, no significant differences exist between the two groups for the scores 


\section{CHAPTER 5 DESCRIPTIVE STATISTICS AND ITEM ANALYSES}

on these statistics, this would support the contention that no bias from nonresponse is present in the sample. A consideration in choosing this comparison-type test, instead of trying to obtain additional information about nonrespondents from the organizations and compare it with information on respondents, was that this latter type of test would break the promise of anonymity [Oppenheim 1966, p. 34; Brownell 1995, p. 34]. The results of this analysis are reported in Appendix J, and, overall, show little evidence of systematic bias from nonresponse.

\subsection{Summary}

In this chapter, we presented a preliminary analysis of the data obtained with the questionnaire survey, before performing the statistical analyses of the hypotheses in the next chapters. Section 5.2 described the main characteristics of the sample. Here we concluded that our sampling method resulted in an apparent wide spread of respondents over different functional areas. Section 5.3 contained the item-analyses for each of the measurement instruments contained in the questionnaire. This section also described the derivation of variables scores from the raw scores obtained with the measurement instruments. In general, the data obtained appeared to have lead to a relatively high level of reliability in the measurement of the individual variable scores, with the reliability for the TFA instrument somewhat as an exception. In this section we also tested the validity of the focal variables of this study, by exploring the relationships between these variables and the variables included in the questionnaire for validation purposes only. These analyses generally provide support for the validity of our focal dependent variables. Finally, Section 5.4 presented the results of the test for potential bias from non-response. 


\section{Notes to Chapter 5 :}

1. For these descriptive variables there was some nonresponse. This however was no reason to drop the specific questionnaire entirely as the main criterion was that the measurement instruments for the key research variables should have been filled out [see Chapter 4].

2. Reliability tests essentially establish whether an instrument provides an accurate or precise score for the attribute it attempts to measures [e.g., Kerlinger 1986, p. 405].

3. The step from the definition of reliability, as the accuracy or precision of an instrument, to the operationalization of reliability as the internal consistency of multi-item instruments is based on 'measurement theory' and 'reliability theory" [see, e.g., Kerlinger 1986, pp. 407412; Oppenheim 1992, p. 160; Nunnally and Bernstein 1994, pp. 215-220].

4. The disaggregation of reliability into internal consistency of an instrument, and its homogeneity is often not made [see, e.g., Kerlinger 1986, p. 413]. A possible reason for this is that homogeneity is also a matter of validity, i.e., does the instrument "really" measure the single concept it intends to measure, given the intended unidimensionality of theoretical constructs and variables. Therefore, the investigation of dimensionality made bere is important for the assessment of an instrument's validity [cf. Carmines and Zeller 1979, pp. 63-64].

5. Several methods exist for factor analysis, regarding factor-calculation, factor-extraction and factor-rotation [see, e.g., Numally and Bernstein 1994, pp. 447-594]. A relatively "straightforward' method for factor analysis is followed here, because of the limited purposes of factor analysis in this study [e.g., Dunk 1993]. For the interpretation of factors, the initial factor-solutions are rotated using the Varimax rotation method. The use of Varimax-rotation is based on the explicit preference for Varimax rotation for detecting separate factors instead of emphasizing a single overall factor, for which the Quartimax-rotation is advocated [Nunnally and Bernstein 1994, pp. 506-507].

6. Besides, the use of factor anallysis for testing for unidimensionality is not very common in APM and budgetary research. The reasons could be the, faulty, equation of high coefficient- $\alpha$ with unidimensionality (see also note 4 above) and the typically small sample sizes. Kerlinger [1986, pp. 593] uses a lower limit of ten subjects for each item as a rule-of-thumb for doing factor analyses.

7. This point of critique adds to the general critique of the careless use of factor-analytic methods and opportunistic interpretation of its outcomes [Nunnally and Bernstein 1994, p. $317]$.

8. For all statistical analyses presented in this chapter as well as in the remainder of this dissertation, we use the statistical software package 'SPSS for Windows, version 6.1' as described in Norusis $[1993,1994 \mathrm{a}, 1994 \mathrm{~b}, 1994 \mathrm{c}]$.

9. This also implies that in our analyses we focus on the overall effect size of environmental uncertainty ${ }_{3}$ rather than on its potentially different sources.

10. There is no absolute 'standard' or minimum level for coefficient- $\alpha$ scores [Pedhazur and Pedhazur 1991, pp. 109-110]. Notably, the literature shows many examples of applying ad. hoc lower limits to coefficient- $\alpha$ scores. 


\section{CHAPTER 5 DESCRIPTIVE STATISTICS AND ITEM ANALYSES}

11. For scales composed of dichotomous items, the coefficient- $\alpha$ equals the Kuder-Richardson 20 (KR-20) coefficient [Cortina 1993, p. 99; Nonušis 1994c, p. 152; Nunnally and Bernstein 1994, p. 235].

12. The exclusion of the two items in the calculation of the TFA-score, as based on negative item-total correlations, follows the procedures outlined by Emory and Cooper [1991, pp. 187 188] and Pedhazur and Pedhazur [1991, p. 124]. Although this procedure usually applies in the testing phase of an instrument, Kirton's [1981] analysis suggests that the MacDonald instrument is still capable of further refinement. Coefficient- $\alpha$ for the twenty-item scale was 0.57. The correlation coefficient for the scores of the two scales (with 20 and 18 items respectively) was $0.98(p=0.000)$. Notably, in the two previous uses of the Dutch TFA scale, the ultimate TFA scores were based on 16 items.

13. The correlation coefficients presented in this chapter and the next are Pearson correlation coefficients. All p-values reported in this dissertation relate to two-tailed tests. See Appendix I for the correlation matrix containing all variables, and a remark about the robustness of using parametric correlation coefficients for our data.

14. As was discussed in Chapter 3, a third source of variance in RAPM-measurements stems from differences in the number of performance criteria used in the instruments. Here, the discussion is limited to the derivation of RAPM scores from the instrument chosen.

15. Recall that these two items are regarded equivalent for cost-center and profit-center managers [cf. Otley 1978].

16. To be precise, the two sub-scores were negatively correlated. The scores for role ambiguity were first reversed.

17. Note that these analyses are only done to validate our selection of $\mathrm{AEC}$ and $\mathrm{GC}$ as focial outcome variables, and not to anticipate on the results of testing the hypotheses.

18. For the 12-item instrument, the Kaiser-Meyer-Olkin (KMO) measure of sampling adequacy was high (0.89) supporting the use of factor analysis [Norušis, 1994c, p. 52]. The KMOmeasure is an index for the ratio of correlation coefficients to partial correlation coefficients. 
ACCOUNTING FOR PERFORMANCE EVALUATION 


\section{Chapter 6 \\ Results: tests of hypotheses}

\subsection{Introduction}

In this chapter we present the tests of the hypotheses developed in Chapter 3 of this dissertation. For most of these tests, we will use a statistical technique called Moderated Regression Analysis (MRA). This technique is used here for testing the hypotheses in which we predicted that a contextual variable 'moderates' the relationship between an independent variable and a dependent variable. The MRA technique has become the dominant technique in contextual APM research for testing hypotheses with this theoretical format. Therefore, the use of MRA here aims at enhancing the comparability of findings, controlling for the risk that conclusions are based on differences in testing method alone. 'The MRA technique, and the interpretation of its outcomes are discussed in Appendix K. The structure of this chapter is as follows.

Sections 6.2 through 6.4 present the tests of the hypotheses. In Section 6.2 we test the hypotheses concerning the effect of environmental uncertainty and task uncertainty on the appropriateness of APM. Section 6.3 contains the tests of the hypotheses concerning the personality variable tolerance for ambiguity. Section 6.4 presents the tests for the hypotheses predicting an interaction effect of uncertainty and the APM variables reliance on financial and quantitative information and reliance on targets that we distinguished in Chapter 3. Finally, Section 6.5 summarizes the chapter, and provides an overview of the results of the tests of the hypotheses. The focus in this chapter is on the tests of the hypotheses; the interpretation of the findings and their implications are the subject of Chapter 7 .

\subsection{The impact of task and environmental uncertainty on the appropriateness of APM}

\subsubsection{Environmental uncertainty and the appropriateness of APM $(\mathrm{H} 1 \mathrm{a}, \mathrm{H} 1 \mathrm{~b}$ and H1c)}

In this section we test the three hypotheses in which we predicted the effect of environmental uncertainty (EU) on the appropriateness of APM. 
Hypothesis la stated that:

HIa: The effect of RAPM on $G C$ is more positive for higher levels of $E U$.

This hypothesis was tested using the following model:

$$
\mathrm{Y}=\beta_{0}+\beta_{1} \mathrm{X}_{1}+\beta_{2} \mathrm{X}_{2}+\beta_{3} \mathrm{X}_{1} \times \mathrm{X}_{2}+\epsilon
$$

where: $Y$ is goal clarity (GC)

$X_{1}$ is RAPM

$\mathrm{X}_{2}$ is environmental uncertainty (EU).

Since Hypothesis 1a indicates that we expect that the relationship between RAPM and $\mathrm{GC}$ is more positive for higher values of EU, we expect a positive interaction $\mathrm{X}_{1} \times \mathrm{X}_{2}$. This means that we expect a positive coefficient of the interaction term $\left(\beta_{3}\right)$. The results of the test are presented in Table 6.1a below. ${ }^{2}$

Table 6.1a Results of regressing GC on RAPM and EU

\begin{tabular}{|l|c|r|r|r|r|}
\hline Variable & Coefficient & Value & Std Error & $\mathrm{t}$ & $\mathrm{P}$ \\
\hline Constant & $\beta_{\mathrm{o}}$ & 4.1510 & 0.5828 & 7.122 & 0.0000 \\
RAPM & $\beta_{1}$ & -1.7305 & 2.0702 & -0.836 & 0.4043 \\
Environmental uncertainty (EU) & $\beta_{2}$ & -0.3163 & 0.2203 & -1.436 & 0.1527 \\
RAPM $\times$ EU & $\beta_{3}$ & 1.2982 & 0.7578 & 1.713 & 0.0883 \\
\hline Adjusted $\mathrm{R}^{2}=5.755 \% ; \mathrm{F}_{3,192}=4.9695 ; \mathrm{p}=0.0024 ; \mathrm{n}=196$ \\
\hline
\end{tabular}

These results provide support for Hypothesis 1a, since the coefficient $\left(\beta_{3}\right)$ of the interaction term is positive and significant. This means that the data support our expectation that the effect of RAPM on goal clarity is more positive for higher levels of environmental uncertainty. This indicates that the use of APM is more appropriate in terms of providing managerial goal clarity for higher levels of environmental uncertainty.

For the effect of environmental uncertainty on the relationship between the use of APM and agreement with evaluation criteria (AEC) we did not formulate a directional hypothesis. Therefore, Hypothesis $1 \mathrm{~b}$ was formulated in the null-form and stated that:

$H 1 b$ : The effect of RAPM on AEC is not affected by the level of $E U$.

This hypothesis was tested using the following regression model:

$$
Y=\beta_{0}+\beta_{1} X_{1}+\beta_{2} X_{2}+\beta_{3} X_{1} \times X_{2}+\epsilon
$$

where: $\mathrm{Y}$ is agreement with evaluation criteria (AEC)

$X_{1}$ is RAPM

$\mathrm{X}_{2}$ is environmental uncertainty (EU). 
The results are presented in Table $6.1 \mathrm{~b}$ below.

Table 6.1 b Results of regressing AEC on RAPM and EU

\begin{tabular}{|l|c|r|r|r|r|}
\hline Variable & Coefficient & Value & Std Error & t & P \\
\hline Constant & $\beta_{0}$ & -3.7630 & 0.6161 & -6.108 & 0.0000 \\
RAPM & $\beta_{1}$ & -0.1134 & 2.1885 & 0.052 & 0.9587 \\
Environmental uncertainty $(E U)$ & $\beta_{2}$ & 0.1075 & 0.2329 & 0.462 & 0.6448 \\
RAPM $\times$ EU & $\beta_{3}$ & -0.3465 & 0.8011 & -0.433 & 0.6658 \\
\hline Adjusted $R^{2}=0.140 \% ; F_{3,992}=1.0909 ; p=0.3542 ; n=196$ & & & \\
\hline
\end{tabular}

Based on these results, the null-hypothesis cannot be rejected, since the coefficient of the interaction term $\left(\beta_{3}\right)$ is not significant. Therefore, and because the explanatory power of the relationship overall is very low, the data suggest that the relationship between RAPM and agreement with evaluation criteria is not affected by the level of environmental uncertainty. This supports our contention from Chapter 3 , where we argued that the effects of environmental uncertainty on the relationship between RAPM and agreement with evaluation criteria are a combination of positive and negative effects.

The third hypothesis concerning the effect of environmental uncertainty on the appropriateness of APM predicted a positive relation between environmental uncertainty and managers' felt appropriateness of APM (FAAPM). Hypothesis $1 \mathrm{c}$ thus stated that:

HIc: FAAPM is higher for higher levels of EU.

To test this hypothesis the Pearson correlation coefficient was calculated. The result is presented in Table $6.1 \mathrm{c}$ below, and shows a significant and positive correlation between environmental uncertainty and felt appropriateness of APM. This result supports our expectation, since it suggests that managers have more favorable opinions about the appropriateness of APM, when they are confronted with higher levels of environmental uncertainty.

Table 6.1c Correlation of FAAPM and EU

\begin{tabular}{|l|c|}
\hline Pearson correl ation coefficient (p value) $\mathrm{n}=196$ & Felt appropriateness of APM (FAAPM) \\
\hline Environmental uncertainty (EU) & $0.3595(\mathrm{p}=0.0000)$ \\
\hline
\end{tabular}

In combination with the results of Hypotheses $1 \mathrm{a}$ and $\mathrm{lb}$, this finding suggests that environmental uncertainty has a positive effect on the effectivity of RAPM, as a means to enhance managerial goal clarity. 


\subsubsection{Task uncertainty and the appropriateness of APM (H2a, $\mathrm{H} 2 \mathrm{~b}$ and $\mathrm{H} 2 \mathrm{c}$ )}

In this section we test the three hypotheses in which we predicted the effect of task uncertainty (TU) on the appropriateness of APM.

Since we were unable to formulate a directional hypothesis for the effect of task uncertainty on the relationship between the use of APM and managerial goal clarity (GC), Hypothesis $2 a$ was formulated in the null-form. It stated that:

H2a: The effect of RAPM on GC is not affected by the level of TU.

This hypothesis was tested using the following model:

$$
Y=\beta_{0}+\beta_{1} X_{1}+\beta_{2} X_{2}+\beta_{3} X_{1} \times X_{2}+\epsilon
$$

where: $\mathrm{Y}$ is goal clarity (GC)

$\mathrm{X}_{1}$ is RAPM

$\mathrm{X}_{2}$ is task uncertainty (TU).

The results are depicted in Table $6.2 \mathrm{a}$ below.

Table 6.2a Results of regressing GC on RAPM and TU

\begin{tabular}{|l|l|r|r|r|r|}
\hline Variable & Coefficient & Value & Std. Error & \multicolumn{1}{c|}{1} & $\mathrm{P}$ \\
\hline Constant & $\beta_{0}$ & 3.6519 & 0.8317 & 4.391 & 0.0000 \\
RAPM & $\beta_{1}$ & 3.0718 & 2.7422 & 1.120 & 0.2640 \\
Task uncertainty (TU) & $\beta_{2}$ & -0.0683 & 0.2318 & -0.081 & 0.7687 \\
RAPM $\times$ TU & $\beta_{3}$ & -0.4665 & 0.7784 & -0.599 & 0.5497 \\
\hline Adjusted $R^{2}=9.831 \% ; F_{3,192}=8.0865 ; p=0.0000 ; n=196$ & & & \\
\hline
\end{tabular}

Based on the results the null-hypothesis cannot be rejected, since the coefficient of the interaction term $\left(\beta_{3}\right)$ is not significant. Therefore, the data suggest that the relationshir between RAPM and goal clarity is not affected by the level of task uncertainty. Thi: finding provides support for the arguments we proposed in Chapter 3 , in which we argued that task uncertainty may have two opposite effects on the relationship betweer RAPM and goal clarity. On the one hand, high RAPM provides managers with clear anc specific targets, which are particularly useful under conditions of high uncertainty. Or the other hand, the attainment of such clear and specific targets may be especiall. difficult under conditions of high uncertainty.

Hypotheses $2 b$ stated that:

$H 2 b$ : The effect of RAPM on AEC is more negative for higher levels of TU. 
This hypothesis was tested using the following model:

$$
Y=\beta_{0}+\beta_{1} X_{1}+\beta_{2} X_{2}+\beta_{3} X_{1} \times X_{2}+\epsilon
$$

where: $Y$ is agreement with evaluation criteria (AEC)

$\mathrm{X}_{\mathrm{I}}$ is RAPM

$\mathrm{X}_{2}$ is task uncertainty (TU).

Since hypotheses $2 \mathrm{~b}$ indicates that we expect that the relationship between RAPM and $A E C$ is more negative for higher values of $T U$, we expect a negative interaction $X_{1} \times X_{2}$. This means that we expect a negative coefficient of the interaction term $\left(\beta_{3}\right)$. The results are presented in Table $6.2 \mathrm{~b}$ below.

Table 6.2b Results of regressing AEC on RAPM and TU

\begin{tabular}{|l|c|r|r|r|r|}
\hline Variable & Coefficlent & Value & Std Error & t & P \\
\hline Constant & $\beta_{0}$ & 4.7465 & 0.8879 & 5.346 & 0.0000 \\
RAPM & $\beta_{1}$ & -4.7783 & 2.9274 & -1.632 & 0.1043 \\
Task uncertainty (TU) & $\beta_{2}$ & -0.2220 & 0.2475 & -0.897 & 0.3709 \\
RAPM $\times$ TU & $\beta_{3}$ & 1.1488 & 0.8310 & 1.382 & 0.1685 \\
\hline Adjusted $\mathbb{R}^{2}=2.568 \% ; F_{3,192}=2.7135 ; p=0.0461 ; n=196$ \\
\hline
\end{tabular}

As these results show, our data do not provide support for Hypothesis $2 b$. The coefficient of the interaction term $\left(\beta_{3}\right)$ is not significant, and furthermore the coefficient tends toward being positive rather than the hypothesized negative. Since the results do not provide evidence of a significant positive effect, the data suggest that task uncertainty does not have an effect on the relationship between RAPM and agreement with evaluation criteria. This implies that, in terms of agreement with evaluation criteria, there is no evidence that task uncertainty negatively affects the appropriateness of APM.

Concerning the effect of task uncertainty on managers' opinions about the appropriateness of APM, Hypotheses $2 \mathrm{c}$ stated that:

H2c: FAAPM is lower for higher levels of TU.

To test this hypothesis the Pearson correlation coefficient was calculated. The result, which is presented in Table $6.2 \mathrm{c}$ below, shows a significant and negative correlation between TU and FAAPM. This result supports our hypothesis, since it suggests that managers have more favorable opinions about the appropriateness of APM, when they are confronted with lower levels of task uncertainty. 
Table 6.2c Correlation of FAAPM and TU

Pearson conelation coefficient $(p$ value) $n=196$

Task uncertainty (TU)

Felt appropriateness of APM (FAAP)

$-0.3260(p=0.0000)$

Note that this finding appears not to be in conformity with our finding regarding Hypothesis $2 b$. There we did not find a negative interaction between RAPM and TU to affect AEC. This means that we cannot explain in terms of AEC why managers have more unfavorable attitudes towards the use of APM for higher levels of uncertainty. We will further discuss this issue in Chapter 7.

\subsection{The impact of TFA and uncertainty on the appropriateness of APM}

\subsubsection{Tests of hypotheses concerning TFA}

The hypotheses concerning the direct and moderating effects of TFA on the appropriateness of APM were tested by using two subgroups of subjects. For this purpose, the sample was split at the mean score for TFA into a group of subjects with a TFA score below the mean, and a second group of subjects with a TFA score above the mean. Subjects with high TFA were coded 1 , and subjects with low TFA were coded 0 . These scores were subsequently used in hypothesis testing. The reasons for the use of a dichotomous score for the TFA variable were threefold. First, the item-analyses in Chapter 5 revealed a relatively low reliability of the TFA instrument, indicating a relatively large amount of measurement error. Dichotomization is advised to reduce the threat this poses to the power of the analytic technique used [Arnold 1982, p. 221]. ${ }^{3}$ Second, in our hypotheses we developed arguments that differentiate between subjects with high TFA and subjects with low TFA, which is another reason mentioned by Arnold [1982, p. 221] in support of using a dichotomized moderating variable. ${ }^{4}$ Third, and what is more important, since a large number of the hypotheses about TFA require the use of three-way interaction regression models, we believed that a dichotomous TFA variable would substantially reduce the complexity of the interpretation of results. For the same reason, previous APM research frequently shows the use of subgroup analysis, using dichotomized independent (moderator) variables for hypothesis testing [e.g., Merchant 1981; Merchant 1984; Brownell 1982; Hirst 1983b; Dunk 1993]. In addition, we avoided the loss of observations that is often associated with the use of dichotomized variables, since we use a mean split rather than a median split to divide the sample in subjects with low and with high TFA. This ensured that the analysis was based on all 196 observations. 


\subsubsection{TFA and the appropriateness of APM $(\mathrm{H} 3 \mathrm{a}, \mathrm{H} 3 \mathrm{~b}$ and $\mathrm{H} 3 \mathrm{c})$}

In this section we test the three hypotheses in which we predicted the effect of tolerance for ambiguity (TFA) on the appropriateness of APM.

Hypothesis 3a stated that:

H3a: The effect of RAPM on GC is more positive for individuals with low TFA than for individuals with high TFA.

To test this hypothesis, a regression was run using the following model:

$$
Y=\beta_{0}+\beta_{1} X_{1}+\beta_{2} X_{2}+\beta_{3} X_{1} \times X_{2}+\epsilon
$$

where: $\mathrm{Y}$ is goal clarity $(\mathrm{GC})$

$\mathrm{X}_{1}$ is RAPM

$\mathrm{X}_{2}$ is tolerance for ambiguity (TFA, with $\mathrm{X}_{2}=0$ for low TFA and $\mathrm{X}_{2}=1$ for high TFA).

Since Hypotheses 3a indicates that we expect that the relationship between RAPM and $\mathrm{GC}$ is more positive for lower values of TFA, we expect a negative interaction $\mathrm{X}_{1} \times \mathrm{X}_{2}$. This means that we expect that the coefficient of the interaction term $\left(\beta_{3}\right)$ is negative. The results are presented in Table 6.3a below.

Table 6.3a Results of regressing GC on RAPM and TFA

\begin{tabular}{|l|c|r|r|r|r|}
\hline Variable & Coefficient & Value & std Error & $\mathbf{t}$ & $\mathbf{p}$ \\
\hline Constant & $\beta_{0}$ & 3.1359 & 0.2283 & 13.738 & 0.0000 \\
RAPM & $\beta_{1}$ & 2.6488 & 0.7464 & 3.549 & 0.0000 \\
Tolerance for ambiguity (TFA) & $\beta_{2}$ & 0.4020 & 0.3216 & 1.250 & 0.2128 \\
RAPM $\times$ TFA & $\beta_{3}$ & -1.9129 & 1.0756 & -1.778 & 0.0769 \\
\hline Adjusted $R^{2}=7.321 \% ; F_{3,152}=6.1345 ; p=0.0005 ; n=196$ & & & & \\
\hline
\end{tabular}

The results show a significant and negative coefficient of the interaction term $\left(\beta_{3}\right)$. This supports our hypothesis, since it suggests that the effect of RAPM on goal clarity is more positive for subjects with low TFA than for subjects with high TFA. Thus, the results suggest, in conformity with our expectation, that the use of APM is more appropriate in terms of goal clarity for managers with low TFA than for managers with high TFA.

Hypothesis $3 \mathrm{~b}$ stated:

H3b: The effect of RAPM on AEC is more positive for individuals with low TFA than for individuals with high TFA. 
To test this hypothesis, a regression was run using the following model:

$$
Y=\beta_{0}+\beta_{1} X_{1}+\beta_{2} X_{2}+\beta_{3} X_{1} \times X_{2}+\epsilon
$$

where: $Y$ is agreement with evaluation criteria (AEC)

$\mathrm{X}_{1}$ is RAPM

$\mathrm{X}_{2}$ is tolerance for ambiguity (TFA, with $\mathrm{X}_{2}=0$ for low TFA and $\mathrm{X}_{2}=1$ for high TFA).

Since Hypotheses $3 \mathrm{~b}$ indicates that we expect that the relationship between RAPM and $A E C$ is more negative for higher values of TFA, we expect a negative interaction $X_{1} \times X_{2}$. This means that we expect a negative coefficient of the interaction term $\left(\beta_{3}\right)$. The results of the test are presented in Table $6.3 \mathrm{~b}$ below.

Table 6.3b Results of regressing AEC on RAPM and TFA

\begin{tabular}{|l|c|r|r|r|r|}
\hline Variable & Coefficient & Value & Std Error & $\mathrm{l}$ & $\mathrm{p}$ \\
\hline Constant & $\beta_{0}$ & 4.0282 & 0.2423 & 16.623 & 0.0000 \\
RAPM & $\beta_{1}$ & -1.1751 & 0.7924 & -1.483 & 0.1397 \\
Tolerance for ambiguity (TFA) & $\beta_{2}$ & -0.0346 & 0.3414 & -0.101 & 0.9193 \\
RAPM $\times$ TFA & $\beta_{3}$ & 0.4861 & 1.1419 & 0.426 & 0.6708 \\
\hline Adjusted $R^{2}=0.907 \% ; F_{3,992}=1.6361 ; \mathrm{p}=0.1824 ; \mathrm{n}=196$ \\
\hline
\end{tabular}

The results do not provide support for the hypothesis. The coefficient of the interaction term $\left(\beta_{3}\right)$ has a positive sign, which is opposite to our expectation, and does not reach a sufficient level of significance. Furthermore, the reliability for the whole model is low. Therefore, we do not accept Hypothesis $3 \mathrm{~b}$, and conclude that TFA does not affect the relationship between the use of APM and managers' agreement with evaluation criteria.

For the relationship between tolerance for ambiguity and managers' opinions about the appropriateness of APM, we formulated Hypothesis 3c. It stated:

H3c: FAAPM is higher for individuals with low TFA than for individuals with high TFA.

To test the hypothesis the mean scores for FAAPM for the high and low TFA subsamples were calculated and compared using a t-test for differences of means. As Table $6.3 \mathrm{c}$ shows, the data support the hypothesis, since the mean appropriateness of APM is significantly higher for subjects with low TFA than for subjects with high TFA. 
CHAPTER 6 RESULTS: TESTS OF HYPOTHESES

Table 6.3c Difference of means test for FAAPM based on low and high TFA

\begin{tabular}{|l|c|c|c|c|c|c|}
\hline$n=196$ & low TFA $(n=89)$ & high TFA $(\mathrm{n}=107)$ & \multicolumn{3}{c|}{ Difference of mean } \\
\hline FAAPM & mean $($ std dev) & mean (std dev) & difference (std. dev) & $t$ & $p$ \\
\hline
\end{tabular}

In combination with the results for Hypotheses $3 \mathrm{a}$ and $3 \mathrm{~b}$ this latter result suggests that the use of APM is more appropriate for individuals with low than with high TFA. In particular, our data suggest that this effect is mainly due to the effect the use of APM has on managerial goal clarity. ${ }^{5}$

\subsubsection{TFA, environmental uncertainty and the appropriateness of APM ( $\mathrm{H} 4 \mathrm{a}, \mathrm{H} 4 \mathrm{~b}$ and $\mathrm{H} 4 \mathrm{c}$ )}

In this section, we test hypotheses concerning the joint and interaction effects of environmental uncertainty and tolerance for ambiguity. First, with Hypothesis 4 a we formulated the expectation that the positive effect of environmental uncertainty on the relationship between the use of APM and managerial goal clarity, is more positive for subjects with low TFA. Hypothesis 4a thus stated that:

H4a: The effect of EU on the relationship between RAPM and GC is more positive for individuals with low TFA than for individuals with high TFA

To test this hypothesis, the following three-way interaction model was fitted to the data:

(2) $Y=\beta_{0}+\beta_{1} X_{1}+\beta_{2} X_{2}+\beta_{3} X_{3}+\beta_{4} X_{1} \times X_{2}+\beta_{5} X_{1} \times X_{3}+\beta_{6} X_{2} \times X_{3}+\beta_{7} X_{1} \times X_{2} \times X_{3}+\epsilon$

where: $\mathrm{Y}$ is goal clarity (GC)

$X_{1}$ is RAPM

$\mathrm{X}_{2}$ is environmental uncertainty (EU)

$\mathrm{X}_{3}$ is tolerance for ambiguity (TFA, with $\mathrm{X}_{3}=0$ for low TFA and $\mathrm{X}_{3}=1$ for high TFA).

Since we expect that the effect of environmental uncertainty is more positive for subjects with low TFA, we expect a significant negative three-way interaction $X_{1} \times X_{2} \times X_{3}$. This means that we expect that the coefficient of the interaction term $\left(\beta_{7}\right)$ is negative. The results of the test are presented in Table $6.4 \mathrm{a}$ below. 
Table 6.4a Results of regressing GC on RAPM, TFA and EU

\begin{tabular}{|l|r|r|r|r|r|}
\hline Variable & Coefficient & Value & Std Error & $\mathbf{t}$ & \multicolumn{1}{c|}{$\mathbf{P}$} \\
\hline Constant & $\beta_{3}$ & 2.9013 & 0.8093 & 3.585 & 0.0004 \\
RAPM & $\beta_{3}$ & 3.1216 & 2.9417 & 1.061 & 0.2900 \\
Environmental uncertainty (EU) & $\beta_{2}$ & 0.1009 & 0.2979 & 0.339 & 0.7352 \\
Tolerance for ambiguity (TFA) & $\beta_{3}$ & 2.2711 & 1.1721 & 1.938 & 0.0542 \\
RAPM $\times$ EU & $\beta_{4}$ & -0.2205 & 1.0300 & -0.214 & 0.8307 \\
RAPM $\times$ TFA & $\beta_{5}$ & -8.4047 & 4.2031 & -2.000 & 0.0470 \\
EU $\times$ TFA & $\beta_{6}$ & -0.7576 & 0.4458 & -1.699 & 0.0909 \\
RAPM $\times$ EU $\times$ TFA & $\beta_{7}$ & 2.6129 & 1.5483 & 1.688 & 0.0931 \\
\hline Adjusted $R^{2}=7.591 \% ; F_{7,188}=3.2882 ; p=0.0025 ; n=196$ & & & & \\
\hline
\end{tabular}

The results do not support the hypothesis. The hypothesis suggested the existence of a significant three-way interaction $\left(\beta_{7}\right)$, which is supported by our findings, yet the positive sign of the interaction contradicts our expectation of negative three-way interaction. To further explain this finding, we further analyzed the effect of environmental uncertainty on the relationship between the use of APM and goal clarity for the low TFA and high TFA subgroups separately. The results of this test, which are presented in Appendix L, suggest the existence of a positive significant interaction between environmental uncertainty and RAPM to affect goal clarity only for the high TFA subgroup. This indicates, that environmental uncertainty only has a positive effect on the relationship between the use of APM and goal clarity (see also Hypothesis 1a) for managers with high TFA. Therefore, the results suggest, contrary to our expectation, that the moderating effect of environmental uncertainty on the relationship between RAPM and goal clarity is more positive for subjects with high TFA than for subjects with low TFA. The results do support however, that this relationship is moderated by TFA.

Hypothesis $4 \mathrm{~b}$ stated that:

$H 4 b$ : There is no difference in the effect of EU on the relationship between $R A P M$ and $A E C$ between individuals with low TFA and individuals with high TFA.

To investigate this hypothesis, the following model was fitted to the data:

(2) $Y=\beta_{0}+\beta_{1} X_{1}+\beta_{2} X_{2}+\beta_{3} X_{3}+\beta_{4} X_{1} \times X_{2}+\beta_{5} X_{1} \times X_{3}+\beta_{6} X_{2} \times X_{3}+\beta_{7} X_{4} \times X_{2} \times X_{9}+\epsilon$

where: $\mathrm{Y}$ is agreement with evaluation criteria (AEC)

$\mathrm{X}_{1}$ is RAPM

$\mathrm{X}_{2}$ is environmental uncertainty ( $\left.\mathrm{EU}\right)$

$\mathrm{X}_{3}$ is tolerance for ambiguity (TFA, with $\mathrm{X}_{3}=0$ for low TFA and $\mathrm{X}_{3}=1$ for high TFA). 
The results are presented in Table $6.4 \mathrm{~b}$ below.

Table 6.4b Results of regressing AEC on TFA, EU and RAPM

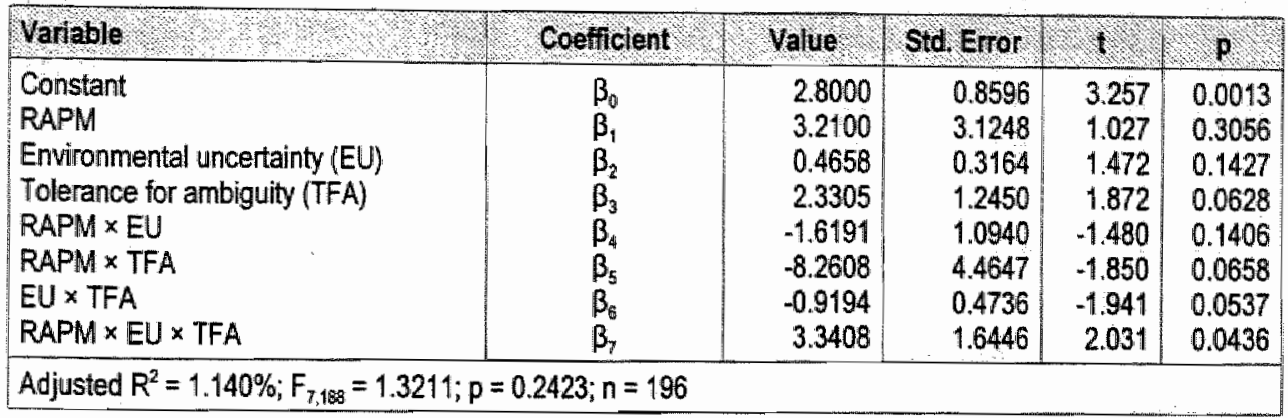

These results do not provide strong evidence against the null-hypothesis. On the one hand, the results show a positive and significant coefficient for the three-way interaction term $\left(\beta_{7}\right)$. This indicates, contrary to our expectation, that the effect of environmental uncertainty on the relationship between RAPM and agreement with evaluation criteria is significantly different between subjects with high TFA and subjects with low TFA. On the other hand, the limited explanatory power and insignificance of the model as a whole provide support for the expected irrelevance of the level of TFA for the effect of environmentall uncertainty on the relationship between RAPM and AEC.

For the effect of TFA on the relationship between environmental uncertainty and managers' opinions about the appropriateness of APM, we formulated Hypothesis $4 \mathrm{c}$, which stated:

H4c: The effect of EU on FAAPM is more positive for individuals with low TFA than for individuals with high TFA.

To test this hypothesis, a regression was run using the following model:

$$
\mathrm{Y}=\beta_{0}+\beta_{1} X_{1}+\beta_{2} X_{2}+\beta_{3} X_{1} \times X_{2}+\epsilon
$$

where: $\mathrm{Y}$ is FAAPM

$X_{1}$ is environmental uncertainty ( $E U$ )

$\mathrm{X}_{2}$ is tolerance for ambiguity (TFA, with $\mathrm{X}_{2}=0$ for low TFA and $\mathrm{X}_{2}=1$ for high TFA).

Since Hypothesis $4 \mathrm{c}$ indicates that we expect that the relationship between $\mathrm{EU}$ and FAAPM is more positive for subjects with low TFA, than for subjects with high TFA, we expect a negative interaction $\mathrm{X}_{1} \times \mathrm{X}_{2}$ and a significant negative coefficient of the interaction term $\left(\beta_{3}\right)$. The results are presented in Table $6.4 \mathrm{c}$ below. 
Table 6.4c Results of regressing FAAPM on EU and TFA

\begin{tabular}{|l|c|r|r|r|r|}
\hline Variable & Coefficient & Value & std. Error & $t$ & $\mathbf{P}$ \\
\hline Constant & $\beta_{0}$ & 1.0588 & 0.3758 & 2.818 & 0.0053 \\
EU & $\beta_{1}$ & 0.6191 & 0.1312 & 4.717 & 0.0000 \\
Tolerance for ambiguity (TFA) & $\beta_{2}$ & 0.6401 & 0.4809 & 1.331 & 0.1848 \\
EU $* \mathrm{TFA}$ & $\beta_{3}$ & -0.3236 & 0.1737 & -1.864 & 0.0639 \\
\hline Adjusted $\mathrm{R}^{2}=14.574 \% ; F_{7 ; 188}=12.0895 ; \rho=0.0000 ; n=196$ \\
\hline
\end{tabular}

These results support the hypothesis, as the value of the coefficient of the interaction term $\left(\beta_{3}\right)$ is significant and in the expected direction. ${ }^{6}$ However, this result appears not to confirm our finding regarding Hypotheses $4 \mathrm{a}$. In our discussion and evaluation of findings in Chapter 7 we will further discuss this result.

\subsubsection{TFA, task uncertainty and the appropriateness of APM ( $\mathrm{H} 5 \mathrm{a}, \mathrm{H} 5 \mathrm{~b}$ and $\mathrm{H} 5 \mathrm{c})$}

Hypothesis 5a stated that:

H5a: There is no difference in the effect of TU on the relationship between RAPM and GC between individuals with low TFA and individuals with high TFA.

To test this hypothesis, the following model was fitted to the data:

(2) $Y=\beta_{0}+\beta_{1} X_{1}+\beta_{2} X_{2}+\beta_{3} X_{3}+\beta_{4} X_{1} \times X_{2}+\beta_{5} X_{1} \times X_{3}+\beta_{6} X_{2} \times X_{3}+\beta_{7} X_{1} \times X_{2} \times X_{3}+\epsilon$

where: $\mathrm{Y}$ is goal clarity $(\mathrm{GC})$

$X_{1}$ is RAPM

$X_{2}$ is task uncertainty (TU)

$X_{3}$ is tolerance for ambiguity (TFA, with $X_{3}=0$ for low TFA and $X_{3}=1$ for high TFA).

The results are depicted in Table 6.5a below. Based on these results, the hypothesis cannot be rejected. Although the positive sign of the coefficient of the interaction term suggests that managers with low TFA are more sensitive for the effect of task uncertainty on the relationship between RAPM and goal clarity than managers with high TFA, the difference is not statistically significant. 
CHAPTER 6 RESULTS: TESTS OF HYPOTHESES

Table 6.5a Results of regressing GC on RAPM, TFA and TU

\begin{tabular}{|l|r|r|r|r|r|}
\hline Variable & Coefficient & Value & Std. Eroo & t & p \\
\hline Constant & $\beta_{0}$ & 2.9791 & 1.1161 & 2.669 & 0.0083 \\
RAPM & $\beta_{1}$ & 5.2028 & 3.5630 & 1.460 & 0.1459 \\
Task uncertainty (TU) & $\beta_{2}$ & 0.0845 & 0.3316 & 0.255 & 0.7992 \\
Tolerance for ambiguity (TFA) & $\beta_{3}$ & 3.2034 & 1.8734 & 1.710 & 0.0889 \\
RAPM $\times$ TU & $\beta_{4}$ & -0.9129 & 1.0853 & -0.841 & 0.4013 \\
RAPM $\times$ TFA & $\beta_{5}$ & -11.7607 & 6.4181 & -1.832 & 0.0685 \\
TU $\times$ TFA & $\beta_{6}$ & -0.7790 & 0.5167 & -1.508 & 0.1333 \\
RAPM $\times$ TU $\times$ TFA & $\beta_{7}$ & 2.8284 & 1.7849 & 1.585 & 0.1147 \\
\hline Adjusted $R^{2}=10.528 \% ; F_{7,188}=4.2778 ; p=0.0002 ; n=196$ \\
\hline
\end{tabular}

Hypothesis 5 b stated that:

H5b: The effect of $T U$ on the relationship between RAPM and $A E C$ is more negative for individuals with low TFA than for individuals with high TFA.

To test this hypothesis, the following three-way interaction model was fitted to the data:

(2) $Y=\beta_{0}+\beta_{1} X_{1}+\beta_{2} X_{2}+\beta_{3} X_{3}+\beta_{4} X_{1} \times X_{2}+\beta_{5} X_{1} \times X_{3}+\beta_{6} X_{2} \times X_{3}+\beta_{7} X_{1} \times X_{2} \times X_{3}+\epsilon$

where: $\mathrm{Y}$ is agreement with evaluation criteria (AEC)

$X_{1}$ is RAPM

$\mathrm{X}_{2}$ is task uncertainty (TU)

$\mathrm{X}_{3}$ is tolerance for ambiguity (TFA, with $\mathrm{X}_{3}=0$ for low TFA and $\mathrm{X}_{3}=1$ for high TFA).

The results are depicted in Table $6.5 \mathrm{~b}$ below.

Table 6.5b Results of regressing AEC on TFA, TU and RAPM

\begin{tabular}{|l|r|r|r|r|r|}
\hline Variable & Coefficient & Value & std, Error & \multicolumn{1}{c|}{ t } & \multicolumn{1}{c|}{$\mathbf{P}$} \\
\hline Constant & $\beta_{0}$ & 5.6718 & 1.1948 & 4.747 & 0.0000 \\
RAPM & $\beta_{1}$ & -8.1477 & 3.8141 & -2.207 & 0.0285 \\
Task uncertainty (TU) & $\beta_{2}$ & -0.5368 & 0.3550 & -1.512 & 0.1321 \\
Tolerance for ambiguity (TFA) & $\beta_{3}$ & -2.9254 & 2.0055 & -1.459 & 0.1463 \\
RAPM $\times$ TU & $\beta_{4}$ & 2.3573 & 1.1618 & 2.029 & 0.0439 \\
RAPM $\times$ TFA & $\beta_{5}$ & 11.9489 & 6.8705 & 1.739 & 0.0836 \\
TU $\times$ TFA & $\beta_{6}$ & 0.8684 & 0.5531 & 1.570 & 0.1181 \\
RAPM $\times$ TU $\times$ TFA & $\beta_{7}$ & -3.4835 & 1.9107 & -1.823 & 0.0699 \\
\hline
\end{tabular}

Adjusted $R^{2}=2.786 \% ; F_{7,188}=1.7982 ; p=0.0898 ; n=196$

These results provide support for the existence of a three-way interaction effect, since the 
coefficient of the interaction term $\left(\beta_{7}\right)$ is significant. Therefore, the data suggest, in line with our expectations, that TFA moderates the effect of task uncertainty on the relationship between RAPM and agreement with evaluation criteria. However, the sign of the interaction coefficient suggests that the interaction of TU and RAPM is more negative for subjects with high TFA than for subjects with low TFA. In other words, the interaction of TU and RAPM (which we found positive but insignificant when testing Hypothesis la) is more negative for high than for low TFA's. This suggests that managers with high TFA are more sensitive for the effect of TU on the appropriateness of RAPM. To further explore this finding, we further analyzed the effect of task uncertainty on the relationship between RAPM and AEC for the low TFA, and high TFA subgroups separately. The results of this test, which are presented in Appendix L, suggest the existence of a positive significant interaction between task uncertainty and RAPM to affect AEC only for the low TFA subgroup. This indicates that task uncertainty has a positive effect on the relationship between RAPM and AEC for managers with low TFA. This latter result provides some more insight in the result we obtained when testing the effect of task uncertainty on the relationship between RAPM and AEC for the whole population (Hypothesis $2 \mathrm{~b}$ ). There we found, contrary to our expectation, a small and insignificant positive effect of task uncertainty. We will further comment on this finding in Chapter 7.

Hypothesis $5 \mathrm{c}$ stated that:

H5c: The effect of TU on FAAPM is more negative for managers with low TFA than for managers with high TFA.

To test this hypothesis, a regression was run using the following model:

$$
Y=\beta_{0}+\beta_{1} X_{1}+\beta_{2} X_{2}+\beta_{3} X_{1} \times X_{2}+\epsilon
$$

where: $Y$ is FAAPM

$\mathrm{X}_{1}$ is task uncertainty (TU)

$\mathrm{X}_{2}$ is tolerance for ambiguity (TFA, with $\mathrm{X}_{2}=0$ for low TFA and $\mathrm{X}_{2}=1$ for high TFA).

Since Hypothesis $5 \mathrm{c}$ indicates that we expect that the relationship between TU and FAAPM is more negative for subjects with low TFA, than for subjects with high TFA, we expect a positive interaction $\mathrm{X}_{1} \times \mathrm{X}_{2}$ and thus a positive coefficient of the interaction term. The results are presented in Table $6.5 \mathrm{c}$ below. 
CHAPTER 6 RESULTS: TESTS OF HYPOTHESES

Table 6.5c Results of regressing FAAPM on TU and TFA

\begin{tabular}{|l|c|r|r|r|r|}
\hline Variable & Coeficient & Value & Std. Error & $t$ \\
\hline Constant & $\beta_{0}$ & 4.7000 & 0.4650 & 10.110 & 0.0000 \\
TU & $\beta_{1}$ & -0.5850 & 0.1387 & -4.217 & 0.0000 \\
Tolerance for ambiguily (TFA) & $\beta_{2}$ & -1.3726 & 0.7122 & -1.927 & 0.0554 \\
TU $\times$ TFA & $\beta_{3}$ & 0.3508 & 0.1985 & 1.768 & 0.0787 \\
\hline Adjusted $R^{2}=11.160 \% ; F_{3,192}=9.1653 ; p=0.0000 ; n=196$ & & & & \\
\hline
\end{tabular}

These results support our hypothesis. The coefficient of the interaction term $\left(\beta_{3}\right)$ is positive and significant. Therefore, the data support our expectation that task uncertainty has a more negative effect on subjects' opinions about the appropriateness of APM for subjects with low TFA than for subjects with high TFA. ${ }^{7}$ This result is in line with the results of the test of Hypothesis $5 b$ as for the existence of an interaction between TU and TFA, but not with regard to its direction.

\subsection{The effects of RFQ and RT on goal clarity (GC) and agreement with evaluation criteria (AEC)}

\subsubsection{Tests of hypotheses concerning RFQ and RT}

This section contains the tests of hypotheses for the APM variables reliance on financial and quantitative information (RFQ) and reliance on targets (RT). As we motivated in Chapter 3, the hypotheses concerning these two variables aim at explicitly testing the proposition that RAPM consist of two relevant underlying dimensions. In particular, they aim at examining the proposed differences in the appropriateness of the reliance on financial and quantitative information (RFQ) and the reliance on targets (RT). In general, these hypotheses are tested using the regression equation presented below:

$$
Y=\beta_{0}+\beta_{1} X_{i}+\beta_{2} X_{2}+\beta_{3} X_{3}+\beta_{4} X_{1} \times X_{2}+\beta_{5} X_{1} \times X_{3}+\epsilon
$$

where: $\mathrm{Y}$ is goal clarity (GC) or agreement with evaluation criteria (AEC)

$\mathrm{X}_{\downarrow}$ is environmental uncertainty (EU) or task uncertainty (TU)

$\mathrm{X}_{2}$ is reliance on financial and quantitative measures (RFQ)

$\mathrm{X}_{3}$ is reliance on targets $(\mathrm{RT})$.

Note that this equation allows a simultaneously test of the effects of RFQ and RT. Two reasons support such a simultaneous test. A substantive reason is the argument from Chapter 3 that RFQ and RT are combined factors of the 'traditional' RAPM construct. An additional reason for testing the effects of RFQ and RT simultaneously is the existence, reported in Chapter 5, of a significant correlation between RFQ and RT. A simultaneous test of RFQ and RT secures that the effects found are attributed to the 
causal factor.

\subsubsection{RFQ, RT, environmental uncertainty and the appropriateness of APM (H6a and $\mathrm{H} 6 \mathrm{~b}$ )}

Hypothesis 6a stated:

H6a: The effect of RFQ on GC is more positive for higher levels of EU, and the effect of $R T$ on $G C$ is not affected by the level of $E U$.

To test this hypothesis the following model was fitted to the data:

$$
Y=\beta_{0}+\beta_{1} X_{1}+\beta_{2} X_{2}+\beta_{3} X_{31}+\beta_{4} X_{1} \times X_{2}+\beta_{5} X_{1} \times X_{3}+\epsilon
$$

where: $\mathrm{Y}$ is goal clarity (GC)

$X_{1}$ is environmental uncertainty (EU)

$X_{2}$ is reliance on financial and quantitative measures (RFQ)

$\mathrm{X}_{3}$ is reliance on targets (RT).

The results are presented in Table 6.6a below.

Table 6.6a Results of regressing GC on RFQ, RT and EU

\begin{tabular}{|c|c|c|c|c|c|}
\hline Varable. & Coefficient & Value & Sto. Enor & 1 & p. \\
\hline $\begin{array}{l}\text { Constant } \\
\text { Environmental uncertainty (EU) } \\
\text { Reliance on Fin. \& Quan. Info (RFQ) } \\
\text { Reliance on Targets (RT) } \\
\text { EU } \times \text { RFQ } \\
\text { EU } \times \text { RT }\end{array}$ & $\begin{array}{l}\beta_{0} \\
\beta_{1} \\
\beta_{2} \\
\beta_{3} \\
\beta_{4} \\
\beta_{5}\end{array}$ & $\begin{array}{r}3.4648 \\
-0.1581 \\
-0.1101 \\
0.1690 \\
0.0986 \\
-0.0260\end{array}$ & $\begin{array}{l}0.5719 \\
0.2068 \\
0.1894 \\
0.2027 \\
0.0708 \\
0.0745\end{array}$ & $\begin{array}{r}6.059 \\
-0.764 \\
-0.581 \\
0.834 \\
1.393 \\
-0.349\end{array}$ & $\begin{array}{l}0.0000 \\
0.4455 \\
0.5617 \\
0.4054 \\
0.1652 \\
0.7278\end{array}$ \\
\hline \multicolumn{6}{|c|}{ Adjusted $R^{2}=12.290 \% ; F_{5,190}=6.4647 ; p=0.0000$} \\
\hline
\end{tabular}

These results show partial support for the hypothesis. As expected, the interaction between $\mathrm{EU}$ and $\mathrm{RT}$ is near zero and insignificant. The interaction between RFQ and EU is in the expected positive direction, yet fails to reach the 0.10 level of significance for a two-tailed t-test. Overall, therefore, we conclude that the hypothesis is not supported by the results.

Hypothesis $6 \mathrm{~b}$ was formulated in the null-form and stated:

H6b: The effect of RFQ on AEC and the effect of RT on AEC are not affected by the level of $E U$. 


\section{CHAPTER 6 RESULTS: TESTS OF HYPOTHESES}

To test this hypothesis the following model was fitted to the data:

(3) $Y=\beta_{0}+\beta_{1} X_{1}+\beta_{2} X_{2}+\beta_{3} X_{3}+\beta_{4} X_{1} \times X_{2}+\beta_{5} X_{1} \times X_{3}+\epsilon$

where: $\mathrm{Y}$ is agreement with evaluation criteria (AEC)

$\mathrm{X}_{1}$ is environmental uncertainty (EU)

$\mathrm{X}_{2}$ is reliance on financial and quantitative measures (RFQ)

$\mathrm{X}_{3}$ is reliance on targets $(\mathrm{RT})$.

The results are presented in Table $6.6 \mathrm{~b}$ below.

Table 6.6b Results of regressing AEC on RFQ, RT and EU

\begin{tabular}{|l|c|r|r|r|r|}
\hline Variable & Coefficient & Value & Std Error & \multicolumn{1}{|c|}{$t$} & $p$ \\
\hline Constant & $\beta_{0}$ & 4.0695 & 0.6086 & 6.687 & 0.0000 \\
Environmental uncertainty (EU) & $\beta_{1}$ & -0.3010 & 0.2200 & -1.368 & 0.1729 \\
Reliance on Fin. \& Quan. Info (RFQ) & $\beta_{2}$ & 0.0093 & 0.2015 & 0.046 & 0.9634 \\
Reliance on Targets (RT) & $\beta_{3}$ & -0.0903 & 0.2157 & -0.419 & 0.6760 \\
EU $\times$ RFQ & $\beta_{4}$ & -0.0284 & 0.0753 & -0.377 & 0.7069 \\
EU $\times$ RT & $\beta_{5}$ & 0.1072 & 0.0792 & 1.353 & 0.1777 \\
\hline Adjusted $R^{2}=5.825 \% ; F_{5,190}=3.4122 ; p=0.0056$ & \\
\hline
\end{tabular}

Based on these results, we cannot reject our null-hypothesis. The results do not show significant interactions between EU, RFQ and RT to affect AEC.

\subsubsection{RFQ, RT, task uncertainty and the appropriateness of APM ( $\mathrm{H7a}$ and $\mathrm{H7b}$ )}

Hypothesis 7a stated:

$H 7 a$ : The effect of RFQ on $G C$ and the effect of $R T$ on $G C$ are not affected by the level of TU.

To test this hypothesis the following model was fitted to the data:

(3) $Y=\beta_{0}+\beta_{1} X_{1}+\beta_{2} X_{2}+\beta_{3} X_{3}+\beta_{4} X_{1} \times X_{2}+\beta_{5} X_{1} \times X_{3}+\epsilon$

where: $\mathrm{Y}$ is goal clarity (GC)

$\mathrm{X}_{1}$ is task uncertainty (TU)

$\mathrm{X}_{2}$ is reliance on financial and quantitative measures (RFQ)

$\mathrm{X}_{3}$ is reliance on targets (RT).

The results are presented in Table $6.7 \mathrm{a}$ below. 
Table 6.7a Results of regressing GC on RFQ, RT and TU

\begin{tabular}{|l|r|r|r|r|r|}
\hline Variable & Cosficient & Value & Std. Error & $t$ & \multicolumn{1}{c|}{$p$} \\
\hline Conistant & $\beta_{0}$ & 4.1100 & 0.8630 & 4.762 & 0.0000 \\
Task uncertainty (TU) & $\beta_{1}$ & -0.2882 & 0.2348 & -1.227 & 0.2212 \\
Reliance on Fin. \& Quan. Info (RFQ) & $\beta_{2}$ & 0.2735 & 0.2550 & 1.073 & 0.2848 \\
Reliance on Targets (RT) & $\beta_{3}$ & -0.1035 & 0.2637 & -0.392 & 0.6953 \\
TU $\times$ RFQ & $\beta_{4}$ & -0.0419 & 0.0699 & -0.599 & 0.5501 \\
TU $\times R T$ & $\beta_{5}$ & 0.0610 & 0.0710 & 0.859 & 0.3913 \\
\hline Adjusted $R^{2}=17.189 \% ; \mathrm{F}_{\mathrm{s}, 180}=9.1001 ; p=0.0000$ & & & \\
\hline
\end{tabular}

Based on the above results, we decide not to reject our null-hypothesis, since there is no evidence of TU significantly moderating the relationships between RFQ, RT and GC.

Hypothesis $7 \mathrm{~b}$ stated:

$H 7 b$ : The effect of $R F Q$ on $A E C$ is not affected by the level of $T U$, whereas the effect of RT on AEC is more negative for higher levels of TU.

To test this hypothesis the following model was fitted to the data:

$$
Y=\beta_{0}+\beta_{1} X_{1}+\beta_{2} X_{2}+\beta_{3} X_{3}+\beta_{4} X_{1} \times X_{2}+\beta_{5} X_{1} \times X_{3}+\epsilon
$$

where: $\quad Y$ is agreement with evaluation criteria (AEC)

$\mathrm{X}_{1}$ is task uncertainty (TU)

$X_{2}$ is reliance on financial and quantitative measures (RFQ)

$\mathrm{X}_{3}$ is reliance on targets $(\mathrm{RT})$.

The results are presented in Table $6.7 \mathrm{~b}$ below.

Table 6.7b Results of regressing AEC on RFQ, RT and TU

\begin{tabular}{|c|c|c|c|c|c|}
\hline Variable. & Coefficient & Value & Std Error & $t$ & p \\
\hline Constant & $\beta_{0}$ & 2.5004 & 0.9248 & 2.704 & 0.0075 \\
\hline Task uncertainty (TU) & $\beta_{i}$ & 0.2035 & -0.2516 & 0.809 & 0.4193 \\
\hline Rellance on Fin. \& Quan. Info (RFQ) & $\beta_{2}$ & -0.6590 & 0.2733 & -2.412 & 0.0168 \\
\hline Rellance on Targets (RT) & $\beta_{3}$ & 0.8040 & 0.2826 & 2.845 & 0.0049 \\
\hline TU $\times R F Q$ & $\hat{\beta}_{4}$ & 0.1698 & 0.0749 & 2.268 & 0.0245 \\
\hline TU $\times R T$ & $\mathrm{~B}_{3}$ & -0.1686 & 0.0761 & -2.214 & 0.0280 \\
\hline
\end{tabular}

The above data suggest support for the hypothesis, since the coefficient of the interaction term of TU and RT is significant, and in the expected negative direction. In addition 
however, the above data also evidence the existence of a positive interaction between TU and RFQ to affect AEC. This means that the relationship between RFQ and AEC is more positive for higher levels of $\mathrm{TU}$. Since the two interactions have opposite signs, this finding seems consistent with our finding concerning Hypothesis $2 b$, where we did not find the expected negative effect of TU on the relationship between RAPM and AEC.

\subsection{Summary and overview}

In this chapter we tested the hypotheses that we developed in Chapter 3 . Sections $6.2,6.3$ and 6.4 presented tests of the hypotheses. Table 6.8 below provides a summary and overview of the hypotheses. In this table, the hypotheses and the results are summarized. For hypotheses labeled 'support', the direction of the coefficient was as expected, and the level of significance was sufficient ( $p<0.100$, two-tailed). In the table, the hypotheses formulated in the null-form are also included, and labeled ' $(\mathrm{HO})$ '. 


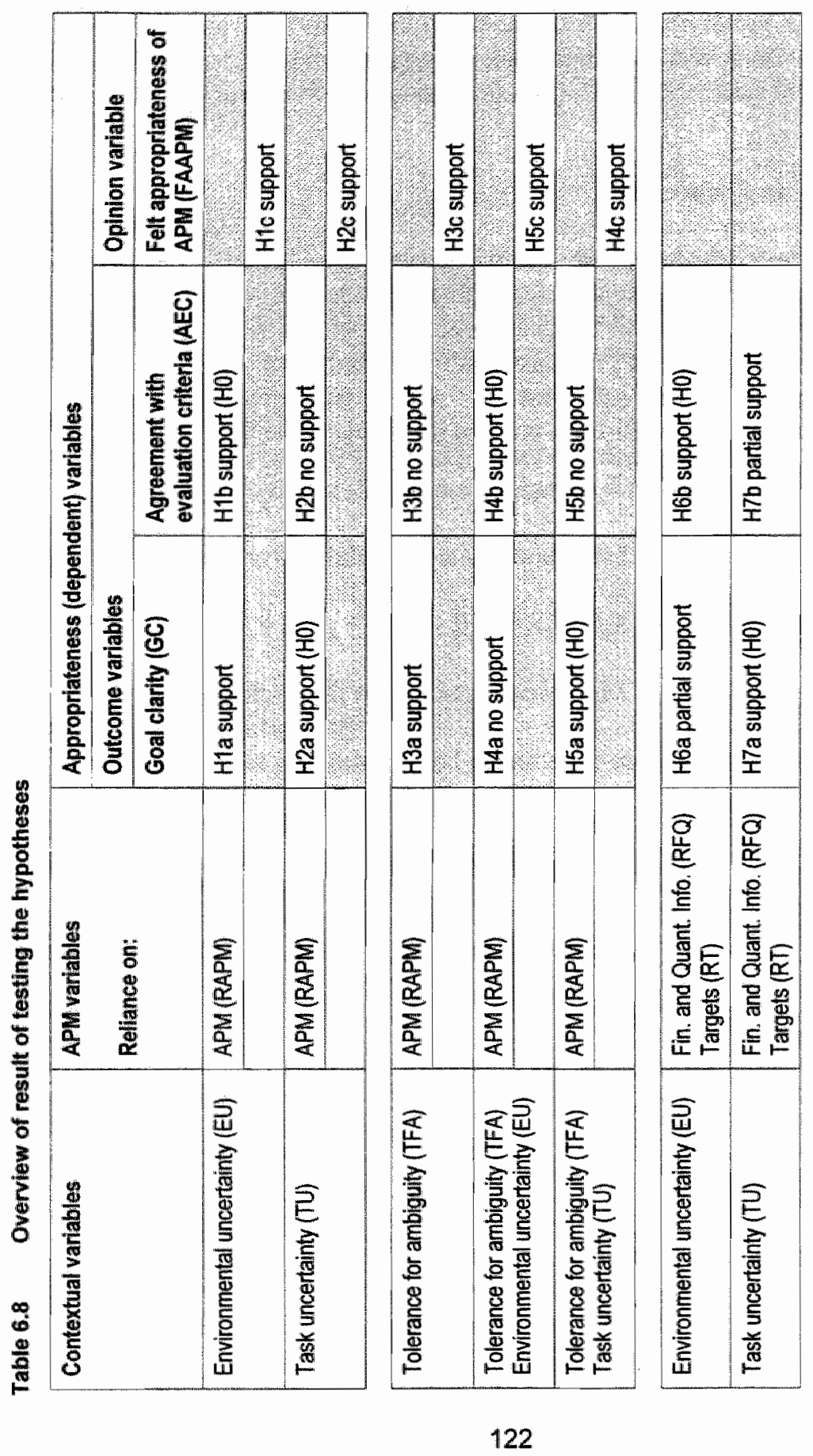




\section{CHAPTER 6 RESULTS: TESTS OF HYPOTHESES}

\section{Notes to Chapter 6:}

1. Recall from Chapter 3 the different theoretical formats for stating contextual hypotheses. As stated there, our hypotheses predicting moderating effects of contextual variable correspond to the 'interaction' model of fit. See Appendix $\mathrm{K}$ for a further discussion on MRA.

2. As already noted in the previous chapter, all p-values relate to two-tailed tests. We chose to denote our findings as 'significant' when $\mathrm{p}<0.100$. See Appendix $\mathrm{K}$ for a motivation to use parametric statistical techniques throughout this dissertation.

3. See also Appendix $\mathbb{K}$ for a discussion of the lack of power problem associated with, in particular, higher-order interactions.

4. Arnold [1982, p. 221] notes: '...there are two types of situations in which such transformations [dichotomization] may be defensible and meaningful. The first is the case in which the measurement scale for the moderator is unreliable. In this case " what appears to be "information" in the multivalued moderator scores may in fact be largely "noise" (i.e. measurement error). This noise may drastically reduce the power of whatever analytic technique is being employed to detect "true" moderator effects of either type [...]. The second situation in which transformation may be defensible is when the investigator hypothesizes that the underlying psychological scale being tapped by the moderator is discontinuous, even though the measurement scale employed is continuous'.

5. See Appendix I for the Pearson correlation coefficient for the continuous TFA scale and FAAPM.

6. An additional analysis revealed that the relationship between EU and FAAPM is significantly positive for both high and low TFA.

7. An additional analysis revealed that the relationship between TU and FAAPM is significantly negative for both high and low TFA. 
ACCOUNTING FOR PERFORMANCE EVALUATION 


\section{Chapter 7 \\ Summary and conclusions}

\subsection{Introduction}

The objective of this study was to enhance our understanding of the impact of uncertainty in the manager's working environment on the appropriateness of APM for managerial performance evaluation. This final chapter provides an overview and discussion of the empirical findings presented in the previous chapter. For this purpose, Section 7.2 summarizes the findings and presents conclusions for each of the four directions of inquiry that we pursued. Section 7.3 then presents some overall conclusions of this study, and discusses some implications. Section 7.4 presents the strengths and weaknesses of this study. Finally, Section 7.5 closes this chapter by pointing out some directions for further research.

\subsection{Summary and overview of empirical findings}

\subsubsection{Four directions of inquiry}

This study built on previous APM research that used contextual frameworks to assess the appropriateness of APM. In particular, with our study we attempted to refine and extend existing theory about the relationship between uncertainty and the appropriateness of APM by exploring the following four directions for further inquiry.

First, we examined the meaning and measurement of the concept of "appropriateness" of APM. This resulted in the selection of three variables that serve as criteria for the contextual appropriateness of APM. Two of these variables, goal clarity and agreement with evaluation criteria, relate to the outcomes of using APM. An additional variable, felt appropriateness of $A P M$, relates to managers' opinions about the appropriateness of APM.

Second, we examined whether explicit recognition of the source of uncertainty is important for understanding the relationship between "uncertainty" and the appropriateness of APM. We focused in particular on potential different effects on the appropriateness of APM of task uncertainty and environmental uncertainty.

Third, we examined whether the appropriateness of APM is also affected by the 
manager's personality, and focused on the tolerance for ambiguity, which has been used previously to describe individual preferences for information in situations characterized by uncertainty.

Fourth and finally, we distinguished two dimensions of the traditional RAPM construct, which we labeled reliance on financial and quantitative information, and reliance on targets. We subsequently used these new variables in an attempt to gain more insight into what aspect of APM explains its appropriateness or inappropriateness under uncertainty.

In the following sections, we summarize and discuss our findings for each of these four directions of inquiry. Since our first direction of inquiry did not result in the formulation of separate hypotheses, we will first present summaries and discussions of the findings concerning the other three directions of inquiry.

\subsubsection{Differences in effects of envilronmental uncertainty and task uncertainty}

\section{Summary of findings}

The results of the tests of the hypotheses related to enviranmental uncertainty (EU) and task uncertainty (TU) are summarized in Table 7.1 below. To enable a clear overview and comparison of the effects of EU and TU on the appropriateness of APM, the last two columns in the table present the direction of the effects found for the two uncertainty variables. In addition these columns contain information about whether the effects found were statistically significant (s), or not significant (ns). ${ }^{1}$

Table 7.1 Overview of results; comparing the effect of EU and TU on the appropriatemess of APMH

\begin{tabular}{|l|l|l|l|l|l|l|}
\hline \multicolumn{2}{|l|}{ Hypotheses } & APM & Appropriateness variables & Sign of (moderating) effect found \\
\hline EU & TU & variables & Outcome & Opinion & EU & TU \\
\hline H1a & H2a & RAPM & GC & & $+(s)$ & $-($ (ns) \\
\hline H1b & H2b & RAPM & AEC & & $-(n s)^{a}$ & $+(n s)$ \\
\hline H1c & H2c & & & FAAPM & $+(s)$ & $-(s)$ \\
\hline
\end{tabular}

a. This hypothesis was formulated in the null-form.

For environmental uncertainty, the results support an overall positive impact on the appropriateness of APM. As predicted, managers show more favorable opinions toward APM (FAAPM) for higher levels of environmental uncertainty (H1c). Furthermore, the use of APM contributes more to managerial goal clarity (GC) for higher levels of environmental uncertainty ( $\mathrm{Hla}$ ). As expected, environmental uncertainty was not found to moderate the relationship between the use of APM and agreement with evaluation 
criteria (AEC; H1b).

Regarding task uncertainty, we found in conformity with expectations that managers have more negative opinions about the appropriateness of APM for higher levels of task uncertainty $(\mathrm{H} 2 \mathrm{c})$. As expected, we did not find that task uncertainty moderates the relationship between the use of APM and goal clarity (H2a). Our results, however, do not support the expected negative impact of task uncertainty on the relationship between the use of APM and agreement with evaluation criteria $(\mathrm{H} 2 \mathrm{~b})$.

\section{Conclusions}

Based on these findings, we draw the following conclusions. Overall, the results seem to support the sensitivity of the appropriateness of APM to the source of uncertainty. In particular, our results support our basic prediction that environmental uncertainty and task uncertainty do not affect the appropriateness of APM in the same way. When interpreting the direction of the effects, our findings suggest that the use of APM may be more appropriate under conditions of high environmental uncertainty. This finding is in line with the results reported by Simons [1987a] and Ezzamel [1990], and appears to confirm the suggestion raised earlier about the role of APM in structuring the manager's job by providing specific and clear goals, which may serve managers' need for control [e.g., Hopwood 1972; Hirst 1983b; Ross 1995]. For task uncertainty, our findings only partially support its expected negative impact on the appropriateness of APM. Although we found, in conformity with our expectation and in line with results from previous APM studies, that task uncertainty has a negative effect on managers' opinions about the appropriateness of APM [cf. Hirst 1983a], our findings do not support that this is caused by managers' disagreeing with the use of 'unfair' performance criteria. This finding thus challenges the suggestion raised in several previous APM studies that negative effects of using APM under uncertainty originate in perceptions of being 'unfairly' evaluated [e.g., Hirst 1983b; Lau et al. 1995], and may explain previous failures to find negative effects of task uncertainty on the appropriateness of APM [e.g., Brownell and Hirst 1986; Ross 1995]. To appreciate this latter conclusion better, recall our finding of a small but significant negative correlation between RAPM and AEC in Chapter 5. In combination with our findings here this suggests that the use of APM may result in a lower agreement with evaluation criteria, regardless the level of 'uncertainty'.

\subsubsection{The effect of tolerance for ambiguity}

\section{Summary of findings}

Two sets of hypotheses were developed predicting an impact of TFA on the appropriateness of APM. The first set of hypotheses contained predictions about a direct impact of TFA on the appropriateness of APM. With the second set of hypotheses we predicted that TFA moderates the relationships between environmental and task uncertainty, and the appropriateness of APM specified earlier (see Table 7.1). The results for the hypotheses related to the direct impact of TFA on the appropriateness of APM are 
summarized in Table 7.2 below.

Table 7.2 Overview of results; the direct effects of TFA on the appropriateness of APM

\begin{tabular}{|l|l|l|l|l|}
\hline Hypotheses & APM & Appropriateness variables & Sign of (moderating) effect found \\
\hline TFA & variabies & Outcone & Opinion & TA \\
\hline H3a & RAPM & GC & & - (s) \\
\hline H3b & RAPM & AEC & & $+(\mathrm{ns})$ \\
\hline $\mathrm{H} 3 \mathrm{C}$ & & & FAAPM & - (s) \\
\hline
\end{tabular}

Overall; our findings suggest that the appropriateness of APM is higher for managers with low TFA than for managers with high TFA. Managers with low TFA show more favorable opinions toward APM (FAAPM) than do managers with high TFA (H3c). Furthermore, the use of APM contributes more to managerial goal clarity (GC) for managers with low TFA than for managers with high TFA (H3a). No support was found for the expectation that TFA moderates the relationship between the use of APM and agreement with evaluation criteria (AEC; $\mathrm{H} 3 \mathrm{~b}$ ). This latter finding suggests that the effect of RAPM on AEC (see Chapter 5) is the same for managers with low TFA as for managers with high TFA.

The results for the hypotheses predicting a moderating effect of TFA on the relationships between environmental (EU) and task uncertainty (TU), and the appropriateness of APM specified before are summarized in Table 7.3.

Table 7.3 Overview of results; TFA, uncertainty and the appropriateness of APM

\begin{tabular}{|c|c|c|c|c|c|}
\hline \multicolumn{2}{|c|}{ Hypotheses } & \multirow{2}{*}{$\begin{array}{l}\text { ApH } \\
\text { vartables }\end{array}$} & \multicolumn{2}{|c|}{ Appropriateness variables } & Sign of (moderating) effect found \\
\hline EUTTFA & TUTTFA & & Outcome & Opinion & TFA \\
\hline $\mathrm{H} 4 \mathrm{a}$ & & RAPM & $\mathrm{GC}$ & & $+(s)$ \\
\hline $\mathrm{H} 4 \mathrm{~b}$ & & RAPM & AEC & & $+(n s)^{b, c}$ \\
\hline \multirow[t]{4}{*}{$\mathrm{H} 4 \mathrm{C}$} & & & & FAAPM & $-(s)$ \\
\hline & $\mathrm{H} 5 \mathrm{a}$ & RAPM & GC & & $+(n s)^{c}$ \\
\hline & $\mathrm{H} 5 \mathrm{~b}$ & RAPM & AEC & & $-(s)^{2}$ \\
\hline & $\mathrm{H} 5 \mathrm{C}$ & & & FAAPM & $+(s)$ \\
\hline
\end{tabular}

a. See Appendix $L$ for a further examination of this finding.

b. For this relationship, the model was insignificant.

c. This hypothesis was formulated in the null-form.

As these results indicate, TFA appears to moderate the relationships between uncertainty 


\section{CHAPTER 7 SUMMARY AND CONCLUSIONS}

and managers' opinions about the appropriateness of APM (FAAPM) significantly. In particular, TFA negatively moderates the relationship between environmental uncertainty (EU) and FAAPM $(\mathrm{H} 4 \mathrm{c})$. This indicates that the positive effect of EU on FAAPM found earlier is less positive for managers with high TFA. In addition, TFA positively moderates the relationship between task uncertainty (TU) and FAAPM (H5c). This indicates that the negative effect of TU on FAAPM found earlier is less negative for managers with high TFA. In conformity with expectations, these findings together suggest that uncertainty has a stronger effect on the appropriateness of APM for managers with low TFA than for managers with high TFA.

For the effects of TFA on the appropriateness of APM in terms of goal clarity (GC) and agreement with evaluation criteria (AEC) our results are mixed. We did not find significant effects of TFA for the two hypotheses stated in the null-form (H4b and H5a), which confirms our suggestion of the existence of opposite effects. In contrast, the results for the two directional hypotheses $(\mathrm{H} 4 \mathrm{a}$ and $\mathrm{H5b}$ ) are statistically significant, but the results suggest the existence of directional effects of TFA that are opposite to our expectations.

For the relationship between environmental uncertainty (EU), RAPM and GC, we found a significant and positive moderating effect of TFA ( $\mathrm{H} 4 \mathrm{a})$. The further analysis of this finding in Appendix L showed that EU positively moderates the relationship between RAPM and GC for managers with high TFA only. Therefore, the results suggest that managers with high TFA are more sensitive to the effects of EU than managers with low TFA. This finding appears not to be in line with our finding regarding FAAPM $(\mathrm{H} 4 \mathrm{c})$.

For the relationship between task uncertainty (TU), RAPM and AEC, a significantly negative moderating effect of TFA was found ( $\mathrm{H} 5 \mathrm{~b})$. The further analysis in Appendix L showed that TU positively moderates the relationship between RAPM and AEC for managers with low TFA only. This suggests that for these managers, the use of RAPM results in higher agreement with evaluation criteria for higher levels of task uncertainty. Also this finding appears not to be in line with our finding regarding FAAPM (H5c).

\section{Conclusions}

Based on these findings, we draw the following conclusions. Overall, we believe that our findings support that managers' TFA affects the appropriateness of APM. This not only supports the relevance of personality variables in accounting research in general [e.g., Harrison 1993], but in particular suggests that the preferences for the use of APM and the effects of using APM differ between managers with low and high TFA. Based on our findings, however, we have to conclude that the direction of the effect of TFA is not yet fully understood. On the one hand, most of our findings suggest that uncertainty has a stronger effect on the appropriateness of APM for managers with low TFA than for managers' with high TFA. Especially for the direct impact of TFA on the appropriateness of APM (see Table 7.2), and for the interactions of uncertainty and TFA to affect managerial opinions (see Table 7.3), our findings are generally in line with expectations, 
suggesting in line with the limited available previous evidence that managers with lower TFA have a higher preference for accounting information [e.g., Dermer 1973]. On the other hand, the findings concerning the moderating effect of TFA on the relationships between uncertainty and RAPM, and GC and AEC are not in support of such a general conclusion. Although these results may be caused by the relatively low reliability of the TFA instrument, together with the use of "statistically demanding" three-way interaction models, they do provide at least some support for the scepticism raised in earlier research about the direction of the effects of TFA [see, e.g., Pratt 1980, p. 503; Pincus 1990, p. 153 and Chapter 3 of this study]. In addition, since our findings show some inconsistencies between the effects of TFA in terms of opinions (FAAPM), and in terms of outcomes (GC and AEC), the specific further conclusion seems warranted that TFA is a better predictor of managers' general attitudes toward APM, than of their reactions to the use of APM.

\subsubsection{Multi-dimensionality of RAPM}

Summary of findings

The results for the hypotheses concerning the two newly developed APM variables reliance on financial and quantitative information (RFQ) and reliance on targets (RT) are summarized in Table 7.4 below. To enable a clear overview and comparison of the findings for RFQ and for RT, the last two columns in the table present the direction of the effect of uncertainty on the relationship between RFQ and RT, and the two outcomes, goal clarity (GC) and agreement with evaluation criteria (AEC).

Table 7.4 Overview of results; comparing the effects of RFQ and RT

\begin{tabular}{|c|c|c|c|c|c|}
\hline \multicolumn{2}{|c|}{ Mypotheses } & \multirow{2}{*}{$\begin{array}{l}\text { APM: } \\
\text { variables }\end{array}$} & \multirow[t]{2}{*}{ outcome variables } & \multicolumn{2}{|c|}{ Dimensions of RAPM } \\
\hline EU & TU & & & RFO & RT \\
\hline 46a & & RFQ \& RT & GC & + (ns) & $-(n s)^{a}$ \\
\hline \multirow[t]{3}{*}{$\mathrm{H} 6 \mathrm{~b}$} & & RFQ \& RT & AEC & $-(n s)^{a}$ & $+(n s)^{a}$ \\
\hline & $\mathrm{H} 7 \mathrm{a}$ & RFQ \& RT & GC & $-(n s)^{a}$ & $+(n s)^{a}$ \\
\hline & $\mathrm{H} 7 \mathrm{~b}$ & RFQ \& RT & AEC & $+(s)^{a}$ & $-(s)$ \\
\hline
\end{tabular}

a. This hypothesis was formulated in the null-form.

As these results indicate, our expectations are only partially supported. Although a comparison of the direction of the effects of RFQ and RT suggest that they have a different impact on the two outcome variables $\mathrm{GC}$ and $\mathrm{AEC}$, most of these relationships are not statistically significant. This is true for the two hypotheses formulated in the exploratory null-form ( $\mathrm{H} 6 \mathrm{~b}$ and $\mathrm{H} 7 \mathrm{a}$ ), as well as for the hypothesis concerning EU and 


\section{CHAPTER 7 SUMMARY AND CONCLUSIONS}

$\mathrm{GC}(\mathrm{H} 7 \mathrm{a})$. The latter finding implies that we cannot confirm that the positive effect of $\mathrm{EU}$ on the relationship between RAPM and $\mathrm{GC}$ (see $\mathrm{Hla}$ ) is the result of using accounting information. Although the positive sign is supportive, the effects found are not statistically significant.

For the other directional hypothesis $(\mathrm{H} 7 \mathrm{~b})$ the findings do suggest a significant effect of task uncertainty (TU) on the relationships between RFQ and RT and AEC. This finding implies, in conformity with our expectation, that for higher levels of task uncertainty the use of preset targets results in less agreement with the evaluation criteria used. It also implies that for higher levels of task uncertainty the use of financial and quantitative performance measure enhances managers' agreement with evaluation criteria. Although this latter effect was not expected, it does provide some evidence that the inappropriateness of APM is a consequence of the use of targets, rather than of the use of accounting information as such.

The latter finding may also provide some further insight in our earlier failure to find an effect of TU on the relationship between RAPM and AEC (H2b), since the results for Hypothesis $7 \mathrm{~b}$ suggests that $\mathrm{TU}$ has a different and opposite effect on the appropriateness of using preset targets, and the appropriateness of using financial and quantitative (accounting) information for performance evaluation.

\section{Conclusions}

Based on these findings, we draw the following conclusions. Overall, we believe that the issue of the multi-dimensionality of the RAPM construct is not settled [Briers and Hirst 1990; Brownell and Dunk 1991]. Although our results suggest that different effects of uncertainty on the appropriateness of RFQ versus RT may exist, the lack of significance requires caution when drawing general conclusions. This caution is also warranted given our earlier finding of a positive and significant correlation between RFQ and RT in Chapter 5. Although this correlation may have been caused by measurement error (see below), it may also indicate that financial and quantitative information and targets are in fact always used jointly. If so, the concern expressed in the APM literature regarding the multi-dimensionality of RAPM may not have been warranted. However, we did find support for different effects of task uncertainty on the relationships between RFQ and $\mathrm{RT}$, and AEC. This finding may not only explain our failure to find an effect of task uncertainty on the relationship between RAPM and AEC earlier, but it also supports the relevance of our decomposition of the RAPM construct. Substantively, it suggests that negative consequence of using APM are caused by using preset targets, rather than by using accounting information as such.

\subsubsection{Meaning and measurement of 'appropriateness' of APM}

\section{Summary of findings}

Our first direction of inquiry, concerning the meaning and measurement of the 'appropriateness of APM' concept did not result in the development of separate 
hypotheses. Our summary of findings below therefore uses the results already presented above to specifically compare the results for the three criterion variables used: goal clarity (GC); agreement with evaluation criteria (AEC), and; felt appropriateness of accounting performance measure (FAAPM).

Table 7.5 below presents a summary of the relevant results concerning the two outcome variables (GC and $\mathrm{AEC}$ ). In particular, in this table we present the sign of the interaction effect between the context variables (EU, TU and TFA) and the APM variables on the two outcome variables $\mathrm{GC}$ and $\mathrm{AEC}$. $^{2}$

Table 7.5 Overview of results; comparing the appropriateness of APM in terms of GC and $A E C$

\begin{tabular}{|c|c|c|c|c|c|}
\hline \multicolumn{2}{|c|}{ Hypotheses: } & \multirow{2}{*}{$\begin{array}{l}\text { Context } \\
\text { rariables }\end{array}$} & \multirow{2}{*}{ Aplyaniables } & \multicolumn{2}{|c|}{ Effects on two outcome variables } \\
\hline GC & AEC & & & 60 & AEC \\
\hline H1a & $\mathrm{H}+\mathrm{b}$ & EU & RAPM & $+(s)$ & $-(n s)$ \\
\hline $\mathrm{H} 2 \mathrm{a}$ & $\mathrm{H} 2 \mathrm{~b}$ & TU & RAPM & $-(n s)$ & + (ns) \\
\hline H3a & $\mathrm{H} 3 \mathrm{~b}$ & TFA & RAPM & $-(s)$ & + (ns) \\
\hline $\mathrm{H} 6 \mathrm{a}$ & $\mathrm{H} 6 \mathrm{~b}$ & EU & $\begin{array}{l}\text { RFQ } \\
\text { RT }\end{array}$ & $\begin{array}{l}+(n s) \\
-(n s)^{a} \\
\end{array}$ & $\begin{array}{r}-(n s)^{a} \\
+\quad(n s)^{a} \\
\end{array}$ \\
\hline $\mathrm{H} 7 \mathrm{a}$ & $H 7 b$ & $\mathrm{TU}$ & $\begin{array}{l}\text { RFQ } \\
\text { RT }\end{array}$ & $\begin{array}{l}-(n s)^{a} \\
+(n s)^{a}\end{array}$ & $\begin{array}{l}+(s)^{a} \\
-(s)\end{array}$ \\
\hline
\end{tabular}

a. This hypothesis was formulated in the null-form.

The results in this table indicate that in all cases the directions of the relationships between the context variables and $A P M$ variables and, respectively, GC and $A E C$ are opposite. This provides some support for our arguments concerning the combined use of AEC and GC for testing the appropriateness of APM. ${ }^{3}$ Note however that for several relationships no directional hypothesis was formulated, and that several findings of directions are not statistically significant. The latter appears to be especially true for the hypotheses in which AEC was the dependent variable. We only found a statistically significant negative effect for the interaction between TU and RT (H7b).

Besides differences in findings concerning GC and AEC, which were for the larger part expected, our findings also suggest the existence of differences between the appropriateness of APM in terms of outcomes (GC and AEC), and in terms of managers' opinions (FAAPM). To allow an explicit comparison of such differences in finding, the relevant results are summarized in Table 7.6 below. In the last three columns, the result: of the tests are presented for GC, AEC and FAAPM. 
CHAPTER 7 SUMMARY AND CONCLUSIONS

Table 7.6 Overview of results; comparing results for outcome and opinion variables

\begin{tabular}{|c|c|c|c|c|c|c|}
\hline \multicolumn{2}{|c|}{ Hypotheses } & \multicolumn{2}{|r|}{ Gontext } & \multicolumn{2}{|c|}{ outcones } & \multirow{2}{*}{$\begin{array}{l}\text { Opinion } \\
\text { FAAPN }\end{array}$} \\
\hline $\mathrm{GC}$ & $\mathrm{AEC}$ & FAAPM & & 66 & AEC & \\
\hline Hla & $\mathrm{H} 1 \mathrm{~b}$ & $\mathrm{H} 1 \mathrm{c}$ & EU & $+(s)$ & $-(\mathrm{ns})^{3}$ & $+(s)$ \\
\hline $\mathrm{H} 1 \mathrm{~b}$ & $\mathrm{H}_{2 \mathrm{~b}}$ & $\mathrm{H} 2 \mathrm{C}$ & TU & $-(n s)^{a}$ & \pm (ns) & $-(s)$ \\
\hline HIc & $\mathrm{H} 2 \mathrm{c}$ & $\mathrm{H} 3 \mathrm{C}$ & TFA & $-(s)$ & $+(n s)$ & $-(s)$ \\
\hline $\mathrm{H} 4 \mathrm{a}$ & $\mathrm{H} 4 \mathrm{~b}$ & $\mathrm{H} 4 \mathrm{C}$ & EU \& TFA & $+(s)^{b}$ & $+(n s)^{a c}$ & $-(s)$ \\
\hline $\mathrm{H} 5 \mathrm{a}$ & $\mathrm{H} 5 \mathrm{~b}$ & $\mathrm{H} 5 \mathrm{c}$ & TU \& TFA & $+(n s)^{c}$ & $-(s)^{b}$ & $+(s)$ \\
\hline
\end{tabular}

a. This hypothesis was formulated in the null-form.

b. See Appendix $L$ for a further examination of this finding.

c. For this relationship, the model was insignificant.

As the table shows, statistically significant results were obtained for all relationships between the contextual variables and FAAPM ( $\mathrm{Hlc}, \mathrm{H} 2 \mathrm{c}, \mathrm{H} 3 \mathrm{c}, \mathrm{H} 4 \mathrm{c}, \mathrm{HSc})$. Furthermore, the effects found were in the expected direction. However, as noted already before, the effects found in terms of outcomes and opinions do not always show consistency. A discrepancy exists for TU, which has a significant effect on FAAPM, which cannot be explained in terms of $\mathrm{GC}$ or $\mathrm{AEC}(\mathrm{H} 2 \mathrm{c}$ versus $\mathrm{H} 2 \mathrm{a}$ and $\mathrm{H} 2 \mathrm{~b}$ ). The same holds for the hypotheses concerning EU and TFA (H4c versus $\mathrm{H} 4 \mathrm{a}$ and $\mathrm{H} 4 \mathrm{~b}$ ), and conceming TU and TFA ( $\mathrm{H} 5 \mathrm{c}$ versus $\mathrm{H} 5 \mathrm{a}$ and $\mathrm{H} 5 \mathrm{~b}$ ). In contrast, for the hypotheses concerning $\mathrm{EU}$ ( $\mathrm{H} 1 \mathrm{c}$ versus $\mathrm{Hla}$ and $\mathrm{H} 1 \mathrm{~b}$ ), and for the hypotheses concerning TFA ( $\mathrm{H} 3 \mathrm{c}$ versus $\mathrm{H} 3 \mathrm{a}$ and $\mathrm{H} 3 \mathrm{~b}$ ) we did find consistency between the effect of uncertainty on the appropriateness of APM in terms of opinions and in terms of outcomes.

\section{Conclusions}

Based on these analyses, we draw the following conclusions. First, we generally conclude that the operationalization of "appropriateness" and its subsequent empirical measurement are critical. Not only did we find (expected) differences between the two outcome variables, but also did we find some (unexpected) differences between appropriateness in terms of outcomes, and in terms of opinions. Second, we believe that our focus on the two outcome variables chosen enriches our understanding of the appropriateness of APM under uncertainty. In particular, we feel that the explicit test of the effects of using APM on goal clarity is important, and may explain inconsistencies in earlier APM studies; especially since our findings generally illustrate that uncertainty positively affects the relationship between RAPM and managerial goal clarity. " Our focus on agreement with evaluation criteria also has been useful, even if for the opposite reason. Overall, the results concerning this variable seem to only partially confirm the relevance of the issue of 'fairness', which commonly underlies expectations about the inappropriateness of APM under uncertainty. In itself this does not imply that "fairness" is irrelevant for performance evaluations (recall our finding a significant negative correlation of RAPM 
and AEC in Chapter 5), but it does suggest that uncertainty does not reduce the fairness of performance evaluations in which APM are used, as generally assumed [e.g., Hirst 1983b; Lau et al. 1995]. Third, we conclude that differences exist between appropriateness of APM in terms of managers' opinions, and in terms of the outcomes of using APM. The noted discrepancy between some of the tests for outcomes and opinions, and the support for all hypotheses about managerial opinions together suggest that uncertainty affects managerial opinions and dispositions more than the factual outcomes.

\subsection{Conclusions and implications}

Based on the analyses above, we draw the following overall conclusions. First, there is no evidence for an overall negative effect of 'uncertainty' on the appropriateness of APM. The use of APM under uncertainty has both positive and negative effects, which can be at least partially described in terms of goal clarity and agreement with evaluation criteria. Second, our study supports that the appropriateness of APM is affected differently by different sources of uncertainty. In particular, higher levels of environmental uncertainty appear to be generally associated with higher appropriateness of APM. Higher levels of task uncertainty appear to be generally associated with lower levels of appropriateness of APM, although the effects found are small. Third, we conclude that the effect of uncertainty on the appropriateness of APM is affected by managers' individual characteristics. Although we do not fully understand the direction of the impact of TFA, our results do support that situational differences and individual differences both contribute to explaining the appropriateness of APM. Fourth, we conclude that tests of the contextual appropriateness of APM are sensitive to the exact way in which 'appropriateness' is defined and measured. We think that our results support the existence of differences between "appropriateness" in terms of managers" opinions, and 'appropriateness' in terms of the outcomes of using APM. Our results clearly support that uncertainty affects managers' opinions about the appropriateness of APM. Our results concerning outcomes are somewhat less clear. This finding is important in itself, since it implies that caution is required in the interpretation of studies that exclusively focus on managers preferences for management accounting information [e.g., Hirst 1983a; Chenhall and Morris 1986; Fisher 1996]. We also conclude that our focus on more 'immediate outcomes' of the use of APM [cf. Briers and Hirst 1990] has been fruitful. In particular, our results provide some explanation of the failure of previous APM studies to detect negative effects of using APM under uncertainty, since some of our results clearly support the positive effect of APM on managerial goal clarity, but show less support for a negative effect on managers' agreement with evaluation criteria.

The following implications should be pointed out. First, our findings suggest that management control frameworks should be extended to include the need for controls. In Chapter 1 , we argued that frameworks that address the contextual appropriateness of 


\section{CHAPTER 7 SUMMARY AND CONCLUSIONS}

controls generally emphasize the feasibility of controls, with a lack of knowledge about cause-effect relationships, and a lack of clear goals hindering the use of formal controls such as APM [e.g., Ouchi 1979]. Such frameworks, however, focus on performance evaluation as a problem of the superior. They do not explicitly recognize that these consequences of uncertainty may simultaneously enhance the need for formal control for the individual subordinate manager.

Second, our results do enhance our understanding of the controllability problem in the management accounting literature, and the associated 'paradox'. Our analyses do not suggest that 'fairness' is the dominant aspect of this problem. Furthermore, for as far as 'fairness' is a relevant consideration, it should not be seen in isolation, but in combination with the overall purposes of budgets in terms of planning, coordination and target setting. In other words, although uncertainty may enhance the problems associated with the ideal of using only fair and controllable performance criteria, our results concerning goal clarity suggest that APM are particularly useful for overcoming 'managerial control problems', for as far as they are caused by managers lacking clear and specific targets in their jobs. This may be an alternative explanation why in practice the controllability principle is not strictly applied [Merchant 1989; Otley 1990, p. 115]. Furthermore, it may explain Hirst's paradox [1983a] concerning the pervasiveness of using apparently 'inappropriate' performance criteria in decentralized, complex and uncertain environments. Our explanation is that a positive balance may exist of the individual negative ("faimess') and positive ("clarity") effects of APM in such situations. In other words, managers may prefer the clarity and specificity of APM, and may take the lower agreement with the performance criteria for granted.

A final and practical implication is that the demand for subjective performance evaluations under higher levels of uncertainty is not unconditionally valid. In particular, our findings imply that the choice of appropriate performance criteria requires not only a specific assessment of the situation in terms of the kinds of uncertainty faced, but also suggest that these criteria need to be tailored to individual managerial characteristics.

\subsection{Strengths and weaknesses of this study}

To be able to evaluate the findings, conclusions and implications from this study better, we pay attention here to what, in our view, are the strengths and weaknesses of the current study. First, in the design of this study we have chosen to adopt methods for data collection and data analysis that are well established in APM research. This reflected our aim to refine and extend APM theory, rather than to advance empirical or analytical method, and to warrant the comparability of findings. However, a consequence of this focus may have been the inheritance of some weaknesses associated with these methods as well. The prime method of data collection in this study was a survey using questionnaires. Therefore, some problems regarding internal and external validity associated with this method may also apply to our study. This may in particular be the case for the 'common-method' problem, associated with the use of a single questionnaire 
using self-reporting measures [e.g., Collins 1978; Salancik and Pfeffer 1977; Podsakoff and Organ 1986]. The common-method problem originates in respondents' tendency to provide "consistent' and 'socially desirable" answers, which may cause the relationships to be overstated and even to be artificial [e.g., Salancik and Pfeffer 1977, pp. 447-448; Podsakoff and Organ 1986, pp. 533-536]. Overall, we believe that the care taken in the design of the empirical study, in obtaining the sample of respondents, in the design and pretests of the questionnaire, and in the follow-up procedures may have provided effective controls against many reliability and validity threats normally associated with survey research [cf. Young 1996]. In addition, we think that the high response rate, the overall high reliability of the measurement instruments, and the size of the sample all compare favorably to many previous APM studies. Also, we believe that the commonmethod problem does not provide a serious threat to our results. Since most of our hypotheses concerned interactions between independent variables, we think that it is unlikely that respondents would be able to systematically bias these complex patterns. ${ }^{5}$

Second, in conformity with most of prior APM studies, the sampling method used in this study is not random. This requires some care in the interpretation of the findings, as well as caution when drawing conclusions about their generalizability. However, we believe that the sampling procedures taken were warranted, especially since additional selection criteria were required to reach the intended (target) population. In addition, we believe that the diversity of the sample, with managers in various functions, and from various types of organizations positively contributes to the generalizability of our findings. Third, the results of many studies in budgetary control are not encouraging in terms of parsimony. Some of the results reported in this study are no exception. In general, this means that a discrepancy exists between the statistical significance of our findings and their substantive importance. Therefore, and because the theories tested are necessarily partial, care should be taken in inferring practical consequences from the results. In addition, it should be noted that our testing procedures are concerned with relationships and cannot establish causality. ${ }^{6}$ However, we believe that the results from this study are practically important in the following respects. As we already noted as a 'practical implication', some results provide an explicit challenge to, and falsification of, much 'commonly held beliefs' about the contextual appropriateness of budgeting and using APM. We believe that especially our examination of different sources of uncertainty, different outcomes of using APM, and the focus on both opinions and outcomes provide a relevant refinement to the practical debate as well. In addition, the study and the results provide evidence as to the variables that matter in designing and using control systems, and the complexity of their interrelations. In this sense, our evidence supports that managers' personality is an important factor that needs to be considered in management control design and use. Finally, despite the general high reliability of the instruments used, we are somewhat concerned with the measurement of some specific variables. For TFA, the reliability of its measurement is disappointing, especially when considering the number of items in the instrument [cf. Cortina 1993]. Although we have used TFA in a dichotomous format for testing the hypotheses, its relatively low reliability may still have had an impact on our findings. Also, we are 


\section{CHAPTER 7 SUMMARY AND CONCLUSIONS}

somewhat concerned about the measurement of the 'new' RFQ and RT variables. Although their measurement was reliable, and although some correlation between the two variables was to be expected, it may be possible that our measurement has not reflected their conceptual distinctiveness. ${ }^{7}$

\subsection{Suggestions for further research}

Evaluating the results and implications of our study, as well as its strengths and weaknesses we suggest that the following directions for further research are worth exploring.

First, we see chances for advancement by a further development of contingency theory. Our findings suggest that the results of this and previous APM studies are sensitive to the exact formulation of contingency expectations. We already suggested that such further development could be done by paying more explicit attention to the advantages and disadvantages of using APM in different organizational settings. In addition, such further development could more specifically address the level of analysis and the associated 'appropriateness' of using APM. In this study, we examined 'appropriateness' in terms of subordinate's attitudes and responses. An alternative level of analysis would be the superior, and a related question would be whether superiors" evaluative behaviors can be explained in terms of contextual 'appropriateness'. Such more comprehensive contingency frameworks may lead to a better understanding of the diversity of roles that APM play in the (control) relationship between superiors and subordinates. In particular they would allow an explicit integration of attempts to better explain the use of APM, and attempts to provide practical recommendations for using APM.

Second, we think that our results support the need for constructive replication studies [cf. Lindsay 1995], especially for the hypotheses that were not confirmed, or for which we found inconsistent effects. Although the APM literature is one of the few areas in management accounting where replication studies have been conducted, we also noted that those studies generally failed to support earlier findings. In particular, we think that there is a great role for further constructive replications. These are more than mere repetitions, in that their investigations are lead by theory, rather than by the mere motivation to fill "gaps" [cf. Otley 1980; Briers and Hirst 1990]. As for future constructive replication of the findings in this study we think that exploring the role of managers' personality is particularly fruitful. Future studies could focus on TFA using alternative instruments, or could focus on alternative concepts that address personal attitudes toward uncertainty. Advances can also be made in terms of a further exploration of the 'uncertainty' and 'APM' variables. For uncertainty, future studies may explore different and alternative dimensions of uncertainty, or may facus more on the objective and physical characteristics of the job and environment. These latter developments are especially important when the aim is to design, rather than explain, contextually appropriate accounting systems. Concerning APM, we think a further exploration of its 


\section{ACCOUNTING FOR PERFORMANCE EVALUATION}

dimensions may be fruitful. This could be done by a replication of the dimensions explored in this study, with other and perhaps more accurate measurement instruments. Alternatively, such further examination could focus, in more detail than is usual in APM research, on the precise information elements contained in budgets ('what elements do organizations choose to budget?'), and their subsequent relative importance for managerial performance evaluation ("which of these elements are emphasized for individual performance assessments? "). Such a more detailed exploration could also reveal whether and how the role of 'traditional' budgets, and their use for managerial performance evaluation in particular, is changing as a result of recent, but apparently persistent, calls for innovation of the techniques used for management accounting and control [e.g., Kaplan 1994; Bromwich and Bhimani 1994].

Finally, we believe that these two directions for further research may eventually require the development and test of more comprehensive research models. The current study was motivated by the attempt to refine and extend APM theory in four specific directions, which implied a focus on several specific and individual relationships. Consequently, we adopted methods for data analysis that can be considered as "best practice' in APM research, and that were appropriate for this aim. However, further developments in APM and budgetary control theory, as outlined, should eventually be directed toward integration of individual findings and the development of a 'more cohesive body of knowledge' [Young 1996, p. 55]. ${ }^{8}$ Such further development and integration of APM and budgetary control theory would also have to imply the adoption of a more advanced level of data analysis, facilitating the simultaneous examination of several relationships that have, to date, been tested only individually in APM research." 


\section{Notes to Chapter 7:}

1. Recall from Chapter 6 that our decision to accept a (moderating) effect as 'significant" is based on statistical criteria. We decided to also present the sign of "insignificant" (moderating) effects in this chapter mainly to provide a complete summary and illustration of our findings.

2. To limit the complexity of our analysis at this stage, we only present the results for the hypotheses that were tested using two-way interaction models. Note that three-way interactions reflect differences between two-way interaction (see Appendices $\mathrm{K}$ and $\mathrm{L}$ ), which causes the interpretation of the sign of the three-way interaction to be different. In particular, the sign of the three-way interaction does not contain information about differences in the direction of the effect between the independent variables and goal clarity and agreement with evaluation criteria.

3. Note that our remark addresses the pattern of signs [cf. Merchant 1984, p. 303], thereby referring to statistically insignificant results as well.

4. Recall also that we found a significant and positive relationship between RAPM and goal clarity in Chapter 5 .

5. In Podsakoff and Organ [1986] the common-method problem is therefore in particular associated with using "simple" bivariate relationships. In this study, we have tested bivariate relationships only for the three hypotheses concerning FAAPM ( $\mathrm{Hla}, \mathrm{Hlb}, \mathrm{Hlc})$. Also in these three cases we feel that potential common-method effects may have been effectively controlled. First, we have chosen a "neutral' order of the items in the questionnaire [cf. Salancik and Pfeffer1977, p. 448; Podsakoff and Organ 1986, p. 540]. Second, in the wording of the questionnaire, no hint was made to the theory to be tested, nor to "uncertainty' as the central concept of interest, nor did we refer to any of the instruments by its "variable label" Third, differences in results between the three uncertainty variables do not support the existence of an underlying systematic pattern of responses to "uncertainty'.

6. Therefore, causality in this study (and in APM research in general) is mainly implied by theory, which states that RAPM and uncertainty "cause" job-related attitudes and opinions. The possibility cannot be excluded that job-related attitudes also 'cause' respondents' perceptions of RAPM and uncertainty [e.g., Salancik and Pfeffer 1978]. Note, however, that the 'reverse' hypothesis is more easily established for simple bivariate relationships than for the more complex interactions in this study. Note also the "weighty philosophical problems" associated with the causation concept [e.g., Davis 1985, p. 8].

7. Since both RFQ and RT were measured with a single "budget-related" questionnaire, respondents may have perceived them as both 'budget-related', and may not have seen them as separate dimensions. This, therefore, may be an illustration of the common-method problem mentioned earlier.

8. Young $[1996$, p. 55] notes the fact that '... 25 years of survey research has yet to yield a cohesive body of knowledge about management accounting and control practices within and across industries and nations:

9. Note that the adoption of such more advanced methods for data analysis [e.g., LISREL] has been very limited so far in budgetary control research [see, for an example, Jaworski and 
ACCOUNTING FOR PERFORMANCE EVALUATION

Young 1992]. 
Appendices 


\section{Appendix A \\ Overview of APM studies concerning uncertainty}

Table A.1 below presents an overview of studies that have addressed the impact of uncertainty on the appropriateness of APM. As we discussed in Chapter 3, in the majority of studies hypotheses are developed predicting a negative effect of uncertainty on the appropriateness of APM. Below, for each of the studies some key characteristics are given. The last column summarizes the results of the study. We report the support for the relationships investigated as claimed by the authors, and add our comments to these results as separate notes below the table.

Table A.1 Overview of findings in empirical APM research using uncertainty as a contextual factor

\begin{tabular}{|c|c|c|c|}
\hline Author & $\begin{array}{l}\text { Sample } \\
\text { (number of } \\
\text { organizations) }\end{array}$ & $\begin{array}{l}\text { Uncertainty affects the } \\
\text { appropilateness of APM } \\
\text { through. (direction) }\end{array}$ & $\begin{array}{l}\text { Criterion for appropriateness of } \\
\text { using APM (results claimed) }\end{array}$ \\
\hline Hirst [1983b] & $\begin{array}{l}111 \text { functional } \\
\text { managers } \\
\text { (not reported) }\end{array}$ & $\begin{array}{l}\text { controllability, } \\
\text { completeness } \\
\text { (negative) }\end{array}$ & $\begin{array}{l}\text { job-related tension (support } \\
\text { relations with superior (no support) }\end{array}$ \\
\hline $\begin{array}{l}\text { Govindarajan } \\
{[1984]}\end{array}$ & $\begin{array}{l}58 \text { SBU managers } \\
(18)\end{array}$ & $\begin{array}{l}\text { completeness, relevance } \\
\text { (negative) }\end{array}$ & use of APM (supportit) \\
\hline $\begin{array}{l}\text { Merchant } \\
{[1984]}\end{array}$ & $\begin{array}{l}170 \text { manufacturing } \\
\text { managers } \\
\text { (19) }\end{array}$ & $\begin{array}{l}\text { controllability } \\
\text { (negative) }\end{array}$ & $\begin{array}{l}\text { use (partial support) } \\
\text { job performance (no support) }\end{array}$ \\
\hline $\begin{array}{l}\text { Brownell } \\
{[1985]}\end{array}$ & $\begin{array}{l}66 \text { R\&D and marketing } \\
\text { managers } \\
\text { (1) }\end{array}$ & $\begin{array}{l}\text { completeness } \\
\text { (negative) }\end{array}$ & job performance (no support) \\
\hline $\begin{array}{l}\text { Govindarajan } \\
\text { and Gupta } \\
{[1985]}\end{array}$ & $\begin{array}{l}\text { see Govindarajan [1984] } \\
46 \text { responses used } \\
\text { (not reported) }\end{array}$ & $\begin{array}{l}\text { controllability, } \\
\text { completeness, relevance } \\
\text { (negative) }\end{array}$ & $\begin{array}{l}\text { use of APM (no support) } \\
\text { SBU performance (support) }\end{array}$ \\
\hline $\begin{array}{l}\text { Brownell and } \\
\text { Hirst [1986] }\end{array}$ & $\begin{array}{l}76 \text { functional managers } \\
\text { (1) }\end{array}$ & $\begin{array}{l}\text { replication and integration } \\
\text { of Hirst [1983b] and } \\
\text { Brownell [1982b] } \\
\text { (negative) }\end{array}$ & job-related tension (no support') \\
\hline $\begin{array}{l}\text { Brownell } \\
\text { [1987a] }\end{array}$ & $\begin{array}{l}50 \text { functional managers } \\
\text { (1) }\end{array}$ & $\begin{array}{l}\text { replication of Brownell } \\
\text { [1985] } \\
\text { (negative) }\end{array}$ & $\begin{array}{l}\text { job performance (support) } \\
\text { job satisfaction (support) }\end{array}$ \\
\hline $\begin{array}{l}\text { Macintosh and } \\
\text { Daft [1987] }\end{array}$ & $\begin{array}{l}90 \text { functional managers } \\
(20)\end{array}$ & $\begin{array}{l}\text { need for coordination } \\
\text { (positive) }\end{array}$ & use of APM (support) \\
\hline $\begin{array}{l}\text { Govindarajan } \\
\text { [1988]: }\end{array}$ & $\begin{array}{l}121 \text { SBU managers } \\
(24)\end{array}$ & $\begin{array}{l}\text { Controllability, } \\
\text { completeness, relevance } \\
\text { (negative) }\end{array}$ & SBU performance (support) \\
\hline Imoisill [1989] & $\begin{array}{l}102 \text { cost center } \\
\text { managers } \\
(3)\end{array}$ & $\begin{array}{l}\text { contrallability } \\
\text { (negative) }\end{array}$ & $\begin{array}{l}\text { job-related tension (no support) } \\
\text { job performance (no support) } \\
\text { attitudes toward budget (no support) }\end{array}$ \\
\hline
\end{tabular}


APPENDICES

\begin{tabular}{|c|c|c|c|}
\hline Author & $\begin{array}{l}\text { Sample } \\
\text { (number of } \\
\text { organizations) }\end{array}$ & $\begin{array}{l}\text { Uncertality affects the } \\
\text { appropriateness of APM } \\
\text { through (direction) }\end{array}$ & $\begin{array}{l}\text { Criterion for appropriateness of } \\
\text { using AP M (resuls clained) }\end{array}$ \\
\hline $\begin{array}{l}\text { Ezzamel } \\
\text { [1990] }\end{array}$ & $\begin{array}{l}81 \text { managers } \\
(81)\end{array}$ & $\begin{array}{l}\text { need for formal } \\
\text { communication } \\
\text { (positive) }\end{array}$ & use of APM (support) \\
\hline $\begin{array}{l}\text { Merchant } \\
{[1990]}\end{array}$ & $\begin{array}{l}54 \text { profit center } \\
\text { managers } \\
\text { (1) }\end{array}$ & $\begin{array}{l}\text { controllability } \\
\text { completeness } \\
\text { (negative) }\end{array}$ & $\begin{array}{l}\text { dysfunctional behavior (partial } \\
\text { supportt") }\end{array}$ \\
\hline $\begin{array}{l}\text { Williams of al } \\
\text { [1990] }\end{array}$ & 201 managers (22) & $\begin{array}{l}\text { need and feasibility of } \\
\text { formal communication } \\
\text { (exploratory, no direction) }\end{array}$ & job performance (support ${ }^{\text {td }}$ ) \\
\hline $\begin{array}{l}\text { Brownell and } \\
\text { Dunk [1991] }\end{array}$ & $\begin{array}{l}79 \text { functional managers } \\
(46)\end{array}$ & $\begin{array}{l}\text { replication of Brownell and } \\
\text { Hirst [1986] } \\
\text { (negative) }\end{array}$ & job performance (no support') \\
\hline Ross [1995] & $\begin{array}{l}215 \text { responsibility center } \\
\text { managers } \\
\text { (18) }\end{array}$ & $\begin{array}{l}\text { replication of Hirst [1983b] } \\
\text { (negative) }\end{array}$ & job-related tension (no support) \\
\hline $\begin{array}{l}\text { Lau et al. } \\
\text { [1995] }\end{array}$ & $\begin{array}{l}114 \text { functional } \\
\text { managers } \\
(80)\end{array}$ & $\begin{array}{l}\text { replication of Brownell and } \\
\text { Dunk [1991] } \\
\text { (negative) }\end{array}$ & $\begin{array}{l}\text { job-related tension (no support) } \\
\text { job performance (no support) }\end{array}$ \\
\hline
\end{tabular}

\section{Comments:}

a. No support was found for the initially expected curvilinear effect of uncertainty. Furthermore, in testing the interaction model, no main effects were included [see Appendix $\mathrm{K}$ for a discussion].

b. This support is claimed by the authors, based on differences between correlation coefficients in two subgroups [see Appendix $\mathrm{K}$ for a critique on this way of analyzing contingency hypotheses].

c. These results relate to a two-way interaction (uncertainty $\times$ RAPM) included in the regression equation used to test a three-way interaction (RAPM uncertainty $x$ budget participation). See for the validity of this interpretation Appendix K.

d. This study was exploratory, the authors claim support for the existence of different relationships between the use of APM and performance for different levels of uncertainty. The 'support' thus here means support for the relation between the use of APM and performance being contingent on the level of uncertainty. 


\section{Appendix B \\ Overview of the accounting literature concerning TFA}

Table B. 1 below presents an overview of studies in accounting and auditing that have used the TFA construct for hypotheses about differences in preference for, and use of information.

Table B.1 Overview of effects of TFA found in accounting research

\begin{tabular}{|c|c|c|}
\hline Author: & Finding: & \\
\hline Demer [1973] & $\begin{array}{l}\text { type: } \\
\text { amount: }\end{array}$ & $\begin{array}{l}\text { low-TFA's prefer "current" and 'financial' information } \\
\text { no differences }\end{array}$ \\
\hline McGhee ot al. [1978] & $\begin{array}{l}\text { amount: } \\
\text { effect: }\end{array}$ & $\begin{array}{l}\text { no differences } \\
\text { no differences }\end{array}$ \\
\hline Oliver and Flamholtz [1978] & $\begin{array}{l}\text { type: } \\
\text { amount: }\end{array}$ & $\begin{array}{l}\text { low-TFA's accept accounting info better than high-TFA's } \\
\text { no differences }\end{array}$ \\
\hline Faircloth and Ricchiute [1981] & amount: & no differences \\
\hline Gul [1984] & effect: & $\begin{array}{l}\text { TFA interacts with 'field dependence' to affect decision } \\
\text { confidence, no direct effect of TFA. }\end{array}$ \\
\hline Gull [1986] & effect: & $\begin{array}{l}\text { TFA interacts with 'Uncertainty' to affect decision confidence, no } \\
\text { direct effect of TFA }\end{array}$ \\
\hline Pincus [1990] & effect: & no differences \\
\hline
\end{tabular}




\section{Appendix C \\ Overview of differences in RAPM measurement}

In this appendix we provide an additional illustration of the variety of instruments to measure RAPM in APM research. Our illustration here is not limited to studies specifically investigating the effects of uncertainty on the appropriateness of RAPM, but instead relates to the whole APM paradigm. The overview is confined to the two most influential instruments, the instrument originally developed and used by Hopwood [1972] and measures for RAPM derived from the Budget-Related Behavior questionnaire, which originates in DeCoster and Fertakis [1968]

\section{Measures of RAPM originating from the Hopwood [1972] instrument}

Table C.1 below an overview is presented of the various uses of the Hopwood [1972] in APM research. The second column indicates the number of items in the instrument. The figure in brackets indicates the number of items used in the calculation of the ultimate RAPM scores. The third and fourth column show the connection between items and final scores. The accounting related items in the measurement instrument are coded as follows:

$\mathrm{B}=$ 'meeting the budget",

$\mathrm{C}=$ 'concern with costs',

$E=$ "how efficiently I run my unit',

$\mathrm{P}=$ 'how much profit I make', and,

$\mathrm{R}=$ 'concern with costs or revenues".

Table C.1 Studies using the Hopwood [1972] instrument

\begin{tabular}{|c|c|c|c|}
\hline Author & $\begin{array}{l}\text { Number } \\
\text { of thems }\end{array}$ & RAPH variable is based on. & $\begin{array}{l}\text { RAPM measure used in } \\
\text { statistical analysis }\end{array}$ \\
\hline Hopwood [1972] & 8 & $B$ and $C$ in top 3 & three classes (nominal) \\
\hline Hopwood [1972] & $8(1)$ & absolute B score & ordinal (range $1-5$ ) \\
\hline Otley [1978] & 8 & $B$ and $P$ in top 3 & five classes (ordinal) \\
\hline Brownell [1982] & 8 & B and $C$ in top 3 & two classes (high/low) \\
\hline Brownell [1985, 1987a] & $8(2)$ & sum of absolute $B$ and $C$ scores & ordinal (range $2-10$ ) \\
\hline Brownell and Hirst [1986] & 10 & $B$ and $R$ in top 4 & two classes (high/low) \\
\hline Brownell and Dunk [1991] & $8(2)$ & sum of absolute $B$ and $C$ scores & ordinal (range 2-14) \\
\hline Govindarajan [1988] & 8 & $B$ and $E$ in top 3 & five classes (ordinal) \\
\hline Imoisili [1989] & 8 & sum of absolute $B$ and $C$ scores & two classes (high/low) \\
\hline Harrison [1992, 1993] & 10 & $\begin{array}{l}\text { sum of } \mathrm{B} \text { and } \mathrm{R} \text { scores, divided by } \\
\text { summed scores on other eight items }\end{array}$ & $\begin{array}{l}\text { ordinal (range } 0.2-5 \text { after } \\
\text { standardization) }\end{array}$ \\
\hline Ross $[1994,1995]$ & 8 & $\mathrm{~B}$ and $\mathrm{P}$ in top 3 & three classes (nominal) \\
\hline Lau et al. [1995] & $10(2)$ & sum of absolute $\mathrm{B}$ and $\mathrm{C}$ scores & ordinal (range 2-14) \\
\hline Lau ef al [1995] & $10(1)$ & absolute B score & ordinal (1-7) \\
\hline
\end{tabular}


Measures originating from the Budget-Related Behavior (BRB) instrument The BRB-instrument was originally developed by DeCoster and Fertakis [1968] as a 97 item scale to measure the single and unidimensional construct budget induced pressur The 97 questions in this scale reflect actions that subjects take in response to budgt requirements, which were regarded indicative of the amount of budget pressur experienced by those subjects. As DeCoster and Fertakis [1968, p. 240] note:

'The 97 questions were based upon the hypothesis that the more the [subject] dae in response to perceived or actual sent role expectations [i.e., the budg requirements] [...], the more pressure he will feels.

The instrument was changed by Swieringa and Moncur [1975] into a 44-item scale fo the measurement of budget-related behovior. As a consequence, the budget relate actions that, in the original scale, were regarded a proxy for budget-induced pressur, now became the object of measurement themselves. As these actions, however, relate 1 a whole number of budgeting aspects, the use of this instrument in RAPM researc typically applies factor-analysis to 'extract' RAPM variable scores for subsequent use hypothesis testing. An overview of the use of this instrument in RAPM research presented in Table C.2 below.

Table C.2

RAPM-measures originating in the BRB-instrument

\begin{tabular}{|l|c|c|l}
\hline author & Items & factors & RAPM-related Items and their factorinterpretation \\
\hline Bruns and Waterhouse [1975] & 44 & 13 & $4:$ 'evaluation by the budget' \\
\hline Kenis [1979] & 26 & 6 & $\begin{array}{l}\text { 4: 'evaluation style - general' + } \\
\text { 6: 'evaluation style - punitive' }\end{array}$ \\
\hline Merchant [1981, 1984] & 42 & 6 & $4:$ 'required explanations of vaniances' \\
\hline Ezzamel [1990] & 14 & 5 & 2: 'budgetary evaluation' \\
\hline Williams ef a1. [1990] & 44 & 10 & $\begin{array}{l}\text { 3: 'evaluation by the budget' + } \\
4: \text { 'required explanation of budget variances' }\end{array}$ \\
\hline
\end{tabular}

This overview shows the existence of differences regarding: (1) the number of items the scale; (2) the number of factors extracted, and; (3) in the labels attached to the factor A closer observation of the factor contents, however, reveals that they are not similar the factor labels seem to indicate. The implications of differences in factor content $f$ the validity of the instrument are, however, never assessed or analyzed. Notab] Merchant [1981, 1984] uses this instrument as a measure of emphasis on meeting t] budget. Yet, two out of the 42 items that directly express budget emphasis do not appe in the extracted factor that is labeled required explanations of variances, as their facto loadings were lower than the 0.40 cut-off point used. 


\section{Appendix D \\ Sample of organizations}

Tables D.1 and D.2 below present descriptive statistics on the participating organizations.

Table D.1 present information on industry, main activity and sector (private and public). Since the companies were promised anonymity, we present the statistics on industry and activity separately from the figures on size. For these latter figures, we present statistics on turnover only for the seven organizations in the private sector.

Table D.1 Sample of participating organizations and managers

\begin{tabular}{|l|l|l|l|c|}
\hline Organization & Sector & Indistry & Uain activity & Sample size \\
\hline A & private & Chemicals & Production & 10 \\
\hline B & private & Consumer electronics & Production & 34 \\
\hline C & private & Consumer electronics & Retail & 27 \\
\hline D & private & Automotive & Production & 15 \\
\hline E & private & Food and drink & Production & 25 \\
\hline F & private & Food and drink & Production & 9 \\
\hline G & private & Electronic office equipment & Production & 24 \\
\hline H & public & City development & Project development & 25 \\
\hline I & public & City council & Governmental services & 15 \\
\hline$ل$ & public & National administration & Legal services & 56 \\
\hline$K$ & public & National government & Defense & 10 \\
\hline Total & & & & 250 \\
\hline
\end{tabular}

Table D.2 Measures of size of participating organizations

\begin{tabular}{|l|c|c|c|c|c|c|}
\hline Measures of size. & mean & std. dev, & median & & range & n \\
\cline { 3 - 7 } & & & & & $\min$ & max \\
\hline Number of employees $(\times 1,000)$ & 39452 & 77084 & 3900 & 275 & 253000 & 11 \\
\hline Tumover $(\times$ Dfl. $1,000,000)$ & 12428 & 22870 & 533 & 137 & 60977 & 7 \\
\hline
\end{tabular}




\section{Appendix $E$ \\ Descriptive statistics on interviews}

Table E.1 below presents statistics on the interviews, held before and after conducting the questionnaire survey. The table indicates both the number of people interviewed, thei functional areas and the interviewing time. The organizations' labels ('A', ' $\mathrm{B}$ ', ' $\mathrm{C}$ ' etc. match those in Table D.1 in Appendix D. Organization $L$ did not participate in th questionnaire survey.

Table E.1 Descriptive statistics on interviews in twelve organizations

\begin{tabular}{|c|c|c|c|c|c|c|}
\hline \multirow{2}{*}{ Organization } & \multicolumn{2}{|c|}{ Intervens } & \multicolumn{2}{|c|}{ before suney } & \multicolumn{2}{|c|}{ after survey } \\
\hline & functional areas & Ipeople & tintervieus & thours & Ifinterviews & thours \\
\hline A & $\begin{array}{l}\text { HRM } \\
\text { control } \\
\text { general management }\end{array}$ & $\begin{array}{l}1 \\
1 \\
1\end{array}$ & $\begin{array}{l}2 \\
1 \\
2\end{array}$ & $\begin{array}{l}3 \\
1 \\
2\end{array}$ & - & $\overline{-}$ \\
\hline $\mathrm{B}$ & $\begin{array}{l}\text { HRM } \\
\text { control } \\
\text { finance \& control }\end{array}$ & $\begin{array}{l}3 \\
2 \\
-\end{array}$ & $\begin{array}{l}4 \\
1 \\
-\end{array}$ & $\begin{array}{l}4 \\
1 \\
-\end{array}$ & $\begin{array}{l}- \\
1\end{array}$ & $\overline{-}$ \\
\hline$c$ & $\begin{array}{l}\text { general management } \\
\text { control }\end{array}$ & $\begin{array}{l}1 \\
1\end{array}$ & $\begin{array}{l}1 \\
2\end{array}$ & $\begin{array}{l}1 \\
3\end{array}$ & $i$ & $\overline{1.5}$ \\
\hline$D$ & control & 1 & 2 & 2 & 1 & 1.5 \\
\hline$E$ & $\begin{array}{l}\text { comporate accounting } \\
\text { marketing } \\
\text { production } \\
\text { control }\end{array}$ & $\begin{array}{l}2 \\
3 \\
1 \\
1\end{array}$ & $\begin{array}{l}2 \\
3 \\
2 \\
1\end{array}$ & $\begin{array}{l}2 \\
3 \\
2 \\
1\end{array}$ & $\frac{-}{-}$ & $\frac{-}{1}$ \\
\hline$F$ & $\begin{array}{l}\text { marketing } \\
\text { control } \\
\text { HRM }\end{array}$ & $\begin{array}{l}1 \\
1 \\
1\end{array}$ & $\begin{array}{l}1 \\
1 \\
2\end{array}$ & $\begin{array}{l}1 \\
1 \\
2\end{array}$ & $\begin{array}{l}- \\
- \\
2\end{array}$ & $\overline{-}$ \\
\hline$G$ & $\begin{array}{l}\text { general management } \\
\text { control } \\
\text { marketing }\end{array}$ & $\begin{array}{l}2 \\
1 \\
1\end{array}$ & $\begin{array}{l}2 \\
- \\
-\end{array}$ & $\begin{array}{l}2 \\
- \\
-\end{array}$ & $\begin{array}{l}1 \\
1 \\
1\end{array}$ & $\begin{array}{l}1 \\
1 \\
1\end{array}$ \\
\hline$H$ & controll & 1 & 2 & 3.5 & 1 & 1 \\
\hline I & finance \& control & 1 & 2 & 2 & 1 & 1 \\
\hline$\sqrt{ }$ & $\begin{array}{l}\text { general management } \\
\text { control }\end{array}$ & $\begin{array}{l}1 \\
1\end{array}$ & 1 & $\begin{array}{l}1 \\
1\end{array}$ & $\overline{1}$ & $-\overline{1.5}$ \\
\hline$k$ & control & 1 & 2 & 2 & 1 & 1.5 \\
\hline L & control & 1 & 2 & 2 & n.a. & n.a. \\
\hline Total & & 31 & 34 & 34.5 & 14 & 16 \\
\hline
\end{tabular}




\section{Appendix F \\ Measurement instruments included in the questionnaire}

Tables F.1 through F.12 below presents the instruments that were included in questionnaire. Each of these tables contains both the Dutch and English version of the items of the instrument. The items are presented in full, whereas the introductory questions are presented in a short format if and when applicable. Items that are reversely coded contain the symbol ' $(\mathrm{R})$ '. Below the items, the answering format for the instrument is given. The final part of each table contains some summary statistics. These statistics have been calculated after correction of the reversed items.

Table F.1 Environmental uncertainty (EU)

1. Invloed op functioneren en prestaties van... - Impact on functioning and performance of..

II. Voorspelbaarheid van (R):... - Predictability of (R)....

a. Gedrag enlof kooppatronen van afnemers of klanten - Behavior and/or buying pattems of customers

b. Gedrag en/of strategieën van concurrenten in de bedrijfstak - Behavior and/or strategies of competitars

c. Technologische ontwikkelingen in uw vakgebied/uw beroep - Technologica/ developments in your profession

d. Gedrag en/of strategieën van leveranciers - Behavior and/or strategies of your suppliers

e. Wettelijke en/of politieke veranderingen - Legal and/or political developments

Source: Govindarajan [1984] and Merchant [1990]

Answering format $\mathrm{l}$ : factor $n . a_{\mathrm{i}}=0$, no $=1$, little $=2$, some $=3$, much $=4$, very much $=5$

Answering format ll: very high $=0$, high $=1$, more or less $=2$, low $=3$, very low $=4$, factor $n . a_{2}=5$

Item-total correlations (range): $-0.0238-0.5193$ (corrected)

Inter-item correlations (range): $-0.1378-0.5396$

Coefficient $\alpha: 0.6988$

Table F.2 Task uncertainty (TU)

a. Mijn taken zijn van dag tot dag hetzelfde - My tasks are the same from day-to-day

b. In het algemeen zou ik mijn werk als "routinematig" willen kenschetsen - In goneral/ would say that may work is faity routhe

c. In het algemeen doen de medewerkers binnen mijn afdeling dagelliks ongeveer hetzelfde werk, op ongeveer dezelfde manier - People in this unit do about the same jab in the same way most of the time

d. In essentie verichten de medewerkers binnen mijn afdeling veel zich herhalende werkzaamheden in hun werk - Basically, unit members pertorm repetitive activities in doing their jobs

e. Mijn eigen taken kennen veel herhalingen - My duties are repetitious

1. Voor het uitvoeren van veel van mijn taken is er een 'bekende weg' - There is a clearly known way to do the major types of work / nomally encounter

g. I k kan bij het uitvoeren van mijn taken goed terugvallen op bekende kennis (handboeken, procedures, advies van anderen etc.) - There is a clearly defined body of knowledge of subject matter which can guide me in doing my work 
h. De utitvoering van mijn taken geschiedt volgens een duidelijke en begrijpelijke volgorde van stappen There is an understandable sequence of steps that can be followed in doing my work

1. Ik kan in mijn werk gebruik maken van bekende stappen, procedures en ervaringen - To do my work, I can rely on established procedures and practices

Source: Withey et al. [1983]

Answering format: fully disagree $=1$, disagree $=2$, neutral $=3$, agree $=4$, fully agree $=5$

Item-total correlations (range): $0.4859-0.6860$ (corrected)

Inter-item correlations (range): $0.2619-0.7929$

Coefficient $\alpha: 0.8689$

Table F.3 Tolerance for Ambigulty (TFA)

a. Als ik vermoed dat een bepaald probleem geen oplossing heeft, vind ik het niet de moeite waard er verder aandacht aan te besteden - A problem has little attraction for me if I don't think it has a solution

b. Bij mensen die ik niet begrijp, voel ik me nooit helemaal op mijn gemak - I'm just a little uncomfortable with people uniess / fee/ that / can understand their behavior

c. Voor vrijwel alles wat je doet geldt: je kunt het of op een juist, of op een onjuiste wijze doen, er is geen middenweg - There is a right way and a wong way to do almost everything

d. Ik doe liever mee aan een loterij met kleine kansen op hoge prijzen, dan met grote karsen op lage prijzen - I would rather bel on a long shot with high prizes than on a probable winner with only small prizes (R)

e. Om een complex probleem te begnijpen moet je het in zijn ruime context zien, in plaats van het in kleine stukjes uiteen te rafelen - The way to understand complex problems is to be concemed with their larger aspects instead of breaking them into smaller pieces $(\mathrm{R})$

f. Ik voel me bijzonder onzeker als ik me in een situatie bevind die ik niet kan beinvloeden - / get pretty anxious when I am in a social situation over which I have no control

g. Praktisch ieder probleem heeft een oplossing - Practically every problem has a solution

$h$. Ik vind het vervelend als $i k$ de gedachtengang van lemand anders niet kan volgen - It bothers me when / am unable to follow an other person's train of thought

1. Ik ben ervan overtuigd dat er allijd een scherp onderscheid te maken is tussen 'goed' en 'slecht' - / have always felt that there is a clear difference between right and wrong

j. Wanneer ik niet weet hoe anderen op mij reageren kan ik daar behoorlijk over inzitten - it bothers me when / do not know how other people react to me

$k$. Als je je niet aan een paar basisregels houdt, maak je in deze wereld niets klaar - Nothing gets accomplished in this world unless you stick to some basic rules

I. Als ik arts was, zou ik de turbulente werksfeer van de psychiater prefereren boven de strak georganiseerde werkomgeving van de chirurg - If/ were a doctor, / would prefer the uncentainties of a psychiatrist to the clear and deifnite work of a surgeon $(R)$

$\mathrm{m}$. Onduidelije en impressionistische afbeeldingen zeggen me niet zoveel - Vague and impressionistic pictures really have little appeal for me

$\mathrm{n}$. Als $\mathrm{k}$ wetenschapper was zou het me storen dat mijn werk nooit af zou zijn omdat er altijd weer nieuwe resultaten komen - I/ $/$ were a scientist, if would bother me that my work would never be completed because science will always make new discoveries

0. Als ik van tevoren weet hoeveel vragen er gesteld worden op een examen voel ik me lang niet zo zenuwachtig - Before an examination, I feel much less anxious if / know how many questions there will be 


\section{APPENDICES}

p. Het leukste moment van het maken van een legpuzzel is het aanbrengen van het laatste stukje - The best part of working on a jigsaw puzzle is putting in the last plece

q. Soms vind ik het leuk om tegen de regels in te gaan en dingen te doen die ik eigenlijk niet geacht wordt te doen - Sometimes / rather enjoy going against the rules and doing things / am not supposed to do $(\mathrm{R})$

r. Ik vind er weinig aan om aan een probleem te werken zander in staat te zijn met een duidelijke en ondubbelzinnige oplossing te komen - I do not like to work on a problem unless there is a possibility of coming out with a clear-cut and unambiguous answer

s. Ik vind het wel aardig om met nieuwe ideeen te spelen, ook al blijkt later dat ze geen enkel nut hebben - / like to fool around with new ideas, even if they turn out later to be a total waste of time (R)

I. Een goed schriftelijk rapport is bovenal everwichtig- Perfect balance is the essence of all good composition

Source: MacDonald [1970]

Answering format: agree/disagree

Items deleted: $a$ and $g$

Item-total correlations (range): $0.0567-0.3599$

Inter-item correlations (range): $-0.1354-0.3232$

Coefficient $\alpha: 0.6122$

\section{Table F.4 RAPM}

Hoeveel belang hecht uw superieur, voor uw beoordeling, aan... - How much importance does your superior, when evaluating your performance, attach to...

a. Hoe gaed ik met collega's samenwerk - How well / cooperate with colleagues

b. Mijn kostenbewustzijn - My concem with costs

c. Hoe goed ik het met mijn superieur kan vinden - How well / get along with my boss

d. Hoeveel ik mij inspan voor mijn werk - How much effort / put into the job

e. Mijn zorg voor kwaliteit - My concern with quality

f. Of ik (steeds) min budget haal - Meeting the budget

g. Mijn houding ten aanzien van mijn werk en de organisatie - My attitude toward my work and the company

h. Mijn winstgerichtheid - How much profit / make

1. Mijn vaardigheid om met mijn medewerkers om te gaan - My ability to handle my men

Source: Hopwood [1972] and Otley ["1978]

Answering format: Importance... no $=1$, little $=2$, some $=3$, much $=4$, very much $=5$ 


\section{ACCOUNTING FOR PERFORMANCE EVALUATION}

Table F.5 Reliance on financial and quantitative criteria (RFQ) and reliance on targets (RT

1. Belang gehecht bij algemene beoordeling aan... - Impontance attached in genera/ evaluation to..

i. Belang voor financiéle beloningen van... - Importance for financial rewards of...

III. Belang voor niet financiële beloningen van... - Importance for non-financial rewards of..

a. ...uw prestaties uitgedrukt in kwanlitatieve gegevens (zoals; kengetallen, produktiecijfers, budgetcijfers) ...your pertormance expressed in quantitalive numbers (1kke: indicators, production numbers, budgetary numbers)

b. ...uw prestaties uitgedruikt in financièle gegevens (zoals: kosten, kostprijzen, uitgaven, winsten, budgetten) - ...your performance expressed in financial numbers (like: costs, cost prices, expenditures, profits, budgets)

c. ...uw prestaties ten opzichte van eerder vastgestelde doelen of targets: (zaals: produlktietargets, budgettaire of andere targets) - ....your pertormance in relation to eartier set goals or targets (like: production targets, budget or other targets)

Source: developed for this study

Answering format: Importance... no $=1$, little $=2$, some $=3$, much $=4$, very imuch $=5$

Item-total correlations (range): a: $0.6263-0.7287 ; b: 0.5527-0.7424 ; c: 0.5676-0.6663$ (corrected)

Inter-item comelations (range): a: $0.5417-0.6815 ; b: 0.3853-0.6211 ; c: 0.4416-0.5870$

Coefficient $\alpha:$ a: $0.8212 ; b: 0.7783 ; c: 0.7540$

Table F.6 Goal clarity (GC)

Goal speciticity:

a. De doelen in mijn werk zijn erg duidelijk en specifiek, ik weet precies wat mijn taken zijn - My work objectives are very clear and specific; I know exactly what my job is

b. Ik begrijp volkomen welke van de doelen in mijn werk belangrijker zijn dan andere, ik heb een duidelijk beeld van de prioriteit van de verschillende doelen - I understand fully wtich of my work objectives are more important than others, I have a clear sense of priorities on these goals

c. Ik vind dat de doelen van mijn werk vaag en onduidelijk zijn - I think my work objectives are ambiguous and unclear(R)

Role ambiguity:

a. Mijn functie kent duidelijke geplande doelen en doelstellingen - Clear, planned goals and objectives exist formy job

b. Ik weet precies wat mijn bevoegdheden zijn in mijn werk - / fee/ certain about how much authorth / have

c. Ik weet precies wat van me verwacht wordt in dit werk - / know exactjy what is expected of me

d. Ik weet altijd precies hoe ik mijn tijd moet verdelen over de verschillende werkzaamheden in mijn functie I know how to divide my time over the different tasks in my job

e. Ik weet precies wat mijn verantwoordelijkheden zijn in mijn functie - I know what my reponsibilities are

Source: goal specificity: Steens [1976]; role ambiguity: Rizzo et al. [1970] and House [1971]

Answering format: fully disagree $=1$, disagree $=2$, neutral $=3$, agree $=4$, fully agree $=5$

Item-total correlations (range): goal specificity: $0.4653-0.5960$; role ambiguity: $0.3548-0.6629$ (corrected)

Inter-item correlations (range): goal specificity: $0.3519-0.5183$; role ambiguity: $0.1870-0.5348$

Coefficient $\alpha$ : goal specificity: 0.7049 ; role ambiguity: 0.7278 


\section{APPENDICES}

Table F.7 Agreement with evaluation criteria (AEC)

a. De beoordeling die ik ontvang is gebaseerd op factoren die ik volledig onder controle heb - The evaluation I receive is based on tactors over which / have full control

b. Het gebeurt vaak dat mijn superieur mij bepaalde (tegenvallende) resultaten aannekent waar ik echt niets aan kan doen - It often happens that my superior holds me accountable for certain (negative) results that" really cannot help $(\mathrm{R})$

c. De beoordeling die ik ontvang is gebaseend op factoren die ook ik relevant vind voor mijn functioneren The evaluation / receive is based on factors that also / find relevant for my functioning

d. Bij de beoordeling van mijn functioneren legt mijn superieur vaak de nadruk op aspecten van mijn werk die ilk niet relevant wind - When evaluating my functioning my superior often emphasizes aspecis of my work which / think are irrelevant $(\mathrm{R})$

e. De beoordeling die ik ontvang is gebaseend op een compleet beeld van mijn werkelijke prestaties - The evaluation i receive is based on a complete picture of my true performance

f. Bepaalde prestaties en acties die ik belangrijk vind in mijn functioneren worden door mijn superieur vergeten als hij mij beoordeelt - Certain achievements and actions which / think are important in my functioning are overlooked by my superior when he evaluates me (R)

g. In het algemeen vind ik dat mijn functioneren en mijn prestaties op een eerlijke en 'faire' manier worden beoordeeld - In general I think that my functioning and performance is evaluated in an honest and fair way

h. In het algemeen vind ik de criteria waarop mijn superieur mij becordeelt eerlijk en "fair" - In general/ think that the critenia my superior uses to evaluate me are honest and fair

i. Ik ben zeer tevreden met de manier waarop ik wordt beoordeeld - I am very satissied with the way in which lam evaluated

Source: developed far this study

Answering format: fully disagree $=1$, disagree $=2$, neutral $=3$, agree $=4$, fully agree $=5$

Item-total correlations (range): $0.3679-0.7866$ (corrected)

Inter-item correlations (range): $0.1507-0.8066$

Coefficient $\alpha: 0.8678$

Table F.8 Job-related tension (JRT)

a. Ik ervaar ( $\mathrm{t} \mathrm{e}$ ) veel stress in mijn werk - lexpenience (too) much tension in my work

b. Tijdens beoordelingsgesprekken voel ik me gespannen - lexperience job-tension during performance evaluations

c. Als ik de doelen in mijn werk niet haal voel ik me gespannen - /f / don't attain my performance goals, / feol tense

d. Ik maak me vaak zorgen over de hoeveelheid werk die ik heb - I often worny about the amount of work I have to do

e. Ik maak me vaak zorgen dat de hoeveetheid werk die ik verricht ten koste gaat van de kwaliteit ervan - I often worry that the amount of work interferes with how well it gets done

f. Mijn baan heeft directe negatieve invloed op mijn gezondheid - My job tends to directly affect my health

g. Problemen in het werk hebben mij 's nachts weleens wakker gehouden - Problems associated with work have kept me awake at night

h. Ik neem vaak werk 'mee naar huis' in de zin dat ik er aan denk terwill ik met iets anders bezig ben - Ioffen take my job home with me' in the sense that / think about it when doing other things 


\section{ACCOUNTING FOR PERFORMANCE EVALUATIONI}

\begin{tabular}{|c|c|}
\hline \multicolumn{2}{|c|}{ Answering format: fully disagree $=1$, disagree $=2$, neutral $=3$, agree $=4$, fully agree $=5$} \\
\hline \multicolumn{2}{|c|}{ llem-total correlations (range): $0.3536-0.6703$ (corrected) } \\
\hline Inter-item correlations (range): $0.1036-0.5514$ & 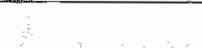 \\
\hline
\end{tabular}

Table F.9 Job satisfaction (JSA)

a. Ik zou liever ander werk hebben dan ik op dit moment doe (binnen deze organisatie of in een andere organisatie) - ( would rather have some other work (either inside our outside this organization) (R)

b. Ik heb al veel vooruitgang gemaakt in deze organisatie - / have made a great deal of progress in this organization

c. Los van mijn precieze baan en mijn precieze functie houd ik bijzonder veel van het soort werk dat ik doe Not counting all the other aspects of my job, I like the kind of work that I do very much

d. Mijn functie geeft mij uitstekend gelegenheid die dingen te doen waarin ik het beste ben - My job gives me the chance to do the things lam best at

e. Het is zeer prettig voor deze organisatie te werken - llike working for this company very much

f. Ik zou een vriend of vriendin zeker adviseren in deze organisatie te komen werken - I would certainly advise a friend to come and work for this organization

g. Als ik mijn huidige werk, tegen hetzelfde salaris, binnen een andere organisatie zou kunnen doen, dan zou ik zeker hier blijven - If / had a chance to do the same kind of work for the same pay, but in another company, I would centainly stay here

Source: Kahn et af. [1964]

Answering format: fully disagree $=1$, disagree $=2$, neutral $=3$, agree $=4$, fully agree $=5$

Item-lotal comelations (range): $0.2663-0.5922$ (comected)

Inter-item correlations (range): $0.1102-0.5438$

Coefficient $\alpha: 0.7184$

\section{Table F.10 Performance}

Beoordeling op een schaal van 1-10 van... - Rating, on a scale from $1-10$, of...

a. Uw eigen functioneren en prestaties - Your own functioning and performance

b. Het functioneren en de prestaties van uw afdeling - The functioning and penformance of your department

Source: developed for this study

Answering format: grade from $1-10$

Inter-item correlation : 0.5012 


\section{APPENDICES}

Table F.11 Felt appropriateness of accounting performance measures (FAAPM)

a. De afdeling waaraan ik leiding geef heeft bovenal een financiële doelstelling (zoals 'het maximaliseren van de winst') - The department / supenise has above all a financial goal (like maximizing profit)

b. Of milin afdeling goed functioneert of niet is nauwkeurig in financiele cijfers uit te drukken - Whether my department functions well or not can be expressed accurately in financial figures

c. Lk vind dat mijn afdeling pas goed heeft gefunctioneerd als er positieve budgetresultaten ontstaan - / fee/ that my department has performed well only if it shows positive budget variances

d. Budgetresultaten geven een volledig overzicht van het functioneren en de resultaten van mijn afdeling Budget variances provide a complete overview of the functioning and pertomance of my department

e. Veel van de activiteiten en taken die mijn afdeling verricht komen niet in de budgetresultaten tot uitdrukking - Many of the activities and tasks my department pertarms do not show up in the budget variances $(R)$

f. Voor het bepalen of mijn afdeling goed heeft gepresteerd of niet zijn budgetresultaten niet rellevant Budget vaviances are irrelevant for determining whether or not my department has performed well $(\mathrm{R})$

g. Voor mij persoonlijk betekent goed presteren: goed presteren in vergelijking met mijn budget - For me personally performing well means: performing well in comparison to my budget

h. Zelfs zonder toelichting zeggen budgetresultaten al veel over het presteren van mijn afdeling - Even without further explanation, budget variances tell a lot about the performance of my department

i. Als ik mijn budget heb gehaald wind ik dat ik goed heb gefunctioneerd - If / meet my budgel / feel that I have pertormed well

j. Als ik, als manager, goed presteer zie je dat direct terug in betere budgetresultaten - If / perform we/l as manager, it is directly refiected in more positive budget variances

k. In mijn functie kun je, terwill je heel goed presteert, toch tegenvallende budgetresultaten halen - in my position one can, while performing very well, get unsatisfactory budget variances (R)

1. Als iemand in mijn functie tegenvallende budgetresultaten behaalt is dat een duidelijk teken dat hij niet zijn best heeft gedaan - If someone in my position gets unsatisfactory budget variances it is a clear sign that he didn't do his best

Source: developed for this study

Answering format: fully disagree $=1$, disagree $=2$, neutral $=3$, agree $=4$, fully agree $=5$

Items not used in determining overall score: $\mathrm{g}$ through $\mathrm{l}$; see Appendix $\mathrm{G}$ for the factor-analysis results

ltem-total correlations (range): $0.5238-0.7218$ (corrected)

Inter-item correlations (range): $0.2763-0.6598$

Coefficient $\alpha: 0.8445$ 
Table F.12 Felt usefulness of budgeting (FUOB)

Mijn budget maakt het mil mogelijk om... - Afy budget enables me...

a. ...een betere manager te zijn - .. to be a better manager

b. ...vernieuwend te zijn - ...to be innovative

c. ...flexibel te zijn -...to be flexible

d. ... mijn prestaties als manager te evalueren - ...to keep track of my succes as a manager

e. ...de processen, waarvoor ik verantwoordelijk ben, te verbeteren - ...to improve the processes that $/$ am responsible for

Source: Swieringa and Moncur [1975]; Bruns and Waterhouse [1975]

Answering format: fully disagree $=1$, disagree $=2$, neutral $=3$, agree $=4$, fully agree $=5$

Item-total correlations (range): 0.5624 - 0.6535 (corrected)

inter-item correlations (range): $0.3402-0.6481$

Coefficient $\alpha: 0.8265$ 


\section{Appendix G \\ Factor-analysis of the FAAPM-instrument}

Table G.1 below presents the results of the factor analysis for the twelve-item FAAPM instrument. For brevity purposes, Table G.1 only contains the English version of items.

Table G.1 Factor analysis of 'felt appropriateness of accounting performance measures' (FAAPM)

\begin{tabular}{|c|c|c|c|}
\hline Items and factor loadings after Varinax rotation & Factor 1 & ractor 2 & Factor? \\
\hline $\begin{array}{l}\text { a. The department I supervise has above all a financial goal (like 'maximizing } \\
\text { profit') }\end{array}$ & $\underline{0.7299}$ & 0.1988 & -0.1208 \\
\hline $\begin{array}{l}\text { b. Whether my department functions well or not cam be expressed accurately } \\
\text { in financial figures }\end{array}$ & $\underline{0.7810}$ & 0.2338 & 0.0137 \\
\hline $\begin{array}{l}\text { c. I feel that my department has performed well only if it shows positive } \\
\text { budget variances }\end{array}$ & $\underline{0.7103}$ & 0.3169 & 0.1928 \\
\hline $\begin{array}{l}\text { d. Budget variances provide a complete overview of the functioning and } \\
\text { performance of my department }\end{array}$ & $\underline{0.7203}$ & 0.3659 & 0.1580 \\
\hline $\begin{array}{l}\text { e. Many of the activities and tasks my department performs do not show up } \\
\text { in the budget variances (R) }\end{array}$ & $\underline{0.6420}$ & 0.1194 & 0.4389 \\
\hline $\begin{array}{l}\text { f. Budget variances are irrelevant for determining whether or not my } \\
\text { department has performed well (R) }\end{array}$ & $\underline{0.5751}$ & 0.0424 & 0.5193 \\
\hline $\begin{array}{l}\text { 9. For me personally performing well means: performing well in comparison } \\
\text { to my budget }\end{array}$ & 0.2922 & $\underline{0.7821}$ & 0.0538 \\
\hline $\begin{array}{l}\text { h. Even without further explanation, budget variances tell a lot about the } \\
\text { performance of my department }\end{array}$ & 0.3952 & $\underline{0.7112}$ & 0.1092 \\
\hline i. If I meet my budget I feel that I have performed well & 0.1827 & $\underline{0.8210}$ & 0.2110 \\
\hline $\begin{array}{l}\text { 1. If I perform well as manager, it is directly reflected in more positive budget } \\
\text { variances }\end{array}$ & 0.3220 & $\underline{0.6198}$ & 0.3271 \\
\hline $\begin{array}{l}\text { k. In my position one can, while pertoming very well, get unsatisfactory } \\
\text { budget variances }(\mathrm{R})\end{array}$ & 0.0334 & 0.1824 & $\underline{0.8533}$ \\
\hline $\begin{array}{l}\text { 1. If someone in my position gets unsatisfactory budget variances it is a clear } \\
\text { sign that he didn't do his best }\end{array}$ & $0.004 B$ & 0.5634 & 0.4156 \\
\hline Eigenvalue & 53368 & 1.2893 & 1.0984 \\
\hline Percentage of variance explained & 44.5 & 10.7 & 9.2 \\
\hline
\end{tabular}

The FAAPM scores used for testing the hypotheses were based on the six items loading on the first factor (items a through $f$ ). Based on their wording, these items seem to share their emphasis on the performance of the "department". The items loading on the second factor seem to share an emphasis on the performance of the 'manager'. Since we did not theoretically differentiate between these (potentially) different constructs in the development of hypotheses, we chose not to attach a meaning to this (potential) difference signalled by the factor analysis. Given the absence of an a-priori expectation 
about different factors, the use of the confirmatory factor analysis, which would be required to substantiate these potential differences, is simply not possible [Nunnally and Bernstein 1994, p. 450 and Chapter 13]. In addition, we decided to put the precision of the new FAAPM instrument before the nuances of the FAAPM construct. Note that the coefficient of the correlation between the FAAPM-scores based on twelve items and the scores based on the reduced, six-item, FAAPM-scale is highly significant $(r=0.92, p=$ 0.000 ). Anticipating our analyses, results and conclusions in Chapters 5,6 and 7 , we also can note our finding here that our results and conclusions concerning FAAPM would have been the same if FAAPM-scores based on the full twelve items would have been used, both in terms of the directions of the relationships found and the level of significance attained. 


\section{Appendix $\mathrm{H}$}

\section{Response analysis}

Table H. 1 below presents the response analysis. The data in the table provide information about the reponse rate per organization, and in total.

Table H.1 Response analysis

\begin{tabular}{|c|c|c|c|c|c|}
\hline \multirow[t]{2}{*}{ Organization } & \multirow[t]{2}{*}{ questionnaires sent out } & \multicolumn{2}{|c|}{ questionnaires returned } & \multicolumn{2}{|c|}{ questionnaires usable } \\
\hline & & absolute & relative $(\%)$ & absolute & relative $(\%)$ \\
\hline A & 10 & 10 & 100.00 & 7 & 70.00 \\
\hline B & 34 & 29 & 85.29 & 29 & 85.29 \\
\hline C & 27 & 21 & 77.78 & 19 & 70.37 \\
\hline D & 15 & 11 & 73.33 & 11 & 73.33 \\
\hline $\mathrm{E}$ & 24 & 21 & 87.50 & 21 & 87.50 \\
\hline $\mathrm{F}$ & 25 & 18 & 72.00 & 17 & 68.00 \\
\hline$G$ & 9 & 7 & 77.78 & 6 & 66.67 \\
\hline H & 56 & 48 & 85.71 & 48 & 85.71 \\
\hline 1 & 15 & 13 & 86.67 & 12 & 80.00 \\
\hline J & 25 & 21 & 84.00 & 19 & 76.00 \\
\hline $\mathrm{K}$ & 10 & 7. & 70.00 & 7 & 70.00 \\
\hline Total & 250 & 206 & 82.40 & 196 & 78.40 \\
\hline
\end{tabular}




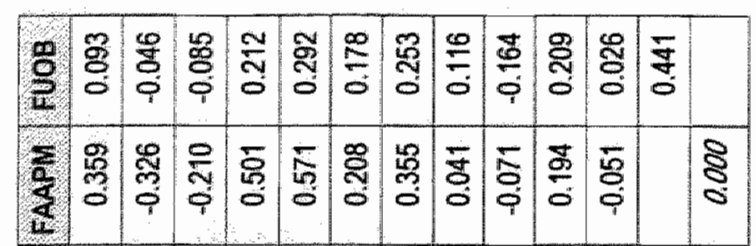

형

向

t్

분

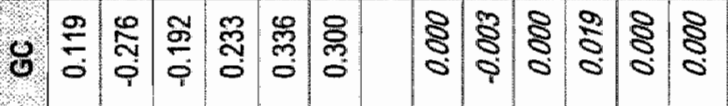

든

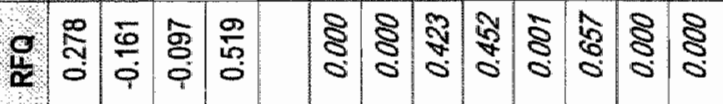

₹

要

- I

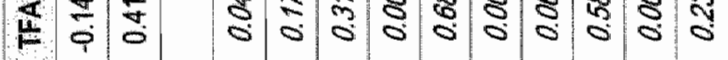

?

害

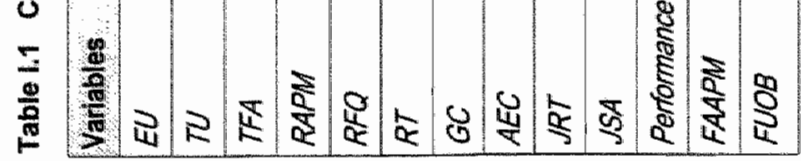

Зิ

$\stackrel{5}{\frac{5}{3}} \stackrel{0}{=}$

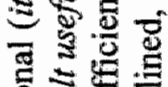

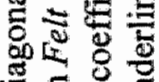

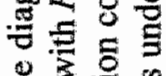

롤

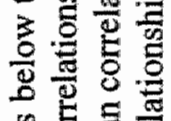

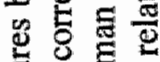

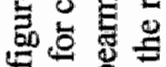

눙

렁열

产

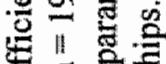

돈

옹

흐을

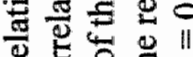

능응

응

흘용

急理总 ๑ $\dot{8}$ ह

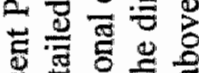

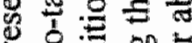

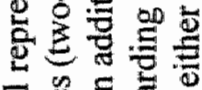

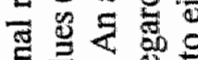

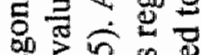

至。

过

$\pm \bar{E}=\overline{0}$

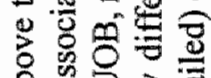

可次

世론

至要

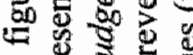

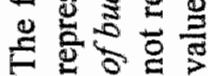




\section{Appendix $J$ \\ Test for bias from non-response}

The test for potential bias from non-response was conducted as follows. First, for each questionnaire the date of both distribution and return were recorded. Second, per organization the sample of respondents was split at the median response time into early (below the median) and late (above the median) respondents. This split at the median was done for each organization separately instead of for the overall sample to correct for potential differences in response-time caused by differences in the internal distribution procedures between organizations, which was not under direct control of the researcher nor of the respondent. Finally, a difference of means t-test was performed for differences between the two groups for each of the contextual, APM and outcome variables. Tabel J.1 below presents the results of a test for potential response bias. The number of respondents with a median response time was 26 , with 86 early responders, and 84 late responders (unless otherwise stated). The table contains all variables in the questionnaire, including the variables that were included for descriptive and validation purposes only.

Table لl.1 Analysis of bias from non-response

\begin{tabular}{|c|c|c|c|c|}
\hline \multirow{2}{*}{ Variables } & \multicolumn{2}{|c|}{ Mean score (std. dev) } & \multirow[t]{2}{*}{$t$} & \multirow[t]{2}{*}{ P. } \\
\hline & early responders & late responders: & & \\
\hline environmental uncertainty (EU) & $2.73(0.71)$ & $2.62(0.74)$ & 1.060 & 0.291 \\
\hline task uncertainty (TU) & $3.63(0.67)$ & $3.45(0.67)$ & 1.790 & 0.075 \\
\hline tolerance for ambiguity (TFA) & $3.14(5.99)$ & $3.69(5.67)$ & -0.620 & 0.895 \\
\hline RAPM & $0.28(0.07)$ & $0.30(0.07)$ & -1.720 & 0.087 \\
\hline reliance on fin. and quant. info. (RFQ) & $2.76(0.94)$ & $2.89(0.89)$ & -0.940 & 0.351 \\
\hline reliance on targets (RT) & $3.25(1.03)$ & $3.53(0.80)$ & -1.950 & 0.053 \\
\hline goal clarity (GC) & $3.83(0.59)$ & $3.86(0.53)$ & -0.310 & 0.755 \\
\hline agreement with evaluation criteria (AEC) & $3.80(0.60)$ & $3.73(0.59)$ & 0.690 & 0.490 \\
\hline job-related tension (JRT) & $2.86(0.66)$ & $2.85(0.68)$ & 0.020 & 0.985 \\
\hline job satisfaction (JSA) & $4.04(0.53)$ & $3.93(0.53)$ & 1.490 & 0.139 \\
\hline performance & $7.51(0.64)$ & $7.61(0.59)$ & -1.060 & 0.289 \\
\hline felt appropriateness of APM (FAAPM) & $2.59(0.89)$ & $2.61(0.81)$ & -0.140 & 0.885 \\
\hline felt usefulness of budgets (FUOB) & $3.37(0.81)$ & $3.27(0.81)$ & 0.740 & 0.459 \\
\hline age (early: 85 - late: 84 ) & $45.80(7.03)$ & $46.69(6.52)$ & -0.850 & 0.395 \\
\hline job-tenure (eariy: 85 - late: 81 ) & $5.64(5.04)$ & $5.54(4.76)$ & 0.120 & 0.904 \\
\hline tenure in organization (early 85 - late:83) & $17.49(10.80)$ & $18.37(9.76)$ & -0.560 & 0.576 \\
\hline span of control (earth: 86 - late:83) & $8.85(8.48)$ & $8.83(7.76)$ & 0.020 & 0.985 \\
\hline number of employees (early: 86 - late: 83 ) & $94.61(278.22)$ & $76.61(160.99)$ & 0.52 & 0.61 \\
\hline
\end{tabular}




\section{ACCOUNTING FOR PERFORMANCE EVALUATION}

The data indicate a higher mean score for late responders for RAPM and reliance on targets, and a lower mean score for task uncertainty. To test whether this indication of bias was also present when considering the sample as a whole, an additional test was performed by dividing the whole sample (196) into early (129) and late (67) responders, based on the mean response time (17.56 days). In this test, there was no significant difference in mean scores for any of the variables. Therefore we believe that, overall, response bias does not pose a threat to the validity of our findings. 


\section{Appendix K}

\section{Moderated Regression Analysis}

\section{K.1 The general principles of Moderated Regression Analysis}

Moderated Regression Analysis (MRA) is a specific application of multiple linear regression analysis, in which the regression equation contains an 'interaction term' [e.g., Southwood 1978; Champoux and Peters 1987]. In a typical equation for the multiple regression of a dependent variable $(Y)$ on two independent variables $\left(X_{1}\right.$ and $\left.X_{2}\right)$ is presented in equation (1) below:

$$
Y=\beta_{0}+\beta_{1} X_{1}+\beta_{2} X_{2}+\epsilon
$$

In contrast, a typical regression equation used in MRA has the format of equation (2) below:

$$
Y=\beta_{0}+\beta_{1} X_{1}+\beta_{2} X_{2}+\beta_{3} X_{1} \times X_{2}+\epsilon
$$

Equation (2) differs from equation (1) by the inclusion of the product of the two independent variables $\left(\mathrm{X}_{1} \times \mathrm{X}_{2}\right)$. This product term is said to represent the moderating effect of variable $\mathrm{X}_{2}$ on the relationship between $\mathrm{X}_{1}$ and $\mathrm{Y}$. In contrast, the other terms in the equation $\left(\mathrm{X}_{1}\right.$ and $\left.\mathrm{X}_{2}\right)$ are said to represent the main effects of variables $\mathrm{X}_{1}$ and $\mathrm{X}_{2}$ on $Y$. The meaning of this product term in establishing a moderating effect can be illustrated by taking the partial derivative $\left(\delta \mathrm{Y} / \delta \mathrm{X}_{1}\right)$ of equation $(2)$, which has the format expressed by equation (3) below:

$$
\delta Y / \delta X_{1}=\beta_{1}+\beta_{3} X_{2}+\epsilon
$$

As equation (3) illustrates, the term representing the partial derivative $\left(\delta \mathrm{Y} / \delta \mathrm{X}_{1}\right)$ is a function of $X_{2}$. This means that the 'form' of the relationship between $Y$ and $X_{1}$ is a function of $\mathrm{X}_{2}$, or in short, that variable $\mathrm{X}_{2}$ moderates the form of the relationship between $X_{1}$ and $Y$ [cf. Champoux and Peters 1987, p. 244; Jaccard et al. 1990, p. 22]. This moderating effect can be graphically illustrated as a variation in the slope of the regression line of $Y$ and $X_{1}$ as a function of $X_{2}$.

Figure K.1 below depicts a situation in which the slope of the regression line between $X_{1}$ and $Y$ is more positive for higher values of $X_{2}$ * 
Figure K.1 Moderating effect

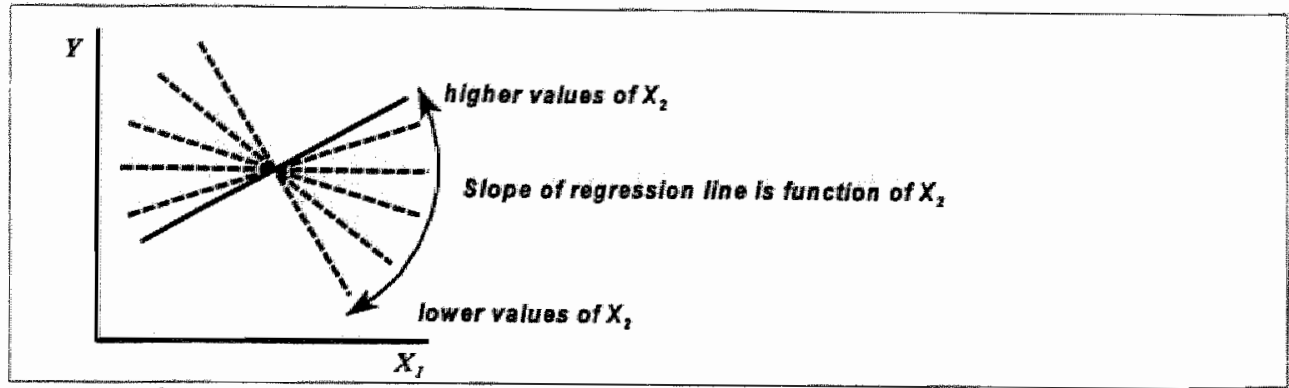

Although we considered $\mathrm{X}_{2}$ the moderator in the example above, a similar analysis applies if we consider $\mathrm{X}_{j}$ the moderator of the relationship between $\mathrm{X}_{2}$ and $\mathrm{Y}$. In that case, illustrated with equation ( $3 \mathrm{a}$ ) below, we take the partial derivative for $\mathrm{X}_{2}\left(\delta \mathrm{Y} / \delta \mathrm{X}_{2}\right)$, and it follows that the relationship between $\mathrm{X}_{2}$ and $\mathrm{Y}$ is a function of $\mathrm{X}_{1}$.

$$
\delta Y / \delta X_{2}=\beta_{2}+\beta_{3} X_{1}+\epsilon
$$

Therefore, it is said that the moderating effect expressed by the interaction term in equation (2) is 'symmetrical' [cf. Southwood 1978; Arnold 1982]. Because of this symmetry, the more neutral expression is to say that there is an interaction of $X_{1}$ and $X_{2}$ to affect $Y$. Labeling a independent variable 'the moderator' thus is a matter of theory rather than statistics [e.g., Arnold 1982, p. 154; 1984, p. 216]. In particular, variables are labeled moderators which are exogenous (such as in contingency hypotheses), or that do not directly affect the dependent variable, but only through an interaction with a second independent variable [e.g., Cohen and Cohen 1983, p. 305]. See Sharma et al. [1981] for an overview and typology.

Equation (2) above is commonly referred as a two-way interaction, since it contains two variables and their interaction. We will discuss higher order interactions below. Since, in our example, we saw that the relationship between $X_{1}$ and $Y$ is more positive (less negative) for higher values of $\mathrm{X}_{2}$, we furthermore speak of a "positive interaction' between $X_{1}$ and $X_{2}$.

A 'negative interaction' would signify that the relationship between $\mathrm{X}_{1}$ and $\mathrm{Y}$ is more negative (or: less positive) for higher values of $\mathrm{X}_{2}$.

\section{K.2 Characteristics of MRA}

The MRA technique is much used throughout the organizational behavior literature to test contingency hypotheses [see Champoux and Peters 1987, p. 243], and is also the dominant technique in APM research to test for moderating effects that would support contextual hypotheses [e.g., Brownell 1981, 1982, 1985, 1987a; Govindarajan and Gupta 


\section{APPENDICES}

1985; Imoisili 1989; Ross 1994]. In the formulation of the regression model and in the interpretation of the outcomes of MRA, there are certain important aspects to which we pay some attention below.

\section{Statistical significance of moderating effect}

Although the exposition above illustrates the general characteristics of MRA, in empirical research MRA usually focuses on the existence of a statistically significant interaction effect. A method to establish whether an interaction is statistically significant is the use of hierarchical regression analysis [e.g., Southwood 1978; Amold and Evans 1979, Cohen and Cohen 1983; Govindarajan and Gupta 1985; Cronbach 1987]. This method implies that two regressions are run, one with the main effects only (see eq. (1) above) and a second with both main effects and the interaction term (see eq. (3) above). A significant interaction effect is displayed by the statistical significance of the additional variance explained by the inclusion of the interaction term (i.e., the significance of the increase in $\mathrm{R}^{2}$ ).

This method is equivalent to a direct assessment of the significance of the t-value associated with the coefficient of the product term [see, Southwood 1978, p. 1168; Amold 1982, p. 157; Jaccard et al. 1990, p. 22]. Cohen and Cohen [1983] also show that the $F$-statistic for the increase in $R^{2}$ equals the square of the $t$-statistic for the interaction term. In our example, this means that a test for a statistically significant interaction effect of $\mathrm{X}_{2}$ on the relationship between $\mathrm{X}_{\mathrm{i}}$ and $\mathrm{Y}$ implies that to test whether the coefficient of the interaction term $\left(\beta_{3}\right)$ in equation $(2)$ is statistically significant. Also here the symmetry applies. A significant t-value of the coefficient of the interaction term thus also means a significant moderating effect of $X_{1}$ on the relationship between $X_{2}$ and $Y$.

\section{Main effects}

As we illustrated above, the equation representing an interaction effect (eq. 2) includes not only the interaction term $\left(\mathrm{X}_{1} \times \mathrm{X}_{2}\right)$, but also the two main effects $\left(\mathrm{X}_{1}\right)$ and $\left(\mathrm{X}_{2}\right)$. There are three topics related to the inclusion of main effects, that warrant some discussion. These are (1) the reason for including main effects; (2) the interpretation of the coefficients for main effects; and (3) the potential problem of multicollinearity. These three issues will be briefly discussed now.

First, the reason for the inclusion of main effects in MRA is to prevent conclusions of the existence of an interaction effect when such an effect is solely due to main effects. Suppose that, for our example, we would test the model as presented by equation (4) below, which does not include main effects:

$$
\mathbf{Y}=\beta_{0}+\beta_{1} X_{1} \times X_{2}+\epsilon
$$

Finding a significant coefficient $\beta_{\Downarrow}$ would not necessarily indicate the existence of an interaction effect, since it could be due to a significant relationship between $X$, and $Y$. In other words, since the interaction term is the product of the two main effects, it is likely to 'steal variance' from its constituting parts [e.g., Cohen and Cohen 1983, p. 305] 
Stone and Hollenbeck [1984, p. 201] argue in this respect:

"... while the cross-product term in a regression equation "carries" the interaction, the same cross-product term is not the interaction'.

This means that when testing for an interaction effect, the main effects should be 'partialed out' by including them in the regression equation [Southwood 1978, p. 1164; Cohen and Cohen 1983, p. 348; Stone and Hollenbeck 1984, p. 201]. Note that this is not always done in APM studies [e.g., Hirst 1983b].

Second, it has been discussed in the literature how the coefficients obtained for the main effects when using MRA should be interpreted. Southwood [1978, p. 1168] shows that such coefficients generally have no theoretical meaning. The reason is that in the behavioral sciences the variables are usually measured using interval scales, and not ratio scales. This means that scale origins and thus linear transformations of variable scores are arbitrary, and have no substantive meaning. Since, as Southwood [1978, pp. 1668, pp. 1198-1201] shows, such linear transformations do change the coefficient of the main effects in the MRA equations, these coefficients cannot be interpreted [for a violation of this rule in APM research, see, e.g., Brownell 1982b, 1985]. It is important to note, however, that such transformations do not change the coefficient of the interaction term, nor its t-statistic and level of significance [Southwood 1978, p. 1168; Cohen and Cohen 1983, pp. 305-306]. This does not imply that the coefficients of the main effects in an interaction model are lacking all meaning. In particular, they signify the main effect of the variable (e.g., $\left.X_{1}\right)$ when the value of the other variable $\left(X_{2}\right)$ is zero [Jaccard et al. 1990]. Only for ratio scales, this zero is a potential 'meaningfull' zero [Southwood 1978, p. 1165]. Our point here is to simply note that the coefficients obtained for the main effects when applying MRA are not the same as those which would be obtained through a regression model without the interaction term. Furthermore, since the coefficient of the interaction term is not sensitive to the scale origins, it follows that for tests of an interaction effect using MRA the independent variables need not be ratioscaled [e.g., Southwood 1978, p. 1167; Amold and Evans 1979].

Finally, authors have pointed to the potential problem of multicollinearity in MRA, caused by the fact that the main effects $\left(X_{1}\right.$ and $\left.X_{2}\right)$ and their product are likely to be correlated [e.g., Drazin and VandeVen 1985]. Yet, from the same arguments that show the insensitivity of the coefficient of the interaction term in MRA to changes in scale origins of $\mathrm{X}_{1}$ and $\mathrm{X}_{2}$ it follows that multicollinearity is not a problem when applying MRA [e.g., Dunlap and Kemery 1987]. In particular, it is possible to use linear transformations of $\mathrm{X}_{1}$ and $\mathrm{X}_{2}$ that remove the correlation between the main terms and the interaction term [Southwood 1978, p. 1167; Jaccard et al. 1990, p. 22]. The 'correct' linear transformation of variable scores to minimize correlation between the independent variables and their product is by deducting the mean score from the "raw score", which is called 'centering' [Jaccard et al. 1990, p. 34]. As we have seen that any such a linear transformation does not affect the coefficient of the interaction term, it follows that the coefficient of the interaction term is always interpretable, and 'centering' is not required. Also this is not always recognized in APM research [see, e.g., Lau et al. 1995]. 


\section{APPENDICES}

Moderated regression with a dummy variable

A special form of MRA is obtained when the moderator variable is a dummy variable, with values of 0 and 1 only. For our example, if the moderator $\mathrm{X}_{2}$ only has values of ' 0 ' and ' 1 ' the original equation, which expressed the interaction effect between $X_{1}$ and $X_{2}$ in equation (2), can be rewritten in the forms represented by equations $2 \mathrm{a}$ and $2 \mathrm{~b}$ below, for the two values of $\mathrm{X}_{2}$ :

$$
\begin{array}{ll}
Y=\beta_{0}+\beta_{1} X_{1}+\beta_{2} X_{2}+\beta_{3} X_{1} \times X_{2}+\epsilon \\
Y=\beta_{0}+\beta_{1} X_{1}+\epsilon & \left(\text { for } X_{2}=0\right) \\
Y=\left(\beta_{0}+\beta_{2}\right)+\left(\beta_{1}+\beta_{3}\right) X_{1}+\epsilon & \left(\text { for } X_{2}=1\right)
\end{array}
$$

While this does not change the interpretation of the coefficient of the interaction term $\left(\beta_{3}\right)$, its decomposition illustrates that an analysis is done for two subgroups. Therefore, the MRA with a dummy variable is sometimes called 'subgroup regression analysis' [e.g., Stone and Hollenbeck 1984], in which the 'subgroups" are distinguished based on, for example, high and low values of the moderator variable. Amold [1984, pp. 219-221] argues that the label 'subgroup regression analysis' may lead to the incorrect conclusion that this is a method different from general MRA. In fact, MRA is always concerned with different 'subgroups', however, taking a dummy variable reduces the number of 'subgroups' to two. A graphical example of MRA when the moderator variable is a dummy variable is presented in Figure K.2 below.

Figure K.2 Interaction effect when moderator is dummy variable

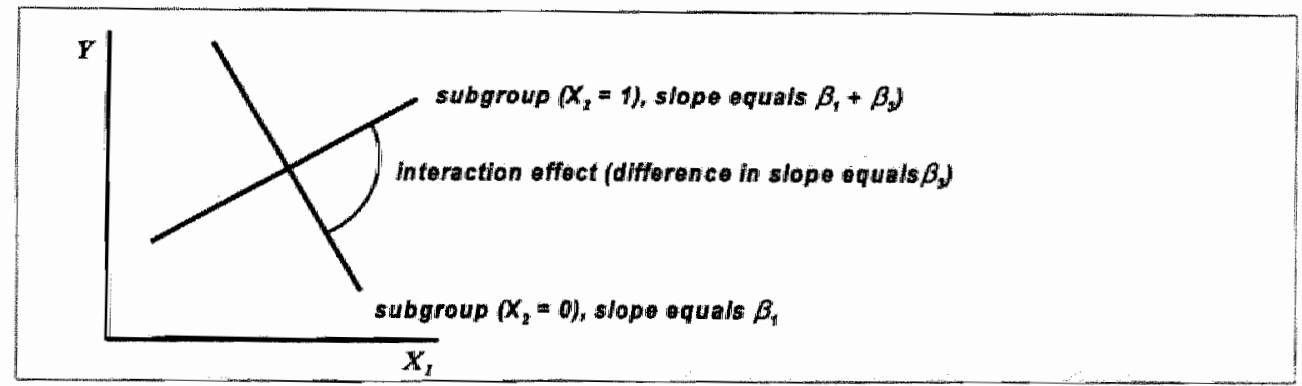

This figure shows two regression lines, for the two values of $X_{2}\left(X_{2}=0\right.$ and $\left.X_{z}=1\right)$, respectively. The figure illustrates a positive interaction, which means that the coefficient $\left(\beta_{3}\right)$ of the interaction term is positive. From a comparison of equations (2a) and (2b) above, it follows that a positive and significant coefficient $\left(\beta_{3}\right)$ suggests that the slope of the regression line for the " $\mathrm{X}_{2}=1$ " subgroup is 'more positive" than the slope of the regression line for the " $\mathrm{X}_{2}=0$ " subgroup. Note that the label of 'positive interaction' is 
only meaningfull if the dummy values 0 and 1 reflect underlying values (low and high) of the moderator variable. However, nothing prevents the meaningfull application of MRA using a dummy that does not reflect an underlying quantitative variable.

Although some moderator variables may come as 'natural dummies' (e.g., male-female), the 'subgroup analysis' is commonly performed based on a categorization of the scores on an underlying continuous variable. Although such categorization has been argued to be unadvisable, since it implies a loss of information [e.g., Cohen and Cohen 1983, p. 310; Pedhazur and Pedhazur 1991, p. 539], it has substantial advantages relating to the understandability of the MRA outcomes and the statistical power of the MRA technique [Arnold 1984, pp. 221-222]. These advantages are especially important when the analysis moves up to higher-order interactions, than the two-way interactions we have discussed sofar.

\section{Higher order interactions}

In Section K.1, we discussed the general format and two-way interactions in MRA, which are interactions between two independent variables. MRA, however, is not restricted to the analysis of two-way interactions only, and can be used to analyze any $n$ way interaction. As an example of higher order interactions, we discuss a three-way interaction which generally has the form as expressed by equation (5).

$$
Y=\beta_{0}+\beta_{1} X_{1}+\beta_{2} X_{2}+\beta_{3} X_{3}+\beta_{4} X_{1} \times X_{2}+\beta_{5} X_{1} \times X_{3}+\beta_{6} X_{2} \times X_{3}+\beta_{7} X_{1} \times X_{2} \times X_{3}+\epsilon
$$

In conformity with the interpretation of the product term for two-way interactions, the product term $\left(\mathrm{X}_{1} \times \mathrm{X}_{2} \times \mathrm{X}_{3}\right)$ in equation (5) represents the three-way interaction among the (three) independent variables. The issues that we discussed above regarding use and interpretation of MRA for two-way interactions also hold for three-way interactions. This implies that, regarding the inclusion of main effects in MRA, in a three-way regression equation also all two-way interactions should be included, and that the coefficients obtained for these two-way interactions are not interpretable [Cohen and Cohen 1983, p. 348]. In general, for an $n$-way interaction, the main effects and all possible interactions of a lower-than- $n$ order should be included. The difference between two-way and higherorder interactions therefore does not lie in its mathematics or statistics, but in the interpretation of its meaning [Cohen and Cohen 1983, p. 306]. They note in this respect: 'The fact that the mathematics can rigorously support the analysis of interactions of high order, however, does not mean that they should necessarily be constructed and used: Interactions greater than three-way are most difficult to conceptualize, not likely to exist, and are costly in statistical inference [...]' [Cohen and Cohen 1983, p. 306].

However, already for a three-way interaction, the problems noted by Cohen and Cohen exist. First, Schmidt and Hunter [1978] and Champoux and Peters [1987], for example, note that the sample sizes typical in (organizational) research lack the power to find 


\section{APPENDICES}

interactions of a high-order. Studies in budgetary control are no exception, with sample sizes often far below 100 [cf. Young 1996; see also Appendix A for sample sizes in APM research].

Second, the difficulty of conceptualizing three-way interactions becomes clear if we consider that a three-way interaction expresses that the coefficient of a two-way interaction is a function of a third variable. For equation (5) this means that a significant coefficient of the three-way interaction term $\left(\beta_{7}\right)$ indicates that the interaction effect of $X_{1}$ and $X_{2}$ on $Y$ is a function of $X_{3}$. Because of the symmetry mentioned earlier, a threeway interaction therefore simultaneously expresses:

(a) the moderating effect of $\mathrm{X}_{3}$ on the $\mathrm{X}_{1} \times \mathrm{X}_{2}$ interaction affecting $\mathrm{Y}$;

(b) the moderating effect of $X_{2}$ on the $X_{1} \times X_{3}$ interaction affecting $Y$; and,

(c) the moderating effect of $X_{1}$ on the $X_{2} \times X_{3}$ interaction affecting $Y$.

The complexity is evident if we consider that (a) implies that $X_{3}$ is 'moderating the moderating effect' that $\mathrm{X}_{2}$ has on the relationship between $\mathrm{X}_{1}$ and $\mathrm{Y}$, and that also here the symmetry applies. A three-way interaction is graphically illustrated in Figure K.3 below, which depicts a three-way interaction for one continuous and two dichotomous independent variables. Panel A and B both show a two-way interaction, and illustrate how the relationship between $X_{1}$ and $Y$ is different for high and low values of $X_{2}$. Panel A shows the two-way interaction for low values of $X_{3}$. Panel $B$ shows the two-way interaction for high values of $X_{3}$. The three-way interaction signifies the difference between the two changes in slope for high and low values of $\mathrm{X}_{3}$. It does not indicate that a two-way interaction is significant for some values of $X_{3}$, and not for others, as is frequently assumed in APM studies [see, e.g., Brownell and Dunk 1991; Lau et al. 1995]. Indeed, a three-way interaction can be significant, both when the 'underlying' two-way interactions are significant, and when they are not.

\section{Figure K.3 Three-way interactions for two dichotomous moderators}

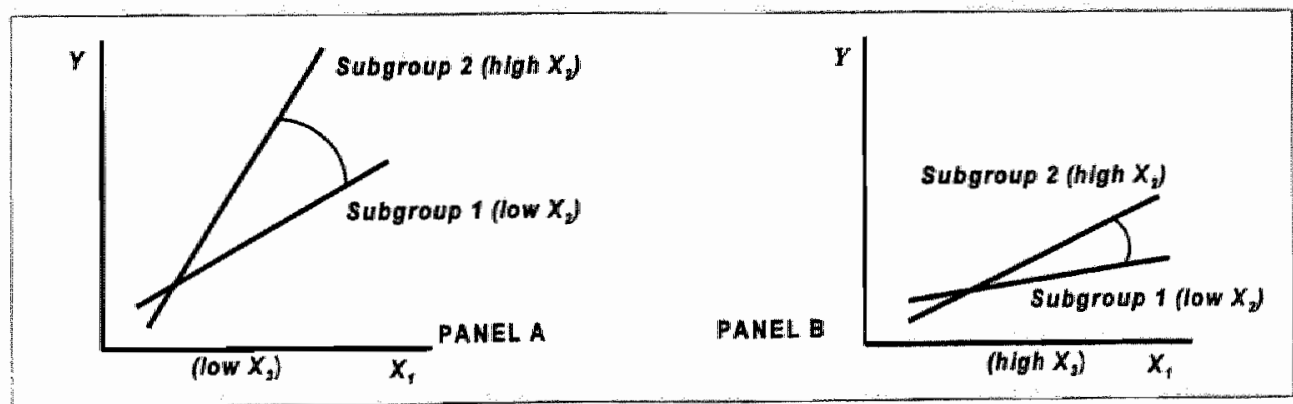

Note that in these examples, the analysis is simplified since we have used two dichotomic 


\section{ACCOUNTING FOR PERFORMANCE EVALUATION}

variables. For three continuous variables, the analysis would have been far more complex. Therefore, Cohen and Cohen [1983, pp. 347-348] advocate a restricted use of higher order interactions:

No interaction set should be included in the $I V$ 's [independent variables] unless it is seriousily entertained on substantive grounds [...]. This requires as a minimum condition that it be understood by the investigator and on practical grounds that it can be clearly explicable to his audience:

\section{Moderated regression as a parametric statistical technique}

Since MRA is a specific application of 'ordinary' multiple linear regression, MRA is a parametric statistical technique. We use this technique for the following reasons. First, it is the dominant technique used in previous, contextual APM studies, and thus allows a better comparison of findings. Second, comparable non-parametric techniques for testing interaction effects are simply not available [Siegel 1965, p. 33; Siegel and Castellan 1988]. Third, as we have seen, the use of MRA does not require ratio-scales, and the types of instruments used in this study approach the interval-level of measurement well [cf. Roiskin and Margerison 1983, p. 874-875]. In general, support for the robustness of applying parametric statistics in case where no non-parametric alternative was available is found throughout the methodological literature [cf. Kerlinger and Pedhazur 1973; Southwood 1978; Cohen and Cohen 1983]. Since the tests for interaction dominate our hypotheses and to obtain unity in analytic method, we use parametric statistical techniques throughout the dissertation and for the analyses in Chapter 6 . This means that the correlations reported are Pearson correlations, and that we use the t-test for difference of means test where applicable. From the calculations reported in Appendix I we found no differences between Pearson and Spearman correlation coefficients for any of the relationships explicitly tested in Chapters 5 and 6 .

\section{K.3 The interpretation of outcomes of MRA}

We return to our "general' two-way interaction model to address two issues related to the interpretation of a significant interaction effect. In particular we will use our two-way interaction model, in which 'moderation' and 'interaction' were defined as variations in the slope of a regression line between $\mathrm{Y}$ and $\mathrm{X}_{1}$ which can be attributed to variations in $\mathrm{X}_{2}$ [e.g., Cohen and Cohen 1983, p. 305].

\section{Interaction and the strength of relationships}

In our example of interaction in MRA, we referred to the 'subgroup' method for illustrating the difference in the slope of the regression line for two subgroups. The literature evidences another use of subgroup analysis, in which it is tested whether differences exist between subgroups in the strength of the relationships between the independent and dependent variable [e.g., Stone and Hollenbeck 1.984; Champoux and Peters 1987, p. 243]. Regarding our example, this 'subgroup correlation analysis' would 


\section{APPENDICES}

imply that we test for differences between the correlation of $\mathrm{X}_{1}$ and $\mathrm{Y}$ for high and low values of $\mathrm{X}_{2}$. The difference in substantive meaning of the two kinds of analyses is graphically illustrated in Figure K.4.

In this figure, the shaded areas represent the "clouds" of observations of the relationship between $X$ and $Y$. A "wide' cloud indicates a low correlation and a "narrow" cloud indicates a high correlation. For each of the clouds the appropriate regression lines are depicted as well. Panel A of Figure K.4 shows no sign of interaction, both correlations and regression lines are equal for the two subgroups. Panel B illustrates a 'form' interaction since the slope of the regression line is different for the two subgroups. No indication of interaction for 'strength' exist, since $\mathrm{X}$ appears to equally well predict $\mathrm{Y}$ in both subgroups, evidenced by the absolute values of the correlation coefficients being equal. Panel $\mathrm{C}$ is the opposite of panel $\mathrm{B}$ since there is no difference in slope, but there is a difference in "strength". This means that in subgroup $1, X$ is a better predictor of $\mathrm{Y}$ than in subgroup 2. Panel D shows a combination of "form' and 'strength" interactions, since both the slope of the regression line and the correlation of $\mathrm{X}$ and $\mathrm{Y}$ is different for the two subgroups.

Figure K.4 Interaction as strength and as form

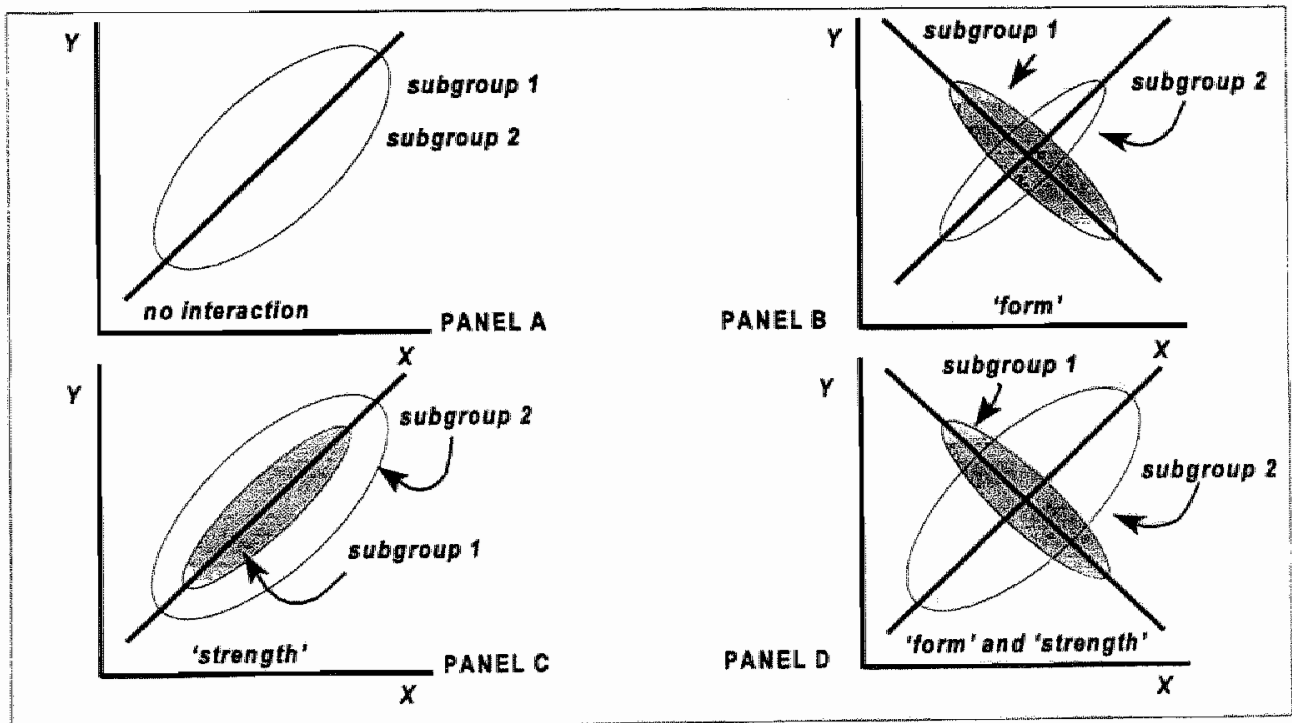

There has been some confusion in the literature about whether contingency hypotheses reflect differences in 'form' or in 'strength' [see, e.g., Amold 1982; 1984; Stone and Hollenbeck 1984]. Tests for differences in strength imply that the sample is split in two subgroups, based on the value of the moderator variable, and correlation coefficients of $\mathrm{Y}$ and $\mathrm{X}$ are compared between subgroups. The correct interpretation, when differences 
are found, is that $X$ is a better predictor of $Y$ in one subgroup than in the other.

It is now generally recognized that contingency hypotheses are of the form type (panels B and D), and it is even argued that differences in strength are in most cases meaningless [Schmidt and Hunter 1978, p. 216; Arnold 1982, pp. 153-154]. Despite this, there are several examples of contingency hypotheses which are tested with subgroup correlation analyses [e.g., Govindarajan 1984; Merchant 1981, 1984]. Govindarajan [1984, p. 129] tested whether the relationship between EU and emphasis on subjective performance criteria would be more 'pronounced' for effective SBU's than for less effective SBU's. His results showed a difference in correlation coefficient $(r=0.59$ and $r=0.19$ ) for the two subgroups, a finding that may correspond with panel $C$ in Figure K.4. Whatever this finding may mean, it does not provide support for the hypothesis that the effect of EU on the use of subjective performance criteria is greater for high effectiveness SBU's, nor that subjective performance evaluation is more appropriate for high levels of EU. Although we are not sure if these two hypotheses are equivalent to Govindarajan's formulated expectation of a "pronounced" relationship, they do represent the contingency hypotheses that should have been tested based on the theory development. See Schoonhoven [1981] for a critical discussion of the formulation of contingency hypotheses. Obviously, these studies do not provide insight in hypotheses of the form type, although the results of these studies seem to be interpreted in that way.

\section{Interaction and effect size}

A second issue related to the interpretation of the outcomes of MRA is that a (significant) coefficient of the interaction does only contain information about changes in relationship between variables, and does not contain information about the value of the dependent variable. We will illustrate this with Figure K.5 below. In panel $A, Y$ has the highest (lowest) value when both $\mathrm{X}_{1}$ and $\mathrm{X}_{2}$ are high (low). In contrast, in panel $\mathrm{B}, \mathrm{Y}$ has the highest (lowest) value when $X_{1}$ is high (low) and $X_{2}$ is low (high).

Note that in both cases the interactions $\left(\mathrm{X}_{1} \times \mathrm{X}_{2}\right)$ are equal regarding both direction and size. This means that in both cases, an increase in the value of $X_{2}$ has an equal positive effect on the form of the relationship between $X_{1}$ and $Y$. The difference that exists between the cases is due to a main effect of the moderating variable on the dependent variable [cf. Kren and Kerr 1993]. The proper interpretation of a positive interaction therefore is not that $Y$ achieves the highest values for the highest values of $X_{1}$ and $X_{2}$, but that for a given value of $X_{1}$, higher values of $X_{2}$ are associated with higher levels of $Y$.

In sum, MRA can not be used to test expectations about the values of $X_{1}$ and $X_{2}$ for which $Y$ will have the highest values. This is the consequence of MRA testing differences in the slope of the regression line for different values of a moderator variable, and not testing for potential main effects. Note however that the question of the "highest $Y^{\prime}$ ' is also irrelevant in testing contingency models, especially when the main effects are due to exogenous or 'uncontrollable' contingency factors. Unfortunately, this is not always clearly recognized in APM studies [e.g., Brownell and Hirst 1986; Brownell and Dunk 1990; Dunk 1993]. 


\section{APPENDICES}

Figure K.5 Interaction contains no information on value independent variable

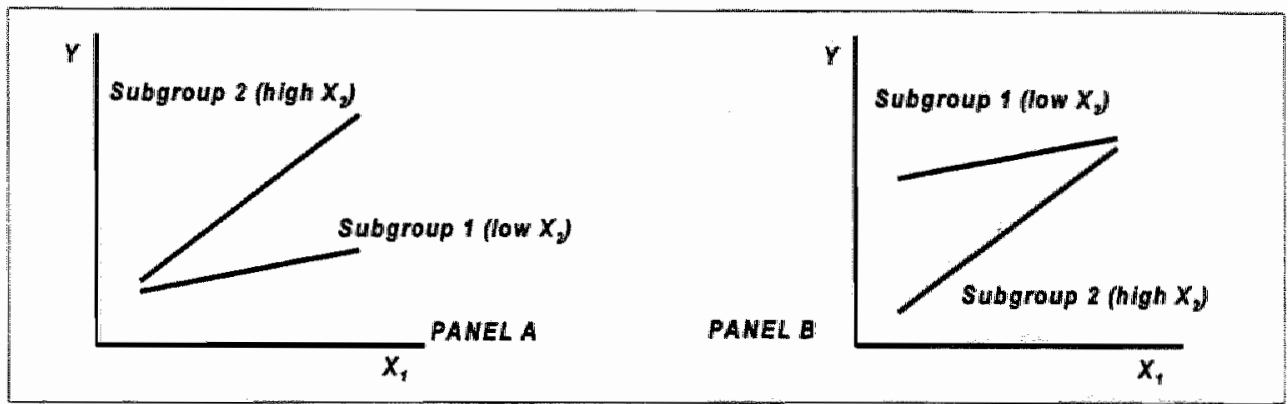

Interaction and the change in slope

A third issue is rellated to the concept of "monotonicity' that is often associated with the use of MRA. Monotonic functions are functions that do not cross the horizontal axis, meaning that if a moderating effect occurs, it changes the slope of the function within positive values (or negative values) only [e.g., Schoonhoven 1981]. In general, a statistically significant coefficient of the interaction term does not contain information about whether the relationship found is monotonic or non-monotonic, but in contrast not the (non-)monotonicity but a (significant) interaction is the most convincing proof of the existence of moderating effects [see, in contrast, e.g., Gul 1991, p. 58]. 
Appendix L

Further analyses of the three-way interactions between uncertainty and TFA

Below we further analyze our findings concerning hypothesis $4 \mathrm{a}$ and $5 \mathrm{~b}$. We chose to further examine these two hypotheses in particular because our initial analysis showed results that are significantly opposite to those expected.

Further analysis of hypothesis $4 a$

Here we further analyse the results of testing Hypothesis $4 \mathrm{a}$, in which we expected a negative threeway interaction between TFA, EU and RAPM to affect GC. In particular, we applied the following model to the two subgroups with low TFA and high TFA.

$$
\mathrm{Y}=\beta_{0}+\beta_{1} \mathrm{X}_{1}+\beta_{2} \mathrm{X}_{2}+\beta_{3} \mathrm{X}_{1} \times \mathrm{X}_{2}+\epsilon
$$

where $\mathrm{Y}$ is goal clarity (GC)

$X_{1}$ is RAPM

$\mathrm{X}_{2}$ is environmental uncertainty (EU).

The results of this test are presented in Tables L.1 and L.2.

Table L.1 Results of regressing GC on RAPM and EU (low TFA subgroup)

\begin{tabular}{|l|c|r|r|r|r|}
\hline Variable & Coeificient & Value & std Error & t & P \\
\hline Constant & $\beta_{0}$ & 2.9013 & 0.8468 & 3.426 & 0.0009 \\
RAPM & $\beta_{1}$ & 3.1216 & 3.0782 & 1.014 & 0.3134 \\
Environmental uncertainty (EU) & $\beta_{2}$ & 0.1009 & 0.3117 & 0.324 & 0.7469 \\
RAPM $\times$ EU & $\beta_{3}$ & -0.2254 & 1.0778 & -0.205 & 0.8383 \\
\hline Adjusted $\mathrm{R}^{2}=9.053 \% ; F_{3.84}=3.9198 ; p=0.0113 ; n=88$ & & & \\
\hline
\end{tabular}

Tabile L.2 Results of regressing GC on RAPM and EU (high TFA subgroup)

\begin{tabular}{|l|c|r|r|r|r|}
\hline Variable & Coeficient & Value & std. Error & t & p \\
\hline Constant & $\beta_{0}$ & 5.1724 & 0.8140 & 6.354 & 0.0000 \\
RAPM & $\beta_{1}$ & -5.2831 & 2.8821 & -1.833 & 0.0697 \\
Environmental uncertainty $(E U)$ & $\beta_{2}$ & -0.6567 & 0.3185 & -2.062 & 0.0417 \\
RAPM $\times$ EU & $\beta_{3}$ & 2.3924 & 1.1098 & 2.156 & 0.0334 \\
\hline Adjusted $R^{2}=2.451 \% ; F_{3,102}=1.8880 ; p=0.1363 ; n=106$ & & & & \\
\hline
\end{tabular}

These results indicate the existence of a positive interaction between environmental uncertainty and RAPM to affect goal clarity, for the high TFA subgroup only. The value of the coefficient of the three-way interaction term (2.6129, see main text), is the 


\section{APPENDICES}

difference between the small and insignificant two-way interaction $(-0.2254$, see Table L.1) for the low-TFA subgroup, and a positive and significant two-way interaction (2.3924, see Table L.2) for the high TFA subgroup. This suggests, indeed contrary to the expectation that the use of APM to enhance managerial goal clarity is most effective for managers with high TFA. Furthermore, it suggests that our earlier finding of a positive interaction between environmental uncertainty and RAPM to affect goal clarity for the whole population (see Hypothesis 1a), only holds for managers with high TFA. However, it should be noted that the reliability of the whole model for the high TFA subgroup is low (see Table L.2).

Further analysis of hypothesis $5 b$

Here we further analyse the results of testing Hypothesis $5 b$, in which we expected a positive three-way interaction between TFA, TU and RAPM to affect AEC. In particular, we applied the following model to the two subgroups with low TFA and high TFA.

$$
\text { (1) } \mathrm{Y}=\beta_{0}+\beta_{1} \mathrm{X}_{1}+\beta_{2} \mathrm{X}_{2}+\beta_{3} \mathrm{X}_{1} \times \mathrm{X}_{2}+\epsilon
$$

where $\mathrm{Y}$ is agreement with evaluation criteria (AEC)

$X_{1}$ is RAPM

$\mathrm{X}_{2}$ is task uncertainty (TU).

The results of this test are presented in Tables L.3 and L.4.

Table L.3 Results of regressing AEC on RAPM and TU (low TFA subgroup)

\begin{tabular}{|l|c|r|r|r|c|}
\hline Variable & Coefficient & Value & std Error & $\mathrm{t}$ & $\mathrm{P}$ \\
\hline Constant & $\beta_{0}$ & 5.6718 & 1.1253 & 5.040 & 0.0000 \\
RAPM & $\beta_{4}$ & -8.4177 & 3.5924 & -2.343 & 0.0215 \\
Task uncertainty (TU) & $\beta_{2}$ & -0.5368 & 0.3343 & -1.606 & 0.1121 \\
RAPM $\times$ TU & $\beta_{3}$ & 2.3573 & 1.1254 & 2.154 & 0.0340 \\
\hline Adjusted $R^{2}=7.774 \% ; F_{3,84}=3.4603 ; p=0.0199 ; n=88$
\end{tabular}

Table L.4 Results of regressing AEC on RAPM and TU (high TFA subgroup)

\begin{tabular}{|l|c|r|r|r|r|}
\hline Variable & Coefficient & Value & Std. Error & $\mathbf{t}$ & $\mathbf{p}$ \\
\hline Constant & $\beta_{0}$ & 2.7465 & 1.6841 & 1.631 & 0.1060 \\
RAPM & $\beta_{1}$ & 3.5312 & 5.9749 & 0.591 & 0.5558 \\
Task uncertainty (TU) & $\beta_{2}$ & 0.3315 & 0.4435 & 0.748 & 0.4565 \\
RAPM $\times$ TU & $\beta_{3}$ & -1.1261 & 1.5860 & -0.710 & 0.4793 \\
\hline Adjusted $\mathrm{R}^{2}=0.0170 \% ; F_{3.102}=0.4069 ; p=0.7484 ; n=106$ & & & \\
\hline
\end{tabular}


These results indicate the existence of a positive interaction between task uncertainty and RAPM to affect agreement with evaluation criteria (AEC) for the low TFA subgroup. The value of the coefficient of the three-way interaction term $(-3.4835$, see main text), is the difference between the positive and significant two-way interaction (2.3573, see Table L.3) for the low TFA subgroup, and a negative and insignificant two-way interaction (-1.1261, see Table L.4) for the high TFA subgroup. This suggests, indeed contrary to the expectation, that the effect of task uncertainty on the relationship between RAPM and AEC is positive for managers with low TFA. This is consistent with our finding concerning the hypothesized negative interaction of task uncertainty and RAPM to affect AEC for the whole population (see Hypothesis $2 \mathrm{~b}$ ), which we did not find supported by the data. Note in addition, that the reliability of the whole model for the high TFA subgroup is extremely low (see Table L.4). 


\section{References}

ALRECK, P.L. AND R.B. SETTLE, The Survey Research Handbook, Irwin, Homewood (1985).

AMIGIONI, F., Planning Management Control Systems, Journal of Business Finance and Accounting, Vol. 5 (1978), pp. 297-291.

ANSARI, S.L., An Integrated Approach to Control System Design, Accounting, Organizations and Society, Vol. 2 (1977), pp. 101-112.

ANSARI, S.L., Towards an Open Systems Approach to Budgeting, Accounting, Organizations and Society, Vol. 4 (1979), pp. 149-161.

ANTHONY, R.N., Planning and Control Systems: A Framework for Analysis, Harvard Graduate School of Business, Boston (1965).

ANTHONy, R.N., The Management Control Function, Harvard Business School Press, Boston (1981).

ANTHONY, R.N., AND V. GOVINDARAJAN, Management Control Systems, Irwin, Chicago (1995).

ARANYA, N., Budget Instrumentality, Participation and Organizational Effectiveness, Journal of Management Accounting Research, Vol. 2 (1990), pp. 67-77.

ARGYRIS, C., The Impact of Budgets an People, The Controllership Foundation, Ithaca, New York (1952).

ARGYRIs, C., Producing Knowledge that is Generalizable and Usable for Practice: A Review, Accounting, Organizations and Society, Vol. 13 (1988), pp. 101-106.

ARGYRIS, C., The Dilemma of Implementing Controls: The Case of Managerial Accounting, Accounting, Organizations and Society, Vol. 15 (1990), pp. 503-511.

ARMSTRONG, P., Variance Reporting and the Delegation of Blame: a Case Study, Accounting, Auditing and Accountability Journal, Vol. 2 (1989), pp. $29-46$.

ARNoLD, H.J., Moderator Variables: A Clarification of Conceptual, Analytic, and Psychometric Issues, Organizational Behavior and Human Performance, Vol. 29 (1982), pp. 143-174.

ARNOLD, H.J., Testing Moderator Variables Hypotheses: A Reply to Stone and Hollenbeck, Organizational Behavior and Human Performance, Vol. 34 (1984), pp. 214-224.

ARNOLD, H.J. AND M.G. Evans, Testing Multiplicative Models Does Not Require Ratio Scales, Organizational Behavior and Human Performance, Vol. 24 (1979), pp. 
41-59.

ATKNSON, A.A., R.J. BANKER, R.S. KAPLAN AND S.M. YOUNG, Management Accounting, Prentice-Hall, Upper Saddle River (1997).

BACKSTROM, C.H. AND G. HuRSH-CESAR, Survey Research, Macmillan, New York (1981).

BAMAN, S., Agency Research in Managerial Accounting: A Survey, Journal of Accounting Literature, Vol. 1 (1982), pp. 154-213.

BAIMAN, S., Agency Research in Managerial Accounting: A Second Look, Accounting, Organizations and Society, Vol. 15 (1990), pp. 341-371.

BAIMAN, S. AND J. NOEL, Noncontrollable Costs and Responsibility Accounting, Journal of Accounting Research, Vol. 23 (1985), pp. 486-501.

BAKER, G.P., Pay-for-performance for Middle Managers: Causes and Consequences, Journal of Applied Corporate Finance, Vol. 5 (1992), pp. 50-61.

BAKER, G.P., M.C. JENSEN AND K.J. MURPHY, Compensation and Incentives: Practice vs. Theory, The Journal of Finance, Vol. 43 (1988), pp. 593-616.

BARRET, T.F., P. MCDONAGH AND J. GRANLEESE, The Contagion Effect in Performance Evaluation: Evidence from the Evaluations of Marketing Managers: a Research Note, British Accounting Review, Vol. 24 (1992), pp. 331-341.

BENNETT, N., D.M. HEROLD AND S.J. ASHFORD, The Effects of Tolerance for Ambiguity on Feedback-Seeking Behaviour, Journal of Occupational Psychology, Vol. 63 (1990), pp. 343-348.

Birnberg, J.G., M.D. ShIEldS AND W. MCGHEE, The Effects of Personality on a Subject's Information Processing: a Reply, The Accounting Review, Vol. 55 (1980), pp. 507-510.

BIRNBERG, J.G., L. TUROPOLEC AND S.M. YOUNG, The Organizational Context of Accounting, Accounting, Organizations and Society, Vol. 8 (1983), pp. 111-129.

BIRNBERG J.G. AND C. SNODGRASS, Culture and Control: A Field Study, Accounting, Organizations and Society, Vol. 13 (1988), pp. 447-464.

BRIERS, M. AND M.K. HIRST, The Role of Budgetary Information in Performance Evaluation, Accounting, Organizations and Society, Vol. 15 (1990), pp. 373-398.

BRomWICH, M., AND A. BHIMANI, Pathways to Progress, CIMA, London (1994).

BRoWNELL, P., Participation in Budgeting, Locus of Control and Organizational Effectiveness, The Accounting Review, Vol. 56 (1981), pp. 844-860.

BROWNELL, P., Participation in the Budgeting Process: When it Works and When it Doesn"t, Journal of Accounting Literature, Vol. 1 (1982a), pp. 124-153.

BRowNELL, P., The Role of Accounting Data in Performance Evaluation, Budgetary Participation and Organizational Effectiveness, Journal of Accounting Research, Vol. 20 (1982b), pp. 12-27.

BROWNELL, P., A Field Study Examination of Budgetary Participation and Locus of

Control, The Accounting Review, Vol. 57 (1982c), pp. 766-777.

BRoWNELL, P., Leadership Style, Budgetary Participation and Managerial Behavior, Accounting, Organizations and Saciety, Voll. 8 (1983a), pp. 307-321.

BROWNELL, $\mathbb{P}$., The Motivational Impact of Management-by-Exception in a Budgetary 


\section{REFERENCES}

Context, Jownal of Accounting Research, Vol. 21 (1983b), pp. 456-472.

BROWNELL, P., Budgetary Systems and the Control of Functionally Differentiated Organizational Activities, Journal of Accownting Research, Vol. 23 (1985), pp. 502-512.

BROWNELL, P., The Role of Accounting Information, Environment and Management Control in Multinational Organisations, Accounting and Finance, Vol. 27 (1987a), pp. 1-16.

BROWNELL, P., The Use of Accounting Information in Management Control. In: Management Planning and Control, Ferris and Livingstone eds., Columbus Ohio (1987b).

BROWNELL, P., Research Methods in Management Accounting, Coopers \& Lybrand, Accounting Research Methodology, Monograph No.2, Melboume (1995).

BROWNELL, P. AND A.S. DUNK, Task Uncertainty and its Interactions with Budgetary Participation and Budget Emphasis: Some Methodological Issues and Empirical Investigation, Accounting, Organizations and Society, Vol. 16 (1991), pp. 693703.

BROWNELL, P. AND M.K. HIRST, Reliance on Accounting Information, Budgetary Participation, and Task Uncertainty: Tests of a Three-way Interaction, Journal of Accounting Research, Vol. 24 (1986), pp. $241-249$.

BROWNELL, P. AND M. MCINNES, Budgetary Participation, Motivation and Managerial Performance, The Accounting Review, Vol. 61 (1986), pp. 587-600.

BROWNELL, P. AND K.A. MERCHANT, The Budgetary and Performance Influences of Product Standardization and Manufacturing Process Automation, Journal of Accounting Research, Vol. 28 (1990), pp. 388-397.

BRUNS, W.J. AND J.H. WATERHOUSE, Budgetary Control and Organization Structure, Journal of Accounting Research, Vol. 13 (1975), pp. 177-203.

BRUNS, W.J., Introduction, in: Performance Measurement, Evaluation and Incentives, W.J. Bruns ed., Harvard Business School Press, Boston (1992), pp. 1-14.

BUCHKO, A.A., Conceptualization and Measurement of Environmental Uncertainty: An Assessment of the Miles and Snow Perceived Environmental Uncertainty Scale, Academy of Management Journal, Vol. 37 (1994), pp. 410-425.

BUDNER S., Intolerance of Ambiguity as a Personality Variable, Journal of Personality, Vol. 30 (1962), pp. 29-50.

Burchell, S., C. ClubB, A. Hopwood, J. Hughes AND J. NAHAPIET, The Roles of Accounting in Organizations and Society, Accounting, Organizations and Society, Vol. $5(1980)$, pp. 5-27.

BUrger, J.M., Personality, Brooks/Cole, Pacific Grove (1993).

BURNS, T. AND G.M. STALKER, The Management of Innovation, Tavistock Institute, London (1961).

CAMMAN, C., Effects of the Use of Control Systems, Accounting, Organizations and Society, Vol. 1 (1976), pp. 301-313.

CAMPBELL, D.J., Task Complexity: A Review and Analysis, Academy of Management Review, Vol. 13 (1988), pp. 40-52. 
CAMPBELL, J.P., On the Nature of Organizational Effectiveness, in: New Perspectives on Organizational Effectiveness, P.S. Goodman and J.M. Pennings eds., Jossey-Bass, San Francisco (1977), pp. 13-55.

CARMINES E.G., AND R.A. ZELLER, Reliability and Validity Assessments, Sage, Beverly Hills (1979).

CARROLL, S.J. AND H.L. TOSI, Goal Characteristics and Personality Factors in a Management-by-Objectives Program, Administrative Science Quarterly, Vol. 15 (1970), pp. 295-305.

ChAmpoux, J.E., AND W.S. Peters, Form, Effect Size and Power in Moderated Regression Analysis, Journal of Occupational Psychalogy, Vol. 60 (1987), pp. 243-255.

CHENHALL, R.H. AND P. BROWNELl, The Effect of Participative Budgeting on Job Satisfaction and Performance: Role Ambiguity as an Intervening Variable, Accounting, Organizations and Society, Vol. 13 (1988), pp. 225-233.

ChENHALl, R.H. AND D. MORRIS, The Impact of Structure, Environment and Interdependence on the Perceived Usefulness of Management Accounting Systems, The Accounting Review, Vol. 61 (1986), pp. 16-35.

CHOUdHURRY, N., Responsibility Accounting and Controllability, Accounting and Business Research, Vol. 16 (1986), pp. 189-198.

CHRISTENSON, C., The Methodology of Positive Accounting, The Accounting Review, Vol. 58 (1983), pp. 1-22.

Cleveland, J.N., K.R. MuRPHy and R.E. Williams, Multiple Uses of Performance Appraisal: Prevalences and Correlates, Journal of Applied Psychology, Vol. 74 (1989), pp. 130-135.

COATES, J.B., E.W. DAVIS, C.R. EMMANUEL, S.G. LONGDEN AND R.J. STACEY, Multinational Companies Performance Measurement Systems: International Perspectives, Management Accounting Research, Vol. 3 (1992), pp. 133-150.

COHEN J., AND P. COHEN, Applied Multiple Regression/Correlation Analysis for the Behavioral Sciences, Erlbaum, Hillsdale (1983).

CoLLINS, F., The Interaction of Budget Characteristics and Personality Variables with Budgetary Response Attitudes, The Accounting Review, Vol. 53 (1978), pp. 324335.

Collins, F., P. Munter and D.W. FinN, The Budgeting Games People Play, The Accounting Review, Vol. 62 (1987), pp. 29-49.

CORTINA, J.M., What is Coefficient Alpha? An Examination of Theory and Applications, Journal of Applied Psychology, Vol. 78 (1993), pp. 98-104.

CRANT, J.M. AND T.S. BATEMAN, Assignment of Credit and Blame for Performance Outcomes, Academy of Management Journal, Vol. 36 (1993), pp. 7-27.

CRONBACH, L.J., Statistical Tests for Moderator Variables: Flaws in Analyses Recently Proposed, Psychological Bulletin, Vol. 102 (1987), pp. 414-417.

CROPANZANO, R. AND M.L. RANDALL, Injustice and Work Behavior, in: Justice in the Workplace, Approaching Fairness in Human Resource Management, R. Cropanzano ed., Erlbaum, Hillsdale (1993), pp. 3-20. 


\section{REFERENCES}

CUSHING. B.E., M.B. ROMNEY AND P. STEINBART, Accounting Information Systems, Addison-Wesley, Reading (1996).

DAFT, R.L. AND N.B. MACINTOSH, A New Approach to Design and Use of Management Information, California Management Review, Vol. 21 (1978), pp. 82-92.

DALEY, L., J. JIAMBAL VO, G.L. SUNDEM AND Y. KONDO, Attitudes Toward Financial Control Systems in the United States and Japan, Journal of International Business Studies, Vol. 16 (1985), pp. 91-110.

DANIEL, S.J. AND W.D. REITSPERGER, Linking Quality Strategy with Management Control Systems: Empirical Evidence from Japanese Industry, Accounting, Organizations and Society, Vol. 16 (1991), pp. 601-618.

DAvIS, J.A., The Logic of Causal Order, Sage, Beverly Hills, 1985.

DECOSTER, D.T. AND J.P. FERTAKIS, Budget-Induced Pressure and its Relationship to Supervisory Behavior, Journal of Accounting Research, Vol. 6 (1968), pp. 237246.

DEMSKI, J.S. AND D.E.M. SAPPINGTON, Hierarchical Structure and Responsibility Accounting, Journal of Accounting Research, Vol. 27 (1989), pp. 40-58.

DERMER, J.D., Cognitive Characteristics and the Perceived Importance of Information, The Accounting Review, Vol. 48 (1973), pp. 511-519.

DERMER, J.D. AND R.G. LUCAS, The Illusion of Managerial Control, Accounting, Organizations and Society, Vol. 11 (1986), pp. 471-482.

DILL, W.R., Environment as an Influence on managerial Autonomy, Administrative Science Quarterly, Vol. 3 (1958), pp. 409-443.

Dillman, D.A., Mail and Telephone Surveys, The Total Design Method, John Wiley \& Sons, New York (1978).

DOWNEY, H.K. AND J.W. SLOCUM, Uncertainty: Measures, Research and Sources of Variation, Academy of Management Journal, Vol. 18 (1975), pp. 562-578.

DOWNEY, H.K., D. HELLRIEGEL AND J.W. SLOCUM, Environmental Uncertainty: The Construct and its Application, Administrative Science Quarterly, Vol. 20 (1975), pp. 613-629.

DOWNEY, H.K., D. HELLRIEGEL AND J.W. SLOCUM, Individual Characteristics as Sources of Perceived Uncertainty Variability, Human Relations, Vol. 30 (1977), pp. 161174.

DRAZIN, R. AND A.H. VANDEVEN, Alternative Forms of Fit in Contingency Theory, Administrative Science Quarterly, Vol. 30 (1985), pp. 514-539.

DUNCAN, R.B., Characteristics of Organizational Environments and Perceived Environmental Uncertainty, Administrative Science Quarterly, Vol. 17 (1972), pp. 313-327.

DUNK, A.S., Budgetary Participation, Agreement on Evaluation Criteria and Managerial Performance: A Research Note, Accounting, Organizations and Society, Vol. 15 (1990), pp. 171-178.

DUNK, A.S., The Effects of Managerial Level on the Relationship Between Budgetary Participation and Job Satisfaction, British Accounting Review, Vol. 24 (1992), pp. 207-218. 


\section{ACCOUNTING FOR PERFORMANCE EVALUATION}

DUNK, A.S., The Effect of Budget Emphasis and Information Asymmetry on the Relation between Budgetary Participation and Slack, The Accounting Review, Vol. 68 (1993), pp. 400-410.

DUNLAP, W.P. AND E.R. KEMERY, Failure to Detect Moderating Effects: Is Multicollinearity the Problem?, Psychological Bulletin, Vol. 102 (1987).

EARLY, P.C., Influence of Information, Choice, and Task Complexity upon Goal Acceptance, Performance, and Personal Goals, Journal of Applied Psychology, Vol. 70 (1985), pp. 481-491.

EARLY, P.C., W. PREST, AND P. WOJNAROSKI, Task Planning and Energy Expended: Exploration of How Goals Influence Performance, Journal of Applied Psychology, Voll. 72 (1987).

EARLY, P.C., T. CONNOLLY AND G. EKEGREN, Goals, Strategy Development, and Task Performance: Some Limits on the Efficacy of Goal Setting, Journal of Applied Psychology, Vol. 74 (1989), pp. 24-33.

EBELING, K.S., AND P.S. SPEAR, Preference and Performance on Two Tasks of Varying Ambiguity as a Function of Ambiguity Tolerance, Australian Journal of Psychology, Vol. 32 (1980), pp. 127-133.

ENN-DOR, P. AND E. SEGEV, Organizational Context and the Success of Management Information Systems, Management Science, Vol. C24 (1978), pp. 1064-1077.

EISENHARDT, K.M., Control: Organizational and Economic Approaches, Management Science, Vol. C31 (1985), pp. 134-149.

EMMANUEL, C., D. OTLEY AND K. MERCHANT, Accounting for Management Control, Chapman \& Hall, New York (1990).

EMORY, C.W. AND D.R. COOPER, Business Research Methods, Irwin, Homewood, Illinois (1991).

EwUSI-MENSAH, K., The External Organizational Environment and its Impact on Management Information Systems, Accounting, Organizations and Society, Vol. 6 (1981), pp. 301-316.

EZZAMEL, M., The Impact of Environmental Uncertainty, Managerial Autonomy and Size on Budget Characteristics, Management Accounting Research, Vol. 1 (1990), pp. 181-197.

FAIRCLOTH, A.W. AND D.N. RICCHUTE, Ambiguity Tolerance and Financial Reporting Alternatives, Accounting, Organizations and Society, Vol. 6 (1981), pp. 53-67.

FERREIRA, L.D. AND K.A. MERCHANT, Field Research in Management Accounting and Control: A Review and Evaluation, Accounting, Auditing and Accountability Journal, Vol. 5 (1992), pp. 3-34.

FERrIS, K.R., Perceived Uncertainty and Job Satisfaction in the Accounting Environment, Accounting, Organizations and Society, Vol. 2 (1977a), pp. 23-28.

FERRIS, K.R., A Test of the Expectancy Theory of Motivation in an Accounting Environment, The Accounting Review, Vol. 52 (1977b), pp. 605-615.

Ferris, K.R. AND M.E. HASKINS, Perspectives on Accounting Systems and Human Behavior, Accounting, Auditing and Accountability Journal, Vol. 1 (1988), pp. 3-18. 


\section{REFERENCES}

FISHER, C., The Impact of Perceived Environmental Uncertainty and Individual Differences on Management Information Requirements: A Research Note, Accounting, Organizations and Society, Vol. 21 (1996), pp. 361-369.

FISHER, C.D., On the Dubious Wisdom of Expecting Job Satisfaction to Correlate with Performance, Academy of Management Review, Vol. 5 (1980), pp. 507-512.

FisHER, J., Technological Interdependence, Labor Production Functions and Control Systems, Accounting, Organizations and Society, Vol. 19 (1994), pp. 493-506.

FISHER, J., Contingency-based Research on Management Control Systems: Categorization by Levels of Complexity, Journal of Accounting Literature, Vol. 14 (1995), pp. 24-53. 1424

FLAMHOLTZ, E.G. AND T.K. DAS, Toward an Integrative Framework of Organizational Control, Accounting, Organizations and Society, Vol. 10 (1985), pp. 35-50.

FOLGER, R., AND D. LEWTS, Self-Appraisal and Faimess in Evaluations, in: Justice in the Workplace, Approaching Faimess in Human Resource Management, R. Cropanzano ed., Erlbaum, Hillsdale (1993), pp. 107-131.

Freedman, D., R. PISANI, R. PURVES AND A. AdHIKARI, Statistics, Norton, New York (1991).

FRENKEL-BRUNSWTK, E., Intolerance of Ambiguity as an Emotional and Perceptual Personality Variable, Journal of Personality, Vol. 18 (1949), pp. 108-143.

FRONE, M.R., Intolerance of Ambiguity as a Moderator of the Occupational Role StressStrain Relationship: A Meta-Analysis, Joumal of Organizational Behavior, Vol.

11 (1990), pp. 309-320.

FruCot, V. AND W.T. SHEARON, Budgetary Participation, Locus of Control, and Mexican Managerial Performance and Job Satisfaction, The Accounting Review, Vol. 66 (1991), pp. 80-99.

FULK, J., A.P. BRIEF AND S.H. BARR, Trust-in-Supervisor and Perceived Faimess and Accuracy of Performance Evaluations, Journal of Business Research, Vol. 13 (1985), pp. 301-313.

GaLBRAITH, J.R., Organization Design, Addison-Wesley, Reading (1977).

GILES, W.F. AND K.W. MOSSHOLDER, Employee Reactions to Contextual and Session Components of Performance Appraisal, Journal of Applied Psychology, Vol. 75 (1990), pp. 371-377.

GIROUX, G.A., A.G. MAYPER AND R.L. DAFT, Organization size, budget cycle, and budget related influence in city-governments: an empirical study, Accounting, Organizations and Society, Vol. 11 (1986), pp. 499-519.

GORDON, L.A. AND D. MiLLER, A Contingency Framework for the Design of Accounting Information Systems, Accounting, Organizations and Society, Vol. 1 (1976), pp. 59-69.

Gordon, L.A. AND V.K. NARAYANAN, Management Accounting Systems, Perceived Environmental Uncertainty and Organization Structure: An Empirical Investigation, Accounting, Organizations and Society, Vol. 9 (1984), pp. 33-47. GOVINDARAJAN, V., Appropriateness of Accounting Data in Performance Evaluation: An Empirical Investigation of Environmental Uncertainty as an Intervening 
Variable, Accounting, Organizations and Society, Vol. 9 (1984), pp. 125-135.

GOVINDARAJAN, V., A Contingency Approach to Strategy Implementation at the Business-unit Level: Integrating Administrative Mechanisms with Strategy, Academy of Management Journal, Vol. 31 (1988), pp. 828-853.

GOVINDARAJAN, V. AND A.K. GUPTA, Linking Control Systems to Business Unit Strategy: Impact on Performance, Accounting, Organizations and Society, Vol. 10 (1985), pp. 51-66.

GRESOV, C., Exploring Fit and Misfit with Multiple Contingencies, Administrative Science Quarterly, Vol. 34 (1989), pp. 431-453.

GUL, F.A., The Joint and Moderating Role of Personality and Cognitive Style on Decision Making, The Accounting Review, Vol. 59 (1984), pp. $264-277$.

GUL, F.A., Tolerance for Ambiguity, Auditors' Opinions and Their Effects on Decision Making, Accounting and Business Research, Vol. 16 (1986), pp. 99-105.

GUL, F.A., The Effects of Management Accounting Systems and Environmental Uncertainty on Small Business Managers' Performance, Accounting and Business Research, Vol. 21 (1991), pp. 57-61.

GUL, F.A. AND Y.M. CHIA, The Effects of Management Accounting Systems, Perceived Environmental Uncertainty and Decentralization on Managerial Performance: A Test of a Three-way Interaction, Accounting, Organizations and Society, Vol. 19 (1994), pp. 413-426.

GuPTA, A.K. AND V. GovindaraJAN, Business Unit Strategy, Managerial Characteristics and Business Unit Effectiveness At Strategy Implementation, Academy of Management Journal, Vol. 27 (1984), pp. 25-41.

GUPTA, N. AND T.A. BEEHR, Job Stress and Employee Behaviors, Organizational Behavior and Human Performance, Vol. 24 (1979), pp. 373-387.

HARRIS, R.J. AND M.A. JOYCE, What's Fair? It Depends on How You Phrase the Question, Journal of Personatity and Social Psychology, Vol. 38 (1980), pp. 165179.

HARRISON, G.L., The Cross-Cultural Generalizability of the Relation Between Participation, Budget Emphasis and Job-Related Attitudes, Accounting, Organizations and Society, Vol. 17 (1992), pp. 1-15.

HARRISON, G.L., Reliance on Accounting Performance Measures in Superior Evaluative Style, The Influence of National Culture and Personality, Accounting, Organizations and Society, Vol. 18 (1993), pp. 319-339.

HARTMANN, F.G.H., Accounting Information, MBO systems and Performance Judgment Accuracy: A Research Note, unpublished working paper, University Maastricht (1995).

HAYES, D.C., The Contingency Theory of Managerial Accounting, The Accounting Review, Vol. 52 (1977), pp. 22-39.

HIRST, M.K., Accounting Information and the Evaluation of Subordinate Performance: A Situational Approach, The Accounting Review, Vol. 56 (1981), pp. 771-784.

HIRST, M.K., The Controllability of Financial Outcomes, Abacus, Vol. 19 (1983a), pp. 29-38. 


\section{REFERENCES}

HIRST, M.K., Reliance on Accounting Performance Measures, Task Uncertainty and Dysfunctional Behavior: Some Extensions, Journal of Accounting Research, Vol. 21 (1983b), pp. 596-605.

HIRST, M.K., The Effects of Setting Budget Goals and Task Uncertainty on Performance: A Theoretical Analysis, The Accounting Review, Vol. 62 (1987), pp. 774-784.

HIRST, M.K. AND S.M. LowY, The Linear Additive and Interactive Effects of Budgetary Goals Difficulty and Feedback on Performance, Accounting, Organizations and Society, Vol. 15 (1990), pp. 425-436.

Ho, J.L. AND W. RODGERS, A Review of Accounting Research on Cognitive Characteristics, Journal of Accounting Literature, Vol. 12 (1993), pp. 101-130.

HofstedE, G., The Game of Budget Control, Van Gorcum, Assen (1967).

Hofstede, G., The Poverty of Management Control Philosophy, Academy of Management Review, Vol. 3 (1978), pp. 450-461.

HofstedE, G., Management Control of Public and Not-for-profit Activities, Accounting, Organizations and Society, Vol. 6 (1981), pp. 193-211.

HOLLENBECK, J.R. AND H.J. KLEIN, Goal Commitment and the Goal-setting Process: Problems, Prospects, and Proposals for Future Research, Journal of Applied Psychology, Vol. 72 (1987), pp. 212-220.

Hopwood, A.G., An Empirical Study of the Role of Accounting Data in Performance Evaluation, Journal of Accounting Research, Vol. 10 (1972), pp. 156-182.

Hopwood, A.G., An Accounting System and Managerial Behaviour, Saxon House, Westmead (1973).

HoPwOOD, A.G., Leadership Climate and the Use of Accounting Data in Performance Evaluation, The Accounting Review, Vol. 49 (1974), pp. 485-495.

Hopwood, A.G., Towards an Organizational Perspective for the Study of Accounting and Information Systems, Accounting, Organizations and Society, Vol. 3 (1978), pp. 3-13.

HopwoOD, A.G., On Trying to Study Accounting in the Contexts in Which it Operates, Accounting, Organizations and Society, Vol. 8 (1983), pp. 287-305.

HoRngren C.T. AND G. Foster, Cost Accounting: A Managerial Emphasis, PrenticeHall, Englewood-Cliffs (1991).

Horngren C.T., G. Foster AND S.M. DATAR, Cost Accounting: A Managerial Emphasis, Prentice-Hall, Upper Saddle River (1997).

Horngren C.T. G.L. SUNDEM AND W.O. STRATTON, Introduction to Management Accounting, Prentice-Hall, Upper Saddle River (1996)

House, R.J., A Path Goal Theory of Leader Effectiveness, Administrative Science Quarterly, Vol. 16 (1971), pp. 321-339.

House, R.J., AND J.R. RIzzo, Role Conflict and Ambiguity as Critical Variables in a Model of Organizational Behavior, Organizational Behavior and Human Performance, Vol. 7 (1972), pp. 467-505.

HUSEMAN, R.C., J.D. HATfielD AND E.W. Miles, A New Perspective on Equity Theory: The Equity Sensitivity Construct, Academy of Management Review, Vol. 12 (1987), pp. 222-234. 
IAFFALDANO, M.T. AND P.M. MUCHINSKY, Job Satisfaction and Job Performance: a Meta-Analysis, Psychological Bulletin, Vol. 97 (1985), pp. 251-273.

ILGEN, D.R. AND J. SCHNEIDER, Performance Measurement: A Multi-Discipline View, International Review of Industrial and Organizational Psychology, Vol. 6 (1991).

IMOISILI, O.A., The Role of Budget Data in the Evaluation of Managerial Performance, Accounting Organizations and Saciety, Vol. 14 (1989), pp. 325-335.

JACCARD, J., R. TURRISI AND C.K. WAN, Interaction Effects in Multiple Regression, Sage, Newbury Park, 1990.

JAMAL, M., Job Stress and Job Performance Controversy: An Empirical Assessment, Organizational Behavior and Human Performance, Vol. 33 (1984), pp. 1-21.

JA WORSKI, B.J. AND S.M. YOUNG, Dysfunctional Behavior and Management Control: An Empirical Study of Marketing Managers, Accounting, Organizations and Society, Vol. 17 (1992), pp. 17-35.

JEX, S.M., T.A. BEEHR AND C. K. RoBERTS, The Meaning of Occupational Stress Items to Survey Respondents, Journal of Applied Psychology, Vol. 77 (1992), pp. 623628.

JUDGE, T.A. AND G.R. FERRIS, Social Context of Performance Evaluation Decisions, Academy of Management Journal, Vol. 36 (1993), pp. 80-105.

KAHN, R.L., Discussion of: An Empirical Study of the Role of Accounting Data in Performance Evaluation, Journal of Accounting Research, Vol. 10 (1972), pp. 183-186.

KAHN, R.L., Organizational Effectiveness: An Overview, in: New Perspectives on Organizational Effectiveness, P.S. Goodman and J.M. Pennings eds., Jossey-Bass, San Francisco (1977), pp. 235-248.

KAHN, L.M. AND P.D. SHERER, Contingent Pay and Managerial Performance, Industrial and Labor Relations Review, Vol. 43 (1990).

KAHN, R.L., D.M. WOLFE, R.P. QUINN AND J.D. SNOEK, Organizational Stress: Studies in Role Conflict and Ambiguity, John Wiley \& Sons, New York (1964).

KALLMAN, E.A., AND W.P. MCKINNON, Case Study: Evaluating IS by Using an Executive Information System, Journal of Information Systems Management, Vol. 6(1989), pp. 58-68.

KALTON, G., Introduction to Survey Sampling, Sage, Newbury Park (1983).

KAPLAN, R.S., AND A.A. ATKINSON, Advanced Management Accounting, Prentice-Hall, Englewood-Cliffs (1989).

K.APLAN, R.S., Management Accounting (1984-1994): Development of New Practice and Theory, Management Accounting Research, Vol. 5 (1994), pp. 247-260.

KAPLAN, S.E. AND J.T. MACKEY, An Examination of the Association Between Organizational Design Factors and the Use of Accounting Information for Managerial Performance Evaluation, Journal of Management Accounting Research, Vol. 4 (1992), pp. 116-130.

Keeley, M., Subjective Performance Evaluation and Person-Role Conflict under Conditions of Uncertainty, Academy of Management Journal, Vol. 20 (1977), pp. 30l-314. 


\section{REFERENCES}

KENIS, I., Effects of Budgetary Goals Characteristics on Managerial Attitudes and Performance, The Accounting Review, Vol. 54 (1979), pp. 707-721.

KERLNGER, F.N., Foundations of Behavional Research, Holt, Rinehart and Winston, Fort Worth (1986).

KERLINGER, F.N., AND E.J. PEDHAZUR, Multiple Regression in Behavioral Research, Holt, Rinehart and Winston, New York (1973).

KHANDWALLA, P.N., The Effect of Different Types of Competition on the Use of Management Controls, Joumal of Accounting Research, Vol. 10 (1972), pp. 275285.

KIM, K.K., Organizational Coordination and Performance in Hospital Accounting Information Systems: An Empirical Investigation, The Accounting Review, Vol. 63 (1988), pp. 472-489.

KIM J-O., AND C.W. MUELler, Factor Analysis: Statistical Methods and Practical Issues, Sage, Beverly Hills (1978).

KiRBY, A.K., S. ReichelsteIN, P.D. SEN AND T.Y. PAIK, Participation, Slack and Budget-based Performance Evaluation, Journal of Accounting Research, Vol. 29 (1991), pp. 109-128.

KIRTON, M.J., A Reanalysis of Two Scales of Tolerance of Ambiguity, Journal of Personality Assessment, Vol. 45 (1981), pp. 407-414.

KLEIN, H.J., An Integrated Control Theory Model of Work Motivation, Academy of Management Review, Vol. 14 (1989), pp. 165-172.

KREN, L., Performance in a Budget-Based Control System: An Extended Expectancy Theory Model Approach, Journal of Management Accounting Research, Vol. 2 (1990), pp. 100-112.

KREN, L., Budgetary Participation and Managerial Performance: The Impact of Information and Environmental Volatility, The Accounting Review, Vol. 67 (1992).

KREN, L. AND J.L. KERR, The Effect of Behaviour Monitoring and Uncertainty on the Use of Performance-Contingent Compensation, Accounting and Business Research, Vol. 23 (1993), pp. 159-168.

KREN L. AND W.M. LIAO, The Role of Accounting Information in the Control of Organizations: A Review of the Evidence, Journal of Accounting Literature, Vol. 7 (1988), pp. 280-309.

LAL, M., A.S. DUNK AND G.D. SMTTH, The Proprensity of Managers to Create Budgetary Slack: a Cross-national Re-examination Using Random Sampling, The International Journal of Accounting, Vol. 31 (1996), Pp. 483-496.

LANDY, F.J., J.L. BARNES AND K.R. MURPHY, Correlates of Perceived Fairness and Accuracy of Performance Evaluation, Journal of Applied Psychology, Vol 63 (1978), pp. 751-754.

LANDY, F.J., AND J.L. FARR, Performance Rating, Psychological Bulletin, Vol. 87 (1980), pp. 72-107.

LANDY, F.J., Psychology and Work Behavior, Brooks/Cole, Pacific Grove (1989).

LANDY, F.J., J. BARNES-FARRELL, AND J.N. CLEVELAND, Perceived Fairness and 


\section{ACCOUNTING FOR PERFoRMANCE EVALUATION}

Accuracy of Performance Evaluation: A Follow-up, Journal of Applied Psychology, Vol. 65 (1980), pp. 355-356.

L.AU, C.M., L.C. LOW AND I.R.C. EGGLETON, The Impact of Reliance on Accounting Performance Measures on Job-related Tension and Managerial Performance: Additional Evidence, Accounting, Organizations and Society, Vol. 20 (1995), pp. 359-381.

LAUDON, K.C. AND J.P. LAUDON, Management Information Systems: Organization and Technology, Prentice Hall, Upper Saddle River (1996).

LAWLER, E.E. AND J.G. RHODE, Information and Control in Organizations, Goodyear, Pacific Palisades (1976).

LAWRENCE, P.R. AND J.W. LORSCH, Organization and Environment, Managing Differentiation and Integration, Harvard, Boston (1967).

LEWIN, A.Y. AND C.U. STEPHENS, CEO Attitudes as Determinants of Organization Design: An Integrated Model, Organizations Studies, Vol. 15 (1994), pp. 183212.

LINDQUIST, T.M., Fairness as an Antecedent to Participative Budgeting: Examining the Effects of Distributive Justice, Procedural Justice and Referent Cognitions on Satisfaction and Performance, Journal of Management Accounting Research; Vol. 7 (1995), pp. $122-147$.

LINDSAY, R. M., Reconsidering the Status of Tests of Significance: An Alternative Criterion of Adequacy, Accounting, Organizations and Saciety, Vol. 20 (1995), pp. 35-53.

LockE, E.A., Toward a Theory of Task Motivation and Incentives, Organizational Behavior and Human Performance, Vol. 3 (1968), pp. 157-189.

LOCKE, E.A., D.O. CHAH, S. HARRISON AND N. LUSTGARTEN, Separating the Effects of Goal Specificity from Goal Level, Organizational Behavior and Human Decision Processes, Vol. 45 (1989), pp. 270-287.

Locke, E.A. AND G.P. LATHAM, A Theory of Goal Setting \& Task Performance, Prentice-Hall, Englewood-Cliffs (1990).

LORANGE, P. AND M.S. SCOTT MORTON, A Framework for Management Control Systems, Sloan Management Review, Vol. 16 (1974), pp. 41-56.

LORSCH J.W. AND S.A. ALLEN, Managing Diversity and Interdependency: An Organizational Study of Multidivisional Firms, Graduate School of Business Administration, Harvard University, Boston (1973).

LOWE, E.A., On the Idea of a Management Control System: Integrating Accounting and Management Control, The Jounnal of Management Studies, Vol. 8 (1971), pp. 112.

LUCKETT, P.F. AND I.R. EGGLETON, Feedback and Management Accounting: A Review of Research into Behavioural Consequences, Accounting, Organizations and Society, Vol. 16 (1991), pp. 371-394.

LUCKETT, P.F. AND M.K. HIRST, The Impact of Feedback on Inter-rater Agreement and Self Insight in Performance Evaluation Decisions, Accounting, Organizations and Society, Vol. 14 (1989), pp. 379-387. 


\section{REFERENCES}

LYKKEN, D.T., Statistical Significance in Psychological Research, Psychological Bulletin, Vol. 70 (1968), pp. 151-159.

LYNCH, B.P., An Empirical Assessment of Perrow's Technology Construct, Administrative Science Quarterly, Vol. 19 (1974), pp. 338-356.

LYNE, S.R., Perceptions and Attitudes of Different User-groups to the Role of the Budget, Budget Pressure and Budget Participation, Accounting and Business Research, Vol. 22 (1992), pp. 357-369.

LYONS, T.F., Role Clarity, Need for Clarity, Satisfaction, and Withdrawal, Organizational Behavior and Human Performance, Vol. 6 (1971), pp. 99-110.

LYSONSKI, S., AND S. DURVAsUlA, Effects of Moderating Variables on Product Managers” Behavior: A Reexamination, Psychological Reports, Vol. 67 (1990), pp. 687-690.

MACDONALD, A.P., Revised Scale for Ambiguity Tolerance: Reliability and Validity, Psychological Reports, Vol. 26 (1970), pp. 791-798.

MACHIN, J.L.J., Management Control Systems: Whence and Whither, in: New Perspectives in Management Control, E.A. Lowe and J.L.J. Machin, Macmillan, London (1983).

MACINTOSH, N.B. AND R.L. DAFT, Management Control Systems and Departmental Interdependencies: An Empirical Study, Accounting, Organizations and Society, Vol. 12 (1987), pp. 49-61.

MACINTOSH, N.B. AND R.W. SCAPENS, Structuration Theory in Management Accounting, Accounting, Organizations and Society, Vol. 15 (1990), pp. 455-477.

MACINTOSH, N.B. AND R.W. SCAPENS, Management Accounting and Control Systems: A Structuration Theory Analysis, Journal of Management Accounting Research, Vol. 3 (1991), pp. 131-158.

MAGNER, N., R.B. WELKER AND T.L. CAMPBELL, The Interactive Effect of Budgetary Participation and Budget Favorability on Attitudes Toward Budgetary Decision Makers: A Research Note, Accounting, Organizations and Society, Vol. 20 (1995), pp. 611-618.

MAHONEY, T.A., Development of Managerial Performance, a Research Approach, Monograph, Cincinnatti (1963).

MAK, Y.T., Contingency Fit, Internal Consistency and Financial Performance, Journal of Business Finance and Accounting, Vol. 16 (1989), pp. 273-300.

MARTIN, J.G. AND F.R. WESTIE, The Tolerant Personality, American Sociological Review, Vol. 24 (1959), pp. 521-528.

MCCONKIE, M.L., A Clarification of the Goal Setting and Appraisal Processes in MBO, Academy of Management Journal, Voll 4 (1979), pp. 29-40.

MCGHEE, W., M.D. SHIELDS AND J.G. BIRNBERG, The Effects of Personality on a Subject"s Information Processing, The Accounting Review, Vol. 53 (1978), pp. 681-697.

MERCHANT, K.A., The Design of the Corporate Budgeting System: Influences on Managerial Behavior and Performance, The Accounting Review, Vol. 56 (1981), pp. 813-829. 
MERCHANT, K.A., The Control Function of Management, Sloan Management Review, Vol. 23 (1982); pp. 43-55.

MERCHANT, K.A., Influences on Departmental Budgeting: An Empirical Examination of a Contingency Model, Accounting, Organizations and Society, Vol. 9 (1984), pp. 291-307.

MERCHANT, K.A., Control in Business Organizations, Pitman, Boston (1985a).

MERCHANT, K.A., Organizational Controls and Discretionary Program Decision Making: A Field Study, Accounting, Organizations and Saciety, Vol. 10 (1985b), pp. 6785.

MERCHANT, K.A., Budgeting and the Propensity to Create Budget Slack, Accounting, Organizations and Society, Vol. 10 (1985c), pp. 201-210.

MERCHANT, K.A., How and Why Firms Disregard the Controllability Principle. In: Field Studies in Management Accounting, W.J. Bruns and R.S. Kaplan eds., Harvard Business School Press, Boston (1987).

MERCHANT, K.A., Rewarding Results: Motivating Profit Center Managers, Harvard Business School Press, Boston (1989).

MERCHANT, K.A., The Effects of Financial Controls on Data Manipulation and Management Myopia, Accounting, Organizations and Society, Vol. 15 (1990), pp. 297-313.

MERChANT, K.A. AND J.F. MANZONI, The Achievability of Budget Targets in Profit Centers: a Field Study, The Accounting Review, Vol. 64 (1989), pp. 539-558.

MERCHANT, K.A. AND A. RICCABONI, Performance-based Management Incentives at the Fiat Group: A Field Study, Management Accounting Research, Vol. 1 (1990), pp. 281-303.

MERCHANT, K.A. AND R. SIMONS, Research and Control in Complex Organizations: An Overview, Journal of Accounting Literature, Vol. 5 (1986), pp. 183-203.

MESSICK, D.M. AND K. SENTIS, Faimess, Preference, and Fairness Biases, in: Equity Theory, Psychological and Sociological Perspectives, D.M. Messick and K.S. Cook eds., Preager, New York (1983), pp. 61-94.

MEYER, J.P., S.V. PAUNONEN, I.R. GellatlY, R.D. GofFIN AND D.N. JACKSON, Organizational Commitment and Job Performance: It's the Nature of the Commitment That Counts, Journal of Applied Psychology, Vol. 74 (1989), pp. 152-156.

MIA, L. AND R.H. CHENHALL, The Usefulness of Management Accounting Systems, Functional Differentiation and Management Effectiveness, Accounting, Organizations and Society, Vol. 19 (1994), pp. 1-13.

MICELI, M.P., Justice and Pay System Satisfaction, in: Justice in the Workplace, Approaching Fairness in Human Resource Management, R. Cropanzano ed., Erlbaum, Hillsdale (1993), pp. 257-283.

MILANI, K., The Relationship of Participation in Budget-setting to Industrial Supervisor Performance and attitudes: a Field Study, The Accounting Review, Vol. 50 (1975), pp. 274-284.

MiLes, R.E. AND C.C. SNOW, Organizational Strategy, Structure and Process, McGraw- 


\section{REFERENCES}

Hill, New York (1978).

MILLER, E.L., Responsibility Accounting and Performance Evaluations, Van Nostrand Rheingold, New York (1982).

MILLIKEN, F.J., Three Types of Perceived Uncertainty About the Environment: State, Effect, and Response Uncertainty, Academy of Management Review, Vol. 12 (1987), pp. 133-143.

MilKovich, G.T. AND J.M. NeWMaN, Compensation, Irwin, Homewood (1993).

MinTzBeRG, H., The Structuring of Organizations, Prentice-Hall, Englewood Cliffs (1979).

MURPHY, K.R., AND W.K. BALZER, Rater Errors and Rating Accuracy, Journal of Applied Psychology, Vol. 74 (1989), pp. 619-624.

MURRAY, D., The Performance Effects of Participative Budgeting: An Integration of Intervening and Moderating Variables, Behavioral Research in Accounting, Vol. 2 (1990), pp. 104-123.

NEU, D., The Social Construction of Positive Choices, Accounting, Organizations and Society, Vol. 17 (1992), pp. 223-237.

NEUBERG, S.L. AND J.T. NEWSOM, Personal Need for Structure: Individual Differences in the Desire for Simple Structure, Journal of Personality and Social Psychology, Vol. 65 (1993), pp. 113-131.

NoRTON, R.W., Measurement of Ambiguity Tolerance, Journal of Personality Assessment, Vol. 39 (1975), pp. 607-619.

NoRUŠIS, M.J., SPSS for Windows Base System User Guide, Release 6.0, SPSS Inc., Chicago (1993).

NoRUŠIS, M.J., SPSS 6.1 for Windows Update, SPSS Inc., Chicago (1994a).

NoRUŠIS, M.J., SPSS Advanced Statistics 6.1, SPSS Inc., Chicago (1994b).

NoRUŠIs, M.J., SPSS Professional Statistics 6.1, SPSS Inc., Chicago (1994c).

NUNNALl Y J.C., AND I.H. BERNSTEIN, Psychometric Theory, McGraw-Hill, New York (1994).

OLIVER, J. AND E. FLAMHOLTZ, Human Resource Replacement Cost Numbers. Cognitive Information Processing, and Personnel Decisions: A Laboratory Experiment, Journal of Business Finance and Accounting, Vol. 5 (1987), pp. 137-157.

OPPENHEIM, A.N., Questionnaire Design and Attitude Measurement, Basic Books, New York (1966).

OPPENHEIM, A.N., Questionnaire Design, Interviewing and Attitude Measurement, Pinter, London (1992).

OsIGWEH, C.A.B., Concept Fallibility in Organizational Science, Academy of Management Review, Vol. 14 (1989), pp. 579-594.

OTLEY, D.T., Budget Use and Managerial Performance, Journal of Accounting Research, Vol. 16 (1978), pp. 122-149.

OTLEY, D.T., The Contingency Theory of Management Accounting: Achievement and Prognosis, Accounting, Organizations and Society, Vol. 5 (1980), pp. 413-428.

OTLEY, D.T., Issues in Accountability and Control: Some Observations from a Study of Colliery Accountability in the British Coal Corporation, Management Accounting 


\section{ACCOUNTING FOR PERFORMANCE EVALUATION}

Research, Vol. 1 (1990), pp. 101-123.

OTLEY, D.T., Management Control in Contemporary Organizations: Towards a Wider

Framework, Management Accounting Research, Vol. 5 (1994), pp. 289-299.

OTLEY, D.T. AND A.J. BERRY, Control, Organization and Accounting, Accounting, Organizations and Society, Vol. 5 (1980), pp. 231-244.

OTLEY, D.T, J. BROADBENT AND A.J. BERRY, Research in Management Control: An Overview of its Development, British Journal of Management, Vol. 6 (1995), pp. $31-44$.

OUCHI, W.G., The Relationship Between Organizational Structure and Organizational Control, Administrative Science Quarterly, Vol. 22 (1977), pp. 95-113.

OUCHI, W.G., The Transmission of Control Through Organizational Hierarchy, Academy of Management Journal, Vol. 21 (1978), pp. 173-192.

OUCHI, W.G., A Conceptual Framework for the Design of Organizational Control Mechanisms, Management Science, Vol. 25 (1979), pp. 833-848.

OUCHI, W.G. AND M.A. MAGUIRE, Organizational Control: Two Functions, Administrative Science Quarterly, Vol. 20 (1975), pp. 559-569.

PARKER, L.D., The Classical Model of Control in the Accounting Literature, The Accounting Historians Journal, Vol. 13 (1986), pp. 71-92.

PARKER, L.D. AND N.R. LEWIS, Classical Management Control in Contemporary Management and Accounting: The Persistence of Taylor and Fayol's World, Accounting, Business and Financial History, Vol. 5 (1995), pp. 21 1-235.

PEDHAZUR, E.J. AND L. PeDHAZUR-SCHMELKIN, Measurement, Design and Analysis: an Integrated Approach, Erlbaum, Hillsdale (1991).

PERRow, C., A Framework for Comparative Organizational Analysis, American Sciological Review, Vol. 32 (1967), pp. 194-208.

PERRow, C., Organizational Analysis: A Sociological View, Tavistock, London (1970).

PERvin, L.A., The Science of Personality, John Wiley \& Sons, New York (1996).

PINCUS, K.V., Auditor Individual Differences and Fairness of Presentation Judgments, Auditing: A Journal of Practice and Theory, Vol. 9 (1990), pp. 150-166.

PODSAKOFF, P.M., AND D.W. ORGAN, Self-reports in Organizational Research: Problems and Prospects, Journal of Management, Vol. 12 (1986), pp. 531-544.

POEL, J. VAN DE, Judgment and Control. Individual and Organizational Aspects of Performance Evaluation, Wolters-Noordhof, Groningen (1986).

PRATT, J., The Effects of Personality on a Subject's Information Processing: a Comment, The Accounting Review, Vol. 55 (1980), pp. 501-506.

PRENDERGAST, C. AND R. TOPEL, Discretion and Bias in Performance Evaluation, European Economic Review, Vol. 37 (1993), pp. 355-265.

PUXTY, T. AND W.F. CHUA, Ideology, Rationality and the Management Control Process, in: Critical Perspectives in Management Control, W.F. Chua, T. Lowe and T. Puxty eds., MacMillan, Houndmillss (1989), pp. 115-139.

RAHMAN, M. AND A.M. MCGOSH, The Influence of Organisational and Personal Factors on the Use of Accounting Information: An Empirical Study, Accounting, Organizations and Society, Vol. 1 (1976), pp. 339-355. 


\section{REFERENCES}

RIDGWAY, V.F., Dysfunctional Consequences of Performance Measurements, Administrative Science Quarterly, Vol. 1 (1956), pp. 240-247.

RIZZO, J.R., R.J. HoUSE AND S.I. LIRTZMAN, Role Conflict and Ambiguity in Complex Organizations, Administrative Science Quarterly, Vol. 15 (1970), pp. 151-163.

ROBERTS, J., The Possibilities of Accountability, Accounting, Organizations and Society, Vol. 16 (1991), pp. 355-368.

RoCKNESS, H.O., Expectancy Theory in a Budgetary Setting: An Experimental Examination, The Accounting Review, Vol. 52 (1977), pp. 893-903.

ROCKNESS, H.O. AND M.D. SHIELDS, Organizational Control Systems in Research and Development, Accounting, Organizations and Society, Vol. 9 (1984), pp. 165177.

RODGERS, R. AND J. E. HUNTER, Impact of Management by Objectives on Organizational Productivity, Journal of Applied Psychology, Vol. 76 (1991), pp. 322-336.

RONEN, J. AND J.L. LIVINGSTONE, An Expectancy Theory Approach to the Motivational Impacts of Budgets, The Accounting Review, Vol. 50 (1975), pp. 671-685.

ROSKIN, R., AND C. MARGERISON, The Effectiveness of Some Measures of Managerial Effectiveness, Human Relations, Vol. 36 (1983), pp. 865-882.

Ross, A., Trust as a Moderator of the Effect of Performance Evaluation Style on JobRelated Tension: A Research Note, Accounting, Organizations and Society, Vol. 19 (1994), pp. 629-635.

Ross, A., Job Related Tension, Budget Emphasis and Uncertainty: A Research Note, Management Accounting Research, Vol. 6 (1995), pp. 1-11.

SALANCIK, G.R. AND J. PFEFFER, An Examination of Need-satisfaction Models of Job Attitudes, Administrative Science Quarterly, Vol. 22 (1977), pp. 427-456.

SALANCIK, G.R. AND J. PFEFFER, A Social Information Processing Approach to Job Attitudes and Task Design, Administrative Science Quarterly, Vol. 23 (1978), pp. 224-253.

SATHE, V., The Relevance of Modern Organization Theory for Managerial Accounting, Accounting, Organizations and Society, Vol. 3 (1978), pp. 89-92.

SAWYER, J.E., Goal and Process Clarity: Specification of Multiple Constructs of Role Ambiguity and a Structural Equation Model of Their Antecedents and Consequences, Journal of Applied Psychology, Vol. 77 (1992), pp. 130-142.

SCHULER, R.S., Definition and Conceptualization of Stress in Organizations, Organizational Behavior and Human Performance, Vol. 27 (1980), pp. 184-215.

SCHULER, R.S., N.J. BEUTELl AND S.A. YOUNGBLOOD, Effective Personnel Management, West Publishing Company, St. Paul (1989).

SCHMIDT, F.L. AND J.E. HuNTER, Moderator Research and the Law of Small Numbers, Personnel Psychology, Vol. 31 (1978), pp. 215-232.

SCHOONHOVEN, C.B., Problems with Contingency Theory: Testing Assumptions Hidden Within the Language of Contingency 'Theory', Administrative Science Quarterly, Vol. 26 (1981), pp. 349-377.

SCorT, W.R., Effectiveness of Organizational Effectiveness Studies, in: New Perspectives on Organizational Effectiveness, P.S. Goodman and J.M. Pennings 
eds., Jossey-Bass, San Francisco (1977), pp. 63-95.

SEARFOSS, D.G., Some Behavioral Aspects of Budgeting for Control: An Empirical Study, Accounting, Organizations and Society, Vol. 1 (1976), pp. 375-385.

SELTO, F.H., C.J. RENNER AND S.M. YOUNG, Assessing the Organizational Fit of a Justin-time Marufacturing System: Testing Selection, Interaction and Systems Models of Contingency Theory, Accownting, Organizations and Society, Vol. 20 (1995), pp. 665-684.

SHARMA, S., R.M. DURAND AND O. GUR-ARIE, Identification and Analysis of Moderator Variables, Journal of Marketing, Vol. 18 (1981), pp. 291-300.

SHEPPARD, B.H., R.J. LEWICKI AND J.W. MNTON, Organizational Justice, The Search for Fairness in the Workplace, Lexington, New York (1992).

SIEGEL S., Nonparametric Statistics for the Behavioral Sciences, McGraw-Hill, New York (1965).

SIEGEL, S. AND N.J. CASTELLAN, Nonparametric Statistics for the Behavioral Sciences, McGraw-Hill, New York (1988).

SIMONS, R., Planning, Control and Uncertainty: A Process View, in: Accounting and Management, Field Study Perspectives, W.J. Bruns and R.S. Kaplan eds., Harvard Business School Press, Boston (1987a), pp. 339-362.

SIMONS, R, Accounting Control Systems and Business Strategy: An Empirical Analysis, Accounting, Organizations and Saciety, Vol. 12 (1987b), pp. 357-374.

SIMONS, R., The Role of Management Control Systems in Creating Competitive Advantage: New Perspectives, Accounting, Organizations and Society, Vol. 15 (1990), pp. 127-143.

SimONS, R., Levers of Control, Harvard Business School Press, Boston (1995).

SINCLAIR, A., The Chameleon of Accountability: Forms and Discourses, Accounting, Organizations and Society, Vol. 20 (1995), pp. 219-237.

SKINNER, R.C., The Role of Profitability in Divisional Decision Making and Performance Evaluation, Accounting and Business Research, Vol. 20 (1990), pp. $135-141$.

SMITH, P.C., Behaviors, Results and Organizational Effectiveness: The Problem of Criteria, in: Handbook of Industrial and Organizational Psychology, M.D. Dunnette ed., John Wiley \& Sons, New York (1983).

SMITH, P.C.. L.M. KENDALL AND C.L. HULIN, The Measurement of Satisfaction in Work and Retirement: a Strategy for the Study of Attitudes, Rand McNally \& Company, Chicago (1969).

SouTHWOOD, K.E., Substantive Theory and Statistical Interaction: Five Models, American Journal of Sociology, Vol. 83 (1978), pp. 1154-1203.

STEERS, R.M., Factors Affecting Job Attitudes in a Goal-Setting Environment, Academy of Management Journal, Vol. 19 (1976), pp. 6-16.

STONE, E.F. AND J.R. HolLENBECK, Some Issues Associated with the Use of Moderated Regression, Organizational Behavior and Human Performance, Vol. 34 (1984), pp. 195-213.

SwIERINGA, R.J. AND R.H. MONCUR, The Relationship Between Managers' Budget- 


\section{REFERENCES}

oriented Behavior and Selected Attitude-Position, Size and Performance Measures, Journal of Accounting Research, Vol. 10 (1972), pp. 194-214.

SWIERINGA, R.J. AND R.H. MONCUR, Some Effects of Participative Budgeting on Managerial Behavior, National Association of Accountants, New York (1975).

THOMPSON, J.D., Organizations in Action. Social Science Base of Administrative Theory. McGraw-Hill, New York (1967).

Tosi, H. L., The Human Effects of Managerial Budgeting Systems, in: Managerial Accounting: The Behavioral Foundations, J.L. Livingstone ed., Georgia Institute of Technology (1975).

TOSI, H.L., R. ALDAG AND R. STOREY, On the Measurement of the Environment: An Assessment of the Lawrence and Lorsch Environmental Uncertainty Subscale, Administrative Science Quarterly, Vol. 15 (1970), pp. 17-36.

TOSI, H.L., J.R. RIZZO AND S.J. CARROLL, Managing Organizational Behavior, Blackwell, Cambridge (1994).

UMaPathY, S., Current Budgeting Practices in U.S. Industry, Quorum, New York (1987).

VAASSEN, E.J.M., Auditors' Decision Processes in Audit Planning Stage Materiality Judgments (unpublished dissertation), Universitaire Pers, Maastricht (1994).

VANCIL, R.F., Decentralization: Managerial Ambiguity by Design, Dow Jones-Irwin, Homewood (1979).

VANDEVEN, A.H. AND A.L.DELBECQ, A Task Contingent Model of Work-unit Structure, Administrative Science Quarterly, Vol. 19 (1974), pp. 183-197.

VANDEVEN, A.H. AND D.L. FERRY, Measuring and Assessing Organizations, John Wiley \& Sons, New York (1980).

Venkatraman, N., The Concept of Fit in Strategy Research: Toward Verbal and Statistical Correspondence, Academy of Management Review, Vol. 14 (1989), pp. 423-444.

VENKATRAMAN, N. AND J.C. CAMILLUS, Exploring the Concept of 'Fit' in Strategic Management, Academy of Management Review, Vol. 9 (1984), pp. 513-525.

WATERHOUSE, J.H. AND P. TIESSEN, A Contingency Framework for Management Accounting Research, Accounting, Organizations and Society, Vol. 3 (1978), pp. 65-76.

WEICK, K.E., M.G. Bougon AND G. MARUYAMA, The Equity Context, Organizational Behavior and Human Performance, Vol. 15 (1976), pp. 32-65.

WEISENFIELD, L.W. AND L.N. KILLOUGH, A Review and Extension of Using Performance Reports: A Field Study Based on Path-Goal Theory, Journal of Management Accounting Research, Vol. 4 (1992), pp. 209-225.

WHOLEY, D.R. AND J. BRITTAIN, Characterizing Environmental Variation, Academy of Management Journal, Vol. 32 (1989), pp. 867-882.

WilliamS, J.J., N.B. MACINTOSH AND J.C. MOORE, Budget-Related Behavior in Public Sector Organizations: Some Empirical Evidence, Accounting, Organizations and Society, Vol. 15 (1990), pp. 221-246.

WitheY, M., R.L. DAFT AND W.H. COOPER, Measures of Pertow's Work Unit 
Technology: An Empirical Assessment and a New Scale, Academy of Management Journal, Vol. 26 (1983), pp. 45-63.

WOOD, R.E., Task Complexity: Definition of the Construct, Organizational Behavior and Human Decision Processes, Vol. 37 (1986), pp. 60-82.

WOOD, R.E., A. BANDURA AND T. BAILEY, Mechanisms Goveming Organizational Performance in Complex Decision-Making Environments, Organizational Behavior and Human Decision Processes, Vol. 46 (1990), pp. 181-201.

WOOD, R.E., A.J. MENTO AND E.A. LOCKE, Task Complexity as a Moderator of Goal Effects: A Meta-analysis, Journal of Applied Psychology, Vol. 72 (1987), pp. 416-425.

WOODWARD, J., Industrial Organization: Theory and Practice, Oxford University Press, London (1965).

YoUNG, S.M., Survey Research in Management Accounting: A Critical Assessment, in: Research Methods in accounting, A.J. Richardson ed., CGA Research Foundation, Vancouver (1996). 


\section{Summary in Dutch (Nederlandse samenvatting)}

\section{Accounting for Performance Evaluation: Effects of Uncertainty on the Appropriateness of Accounting Performance Measures.}

Dit proefschrift beschrijft de opzet, de uitvoering en de resultaten van een empirisch onderzoek naar de geschiktheid ('appropriateness') van het gebruik van accounting informatie voor de beoordeling van managers in gedecentraliseerde organisaties. Zoals in Hoofdstuk 1 ('Inleiding') wordt uiteengezet, past het thema van dit proefschrift in het vakgebied management control. Dit vakgebied behandelt de beheersing van organisaties, met als belangrijkste aandachtspunt de keuze en werking van instrumenten om managers te motiveren de doelstellingen van de organisatie na te streven. De wetenschappelijke inspanning op dit gebied besteedt met name aandacht aan de manier waarop managers voor hun prestaties worden beoordeeld en beloond. In veel organisaties wordt hiervoor accounting informatie gebruikt, waarbij managers worden 'afgerekend' op hun prestaties uitgedrukt in accounting maatstaven (omzet, kosten en winst). Een belangrijk formeel beoordelingsinstrument is het budget, en de daaraan ontleende, zogenaamde, APM ('Accounting Performance Measures').

De vraag die in deze dissertatie centraal staat is welke invloed 'onzekerheid' heeft op de geschiktheid van dergelijke APM voor het beoordelen van managers. Het startpunt bij de beantwoording van deze vraag is het inzicht dat onzekerheid de geschiktheid van APM op tenminste twee manieren zou kunnen beïnvloeden. Enerzijds doet onzekerheid de behoefte van managers aan sturing door middel van formele control maatregelen toenemen. Anderzijds beperkt onzekerheid de mogelijkheid dergelijke formele control instrumenten toe te passen. Op grond hiervan worden voor de nadere bestudering van de 'geschiktheid" van APM twee dimensies van dit begrip onderscheiden: de behoefte aan APM ('need') en de toepasbaarheid van APM ('feasibility').

In Hoofdstuk 2 ('Literatuur overzicht en ontwikkeling van vier richtingen voor verder onderzoek') wordt de stand van de empirische onderzoeksliteratuur op dit gebied besproken. Geconstateerd wordt dat in de voorafgaande empirische literatuur met name aandacht is besteed aan de toepasbaarheid van APM, met als dominant argument dat onzekerheid de geschiktheid van APM reduceert. Geconstateerd wordt echter ook dat de empirische resultaten van eerder onderzoek vaak conflicteren. Onzekerheid blijkt de 
geschiktheid van APM zowel te verhogen als te verlagen. Voorts blijkt in een aantal studies geen verband te bestaan tussen onzekerheid en de geschiktheid van APM. Op grond van deze constateringen wordt Hoofdstuk 2 afgesloten met het voorstellen van vier richtingen voor verder empirisch onderzoek. Deze vier richtingen worden in Hoofdstuk 3 ('Onzekerheid en de geschiktheid van APM: afleiding van hypothesen') uitgewerkt, hetgeen resulteert in de formulering van verschillende hypothesen.

De eerste richting betreft de operationalisatie van het begrip 'geschiktheid'. Op grond van de eerder genoemde dimensies 'behoefte' en 'toepasbaarheid' worden twee maatstaven voorgesteld: (1) de mate waarin de manager beschikt over duidelijke doelen in zijn werk ("goal clarity") en (2) de mate waarin de manager tevreden is met de beoordeling die hij ontvangt ('agreement with evaluation criteria'). Een derde, aanvullende maatstaf wordt voorgesteld betreffende de mening van managers over de geschiktheid van APM voor hun beoordeling ('felt appropriateness of APM).

De tweede richting betreft de het begrip 'onzekerheid'. Beargumenteerd wordt dat het onderscheid tussen taakonzekerheid ("task uncertainty") en omgevingsonzekerheid ('environmental uncertainty') theoretisch relevant is in de zin dat zij de geschiktheid van $A P M$ verschillend beïnvloeden.

Ten derde wordt voorgesteld dat een nadere beschouwing van de persoonlijkheid van managers zal leiden tot een beter begrip van de geschiktheid van APM onder onzekerheid. Aandacht wordt besteed aan de persoonlijkheidsvariabele 'tolerantie voor ambiguiteit' ('tolerance for ambiguity'). Deze variabele is in eerder onderzoek in verband gebracht met de persoonlijke preferente van subjecten ten aanzien van de hoeveelheid en de aard van de informatie, en beargumenteerd wordt dat deze variabele zowel de 'behoefte' als de 'toepasbaarheid' van APM beïnvloedt.

Ten vierde en tenslotte wordt geconstateerd dat verschillen in operationalisatie en meting van het begrip RAPM in eerder onderzoek mogelijk heeft bijgedragen aan de beperkte mate van overeenstemming van de resultaten. Voorgesteld wordt om apart te onderzoeken of de effecten van het gebruik van APM samenhangen met het gebruik van accounting informatie op zich ("reliance on financial and quantitative information") of met het gebruik van targets ('reliance on targets').

Hoofdstuk 4 ("Onderzoeksmethode") beschrijft het ontwerp en de uitvoering van het empirische onderzoek. Dit onderzoek werd uitgevoerd door middel van interviews en een schriftelijke enquête die is gehouden onder 250 managers in 11 Nederlandse organisaties. Hoofdstuk 4 behandelt de verschillende fasen van dit empirische onderzoek, de ontwikkeling en de test van de vragenlijst, de selectie van de participerende organisaties en de daarin werkzame managers alsmede de procedures rondom de verzending en retourontvangst van de vragenlijsten. In totaal werden 206 vragenlijsten terugontvangen waarvan er 196 bruikbaar bleken voor verdere verwerking.

Hoofdstuk 5 ('Beschrijvende statistieken en item analyses') bespreekt de initiële verwerking van de met de vragenlijsten verzamelde data. Deze verwerking behelst enerzijds het testen van de betrouwbaarheid van de verkregen data en anderzijds het afleiden hieruit van scores voor de variabelen die een rol spelen in de test van de 


\section{SUMMARY IN DUTCH}

hypotheses. In het algemeen bleek de data verzameling te hebben geresulteerd in een betrouwbare meting van de variabelen.

In Hoofdstuk 6 ('Resultaten: testen van de hypothesen") worden de resultaten van het testen van de in Hoofdstuk 3 afgeleide hypothesen besproken. Voor het merendeel van de hypothesen is gebruik gemaakt van multiple regressie-analyse met gebruik van zogenaamde 'moderator' variabelen. De techniek ("Moderated Regression Analysis") maakt het mogelijk om interactie-effecten te analyseren en wordt in Appendix K apart toegelicht.

Hoofdstuk 7 ('Samenvatting en conclusie') bespreekt de bevindingen ten aanzien van de in Hoofdstuk 6 gevonden resultaten. Voor de vier onderscheiden specifieke richtingen van onderzoek zijn de belangrijkste conclusies als volgt.

Ten eerste wordt geconcludeerd dat de aandacht voor de verschillende definities en operationalisaties van het begrip 'geschiktheid' vruchtbaar blijkt te zijn geweest. Zoals verwacht, blijkt het gebruik van APM onder grotere omgevingsonzekerheid te leiden tot meer duidelijkheid over de door de manager na te streven doelstellingen (GC). Anderzijds wordt geen bewijs gevonden voor de verwachting dat het gebruik van APM onder grotere hogere onzekerheid leidt tot een lagere tevredenheid met de beoordeling (AEC). Dit kan verklaren dat budgetten een grotere rol spelen in de beoordeling van managers dan men op grond van een strikte toepassing van het zogenaamde 'responsibility principle' zou mogen verwachten. Tenslotte wordt geconcludeerd dat onzekerheid meer invloed heeft op de meningen van managers over de geschiktheid van APM, dan op de effecten van het gebruik van APM.

Ten tweede blijkt de differentiatie binnen het begrip onzekerheid bij te dragen aan het begrip van de geschiktheid van APM onder onzekerheid. Geconcludeerd wordt dat voor omgevingsonzekerheid de positieve effecten van het gebruik van APM overheersen. Voor taakonzekerheid blijken de negatieve effecten te overheersen. De conclusie luidt dat niet onzekerheid op zich, maar de aard van onzekerheid de geschiktheid van APM bepaalt.

Ten derde wordt geconcludeerd dat de persoonlijkheid van de manager van belang is bij het voorspellen van de effecten van het gebruik van APM. Het blijkt dat niet alleen externe onzekerheidsfactoren de geschiktheid van APM bepalen, maar ook dat managers" persoonlijke tolerantie voor ambiguiteit hun attitudes en reacties ten aanzien van het gebruik van APM bepaalt.

Ten vierde en tenslotte wordt geconcludeerd dat de vraag naar de dimensionaliteit van het traditionele RAPM construct maar ten dele is beantwoord. Wel kan worden vastgesteld dat de resultaten het gemaakte onderscheid tussen het gebruik van accounting informatie en het gebruik van targets lijken te ondersteunen. Ook blijkt voor grotere taakonzekerheid de tevredenheid met de beoordeling APM positief samen te hangen met het gebruik van accounting informatie en negatief met het gebruik van targets.

Hoofdstuk 7 sluit af met een bespreking van de relatieve sterkten en zwakten van het onderzoek. Tenslotte worden enkele aanbevelingen gedaan voor verder onderzoek op het gebied van budgettering en beoordeling. 


\section{Acknowledgments}

Many thanks are owed to many people. I thank my three promotors who in their various personal ways have helped me in writing this dissertation. I thank Tom Groot for introducing me to the behavioral literature in management control. His enthousiasm quickly and definitely convinced me of the relevance and pleasure of doing research in this field. I thank Willem Buijink for his outright and challenging support for my efforts. Unfortunately, most of our discussions did not make it to the final version of this dissertation. I thank Ken Merchant for helping me towards, in his words, the 'home stretch'. At many critical moments he challenged me to make choices and 'push forward', while teaching me the subtle differences between research, art and science in the meantime. I also thank the members of the evaluation committee for their evaluation and approval of the manuscript.

I thank my colleagues and friends for their assistance during several stages of the enterprise, and in particular for their help during the design and pretests of the empirical study. A sincere 'thank you' to Anne, Eddy, Gerard, Hans, Harold, Jan Jaap, Jos, Laury, Roger, Rolf, and especially to Frank and Luc. I also thank the many people in the participating organizations for their interest in this project, for their willingness to participate, and for their extensive and critical assessments of draft versions of the questionnaire instrument.

Finally, I thank my home front. Fortunately, there are many other ways to thank them than by these words alone.

Frank Hartmann. 


\section{Curriculum Vitae}

Frank Hartmann was born March 28, 1966 in Rotterdam. From 1978 to 1984 he attended the Gymnasium Erasmianum in Rotterdam, after which he studied Economics, Business Administration and Taxation at the Erasmus University in Rotterdam. From 1989 to 1992 he worked as assistant controller at a Dutch multinational company. From 1990 he studied at the Postdoctoral Controller program at the Maastricht University, where he became certified controller (Registercontroller) in 1992. Since 1992 he has been working at the Department of Accounting at the Maastricht University. 


\section{ACCOUNTING FOR PERFORMANCE EVALUATION}

\section{Errata}

p. 15, line 20: "led" i.o. "lead"

p. 65 and p. 122: $\mathrm{H} 4 \mathrm{c} \leftrightarrow \mathrm{HSc}$

p. 95, Table 5.6: RT; $\alpha$ is 0.75 i.o. 0.80

p. 147, Table D.2: 'Number of employees" not " $(\times 1000)^{3}$

p. 198, line 22: 'preferentie" i.o. 'preferente' 
